Rhode Island College

Digital Commons @ RIC

\title{
An Investigation of Communication Patterns and Strategies between International Teaching Assistants and Undergraduate Students in University-level Science Labs
}

\author{
Barbara Elas Gourlay \\ Rhode Island College
}

Follow this and additional works at: https://digitalcommons.ric.edu/etd

Part of the Educational Assessment, Evaluation, and Research Commons, Higher Education and Teaching Commons, International and Intercultural Communication Commons, and the Other Chemistry Commons

\section{Recommended Citation}

Gourlay, Barbara Elas, "An Investigation of Communication Patterns and Strategies between International Teaching Assistants and Undergraduate Students in University-level Science Labs" (2008). Master's Theses, Dissertations, Graduate Research and Major Papers Overview. 12.

https://digitalcommons.ric.edu/etd/12

This Dissertation is brought to you for free and open access by the Master's Theses, Dissertations, Graduate Research and Major Papers at Digital Commons @ RIC. It has been accepted for inclusion in Master's Theses, Dissertations, Graduate Research and Major Papers Overview by an authorized administrator of Digital Commons @ RIC. For more information, please contact digitalcommons@ric.edu. 


\section{Library Rights Statement}

In presenting this dissertation in partial fulfillment of the requirements for an advanced degree at the University of Rhode Island and Rhode Island College, I agree that the URI and RIC Libraries shall make it freely available for inspection. I further agree that permission for copying, as provided for by the Copyright Law of the United States (Title 17, U.S. Code), of the dissertation for scholarly purposes may be granted by the Librarian. It is understood that any copying or publication of this dissertation for financial gain shall not be allowed without my written permission.

I hereby ( $\checkmark$ do / _ do not) grant permission to the URI and RIC Libraries to copy my dissertation for scholarly purposes.
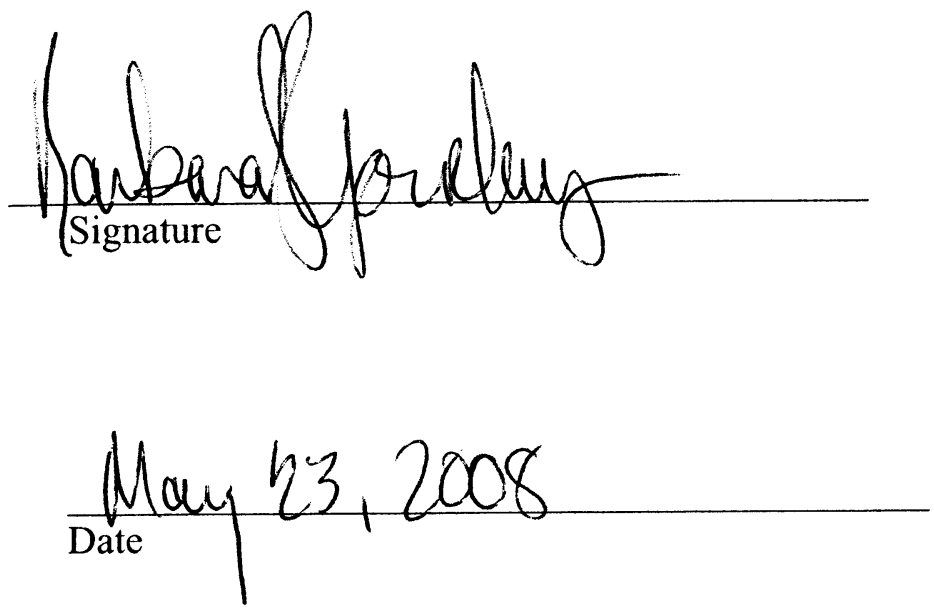


\title{
AN INVESTIGATION OF COMMUNICATION PATTERNS AND STRATEGIES \\ BETWEEN INTERNATIONAL TEACHING ASSISTANTS AND \\ UNDERGRADUATE STUDENTS IN UNIVERSITY-LEVEL SCIENCE LABS \\ BY \\ BARBARA ELAS GOURLAY
}

\begin{abstract}
A DISSERTATION SUBMITTED IN PARTIAL FULFILLMENT OF THE REQUIREMENTS FOR THE DEGREE OF DOCTOR OF PHILOSOPHY IN

EDUCATION
\end{abstract}

UNIVERSITY OF RHODE ISLAND

AND

RHODE ISLAND COLLEGE

2008 
DOCTOR OF PHILOSOPHY DISSERTATION

OF

BARBARA ELAS GOURLAY

APPROVED:

Dissertation Committee
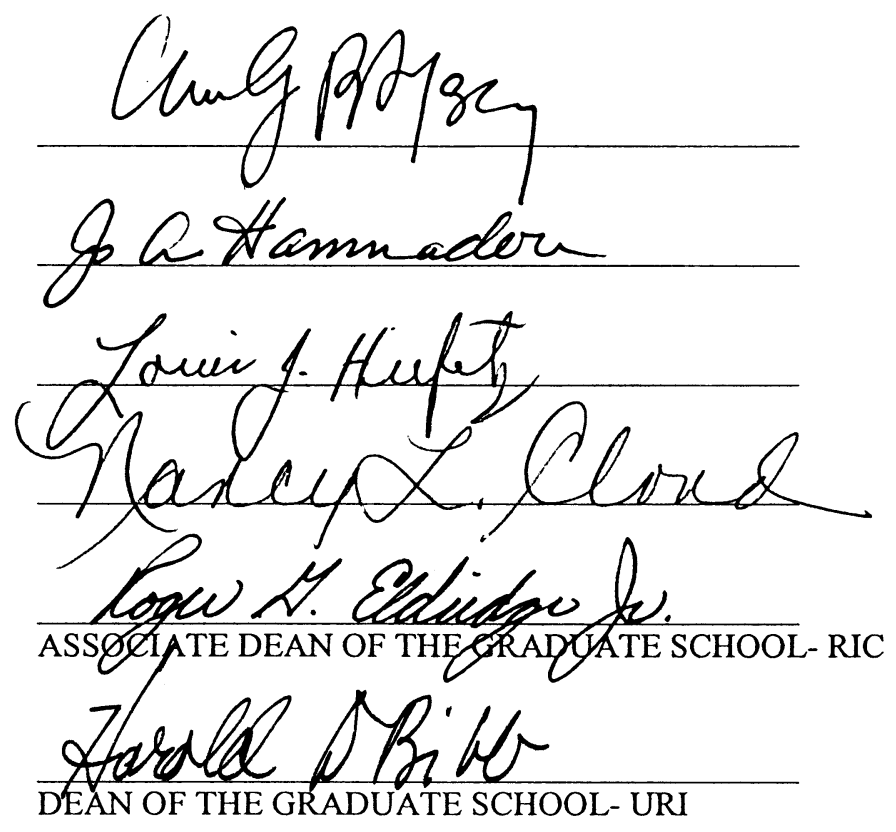

\section{UNIVERSITY OF RHODE ISLAND \\ AND \\ RHODE ISLAND COLLEGE}

2008 


\begin{abstract}
This research project investigates communication between international teaching assistants and their undergraduate students in university-level chemistry labs. During the fall semester, introductory-level chemistry lab sections of three experienced non-native speaking teaching assistants and their undergraduate students were observed. Digital audio and video recordings documented fifteen hours of lab communication, focusing on the activities and interactions in the first hour of the chemistry laboratory sessions. In follow-up one-on-one semi-structured interviews, the participants (undergraduates, teaching assistants, and faculty member) reviewed interactions and responded to a 10item, 7-point Likert-scaled interview. Interactions were classified into success categories based on participants’ opinions. Quantitative and qualitative data from the observations and interviews guided the analysis of the laboratory interactions, which examined patterns of conversational listening.
\end{abstract}

Analysis of laboratory communication reveals that undergraduates initiated nearly two-thirds of laboratory communication, with three-fourths of interactions less than 30 seconds in duration. Issues of gender and topics of interaction activity were also explored. Interview data identified that successful undergraduate-teaching assistant communication in interactive science labs depends on teaching assistant listening comprehension skills to interpret and respond successfully to undergraduate questions. Successful communication in the chemistry lab depended on the coordination of visual and verbal sources of information. Teaching assistant responses that included explanations and elaborations were also seen as positive features in the communicative exchanges. Interaction analysis focusing on the listening comprehension demands placed 
on international teaching assistants revealed that undergraduate-initiated questions often employ deixis (exophoric reference), requiring teaching assistants to demonstrate skills at disambiguating undergraduate discourse. Interaction analysis reinforced that successful undergraduate-teaching assistant communication depends on the coordination of verbal and visual channels of communication, with the physical objects of the chemistry lab environment playing a pivotal role in expressing information and in mutual understanding.

These results have implications for the evaluation of English proficiency and the preparation of non-native speaking teaching assistants by pointing out that teaching assistant listening comprehension skills and the use of contextual artifacts contribute to successful communication and are areas that, to date, have been underrepresented in the research literature on international teaching assistant communication. 


\section{Acknowledgments}

This research project could not have been realized without the help and support of a great many people. First and foremost, I am grateful to Professor Carolyn Panofsky for her intelligent guidance, thoughtful suggestions, and careful reading at all stages of this research project. Her dedication to research, commitment to her students, and refreshing sense of humor were instrumental in keeping this project on track as it evolved. I cannot imagine a better major professor.

I also wish to thank the other members of my committee. I am grateful for the guidance and instruction of Professor Louis Heifetz, whose influence is seen throughout this project, especially by helping me rigorously approach research by asking and answering questions in multiple ways. His wit, support of students, and commitment to research are greatly appreciated. I also thank my other committee members for their guidance, especially in the formative stages of this project. Professor JoAnn HammadouSullivan kept this project grounded in the perspective of the participants, and Professor Nancy Cloud kept it grounded in the activities of the participants.

I owe immense thanks and appreciation to the participants in this study. This project happened because they gave their time, thoughts, and ideas, with enthusiasm for improving communication and learning in the chemistry labs. Professor Joan Lusk's commitment to improving the educational experience of the undergraduates and the teaching experience of the international teaching assistants opened the door for this project, and the willingness of the teaching assistants and undergraduates to allow an outsider to a part of their educational experience made this project possible. Without their contributions, this project would not have existed. I also thank Andrew Ross, whose technical support facilitated obtaining participants’ perspectives.

Finally, and most importantly, I thank my family (Alexander, Jonathan, and Elizabeth) for providing me with support and time. Your endless patience and flexibility gave me the opportunity to carry out and complete this project. 


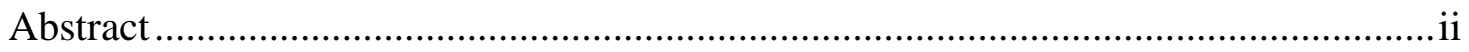

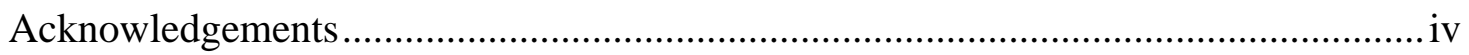

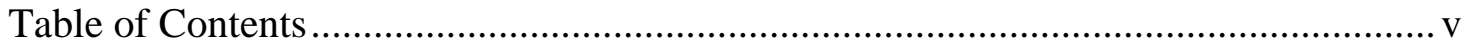

List of Tables ..................................................................................................... ix

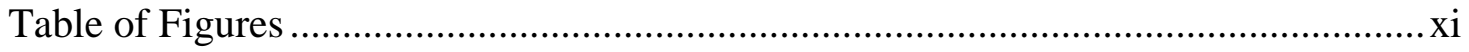

Chapter 1: Introduction and Background................................................................ 1

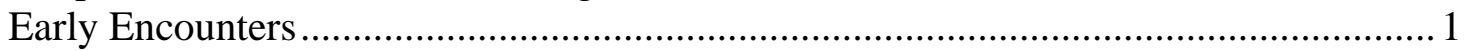

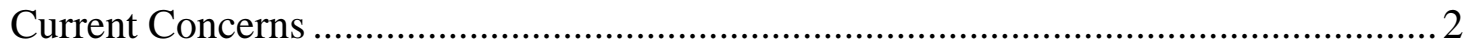

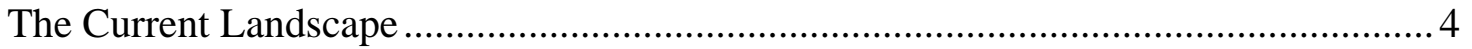

Language Standards and Support for International Teaching Assistants ................. 4

International Graduate Students in American Higher Education ............................. 5

Improving the Undergraduate Educational Experience ..................................... 7

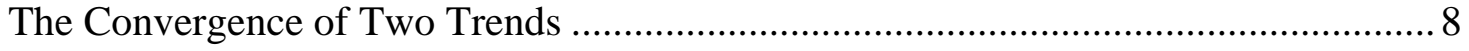

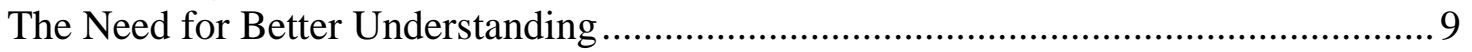

Research Purpose and Research Questions....................................................... 11

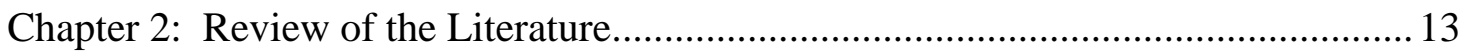

International Teaching Assistant Speech Research ................................................ 15

Accentedness, Comprehensibility, Intelligibility ............................................. 18

Production of Spoken English: Speaker Variables ............................................. 21

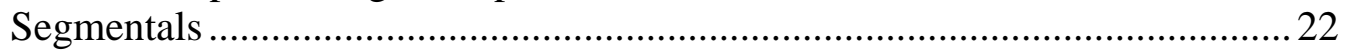

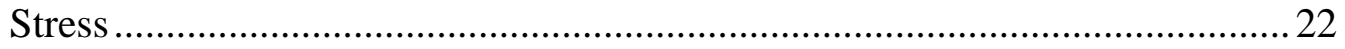

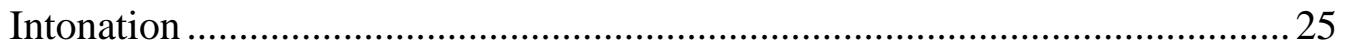

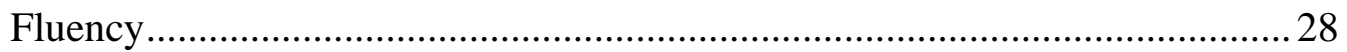

Perceptions of Spoken English: Listener Variables........................................... 29

Communication Research on International Teaching Assistants in Context................33

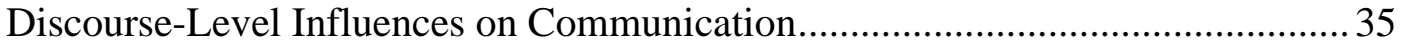

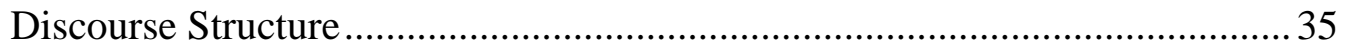

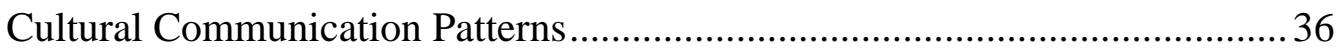

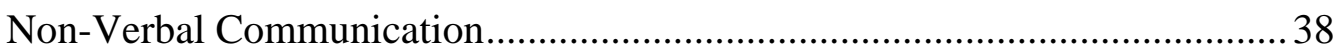

Teaching Contexts of International Teaching Assistants..................................... 40

Interactive Classroom Communication........................................................... 43

International Teaching Assistant Communication ........................................ 44

Undergraduate Communication ........................................................... 49

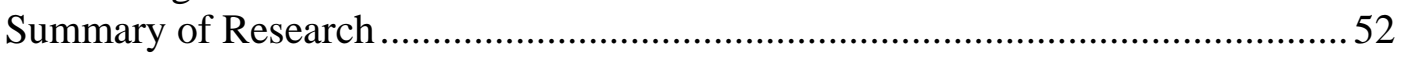

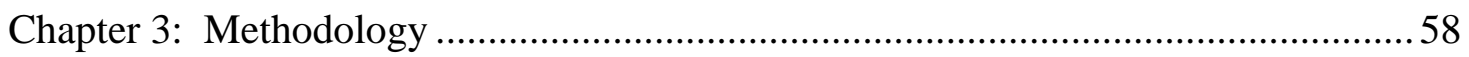

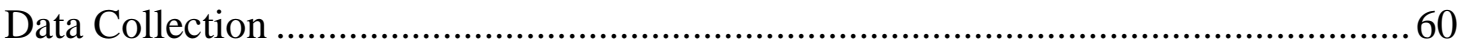

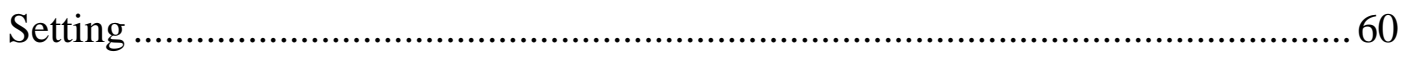

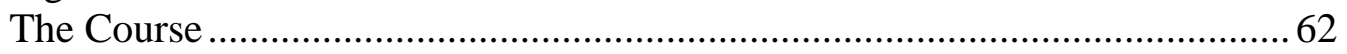

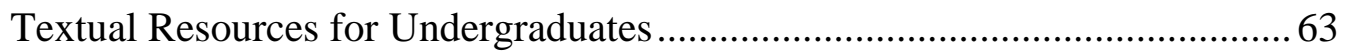

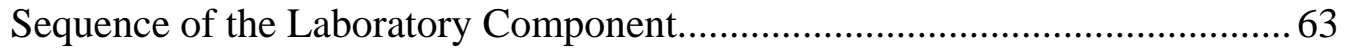

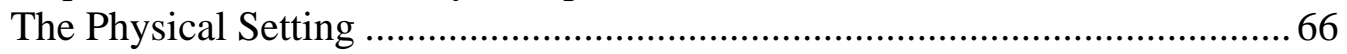




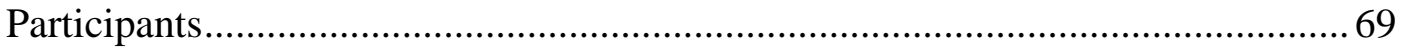

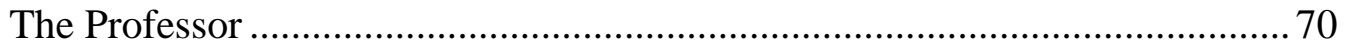

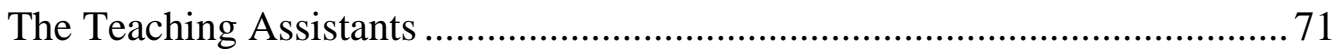

The Undergraduates ...................................................................................... 73

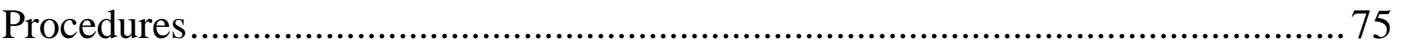

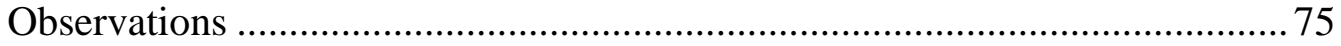

Schedule of observations .......................................................................... 76

Equipment and procedures for audio and video recording .......................... 78

Preparing the audio and video recordings..................................................

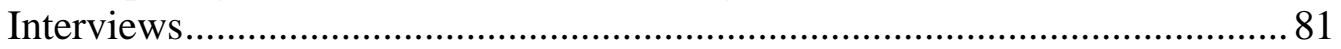

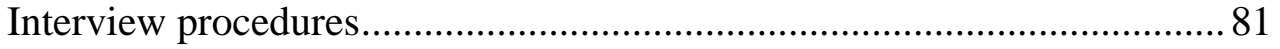

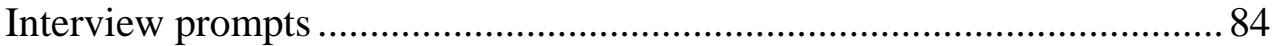

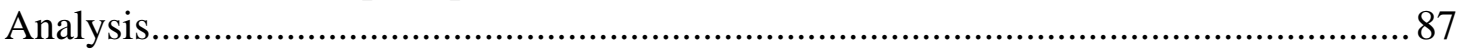

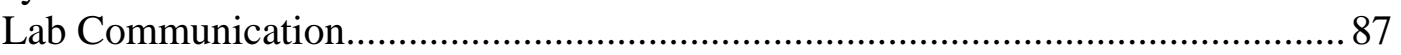

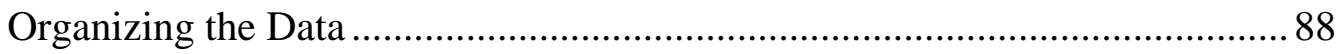

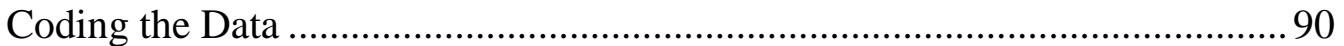

Establishing Reliability .............................................................................. 93

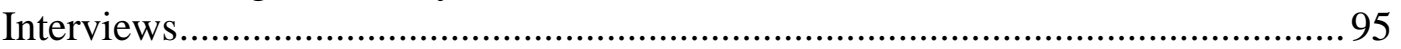

Likert-Scaled Responses ............................................................................95

Participant Comments ....................................................................................99

Analysis of Lab Communication and Interactions.................................................97

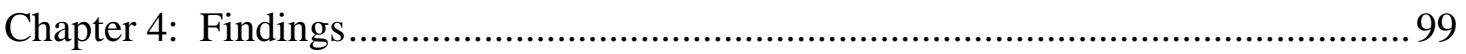

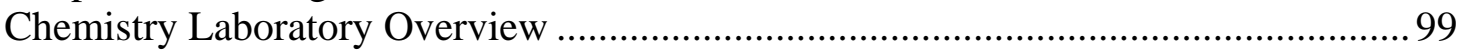

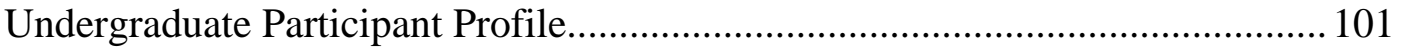

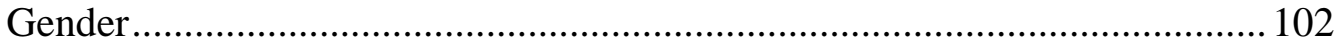

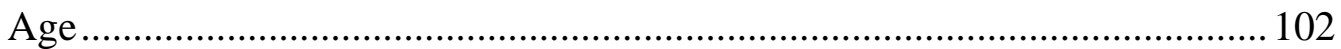

Year in College ...................................................................................... 102

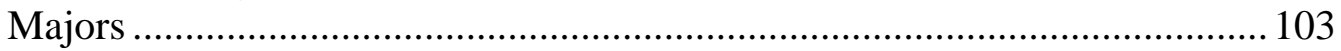

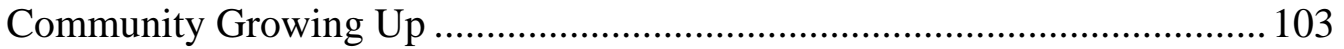

Languages Spoken at Home........................................................................ 104

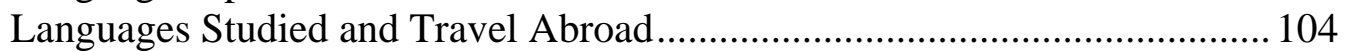

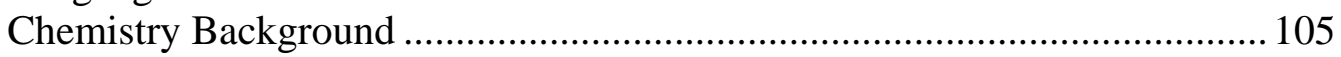

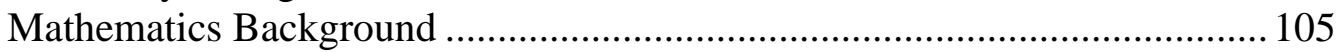

Communication in the Chemistry Labs ............................................................. 107

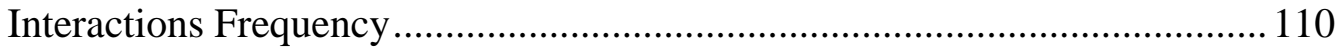

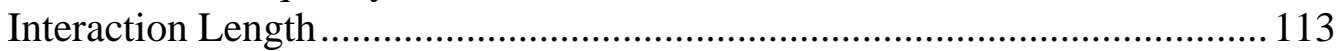

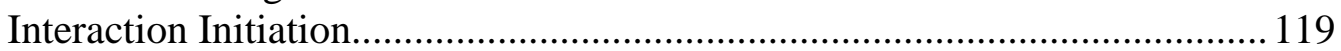

Gender of Undergraduate Participants.......................................................... 129

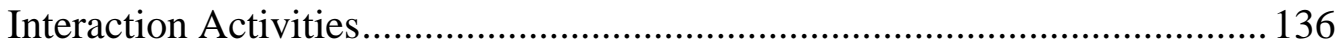

Interaction Initiation and Gender of Undergraduate Participants ..................... 144

Interaction Initiation and Activity.................................................................... 149

Interaction Activity and Gender of Undergraduate Participants....................... 151

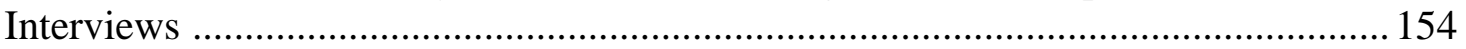

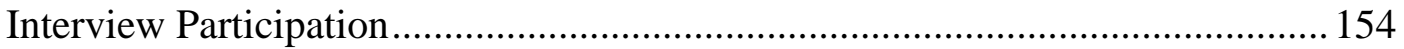

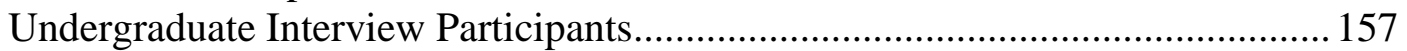


Interview Interactions ......................................................................................... 167

Participant Responses and Comments to the Interview Items ............................... 174

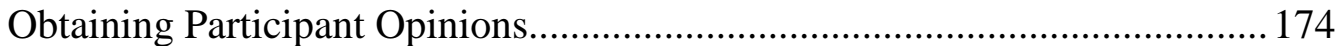

Triangulating Participant Opinions............................................................... 177

Interview Items and Dimensions ................................................................ 179

Interview Item 1: Comprehension of the question..................................... 181

Interview Item 2: Comfort with the question.............................................184

Interview Item 3: Difficulty expressing the question .................................186

Interview Item 4: Requesting clarification ............................................. 188

Interview Item 5: Requesting confirmation ............................................... 189

Interview Item 6: Comprehension of the response ……………………..... 191

Interview Item 7: Satisfaction with the response ......................................... 192

Interview Item 8: Sufficient information in the response ........................... 193

Interview Item 9: Preference for another response ..................................... 194

Interview Item 10: Overall success of the interaction ................................ 196

Successful, Partially Successful, and Unsuccessful Interactions..................... 197

Teaching assistant comments.................................................................. 200

Faculty member comments .................................................................. 201

Undergraduate comments ………………………………..................... 204

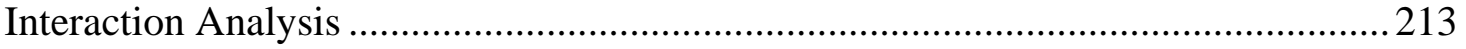

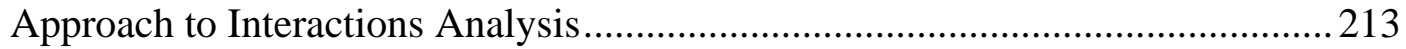

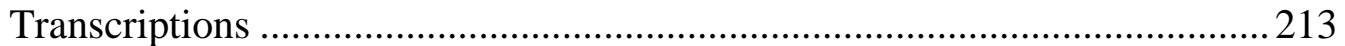

Theoretical Framework ............................................................................... 216

Speaking Styles .................................................................................. 218

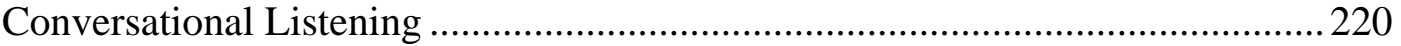

Turn-Taking ...................................................................................... 220

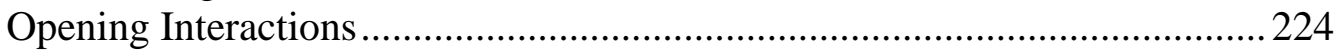

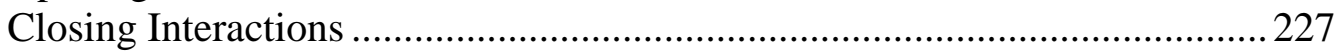

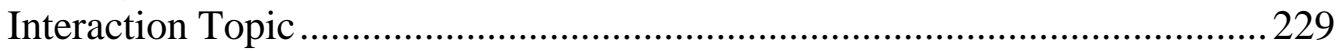

Phrasing of Undergraduate Questions …………………...................... 230

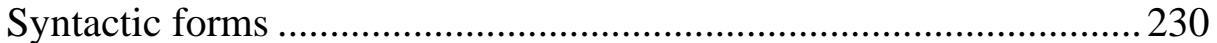

Lexical choices and ambiguity........................................................... 232

Topics of Undergraduate Questions...................................................... 239

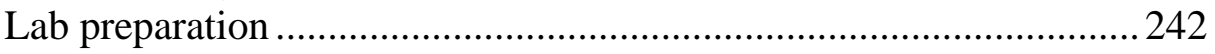

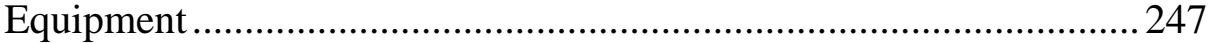

Locating and acquiring equipment................................................ 249

Identifying appropriate equipment..................................................253

Equipment function...................................................................... 260

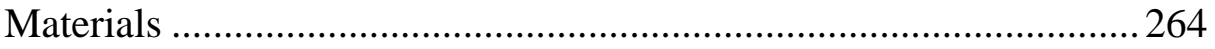

Locating and acquiring materials.................................................. 265

Selecting and identifying appropriate materials ............................ 267

Measurement precision ................................................................. 270

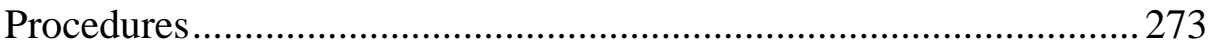

Establishing what to do .............................................................. 274

How to carry out a procedure.........................................................28

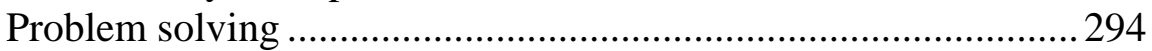




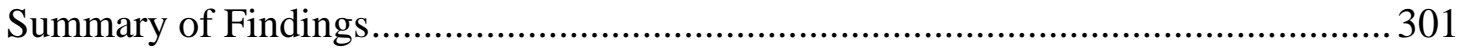

Chemistry Lab Communication............................................................................. 301

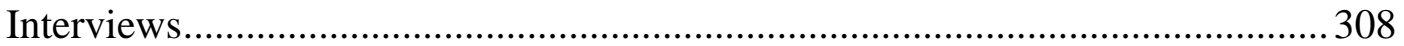

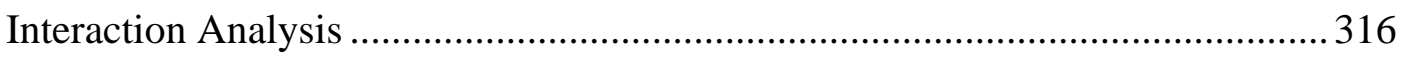

Chapter 5: Discussion of Findings .......................................................................... 324

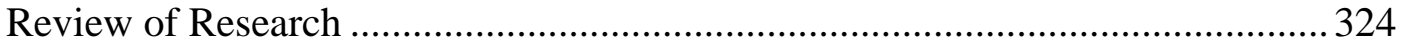

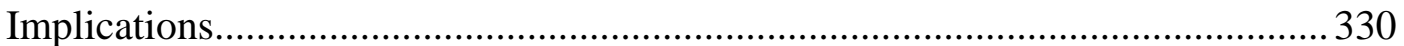

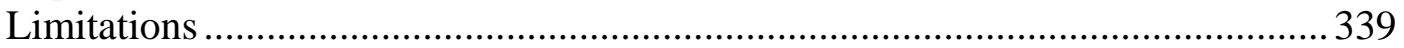

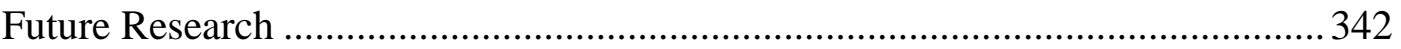

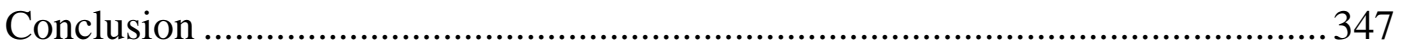

\section{Appendices}

A. Teaching Assistant Participant Informed Consent Form ...................................349

B. Undergraduate Participant Informed Consent Form ............................................ 351

C. Undergraduate Participant Background Information Questionnaire.................. 353

D. Teaching Assistant Participant Background Information Questionnaire .......... 355

E. Undergraduate Background Characteristics Summary Tables........................... 356

F. Lab Communication Summary Tables ................................................................. 359

G. Undergraduate Interview Participant Characteristics Summary Tables............. 361

H. Summary Tables of Participant Agreement of Interview Items......................... 364

I Overview of Successful and Partially Successful Interview Interactions ......... 366

J Transcription Key for Interaction Examples ...................................................... 367

K. Overview of Interview Interaction Examples Used to Illustrate Topics of

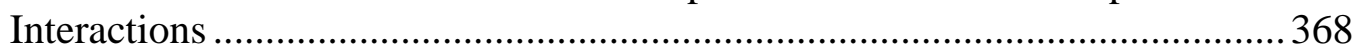

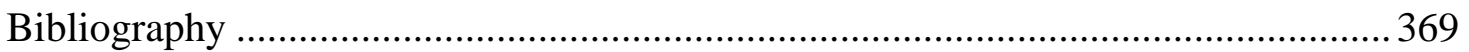




\section{List of Tables}

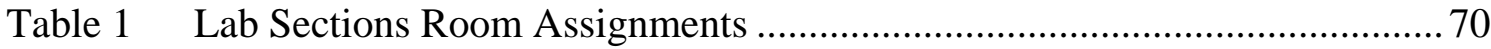

Table 2 Overview of Teaching Assistant Background Characteristics...................... 72

Table 3 Undergraduate Participation by Lab Section ............................................. 75

Table 4 Schedule of Laboratory Experiments and Data Collection............................ 77

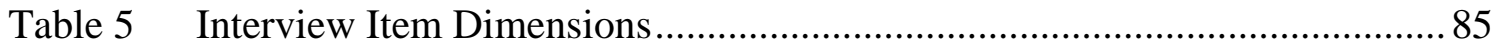

Table 6 Interview Prompts .............................................................................. 86

Table 7 Coding Categories and Definitions for Activities Discussed in Lab

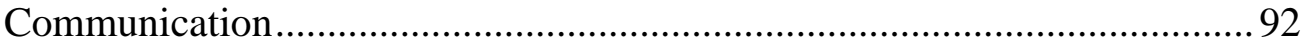

Table 8 Frequency of Interactions by Lab Session and Lab Section ...................... 111

Table $9 \quad$ Frequency and Percentage of Interactions by Length of Interaction ........... 114

Table 10 Frequency and Percentage of Interactions by Lab Session and Length of Interaction ....................................................................................... 116

Table 11 Frequency and Percentage of Interactions by Lab Section and Length of

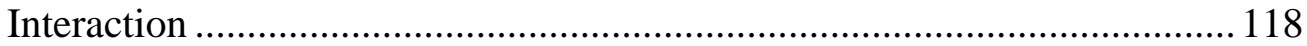

Table 12 Frequency and Percentage of Interactions by Interaction Initiation ............ 120

Table 13 Frequency and Percentage of Interactions by Lab Session and Interaction

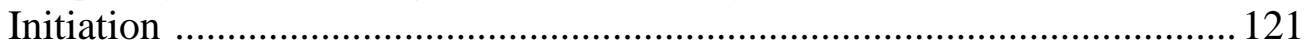

Table 14 Frequency and Percentage of Interactions by Lab Session and Interaction Initiation for the Tuesday and Thursday Sections ..................................... 123

Table 15 Frequency and Percentage of Interactions by Lab Section and Interaction Initiation ..................................................................................... 124

Table 16 Frequency and Percentage of Interaction for Labs 4, 5, \& 6 by Lab Section and Interaction Initiation..................................................... 126

Table 17 Frequency of Interaction Initiation by Lab Session and Lab Section .......... 127

Table 18 Frequency and Percentage of Interactions by Gender of Undergraduate Participants...................................................................................... 132

Table 19 Frequency and Percentage of Interactions by Lab Session and Gender of Undergraduate Participants ...................................................................... 133

Table 20 Frequency and Percentage of Interactions by Lab Section and Gender of Undergraduate Participants .................................................................... 134

Table 21 Frequency and Percentage of Interactions for Labs 4, 5, \& 6 by Lab Section and Gender of Undergraduate Participants............................ 136

Table 22 Frequency and Percentage of Lab Interactions by Topic of Activity .......... 139

Table 23 Frequency and Percentage of Interactions by Lab Session and Topic of Activity

Table 24 Frequency and Percentage of Interactions by Lab Section and Topic of Activity

Table 25 Lab Interactions by Initiation and Gender of Undergraduate Participants .. 145

Table 26 Frequency and Percentage of Undergraduate-Initiated Interactions by Lab Section and Gender of Undergraduate Participants............................ 147

Table 27 Frequency and Percentage of Undergraduate-Initiated Interactions by Lab Session and Gender of Undergraduate Participants. 148

Table 28 Frequency and Percentage of Interactions by Interaction Initiation and Topic of Activity. 
Table 29 Frequency and Percentage of Interactions by Gender of Undergraduate

Participant and Topic of Activity................................................................. 152

Table 30 Frequency and Percentage of Undergraduate Participants by Gender and

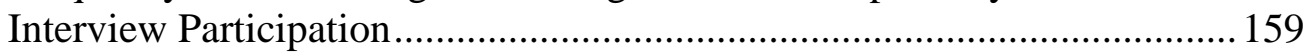

Table 31 Frequency and Percentage of Undergraduate Interview Participants by Lab Session

Table 32 Frequency and Percentage of Undergraduate Interview Participation for Lab 4

Table 33 Frequency and Percentage of Interactions for All Lab Sessions of Undergraduates by Interview Participation for the Tuesday and Thursday Sections 166

Table 34 Frequency and Distribution of Interview Interactions by Lab Session and Lab Section 168

Table 35 Comparison of Frequency and Percentage of Study Interactions and Interview Interactions by Gender of Undergraduate Participants

Table 36 Comparison of Frequency and Percentage of Study Interactions and Interview Interactions by Length of Interaction

Table 37 Comparison of Frequency and Percentage of Study Interactions, Undergraduate-Initiated Interactions, and Interview Interactions by Activity

Table 38 Distribution of Successful and Partially Successful Interactions in the Tuesday and Thursday Sections.

Table 39 Comparison of Frequency and Percentage of Interaction Initiation for Study Interactions and Interview Interactions by Activity

Table 40 Frequency and Percentage of Successful and Partially Successful Interview Interactions by Activity 


\section{List of Figures}

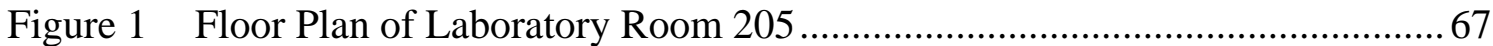

Figure 2 Floor Plan of Laboratory Room 209 .................................................... 67 


\section{CHAPTER 1: INTRODUCTION AND BACKGROUND}

During the past thirty years, American colleges and universities have employed international graduate students as teaching assistants to instruct American undergraduates. Increased populations of undergraduates and international graduate students provide an opportunity for institutions of higher education to place these two populations together in the classroom learning environment. The international graduate students, recognized for knowledge in their disciplines, provide a talented pool of

prospective teaching assistants to instruct undergraduates (Kaufman \& Brownworth, 2006). However, the placement of international students in instructional positions at American institutions of higher education has not been without controversy (Bailey, Pialorsi, \& Zukowski/Faust, 1984; Finder, 2005; Gravois, 2005). Discussion, debate, and concern have placed much emphasis on the question of whether on not the international students are capable of functioning in English to successfully deliver comprehensible instruction to native-English speaking undergraduate students (Finder, 2005; Gravois, 2005; Rounds, 1987).

\section{Early Encounters}

Early attention on the use of international graduate students in instructional positions was well documented in the early 1980s (Bailey et al., 1984). The large numbers of international students enrolled in graduate programs in the physical sciences, life sciences, and mathematics resulted in many of the international teaching assistants (ITAs) teaching introductory-level laboratory and discussion sections in these disciplines (Smith, Byrd, Nelson, Barrett, \& Constantinides, 1992). From their experience with international teaching assistants, American undergraduate students in 
these classrooms and laboratories, as well as their tuition-paying parents, responded to the influx of non-native speakers in instructional positions by asserting that the international students provide inferior classroom experiences. The primary focus of their complaints has been the English language skills, mainly pronunciation and accent, of the international students in teaching positions (Bailey et al., 1984; Nyquist, Abbot, Wulff, \& Sprague, 1991).

In response to students' and parents' complaints about the English language skills of international teaching assistants, colleges, universities, and even some state governments (in the case of state-funded institutions) instituted policies requiring nonnative speakers in instructional positions to demonstrate advanced levels of spoken English proficiency and have also created supporting English language programs for international students who need to improve their English language skills (Bailey et al., 1984; Brown, Fishman, \& Jones, 1991; Smith et al., 1992). The establishment of these policies and English language programs to support ITA language development for classroom teaching, however, has not eliminated complaints about the communication skills of international teaching assistants.

\section{Current Concerns}

In April 8, 2005, The Chronicle of Higher Education published an article addressing the topic. The Chronicle article details an initiative by a North Dakota legislator to allow undergraduates to drop a class and receive a tuition refund if the student “complains in writing that his or her instructor did not 'speak English clearly and with good pronunciation'” (Gravios, 2005). The initiative also requires the instructor of a class to be removed from teaching if $10 \%$ of the class complains about 
the instructor's language skills. Such action suggests that discontent with ITAs is widespread and that the stakes are high for institutions with ITAs.

Later that year, in June 2005, The New York Times published an article titled "Unclear on American Campus: What the Foreign Teacher Said,” by Alan Finder. As the title suggests, the issue of the English language competency of international teaching assistants at American universities was again making national headlines. The article begins with a typical example illustrating the communication failures American undergraduates experience when these two populations come together in American university classrooms. The article describes an undergraduate's encounter with a nonnative speaking teaching assistant, presented from the undergraduate perspective. In this example, the undergraduate student is a freshman at a major research university in the West taking an introductory-level chemistry class in which the teaching assistant is a graduate student from China. The undergraduate characterizes the international graduate student as extremely intelligent, but reports that he speaks with a heavy accent and a limited grasp of spoken English, limiting his ability to communicate in English.

During the semester, the undergraduate receives a $\mathrm{C}$ on a lab report and approaches the teaching assistant with the intention of finding out what she could have done to receive a better grade. According to the undergraduate, the teaching assistant responds by repeating “It’s easy. It’s easy.” The undergraduate describes her anger and feeling of helplessness in the situation. Her perspective was that "it wasn’t easy,” and that while the teaching assistant "was brilliant, absolutely brilliant," he could not communicate the information the student wanted and needed. This encounter had additional significance for the undergraduate: the negative experience in the freshman 
chemistry course contributed to her changing her major from a pre-med major to an economics major. The article goes on to point out that experiences such as this one are "hardly unique,” and the article recounts similar incidents occurring at other major universities across the United States.

\section{The Current Landscape}

\section{Language Standards and Support for International Teaching Assistants}

The recent concerns, calls for legislation, and on-going complaints about the language proficiency and communication skills of international teaching assistants are similar to those expressed by American undergraduates thirty years earlier: the international teaching assistants fail to communicate in comprehensible English with the consequence that the undergraduates have an unsatisfactory educational experience. The undergraduates cannot access the content of a course because of the language and communication difficulties presented by a non-native speaking instructor, and they are frequently forced to drop the class. This situation occurs most often in introductorylevel courses, resulting in the undergraduates altering their programs of study and changing their career plans.

When the "Foreign TA Problem” (Bailey, 1984) first came to light thirty years ago, the assumption was that the language skills of the non-native speaker were the source of the communication problems between undergraduates and their international teaching assistants. At that time, there were no regulations in place to ensure that the non-native speaking teaching assistants had the requisite language skills for classroom teaching. There were no spoken language proficiency evaluation procedures and no specialized training programs for non-native speaking teaching assistants. However, the 
complaints and concerns expressed recently about international teaching assistants’ abilities to communicate with undergraduates are situated in a different educational environment.

Today, there are major efforts to ensure that non-native speakers in instructional positions demonstrate sufficient language skills prior to assuming their instructional duties. Legislation exists in 22 states requiring universities to certify that non-native speaking instructors are sufficiently proficient in spoken English (Finder, 2005). Screening programs for spoken language proficiency exist on most campuses that employ international teaching assistants, and for international graduate students who do not demonstrate adequate command of spoken English for their teaching duties, there are supporting English language programs designed to prepare these students for their work as teaching assistants (Kaufmann \& Brownworth, 2006; Sarwark, 2007). Furthermore, a large professional network has developed for those charged with evaluating and improving the language and communication skills of prospective international teaching assistants. In 1993, TESOL (Teachers of English to Speakers of Other Languages), the main professional organization for English language professionals, established the ITA interest section (TESOL, 2007). This interest section supports English as a Second Language (ESL) professionals who specialize in international teaching assistant instruction, research, and program administration.

\section{International Graduate Students in American Higher Education.}

Enrollments of international graduate students have been increasing steadily over the past twenty years with little indication that this trend will change (Gonzalez, 2004; Piñero, 2006). Currently, international graduate students are an important part of 
the educational landscape of higher education, especially in the sciences, where many of the complaints about international teaching assistants originate. According to the Chronicle of Higher Education's 2006-2007 Almanac, the numbers of international students enrolled in institutions of higher education in the United States are substantial. In the fall of 2004, there were 590,200 international students studying in American institutions of higher education. While there have been minor fluctuations, the numbers of international students have remained stable and have increased slightly over the last ten years, from 453,787 in 1995-1996 to 564,766 in 2005-2006 (Bollag, 2006).

According the Chronicle's 2006-2007 Almanac, for 2004 the number of international graduate students was a large proportion of international students studying in the United States. There were 268,100 foreign graduate students, with an additional 8,200 students in professional programs studying at American institutions. For the same year, four out of the top six countries sending the largest numbers of international students to study in the United States were from East Asia: India $(80,466)$, China (62,523), South Korea $(53,358)$, Japan $(42,215)$, and Canada $(28,140)$, Taiwan $(25,914)$. The impact of international students in the sciences at the graduate level is also substantial. The Chronicle's 2006-2007 Almanac reports that for 2004, of all earned doctorates $27.4 \%$ were awarded to international students, that is, students with non-U.S. temporary visas. The percentages of international students in the sciences receiving doctorates are mostly higher: engineering, 57.2\%; life sciences, $26.1 \%$; physical sciences, $42.2 \%$. As evidenced by the numbers, international graduate students play a significant role in the sciences in higher education in the United States. 
These current numbers and percentages of international graduate students in American higher education point toward the continued reliance on international graduate students especially in the sciences as students and as teaching assistants. Anderson (2005) states that international students benefit the American educational system in significant ways: without these international students, certain science and engineering programs could not be offered or sustained at American universities because the international students populate the classes and serve as teaching assistants. Furthermore, these international graduate students go on to serve as faculty for those programs. He reports that about one-third of American engineering professors are foreign born.

\section{Improving the Undergraduate Educational Experience}

The heavy dependence on international students for graduate programs in the sciences comes at the same time that Americans are recognizing the increased importance of improving the quality of science education in the United States. A critical challenge for American higher education is improving the educational experience of American undergraduates, especially in courses such as introductory science courses, which have traditionally been designed to winnow students out rather than draw them in (Yankelovich, 2005). Discussion of curricular change in introductory-level science courses, with the goal of supporting undergraduate learning and understanding of the material of the discipline, calls attention to ways undergraduates can be drawn into mastering the content material of the discipline (Ege, Coppola, \& Lawton, 1997).

Redden (2006) reports that many factors have been identified as being important for improving the educational experience of undergraduates—undergraduate 
satisfaction and success when engaged in educationally purposeful activities to learn content material. A key finding as reported by Redden is that students who connect with someone or something are likely to persist in learning. One area she identifies to improve the educational experience of undergraduates is for institutions to reform the curricula in Ph.D. programs to offer more training on teaching skills. This emphasis on improving support for graduate students in teaching positions as part of their professional degree programs derives from the understanding that classroom and teaching faculty play an important, direct role in influencing student success.

\section{The Convergence of Two Trends}

These two trends in higher education converge: our dependency on international graduate students in the sciences and our recognition that instruction for undergraduates needs to be supported and improved, especially in the sciences. The first trend results in non-native speakers being placed in instructional positions in university-level science classes because these are the students populating graduate programs in the sciences. The second trend results in our attempts to improve the overall educational experience of undergraduates, and more specifically increase their active participation and engagement in course materials so that American undergraduates continue studying in the sciences.

At present, many institutions of higher education recognize the connection between these two trends and cite the need to improve the quality of the undergraduate educational experience as the primary reason for having English proficiency evaluations and preparation programs for international teaching assistants. Shi (2007) reports on a nationwide survey investigating the scope and extent of international teaching assistant 
preparation and development programs in universities with at least 1,000 international students. She found that $98.2 \%$ of respondents indicated that the goals of international teaching assistant programs were to improve undergraduate education. Only 37.5\% reported the goal of the international teaching assistant programs was to satisfy a legal requirement, and $60.7 \%$ indicated the goal of international teaching assistant programs was to enrich graduate study.

The first-year experience of undergraduates is a significant transition year and the time when many undergraduates enroll in introductory-level science classes. Successful classroom interactions between international teaching assistants and American undergraduates who populate their classes will be critical for improving the undergraduate experience, especially as these relate to program of study selection and ultimately career choice. If American undergraduates are able to communicate and connect with their international teaching assistants, the likelihood that they will continue their studies in these areas increases.

\section{The Need for Better Understanding}

From all indications, international graduate students in the sciences are an asset to the American system of higher education and will continue to be an important part of the educational landscape in higher education. Therefore, it is crucial that we have a better understanding of how international graduate students functioning as teaching assistants interact with their undergraduate students. Educational environments that employ international teaching assistants must engage American undergraduates and encourage them to continue to pursue programs of study and careers that involve science and science courses, rather than leading undergraduates to frustration and 
dropping out of science courses. The "Foreign Student TA Problem” of thirty years ago has now become the "ITA Challenge” (Kaufman \& Brownworth, 2006).

With large numbers of international students enrolled in graduate programs in the sciences and universities continuing to use graduate students in instructional capacities, understanding the classroom interactions between international teaching assistants and American undergraduates is of increased importance. Our failure to understand and promote successful communication between these two groups has serious consequences for American undergraduates. If undergraduates are limited in their access to the content of courses in the physical sciences, life sciences, and mathematics and if undergraduates are dropping courses, especially at the introductory level because they do not understand or become engaged with the content of a course facilitated by a non-native speaker, then for these undergraduates, their educational opportunities are restricted. The undergraduates may then be forced to alter their programs of study, degrees achieved, and career plans.

While much has been done in the past thirty years to improve the educational experience of American undergraduates who have non-native speaking instructors, the need for more improvement remains. The fact that undergraduates indicate that they still struggle to understand what is being said in college classrooms taught by nonnative speakers (Finder, 2005; Gravois, 2005) suggests the need to better analyze classroom interactions between these two populations. Understanding how and why interactions between undergraduates and their non-native speaking international teaching assistants are successful will contribute in significant ways to improving the educational experience of undergraduates, especially those undergraduates who are in 
the early stages of their undergraduate programs and who are making critical choices about their programs of studies and future careers. Understanding and learning from their perspective is crucial to the success of their educational experiences with international teaching assistants. Furthermore, increased information about the demands faced by advanced non-native speakers of English in instructional positions will provide those charged with preparing international graduate students for their teaching duties with increased awareness and understanding of the needs of both the international teaching assistants and the undergraduates in their classes.

\section{Research Purpose and Research Questions}

The purpose of this study is to investigate the language use and communication strategies of native and non-native speakers of English and approaches to negotiating information in university-level science classes. Science labs provide an important context to investigate for two reasons. First, a high number of international students are placed in teaching positions in science labs. Second, the discourse of science labs is such that ITAs engage in both planned speaking activities (e.g., to explain procedures and equipment set-up) and unplanned, spontaneous exchanges with undergraduates (e.g., question-and-answer interactions). Since the goal of this investigation is to better understand how successful communication in academic environments can be encouraged and supported, science labs provide a variety of communicative interactions to examine. 
Research Questions: The research questions guiding this project are as follows:

- In university-level chemistry laboratories, what constitutes successful communication and/or successful negotiation of information between nativeEnglish speaking students and their instructors who are advanced non-native speakers of English?

- What are the communication skills (i.e., linguistic, paralinguistic, non-verbal, cultural, pedagogical) that contribute to successful classroom interactions between non-native English speaking teaching assistants and their nativespeaking undergraduate students? 


\section{CHAPTER 2: REVIEW OF THE LITERATURE}

The research literature on international teaching assistant (ITA) communication has one primary focus: understanding ITA classroom communication so that nonnative-speaking teaching assistants can be screened and prepared for classroom teaching duties. The underlying assumption in all of this research is that non-native speaking teaching assistants become successful communicators in American classrooms when their language skills approach native-speaker control, and the more their language skills deviate from the native-speaker norm, the less successful they are in American classrooms.

This assumption has significantly influenced methodologies used in researching ITA communication. Almost all studies in this area are established to compare the speech or communication patterns of non-native speakers in order to identify how their patterns deviate from those of native-speaking teaching assistants. Not only does this assumption influence the way that research on ITA communication has been structured, but it has also guided how researchers have approached analysis and interpretation of their data: outside observers can observe and measure the deviations from nativespeaker norms in communication to reveal those areas in which ITAs are deficient. Once researchers have identified how ITA communication differs from native speaker communication, researchers can prescribe what international teaching assistants need to control in order to communicate in American classrooms. In the research literature, the outside observers are independent of the communicative exchanges and are either trained language specialists, such as the researcher, or untrained native speakers with a specific background, such as undergraduates. 
A second assumption in the ITA research literature is that the language of the instructor is the significant speech in classroom communication. This emphasis on the instructor's speech holds true in all ITA research literature, from de-contextualized research examining brief recorded speech samples to the more contextualized research documenting actual classroom communication.

In general, the research literature most relevant to understanding the communicative interactions between international teaching assistants and their undergraduates students can be divided into two main areas. The first area investigates the linguistic skills of non-native speakers of English, looking at the pronunciation and production skills of international teaching assistants and how that speech is perceived and understood by native speakers of English. The research in this area has helped establish the vocabulary used to discuss ITA communication and has identified and examined a range of linguistic features of spoken English, from word-level features, such as consonant and vowel articulations or stress patterns, to phrase- and sentencelevel features, such as intonation. In brief, this research base emphasizes the phonetic and phonological aspects of non-native speaking patterns, the mechanics of speaking, and listener responses to these features in non-native speech. While there are some attempts to contextualize this research by using segments of speech that might occur in a teaching context, this research base examines de-contextualized communication, depending on brief segments (isolated words or passages) of recorded speech as the language investigated.

The second area of research examines communication of international teaching assistants and undergraduates in naturalistic settings, mostly classrooms. This area 
focuses primarily on discourse-level communication patterns of non-native speakers in instructional positions: how information is framed, organized, and carried out in faceto-face communication. With its emphasis on discourse-level communication between international teaching assistants and undergraduates, this research also takes into account other aspects of communication associated with real-world communication: contextual demands of communication, styles of discourse, cultural communication patterns, and non-verbal communication. This research literature supports a more contextualized approach to understanding language and communication patterns.

International Teaching Assistant Speech Research

As mentioned in the previous chapter, when international graduate students were first placed in teaching positions at the university level in the early 1980s, undergraduates complained that they were not able to understand them. As a result of the way this issue was framed, early research on the spoken skills of international teaching assistants emphasized their abilities to produce understandable spoken English, focusing on their control of the phonetic features and phonological patterns of spoken English. Current research on ITA communication, such as McGregor (2007), is still invested in this line of investigation.

The early interest in the speaking and production skills of international teaching assistants contributed to a particular focus within the field of English as a Second Language (ESL) on the teaching and learning of pronunciation in general (Morley, 1991). As such, much of the research addressing the spoken language skills of international teaching assistants is interspersed with research and discussion on the teaching and learning of pronunciation to non-native speakers of English in general. 
Early on, this literature on pronunciation established the importance of spoken communication being interactive. Gilbert (1987) explains that there are two complementary and interrelated phenomena that need to be considered when examining non-native speech production and pronunciation: the speaker's production and the listener's perceptions. Further, she emphasizes that mutual comprehension is the result of a continual process of reassessment between speakers and listeners as communicative exchanges develop. The speaker and listener are in what Goffman (1971) termed an anchored relationship; one cannot exist without the other. As the research base in this area has developed, the importance of the speaker-listener connection has remained foundational in the thinking of second language pronunciation researchers. Recent research (Field, 2005) and reviews of research (Derwing \& Munro, 2005) in pronunciation reaffirm the importance of viewing foreign accent as a construct that includes both the speaker's production of language and the listener's perceptions of it.

The speaker-listener relationship has been influential in the research methodologies that examine speech production. While a limited number of studies related to international teaching assistant speech production employ technology to measure acoustical features of English and use this data for analysis by the researcher (Pickering, 2004; Wennerstrom, 1998), most research in this area enlists native speakers of English, either the researchers themselves or other trained native speakers of English, (Derwing, Rossiter, Munro, \& Thomson, 2004) to evaluate the spoken English being examined in the studies. A few studies (Derwing \& Rossiter, 2002; Riney, Takagi, \& Inutsuka, 2005) have also employed non-native speaker listeners to elicit their perspectives on spoken language proficiency. More recently, researchers (Bresnanhan, 
Ohasi, Nebashi, Liu, \& Shearman, 2002; Hahn, 2004) have used specific groups of listeners, e.g., undergraduates, in controlled environments for their perspectives on the speech produced by non-native speakers. These listeners are not trained language specialists; instead, they are an attempt to provide the perspective of a typical listener in a particular setting.

Research on the production of spoken English has been important in establishing the vocabulary for discussing and understanding what figures most prominently in clearly produced spoken English of non-native speakers and how it is perceived. The terms accent or accentedness, comprehensibility, and intelligibility have all become important constructs when discussing international teaching assistant speech production. To define and understand what the essential features are of clearly produced spoken English, this body of research examines the phonetic features and phonological patterns of spoken English: consonant and vowel articulations, stress patterns, intonation, and fluency. Initially, the emphasis of this research was on how non-native speakers produced English consonant and vowels articulations (segmentals), and how non-native speech deviated from native speaker patterns of speech production. However, as researchers have become more aware of the contributions other linguistic features make to clearly produced spoken English, this area of research has evolved to place more emphasis on suprasegmental production, such as stress, intonation, and fluency. Again, the research focus is on how non-native speakers deviate from nativespeaker control of these features of spoken English. 


\section{Accentedness, Comprehensibility, Intelligibility}

Research related to non-native speakers of English in instructional positions has focused attention on understanding and defining more precisely concepts of accuracy of production, fluency, comprehensibility and intelligibility. Leather (1999), Morley (1987, 1991), Levis (2005), Riggenbach (2000), Schmid and Yeni-Komshian (1999), and Wood (2001) have isolated and examined various components of pronunciation: segmentals (consonant and vowel articulations) and suprasegmental features (stress, rhythm, timing, and intonation) to provide detailed background on issues related to the production of spoken English. Central to all of this research are the key terms of accentedness, comprehensibility, and intelligibility.

Much of the early literature uses these three terms (accent, comprehensibility, and intelligibility), but there has been some flexibility with how they have been applied. More recently, however, researchers have more carefully and systematically established precise definitions for these terms. Building on their previous work, Derwing and Munro (2005) define these concepts and detail appropriate measures for each. Inherent in their definitions, once again, is the interconnectedness of the relationship between listener and speaker.

According to Derwing and Munro (2005), the first term, accentedness, refers to the listener's perception of how different a speaker's accent is from that of the language as spoken by members of the native speaking language community. The measure of accent or accentedness is usually measured in judgment tasks, with a range of possibilities from no accent to extremely strong accent. A theoretical native-speaker is assumed to be the norm and point of comparison, and in these studies, non-native 
speech production is measured by how it is perceived to deviate from the native-speaker norm. The term accent relates most closely with segmental (consonant and vowel) production, but is not necessarily limited to describing segmental accuracy in production.

According to Derwing and Munro (2005), the second term, comprehensibility, refers to the listener's perception of how difficult it is to understand a non-native speaker's speech. Once again, the measure of whether speech is comprehensible is obtained by way of judgment tasks and is evaluated on a relative scale of being extremely easy to understand to being extremely difficult to understand. In brief, both accentedness (accuracy of consonant and vowel articulations) and comprehensibility (degree of difficulty to understand) refer to the overall impression that the non-native speaker's speech production has on the listener, with the norm being an archetypal native speaker.

Accentedness and comprehensibility are central to the discussion of international teaching assistant speech, especially since undergraduates have characterized their international teaching assistants as having "heavy accents"-the reason why the undergraduates report that they are not able to understand or comprehend the non-native speech and therefore cannot access the material being taught by international teaching assistants. In many respects, the discussion and research that employ these terms start with the premise that speech can be evaluated in a context-neutral way. The assumption is that a given non-native speaker's speech characteristics are static, regardless of when and in which contexts the non-native speaker is communicating. In fact, as the research base in this area has developed, there 
are growing indications that context, role, relationship, and listener variables influence the degree to which non-native speaker speech is identified or characterized as accented or comprehensible (Bresnahan et al., 2002; Munro and Derwing, 1999)

Derwing and Munro’s (2005) third concept, intelligibility, has become an important construct for investigating and describing non-native speaker speech and its impact on the communicative exchanges in which non-native speakers participate. Unlike accent and comprehensibility, which depend on the listener's point of view of how difficult or easy a speaker is to understand based on the degree to which a nonnative speaker's production skills deviate from those of a native speaker's production, intelligibility is defined as the extent to which a listener actually understands an utterance. Intelligibility is measured not by a listener's perception, but rather it is measured by how accurately a listener can access and reproduce what a speaker has said, either through tasks of recall or transcription. The concept of intelligibility is central to discussions related to international teaching assistants in classroom environments where they are responsible for communicating information that undergraduates must be able to write down, understand, and learn.

How these three concepts relate to each other has also been a part of the discussion of speech produced by non-native speakers of English and how that speech is perceived by native-speaking listeners. Research by Derwing (2001), Derwing and Munro (1997), Derwing, Munro, and Wiebe (1998), and Munro and Derwing (1995, 1998, 1999) has looked at the more complex interaction of the various components of spoken English. Their work has shown that there is no simple correlation between 
intelligibility and nativeness of accent and that little is actually known about what aspects of second language pronunciation are most crucial to intelligibility.

Munro and Derwing (1999) show that accent itself is not necessarily a communication barrier. They point out that there are very few empirical investigations on how the presence of nonnative accent affects intelligibility, and the notions of heavy accent and low intelligibility have been confounded. Some of the key findings of their study are that even heavily accented speech is sometimes perfectly intelligible and that prosodic (suprasegmental) features appear to contribute more toward loss of intelligibility than phonetic (segmental) errors. Their findings suggest that the role of comprehensibility in accent judgments varies from listener to listener and that accent scores cannot be relied on as a means of assessing comprehensibility. Moreover, they find that accent scores are poorer indicators of intelligibility than are perceived comprehensibility scores.

\section{Production of Spoken English: Speaker Variables}

To date, the research has provided ambiguous results about how the concepts of accentedness, comprehensibility, and intelligibility interrelate, but an important goal for second language pronunciation research today continues to be identifying and understanding the factors that contribute to speaker intelligibility (Field, 2005). Research specializing in the examination of discrete linguistic features of spoken English (segmentals, stress, intonation, fluency) has provided important information about what features may facilitate or limit communication and have an impact on intelligibility. Considerable progress has been made in the past thirty years in our understanding of the various features of spoken language that may be important to 
successful communication and how those features might contribute to communication success and breakdown between international teaching assistants and their undergraduate students, even though the majority of this research examines decontextualized speech samples.

Segmentals

A large amount of research on segmentals (Browne \& Huckin, 1991; Derwing \& Rossiter, 2002; Morley, 1987; Morley, 1991) exists indicating that accented speech and imprecise control of consonant and vowel articulations contribute to communication breakdown. Various studies have indicated that the degree to which segmentals are controlled contribute to comprehensibility and intelligibility. Riney et al. (2005) found that native-speaking American listeners relied on segmentals when perceiving accent, and Schmid and Yeni-Komshian, (1999) determined that listeners required increased processing time to understand accented speech when compared to native-sounding speech, resulting in limited communication. A study by Major, Fitzmaurice, Baunta, and Balasubramanian (2002) found that non-native speaking accent contributed to decreased listening comprehension scores of both native-speaking and non-native speaking listeners. This research on control of segmentals indicates that segmental inaccuracies can and do have an impact on intelligibility by reducing it. Stress

Research in the area of English stress patterns indicates that the accuracy of stress placement also contributes to intelligibility and comprehensibility of spoken English. Most of the research on spoken stress patterns in English (Benrabah, 1997; Field, 2005; Hahn, 2004; Murphy, 2004; Piske, Mackay, \& Flege, 2001; 
Yeni-Komshian, Robbins, \& Flege, 2001) looks at lexical or word stress patterns in decontextualized speech, though stress as a feature of English can also have an impact on larger segments of speech, as well.

Looking at stress patterns on the word or lexical level, Benrabah (1997) points out that there are indications that spoken English with inaccurate word-level stress is a greater source of communication breakdown than inaccurate segmental production is and argues that if intelligibility is to be achieved when speaking English, then emphasis needs to be placed on word-level stress. Yeni-Komshian et al. (2001) also examine word-level stress accuracy in spoken English and argue from their study that when examining word stress it is important to recognize the impact of categorical features (e.g., noun or verb) of a word in measuring production and recognition accuracy. They found that for some listeners inaccurate word stress in nouns was more limiting to comprehensibility and intelligibility and that for other listeners with differing backgrounds inaccurate word stress in verbs was more limiting.

Research by Murphy (2004) moves the discussion of the importance of word stress for comprehensible and intelligible speech closer to more contextualized use of language. He states that for non-native speakers to communicate successfully the accuracy of word-level stress is essential for intelligible use of new words and specialized vocabulary. Accurately producing specialized vocabulary is particularly important for international teaching assistants because they are presenting the terminology of the discipline to their undergraduate students. Often, this is the first exposure undergraduates have to the terminology of the discipline: how it is pronounced, what it means, and how it is used. 
Understanding how control of stress patterns contributes to intelligibility on the word level is essential, but stress as a feature of spoken English is important for other reasons. Murphy and Kandil (2004) point out that control of word-level stress is a necessary foundation for non-native speakers because it is paralleled by stress at the phrase, sentence, and even larger discourse level. They also see stress as foundational for communication in that stress can be connected to other linguistic features such as vowel quality, pitch, rhythm, and intonation. Furthermore, they argue that proficient English speakers link non-verbal communication and gestures to rhythmic features such as stress placement to their speech. This observation indicates that stress may be an important feature in face-to-face interactions. Murphy (2004) also reiterates the importance of synchronizing gestures with words based on stress.

Another reason stress may contribute to comprehensibility or intelligibility is identified by Field (2005), who makes a connection between accurately produced stress patterns on the part of the speaker and their importance for the listener. He regards intelligibility as a two-way process, emphasizing the perceptions of listeners rather than the production of speakers. Although his study looks at de-contextualized language use (words presented in isolation rather than in extended discourse), he asserts that an important function of lexical (or word-level) stress is that it enables listeners to divide stretches of continuous English speech into separate words. He argues that this segmentation technique is a critical listening skill and is influential for comprehensibility.

Finally, the most important ITA speech research to date on control of stress is a study by Hahn (2004). In an attempt to understand the impact of stress patterns in a 
slightly more contextualized way, Hahn (2004) examined the reactions that native speakers of English had to non-native primary stress in English discourse. Hahn’s research measured undergraduate processing, comprehension, and evaluation of ITA speech in three conditions: with primary stress placed accurately, primary stress placed inaccurately, and primary stress missing entirely. Although her study depended on recorded speech that manipulated the features of stress, what is noteworthy about her study is that she used more contextualized speech samples, typical classroom lecture information, and had typical listeners, undergraduates, provide their perceptions of the speech they were hearing. Results of her study indicate that participants recalled significantly more content and evaluated the speaker more favorably when primary stress was correctly placed as opposed to when primary stress was missing or incorrect.

In sum, the research on accuracy and control of stress, though mostly decontextualized research focusing on word-level stress patterns, indicates that inaccuracies of stress patterns can reduce a speaker’s intelligibility.

\section{Intonation}

Intonation is another linguistic feature that research has indicated is important for the delivery of comprehensible and intelligible speech. Levis (1999, 2004) identifies the importance of intonation for communicating meaning and notes that researchers have long claimed that prosody, especially intonation, is critical for interpreting speech. Unlike segmentals and stress patterns that can be tied to individual words, intonation patterns (or contours of pitch variation) occur over larger stretches of speech, the phrase or sentence level. Researchers analyzing intonation have, therefore, had to focus on speakers engaged in extended periods of speaking, with lectures the most common 
source of speech examined. The most important research investigating intonation patterns used by international teaching assistants has been carried out by Pickering (2001, 2004) and Wennerstrom (2000).

In much the same way that research on segmental control and stress patterns has used methodologies that compare non-native speaker production to native speaker norms, so too has the research on intonation. Pickering (2001) used speech samples recorded from presentations in classrooms and analyzed tone choices, comparing the speech patterns of non-native speakers of English to native speakers of English. Source materials came from lectures in the fields of chemistry, physics, and engineering. Pickering reports through her analysis of the speech patterns that the native speaking teaching assistants systematically used tone choice to increase the accessibility of the lecture material and establish rapport with their students. Conversely, she finds that the intonational composition of the international teaching assistants’ presentation of information was absent and therefore contributed to listener confusion and led to the perception that these speakers were indifferent and uninvolved. From her analysis and interpretation, she suggests that tone choice contributes to communication failure between international teaching assistants and their students, and she recommends that tone choice be directly addressed in the linguistic and pedagogical component of international teaching assistant preparation programs.

In another study, Pickering (2004) compares how native and non-native speaking teaching assistants use intonation patterns as an organizational tool in instructional discourse. Once again, her analysis and interpretation of the data show that the non-native speaking teaching assistants had weaker control over intonation patterns 
than the native speakers. While she did not directly measure student comprehension of the discourse of the international teaching assistants or the native-speaking teaching assistants, her analysis and interpretation of the data guide her to the conclusion that intonation is important for providing organizational structure and is a strong predictor of the effectiveness of academic lectures.

While the research by Pickering $(2001,2004)$ looked at speech in lectureformatted discourse, some work on intonation has looked at how intonation may contribute to interactive speaking. Wennerstrom (2000) argues that intonation is one of the important variables contributing to fluent speech and conversational interaction. She finds that fluent speakers in her study were better able to use pitch to signal relationships among words and phrases and were better able to segment their speech into turns in conversation, indicating the significance of intonation for interactional speaking.

The ITA research on intonation identifies that this linguistic feature is important for communication and may in fact contribute to comprehensibility and intelligibility. Intonation provides information at the discourse level by indicating cohesion of ideas, degree of involvement, and aspects of interactivity in speaking. Research on intonation has examined speech samples from actual face-to-face communication and is more contextualized. However, researchers external to the communicative activity have been the ones who have judged the impact of intonation on communication. Research on intonation has not verified that these conclusions are supported by the people actually involved in the communication. 


\section{Fluency}

The last area of research on spoken language performance examining linguistic features discusses fluency. Many researchers (Derwing, Thomson, \& Munro, 2006; Riggenbach, 2000) have acknowledged that defining fluency is a complicated task. Wood (2001) indicates that although fluency can be used to describe overall proficiency, it also has the more restricted usage referring to temporal aspects of speech: rate or speed of delivery and pauses-frequency of or length of pauses. The latter definition has been used for examining the speaking patterns of international teaching assistants.

Looking at the temporal measures of spoken English, researchers have been concerned with how fast language is produced and when language is not presentpauses or silence. Overall rate of speech has been shown to be important for successful communication by non-native speakers having difficulties controlling segmental production, with faster rates resulting in decreased intelligibility (Anderson-Hsieh \& Dauer, 1997; Derwing \& Munro, 2001; Derwing, Thomson, \& Munro, 2006). Fayer and Krasinski (1995) have taken a complementary view by investigating how fluency and comprehensibility are influenced by pausing patterns and hesitations in speech. They found that the location and extent of pauses and hesitations also limit communication between native and non-native speakers. They further find that in some cases, pauses and hesitations can cause irritation and frustration for listeners, which further limits the listener’s desire to interact with the non-native speaker.

The ITA research on fluency provides additional information about what linguistic features may contribute to comprehensibility and intelligibility. Temporal 
features of speech influence how information is perceived by the listeners. As is the case with ITA research investigating segmentals, stress, and intonation, research on fluency tends to examine de-contextualized speech samples with observers external to the communicative exchange judging the impact fluency has on the actual communication.

While the research on the linguistic features of non-native speaker production of English contributes to our understanding of where these features may be factors in communication success or breakdown, other research directs attention to how listeners adjust and adapt to non-native speech patterns. Bradlow and Bent (2008) found that even when Chinese-speakers had various degrees of accented English, listeners demonstrated that they were able to adjust to the accented speech. Their research provides evidence that even when spoken English deviates from native-speaker norms, native English speakers can flexibly and fairly quickly adjust to the accented English. Although this research was conducted in de-contextualized experimental conditions, it raises the question of how native speakers might demonstrate the same flexibility in adapting in face-to-face interactions to non-native speech that deviates from native speaker norms.

\section{Perceptions of Spoken English: Listener Variables}

The ITA research on the linguistic aspects of non-native speech has shed light on what may contribute to comprehensible and intelligible speech in terms of variables of speech production. The research has also indicated that various contexts and listener variables may influence how non-native speech is perceived and may contribute to mutual comprehension between speakers and listeners. As Munro and Derwing (1999) 
have mentioned, the discussions of production and perception of spoken English require researchers to take into consideration listener variables.

More recent research (Munro, Derwing, \& Morton, 2006) recognizes that when understanding or evaluating non-native accented speech, listeners are affected not only by properties of the speech itself but by the listeners' own linguistic backgrounds and their experiences with different speech varieties. Munro, Derwing, and Morton (2006) advocate for a position that requires researchers to understand the basis for listener responses and reactions to speech produced by non-native speakers. They acknowledge that reactions to speech may be attributable to the phonological features of the speaker's production, but that responses to that production may vary with the listeners' familiarity with a particular accent or listeners' linguistic backgrounds. They contend that the most valuable information about whether a particular speaker is intelligible is likely to come from the people with whom the speaker seeks to interact.

In classroom interactions with non-native speaking international teaching assistants, undergraduates have been critical of and sensitive to non-native accent and have often displayed a lack of receptivity to and tolerance for non-native speech in university-level classrooms. An important goal for researchers should be to have an understanding of the factors that figure into listener's judgments and, in particular, how much those judgments are influenced by properties of the speech and by characteristics of the listeners (Munro, Derwing, \& Morton, 2006).

To address this research goal, Bresnahan et al. (2002) conducted an innovative study of judgments of fluency (in the sense of overall spoken ability) and intelligibility. The methods used to obtain listener judgments were established to control certain 
variables, and the undergraduate listeners responded to recorded speech crafted to emulate discourse commonly found in classroom lectures and casual communication. Their results indicate that perceptions of a speaker's accent, fluency, and intelligibility can vary based on the role the speaker has in an interaction. In this study, non-native speakers were perceived as being more intelligible when they were cast in friendship roles and less intelligible when they were functioning in the role of an instructor. The researchers also investigated the impact that listener backgrounds had on the judgments made by listeners, finding that more diverse backgrounds led to greater acceptance and tolerance for non-native speech.

This study is significant for three reasons. First, undergraduates, rather than researchers or trained evaluators, were used to evaluate the performance of the nonnative speakers in the experimental study. Second, their findings reveal important contextual considerations: when looking at issues related to perceived intelligibility and fluency, researchers need to take into account the context in which the interaction occurs and the relationship the speaker has with the listener. Third, aspects of listeners' backgrounds can influence their perceptions and evaluations of the speech they hear.

This study moves the research on spoken English closer to investigating and understanding the role and degree of participants' engagement in an interaction. Nonetheless, the study is limited in that the participants were not involved in personally meaningful interactions. The speech evaluated in this study was typical of casual and classroom communication, but it was ultimately de-contextualized speech. The speaking in the recordings was delivered as an uninterrupted monologue, typical of the speech in a lecture. The speech was not interactive, spontaneous speech typical of face- 
to-face interactions, nor was it lecture material that the participants needed to grasp and reproduce. Undergraduates who are invested in communicative interactions in the real world with international teaching assistants may respond and interact differently in face-to-face interactions and in their courses than what the de-contextualized research in this area indicates.

Listener perceptions of speech also have a social dimension that contributes to the way that communicative exchanges develop (Lippi-Green, 1997; Llurda, 2002). Pointing out that much of the research into spoken language has been interested in establishing which linguistic errors are regarded as causing problems of intelligibility and which are most disturbing to native speaker listeners, Llurda (2002) argues that language has a social component, in which features of the spoken language, grammar, vocabulary, pronunciation, and speaking rate determine how listeners perceive speakers and respond to them. His study analyzed the reactions American undergraduates had to passages read by non-native speakers and found that proficiency and intelligibility were more highly correlated with competence-related perceptions, such as intelligence, degree of education, leadership ability, and commitment to working hard. Listener assignment of attributes, qualities, and characteristics of a speaker go beyond the mechanics of speech production. In real-world interactions, the assignment of these characteristics can influence how and to what extent the undergraduates interact with the speaker and their degree of engagement in the communicative exchange.

The de-contextualized research examining listener variables tells us that a listener's response to a speaker is influenced by what the speaker does, the relationship between the speaker and the listener, and the background characteristics of the listener. 
It also indicates that listeners evaluate speakers on social dimensions, which may contribute to how a listener interacts with the speaker. These studies may help us understand what may be happening in the classroom interactions between undergraduates and their international teaching assistants by shedding light on what additional factors may facilitate or interfere with communication.

Overall, the research on international teaching assistant speech production and perceptions suggests the need to examine non-native speech in the contexts and practical situations in which speaking occurs. Research examining linguistic features of spoken language in de-contextualized settings helps us understand the linguistic features that may be important for communicating in real-world communication, yet the research investigating the impact that the listener variables have on how speech is perceived points to the limitation of focusing exclusively on the speech itself, rather than looking at the participants and their roles in shaping how the interactions are understood, develop, and proceed. Research on listener variables highlights that prioritizing the decontextualized linguistic aspects of speech may not provide sufficient understanding for improving the actual classroom communication patterns that exist between undergraduates actively engaged in learning with international teaching assistants. Research that prioritizes communication in real-world classroom interactions is a necessary complement to the research that emphasizes the linguistic aspects of speech production and speech perception.

Communication Research on International Teaching Assistants in Context The second area of research pertinent to understanding the communicative patterns and interactions between international teaching assistants and their 
undergraduate students are studies that look at communicative interactions in context. The research examining production and perceptions of spoken English has identified features that are important in communication between international teaching assistants and their undergraduate students. However, this research does not inform us about when and why an undergraduate in a real-world interaction would stop communicating with a non-native speaking teaching assistant and when the undergraduate would persevere and continue communicating with that teaching assistant. In real-world interactions, communication goes beyond the mechanics of speaking and listening. Treating communication, rather than speech, as primary directs us to investigate in greater depth the context in which communication actually occurs so as to understand how and to what degree the linguistically based deviations from native speaker norms of international teaching assistants matter in their real-world classroom interactions with native English speaking students.

The research base investigating the communication patterns of international teaching assistants and their undergraduate students in teaching contexts is much smaller than the research focusing on the linguistic aspects of non-native speaker speech. However, the few studies that exist are rich sources of information. While some of the real-world based research is from actual classrooms (Tanner, 1991; Williams, Inscoe, \& Tasker, 1997), some research uses different settings related to international teaching assistants. One approach to emulating real-world communication involves role-play situations between international teaching assistants (when they are students in international teaching assistant preparation programs) and undergraduates (Tyler, 1992). 
Researchers have also analyzed interactions of prospective international teaching assistants in English proficiency interviews (Jenkins \& Parra, 2003).

\section{Discourse-Level Influences on Communication}

One cluster of in-context studies investigating international teaching assistant speech is interested in understanding how English is used pedagogically by native and non-native speakers. The impetus for these studies was to see if there were discourselevel factors beyond purely linguistic factors that provide a more complete understanding of why non-native speaker communication with undergraduates was either successful or unsuccessful in actual classrooms. Methodologically, these studies use a comparative approach to examine the issue of international teaching assistant discourse, establishing a native-speaker norm and measuring how closely non-native speakers approach this standard. Success of non-native speech is then determined by how closely it approximates native-speaker speech patterns. These studies identified additional factors that contribute to classroom communication: the way that speakers structure their discourse, the impact that culturally learned styles of communication have on facilitating or impeding communication, and the ways that speakers and listeners communicate information non-verbally.

\section{Discourse Structure}

The main research investigating discourse structure emphasizes discourse marking (the overt indicators of what a speaker's intentions are), the use of pronouns, and patterns of instructional silences. Research (Tyler, 1992; Williams, 1992) has shown that non-native speakers do not mark discourse in the same way that nativespeakers in instructional positions do. The main finding of this research is that non- 
native speakers use discourse marking less often and therefore less effectively than native speakers do. The research findings suggest that overall comprehensibility of the discourse of non-native speakers is reduced as a result.

Other aspects of discourse structure that have been seen as contributing to successful classroom communication include both pronoun use and pacing of lectures through the use of pedagogically inspired silences. Rounds (1987) and Fortanet (2004) examine the use of inclusive pronouns $I$, we, and you. Both researchers determine that pronoun selection and use in instructional discourse contribute to successful classroom communication and are correlated with communicative competence in classrooms. Rounds (1987) also reports that the strategic use of silences for pedagogical purposes in lecture-format classes contributes to successful classroom communication, especially when the non-native speakers' usage approaches native speaker patterns.

\section{Cultural Communication Patterns}

Research related to cultural aspects of communication patterns in university classrooms has focused on cultural communication patterns between native speakers of Chinese and native speakers of English (Flowerdew \& Miller, 1995; Scollon, 1996). In general, this research is situated in lecture-style teaching contexts in which the Chinese speakers are the learners and the native English speakers are the instructors, with much of the research occurring within an Asian educational environment, frequently in Hong Kong. Even though the majority of research relevant to university-level classroom communication between Asians and Westerners reverses the roles of the instructors (English speakers rather than Chinese speakers) and students (Chinese speakers rather than English speakers) from that of international teaching assistants in American 
universities, this research identifies that differing cultural communication patterns may influence how interlocutors interpret and perceive information. This research has found that the meanings, motivations, and intentions that interlocutors assign to classroom communication are often based on different cultural assumptions and practices.

Much of the discussion of cultural differences between Asians and Westerners (Nisbett, 2003; Scollon \& Scollon, 2001; Scollon, 1996; Flowerdew \& Miller, 1995) focuses on how Confucian and Socratic values influence communication patterns in a range of contexts, with a primary focus on academic environments but other professional settings are also considered. Flowerdew and Miller (1995) contrast the Confucian values of respect for authority of the instructor, not questioning the instructor, the positive value placed on silence, and emphasis on group orientation to learning, with the Western values of the instructor being a guide or facilitator who is open to challenges from students, the positive value on student self-expression, and an emphasis on individual development.

This research looks to cultural differences as a way to locate and recognize where communication difficulties may appear, as well as exploring increased cultural understanding as an approach to resolving miscommunication that may arise from culturally influenced styles of communication. As Scollon and Scollon (2001) point out, when communication occurs between people of different cultural backgrounds, it should be assumed that there will be miscommunications originating from the differing inferences people make based on their cultural understanding of how communication should unfold. While much of the culturally based research contrasts Asian and Western educational styles and environments, recent discussion has highlighted how adult 
learners can be open to and culturally receptive to differing styles of communication and supports that adult learners demonstrate cultural adaptability to differing styles of learning and educational environments (Kennedy, 2002). While this research identifies the powerful influence that culture plays in communication patterns and styles, it also indicates that in face-to-face interactions adults demonstrate flexibility and adaptability to different cultural styles of communication in classrooms.

Research investigating international teaching assistant communication patterns with their undergraduate students has found that communication breakdowns in face-toface interactions occur because of differing cultural communication patterns (Davies \& Tyler, 1994). Tyler (1995) analyzed a videotaped interaction of an arranged instructional encounter between an international teaching assistant enrolled in an English language course and an American undergraduate seeking assistance prior to an exam. The analysis revealed that the interactions between the two participants were governed by cultural norms. The non-native speaker adopted communication and teaching strategies that were typical for an Asian teaching environment, but which were confusing and frustrating to the American student. Similarly, the American undergraduate used a communication style typical of an America student, which the non-native speaking teaching assistant did not recognize, and as a result, the teaching assistant responded in ways that limited the success of the interaction.

\section{Non-Verbal Communication}

Just as differing patterns of discourse style and differing cultural assumptions about communication contribute to communicative success or failure in face-to-face interactions, so too does non-verbal communication. In real-world communication, as 
Pennycook (1985) shows, there is a constant interplay of different channels of communication. What is spoken is only one part of the message communicated in faceto-face interactions. Information is also communicated visually. His work points to the importance of non-verbal communication for non-native speakers as a part of their overall communicative competence. Non-verbal communication differs from discourse styles and cultural communication, in that these two aspects of in-context communication are different ways of manipulating the verbal message. However, nonverbal communication, which may include a cultural component, e.g., the amount of eye contact, provides information beyond the verbal message, information that may either be redundant or supplemental.

For communication patterns examining non-verbal communication of international teaching assistants, the most informative work is that of Jenkins and Parra (2003). While their research does not look at classroom interactions per se, they do examine the communicative patterns of international teaching assistants participating in an English oral proficiency interview. Their analysis of the videotaped interactions, using frameworks established by Kendon $(1980,1990)$ and McNeill (1992, 2000), finds that the non-verbal communication patterns of eye contact and gestures carry meaning and contribute to the success of non-native speakers in the interview. In their analysis they also show that the effective use of non-verbal communication patterns can compensate in many cases for weak linguistic skills.

The results of Jenkins and Parra's (2003) investigation identify areas in which non-verbal behaviors or skills increased the non-native speakers' overall communicative effectiveness: active listening, turn-taking behavior, and involvement 
strategies. Attentive listening behaviors included frequent eye contact, facial expressions such as smiling, movements closer to a speaker, vocalizations (e.g., backchannels), and nodding. All of these behaviors were seen as signs that the nonnative speakers were communicatively competent. Turn-taking behaviors, which Jenkins and Parra indicate may be culturally influenced, included the conversational moves that signal that the listener understood the message and that control of the floor was changing. The coordinated behaviors and actions (linguistic, non-verbal, and cultural) were all part of the collection of features that enabled linguistically less proficient speakers to interact successfully in the interactive interview environment. When speakers who were linguistically less competent did not demonstrate these features, they were not considered successful communicators.

The significance of Jenkins and Parra's (2003) study is that non-native speakers who may not have fully developed linguistic resources to communicate do in fact succeed in communicative interactions because of their abilities to access and employ other communicative techniques and strategies necessary for interpersonal communication. Jenkins and Parra’s study reveals that when engaged in face-to-face communication non-native speakers can successfully communicate in spite of linguistic limitations. This observation recalls another by Hamilton (2001) that "people can and do manage the most complex social interactions, even in the face of formidable linguistic and cultural obstacles” (p. 86).

\section{Teaching Contexts of International Teaching Assistants}

In addition to the in-context research that has investigated discourse-level factors that might contribute to successful classroom interactions between international 
teaching assistants and undergraduates, other in-context research has shown that teaching contexts contribute to how speakers and listeners behave and communicate with each other. When researchers on ITA communication in the late 1980s and early 1990s began looking at the discourse of international teaching assistants in actual teaching settings, they found that the characteristics of different teaching environments shaped the communicative demands placed on teaching assistants, native speaking and non-native speaking alike. The language and communication skills required of international teaching assistants needed to be considered within the contexts in which they are used and practiced (Hoekje \& Williams, 1992).

Axelson and Madden's study (1994) is the most extensive examination of the various teaching contexts in which international teaching assistants function and how these educational environments make different demands for instructional communication. The goal of their investigation was to determine the linguistic activities teaching assistants engaged in and what duties they performed so that preparation programs for international teaching assistants could be tailored to meet the demands of the various teaching contexts. Analyzing data collected from office hours, laboratory sections, and classrooms taught by teaching assistants, they catalogued the duties, responsibilities, and linguistic demands placed on teaching assistants in these various teaching contexts. While they identify some features that are common to all teaching environments, such as using greetings to create the appropriate classroom atmosphere, they also report that the three different teaching contexts demand different communicative skills and behaviors. 
Their description of the language functions and tasks required of teaching assistants finds clear differences in the communicative demands of office hours, lab sessions, and discussion or lecture sections. The main distinction occurs between lecture formats of information delivery (lecture sections) and more interactive communication (office hours and labs). This research emphasizes the speaking demands placed on international teaching assistants and how those demands vary based on the context. However, as with the majority of ITA research literature, the focus is on the language or type of language that international teaching assistants are expected to produce in the various teaching environments, with little or no emphasis on receptive language skills required in classrooms.

Axelson and Madden (1994) find that office hours and lab sections share many common characteristics that lecture-type discussion sections do not share. A primary similarity is that office hours and lab settings are both contexts in which attention is paid to individual students. They identify, however, that there is a significant difference in these two settings related to the types of problem solving involved. They find that in the labs, problem solving usually relates to successfully completing an experiment, while in office hours the problem solving revolves around understanding subject matter.

While Axelson and Madden’s research (1994) emphasizes how teaching assistants should use language in various classroom environments, there is limited attention given to aspects of question-answer interactions more common in office hours and lab sections, where international teaching assistants are responding to undergraduate questions, i.e. listening skills. The primary research literature that explores the demands of academic listening is Flowerdew (1994). He identifies some of 
the differences that exist between what can be characterized as conversational listening and academic listening. According to Flowerdew, academic listening, such as listening to a lecture, requires more background knowledge on the part of the listener, while in conversational listening background knowledge is more general in nature. Another difference is that conversational listening requires distinguishing between what is relevant and what is not, i.e., recognizing digressions, asides, and other communicative activities associated with the main message.

Flowerdew (1994) discusses that additional differences between academic and conversational listening include the use of turn-taking behaviors, which are largely absent from academic listening (lecture-style delivery of information), but which are essential for conversational listening (more typical of question-and-answer format interactions). Another difference between academic listening and conversational listening is that academic (lecture-style) listening depends on the abilities of the listeners to concentrate on and understand larger stretches of discourse with little opportunity to engage in interactive discourse, such as asking for repetition, negotiating, and using repair strategies (p. 11). The purpose of lecture-style delivery is to convey information, whereas conversational listening is more interactive and typical of question-answer exchanges.

\section{Interactive Classroom Communication}

The in-context studies investigating actual classroom communication between international teaching assistants and their undergraduate students has looked at the teaching contexts of office hours, lab sections, and lecture sections of courses in mathematics and the sciences. Because this group of studies looks at interactive 
communication between teaching assistants and undergraduates, the studies have focused mostly on question-answer interactions. In general, these studies examine questions that the teaching assistants use to guide undergraduate learning, with some attention paid to questions undergraduates ask. However, within the existing body of ITA interactive communication research, the interactive nature of these communicative exchanges has not been explored as has been done in other areas of sociolinguistic research (Clyne, 1994; Drew \& Heritage, 1992; Tannen, 1989) or research on classroom communication (Cazden, 2001).

Methodologically, all of these studies share a similar approach, documenting the communication of the teaching and learning environment with either audio or video recordings. The researchers then analyze and interpret the collected data. With the exception of one study (Williams et al., 1997), which collected and analyzed data only from non-native speaking teaching assistants, these studies use a comparative approach to analyzing and interpreting their data. The researchers collect data for both native and non-native speaking teaching assistants in the various contexts. The communication patterns of the non-native speakers in these studies are then compared to their native speaking counterparts. The success of the non-native speakers is defined and measured

by how closely they approximate the native-speaker patterns of speech performance and use.

\section{International Teaching Assistant Communication}

Rounds' study (1987) is one of the earliest attempts to look at interactive communication in a classroom setting. She looked at five 50-minute calculus classes taught by native and non-native speakers in the second week of a mathematics course 
delivered in a lecture format. The purpose of the study was to characterize successful teaching discourse for this domain, and the use of questions by the teaching assistants is addressed as one area of significance in the communicative interactions. As she points out, teacher-generated questions provide a pedagogical function when used to walk students through a problem for problem solving. While this study was designed to look at classroom communication that could be seen as interactive, the focus of her analysis was on the information that the instructors of the course delivered to the students. Rather than emphasizing the interactive nature of classroom communication, results of this study focus more on the discourse styles of the teaching assistants.

McChesney (1994) also examined interactive communication in the domain of mathematics. Her study examined communication in the more interactive setting of office hours, focusing on the questions used by the mathematics teaching assistant during office hours and how those questions guide student learning. In this study, the teaching assistant and the undergraduate were engaged in a one-hour session prior to a calculus exam. Analyzing the 432 turns, McChesney concluded that language use and behavior in the office hour can be characterized as the teaching assistant responding to many questions from the undergraduate, and that in general, the topics for the interactions were identified by the undergraduate. While McChesney observes that the undergraduates establish the topics to be covered in the office hour setting, she finds that in office hours the teaching assistant directed undergraduate learning by actively telling undergraduates what to do and by observing and commenting in order to encourage the students to engage in self-directed learning. In order to guide student learning, the teaching assistant asked evaluative wh-questions to break problems into 
manageable steps for the undergraduate and provided praise and other positive reinforcement to the undergraduate. While this study examines more interactive communication in this discipline than the Rounds' (1987) study, it still emphasizes primarily the instructor's communicative behaviors in these interactions.

In-context research in science labs has provided more studies that look at interactive classroom communication between international teaching assistants and undergraduates. Tanner (1991) researched interactions in an introductory-level chemistry lab, comparing a total of six teaching assistants, three native-speaker and three non-native speakers. With data collected through observations and video recordings, Tanner focused his analysis of the question-answer interactions in the lab setting on the questions that teaching assistants pose to undergraduates to guide student learning. His study uses Kearsley’s (1976) typology, which categorizes questions based on form and function of the question. Question forms included open-ended (whquestions) and closed questions (yes/no questions or alternative choice questions). Question functions included referential, display, rhetorical, comprehension check, and confirmation check questions. His findings were that teaching-assistant generated questions served several important functions in helping students by monitoring their progress as they performed the experiments, providing students with encouragement, and assessing their progress. In this study, interactive communication was limited to the questions that the teaching assistants addressed to the undergraduates.

A later and slightly broader investigation of question-answer interactions in science labs is a study by Myers (1994). The goal of her study was to have a clearer picture of the requirements of lab teaching and the communicative demands of the labs. 
To do this, her research project involved observing thirty-five teaching assistants in eight departments. The teaching assistants had a range of teaching experience, from successful, experienced teaching assistants to novice teachers. The teaching assistants included both native and non-native speaking teaching assistants. Recorded data from a subset of five international teaching assistants' question-answer interactions in the labs were analyzed and reported in this study.

The focus of Myers' (1994) research project was on the functions of questions lab assistants ask their students. The classification scheme for the questions asked by teaching assistants was again based on Kearsley’s (1976) typology, categorizing questions based on their form and function. According to Myers, the discourse of labs is varied and unpredictable. She found that the teaching assistants in labs must be able to engage in a wide range of communicative interactions including explaining the procedures of an experiment; explaining and reinforcing safety regulations; carrying out administrative responsibilities, such as managing time and people; having knowledge of the apparatus and being able to describe it; formulating questions to facilitate student learning; being able to adjust apparatus when it malfunctions; and, answering student questions. From this extensive list of teaching assistant duties and responsibilities, it is clear that the laboratory teaching environment makes multiple demands on any teaching assistant’s linguistic and pedagogical abilities.

The most recent study investigating teaching assistant-initiated question-answer interactions looked at communication in a chemistry lab and was conducted by Williams et al. (1997). This study differs substantially from other in-context research: it is the only study that looks exclusively at the interactions of non-native speaker 
teaching assistants with their undergraduate students and intentionally avoids comparing the communication patterns of the non-native speakers to those of native speakers. They argue that even though international teaching assistants have accented English, they can be successful in their interactions with their undergraduate students. Unlike other research that attempts to explain communication failures of international teaching assistants as the result of their differing communication patterns from native speakers in similar environments, the goal of this study was to shed light on the question of how these non-native speakers, with limited oral proficiency, can communicate successfully in the setting of an advanced organic chemistry lab.

This research project looked at an advanced-level chemistry course because the researchers wanted to avoid some of the complexities associated with teaching first-year students in an introductory-level course. As such, the undergraduates in this study were established as majors in chemistry or a related field and were not first-year students. The undergraduates already had a favorable attitude toward the discipline and had identified that it was an important course for their future career goals. In essence, these students were already familiar with the chemistry lab environment and were committed to learning the material.

Using data collected from three videotaped organic chemistry laboratory sessions of two hours each, the three researchers analyzed the question-answer interactions between the international teaching assistants and their undergraduate students. Once again, this study focused on the types of questions generated by the teaching assistant, examining the teaching assistants' use of confirmation checks, comprehension checks, clarification requests, and reformulations. They determined that 
most teaching assistant-initiated communication functions to provide confirmation or clarification of information the students needed to know in order to complete the experiments.

The results of their study indicate that the success of these interactions was a collaborative undertaking on the part of both parties. The researchers also identify that there was a tendency to break down the tasks into smaller more manageable tasks that more directly focused the interactions. In summary, the results of this investigation were that even though the international teaching assistants had limitations with their language and communication skills, their interactions with their undergraduate students were in general successful because both the teaching assistants and the undergraduates were committed to achieving success in the interactions. Furthermore, this study points out that, unlike the previous research which posited a native-speaker norm for communicative success, internationals teaching assistants can and do achieve success in university classrooms, in this study of a lab environment.

\section{Undergraduate Communication}

Undergraduate classroom communication with international teaching assistants has received limited attention in the research literature. Research related to undergraduate communication has tended to look at undergraduate preferences for styles of communication in classrooms taught by international teaching assistants. For example, Plakans (1997) and Axelson and Madden (1994) present evidence suggesting that undergraduates strongly prefer an interactive, informal, personalized, and supportive atmosphere, especially in courses taught by teaching assistants. 
Researchers (McChesney, 1994; Myers, 1994; Yule, 1994) have identified that one of the discourse competencies required of international teaching assistants in interactive classrooms is responding to undergraduate questions. In approaching undergraduate questions, it has been noted that international teaching assistants often experience difficulties interpreting questions directed at them, even if they understand the individual words contained in them (Hoekje \& Williams, 1992). However, only a few studies have looked at or made mention of what undergraduate classroom communication is, with a few studies suggesting that studies looking at undergraduate communication might be useful avenues of investigation (Rounds, 1994; Tanner, 1991).

McChesney (1994) notes that teaching assistants respond to many student questions; however, her discussion does not investigate how undergraduates communicate in classrooms taught by international teaching assistants. To date, only one research study has been devoted to exploring issues related to undergraduate questions. Rounds (1994) has attempted to look at the kinds of questions undergraduates ask as a way of increasing the understanding of questions in the university classroom and providing a basis for developing a model of international teaching assistant communicative competence with regard to questions.

Rounds’ (1994) data from a university-level lecture-style mathematics class show that questions are a "relatively minor part of the mathematics classroom discourse” (p. 107). She speculates that there are few student-initiated questions because the undergraduates experience peer pressure and are afraid to ask questions for fear of losing face. Further, she asserts that this reluctance to ask or distaste for asking questions is evident in student reactions to teachers' solicitations for questions, which in 
her data were met with no response. She further characterizes undergraduate questions as being "informal and ill-formed questions" (p. 113), citing this as one of the difficulties international teaching assistants face in classroom communication. While Rounds sees questions as the first step in developing an interactive learning environment and as highly valued in an American educational context, she suggests that international teaching assistants can learn strategies to "control the occurrence and flow of questions” (p. 112), though it is unclear whether she means that the international teaching assistants should encourage undergraduate questions or discourage them.

In other classroom research that mentions undergraduate questions, the undergraduate questions are frequently dismissed as unimportant or disparaged. Rounds (1987) states that one of the linguistic demands of teaching assistants is "the ability to respond to student questions, which are often ill-formed and colloquially phrased” (p. 644). Myers (1994) identifies much of the discourse of the science lab is motivated by undergraduate questions, and she notes that answering questions generated by students should be an important part of the preparation of international teaching assistants. However, she minimizes the questions that undergraduate ask by stating "the content of these questions, especially in an introductory course, is often superficial” (p. 91). She concludes that undergraduate questions about getting the experiments to work and making sure that they are following directions properly are not sufficiently important questions. She further criticizes undergraduates for not asking questions about "why the experiment is set up the way it is, how the experiment validates their theoretical knowledge of the discipline, or what the processes of the experiment will teach them” (p. 91). 


\section{Summary of Research}

Collectively, the research literature on international teaching assistant communication is united by a shared assumption: the closer a non-native speaker can produce language that approaches the accuracy of a native English speaker, the more successful the non-native speaker will be as a teaching assistant. This assumption has influenced how almost all research in this area has been structured: comparing nonnative speakers with native speakers to understand how non-native speakers deviate from the native-speaking norm, which will explain why the non-native speaking teaching assistants are not successful communicators in classrooms.

The majority of research related to non-native speakers of English in instructional positions has been grounded in research related to pronunciation. This is not surprising given that the issues and concerns about international teaching assistants in instructional positions have focused on the ability of the non-native speakers to accurately produce comprehensible and intelligible spoken English. This area of research has provided us with a vocabulary for discussing communication patterns between these two populations, specifically the constructs of accentedness, comprehensibility, and intelligibility.

Research has identified that the mechanics of spoken English, i.e., control of stress patterns, intonation patterns, segmentals, rate of speech, hesitations and pauses, all contribute to communication success and difficulties. Furthermore, this research base directs attention to examining the listener variables in interactions, as listener background characteristics and relationship to a speaker influence how the listeners perceive non-native speaking and react to non-native speakers. However, this research, 
conducted primarily in de-contextualized settings with judgments about the communication coming from people who are external to the communicative exchange, does not provide information about how these features are prioritized in real-world communication, nor does it provide information about how the people actually engaged in communicative exchanges view or perceive the communication.

More contextualized research of ITA speech has provided information about the speaking patterns of non-native speakers and native speakers in teaching contexts and how the speech and speaking style are perceived by native speakers of English in these educational environments. The research indicates that non-native speakers in these environments employ different communication strategies and patterns, beyond the purely phonological differences. Some of these communication pattern differences originate from differing cultural assumptions and practices related to communication in teaching contexts (that is, miscommunication can be traced to differing cultural patterns of communicative expectations in the classroom environment). Other sources of communication difficulties between these two populations have been traced to differing styles of discourse organization between non-native speakers and their native speaking counterparts (for example, differing use of organizational features such as discourse marking or pronoun usage). The research on ITA classroom communication to date assumes that undergraduates expect and prefer these organizational features of communication patterns of the native speakers, whom they are more accustomed to hearing and learning from in classroom settings. However, there is no research to confirm that undergraduates actually engaged in classroom communication with international teaching assistants think this way. 
The more contextualized ITA research also indicates that additional information available in face-to-face interactions can facilitate or inhibit communication, by supplementing and providing redundancy for what is already available in these interactions. Research related to non-verbal communication in educational contexts of international teaching assistants provides the understanding that in real-world communication, verbal channels of communication are coordinated with and supplemented by visual channels of communication. Information conveyed in face-toface interactions through both channels of communication has been shown to facilitate successful communication.

Research looking at interactions between undergraduates and international teaching assistants in classroom contexts has also provided important information about the communicative demands that exist in real-world teaching and learning environments. This research has attempted to uncover more interactive speaking in naturalistic environments, and essentially all of this research has looked at the speech and speaking style of the teaching assistants. Researchers themselves have analyzed the communication patterns they observe and have not solicited feedback on the classroom communicative activities from the participants actually involved in the interactions. As a result, the interpretations of the activities and communication of the classroom activities is from a perspective that is external to the interaction, rather than grounded in the experiences and perceptions of the participants engaged in meaningful communication. However, as we know from the research base of the linguistic aspects of speech, the listener's background characteristics and assumptions about the speaker may influence the interpretation of the communicative event. Researchers have assigned 
their interpretations to the intentions and motives of the speakers and listeners in these communicative exchanges. However, the people involved in the interactions of realworld communication may have different interpretations of the communicative exchanges.

The linguistically based research and the in-context research on ITA communication have found that non-native speech differs from native-speaker speech. Both avenues of research are based on the assumption that understanding what these differences are is sufficient to understanding why and how non-native speaking teaching assistants are not successful communicators as teaching assistants. Furthermore, all of this research depends on defining successful communication from the perspective of people external to the communicative exchange. No ITA research has employed a methodology that investigates what the perceptions and perspectives are of those actually involved in the communicative exchanges to define and understand what successful communication between undergraduates and international teaching assistants engaged in face-to-face learning in the classroom is.

What is missing from the current research in the area of undergraduate and international teaching assistant communication patterns and strategies are studies that examine classroom interactions in introductory-level classrooms, where many of the complaints about international teaching assistants have arisen, that obtain the perspectives of the actual participants in the educational experience, and that define the success or failure of communication from the perspective of the actual participants. Furthermore, because so few in-context research studies of these populations exist, research in this area will be a fruitful avenue of investigation for developing our 
understanding of the activities, interactions, and expectations of the undergraduates and international teaching assistants.

While there have been studies that look at international teaching assistant and undergraduate communication in real-world interactive contexts, those studies have mostly examined lecture-style delivery of information. When interactive studies have been carried out, they have focused exclusively on the speech initiated by the teaching assistant. In-context studies of undergraduate communication with international teaching assistants have been limited. To expand our understanding of the ways international teaching assistants and their undergraduates students communicate with each other in classroom environments, studies need to examine language and communication of both participants in the communicative exchanges.

If science labs have been characterized as learning environments that are focused on individual learning in problem-solving activities (Axelson \& Madden, 1994), then an investigation of all communication in labs would prove a useful area to understanding interactive communication between undergraduates and international teaching assistants. The topic of undergraduate-initiated questions has been mentioned in the research literature, but often in the research, the topic of student-initiated questions has been minimized as not being as important in classroom communication as instructor-initiated discourse is.

International teaching assistants in classroom environments are speakers, but as the linguistically based research reminds us, they are also listeners in these communicative interactions. If we are to have a more complete understanding of the classroom interactions between international teaching assistants and their undergraduate 
students, a productive area of research needs to include an examination of all interactions in these classrooms between international teaching assistants and their undergraduate students. The research also needs to employ a methodology that will allow participants of the communicative exchanges to provide their perspectives on and perceptions of the success or failure of classroom communication since they are the ones engaged and invested in the activity of learning the material of the discipline. 


\section{CHAPTER 3: METHODOLOGY}

This research project investigates the language use and communication strategies between native and non-native speakers of English in university-level science classes as they negotiate information when engaged in teaching and learning. Understanding successful communication between international teaching assistants and their undergraduate undergraduates will contribute to our ability to support and encourage successful interactions between these two populations. The guiding research questions ask what constitutes successful communication between these two populations and what communication skills contribute to successful interactions between these two populations.

This research project seeks the emic perspective to identify what successful communication is in this context. That is, participants engaged in the classroom communication provide their perspectives to identify what is and is not successful communication. As such, the research methodology employed by this study is primarily qualitative, depending on observations and interviews. However, quantitative analysis is also employed. The research project is divided into two parts: (1) data collected in the form of field notes, background questionnaires, and digital recordings of the lab sessions and (2) semi-structured interviews with study participants (teaching assistants, undergraduates, and faculty member overseeing the course). The process of using multiple methods of data collection through direct observations, questionnaires, and interviews provides triangulation of data sources and methods (Patton, 2002).

This project investigates communication between individuals engaged in learning in a university-level chemistry lab. Therefore, the communicative exchanges 
and interactions between the international teaching assistants and their undergraduates as they occur in the classroom setting will be the unit of analysis. A communicative exchange or an interaction in this study is taken to be an uninterrupted sequence of two or more alternating conversational turns (Fairclough, 2003).

I used purposeful sampling to select the international teaching assistants from the pool of international graduate serving as teaching assistants in the fall semester of the introductory-level chemistry course. The undergraduates were essentially randomly selected. Undergraduates chose the day of the week they could attended the laboratory section; however, there were multiple sections that were available on any given day. In the registration process, the undergraduates were randomly assigned to a section on their preferred day.

Rather than focusing on communication in one lab section between the teaching assistant and the undergraduates in that section, I selected multiple lab sections, three teaching assistants and their undergraduates, to reduce the chances that the communication patterns observed were idiosyncratic and to increase the possibility of obtaining a greater variety of communicative interactions, providing a broader understanding of successful communication in this context. I also hope this broad approach to data collection increases reliability of the results and reduces idiosyncrasies in the findings.

In order to understand the characteristics of successful interactions, this research project first depends on the participants to identify successful and unsuccessful interactions. Three different constituencies and their perspectives are represented in these interactions: undergraduates, graduate students, and faculty. The perspectives of 
all three types of participants, obtained through semi-structured interviews, provide triangulation of data sources and are needed in order to accurately determine the success of an interaction. The use of multiple perspectives in defining successful interactions will also strengthen the consistency and reliability of the findings.

This chapter details procedures for collecting, organizing, and analyzing data and is divided into two main sections. The first section discusses data collection: the setting, participants, and procedures. In the first section, data consists of field notes from observations and from conversations with those affiliated with the setting, information in digital audio (6 hours of data) and video (9 hours of data) recordings of lab communication, background information collected through questionnaires, and Likert-scaled responses and comments from semi-structured interviews. The second section of the chapter discusses approaches to organizing and analyzing the data.

\section{Data Collection}

\section{Setting}

This study looks at interactions between undergraduate students and their international teaching assistants in a chemistry laboratory Science labs were selected because they have the potential for a substantial number of communicative exchanges (Axelson \& Madden, 1994; Myers, 1994) initiated by both the teaching assistants and the undergraduates. Science labs have also been identified as being learning environments where undergraduates and international teaching assistant have experienced difficulties communicating (Finder, 2005). A chemistry laboratory was selected for this project because the department at the university where this research project was conducted has a high number of international teaching assistants in this 
discipline, and the department was interested in improving the educational experience of the undergraduates taking the course and improving the teaching experience for the international teaching assistants. The professor of the laboratory component of the introductory-level chemistry course agreed to allow me access to laboratory sections of the course for this study during the fall 2005 semester.

The fall semester of the introductory-level chemistry class was selected because this level of class has been identified as being particularly problematic for undergraduates who have been assigned international teaching assistants. Undergraduates enrolled in the introductory-level chemistry course are new to the university, and for many this is their first exposure to science instruction at the university-level. If undergraduates drop out of science courses at this time, it becomes a critical transition for their learning in that they are not continuing with the foundational science classes they need for programs based in the sciences. This is also the time when many international teaching assistants are teaching for the first time in a university in the United States. In other words, when these two populations come together, they are both transitioning to new learning environments and new educational experiences. Selecting a more advanced class, e.g., second semester or beyond, would have presented a different population of undergraduates, those who were familiar with the discipline and had committed themselves to studying it. From previous observations and discussions with former lab teaching assistants, I identified that the first hour in the lab would provide the potential for the largest number of communicative exchanges between the teaching assistants and the undergraduates. 


\section{The Course}

The course is the first-semester of the introductory-level chemistry course, a basic course taken as a prerequisite for multiple majors in the sciences, as well as for those undergraduates majoring in chemistry. Each fall approximately 500 undergraduates enroll. The majority of undergraduates take the course to satisfy program requirements; however, a few undergraduates take it as an elective. The topics for the course include the electronic structure of atoms and molecules, thermodynamics, solution equilibrium, electrochemistry, chemical kinetics, and reaction mechanisms. For undergraduates, the course requires a substantial investment of time. Each week, in addition to the three-hour lecture session, undergraduates are required to participate in five hours of a laboratory component (1 hour of pre-lab lecture and 4 hours in a lab session).

The faculty members teaching the lecture portion of the course differ from the faculty member who instructs and oversees the laboratory portion of the course. The lab instructor determines all experiments for the lab, is responsible for all logistic aspects of the lab sections, oversees all teaching in the lab, and supervises all teaching assistants. While there is some coordination between the lab and lecture components for the course, the two components are distinct educational experiences. The lecture section emphasizes the theoretical and conceptual aspects of the subject, and the laboratory component develops the undergraduates' practical skills in chemistry. That is, the lab component connects undergraduates' theoretical understanding of chemistry as they are developing the hands-on skills of the discipline. The final grade for the course is determined by the undergraduates’ performance in both parts of the course. 
Undergraduates receive one final grade for the chemistry course, but that final grade is composed of two separate grades: the lecture grade and the laboratory grade. The focus of this study is the laboratory section of the course, where undergraduates are developing the hands-on experience of the discipline of chemistry.

\section{Textual Resources for Undergraduates}

In addition to the textbook that undergraduates have for the lecture component of the class, undergraduates have a separate manual for the lab. In the semester in which this study took place, the lab manual was developed by a previous instructor for the lab and was modified by the current instructor. The manual includes laboratory schedules, an introductory chapter explaining the significance of the lab experience for developing undergraduate understanding of chemistry, a discussion of the goals of the course, reading assignments, contextual information related to each lab experiments, and an overview of each experiment. Individual chapters for each experiment provide the undergraduates with detailed information about each lab: an outline, its purpose, the procedures, safety precautions, pre-lab questions, information about equipment and procedures, theoretical overviews, and requirements for documenting information. The course also has a WebCT site for weekly updates and discussions.

\section{Sequence of the Laboratory Component.}

The laboratory component is consistent from week to week. Each week undergraduates attend a pre-lab lecture taught by the faculty member, in this case a native English speaker, overseeing the teaching of the labs. Pre-lab lectures are held Monday through Friday from 12:00-12:50. Undergraduates may attend any pre-lab lecture that occurs prior to their scheduled day in the lab. However, undergraduates are 
assigned to and register for a particular lab section in which they run their experiments, and they must attend that lab section for the entire semester. Each chemistry laboratory room is set up to hold two lab groups. To efficiently use the facilities, the two labs have staggered starts. One lab section in a given room runs from 1:00-5:00 and the second lab section runs from 2:00-6:00. Each lab section has its own teaching assistant assigned to it.

The lab component of the class requires that the undergraduates be extensively prepared prior to attending the pre-lab lecture. First, undergraduates are to read the appropriate section in the lab manual. Next, undergraduates are asked to prepare an outline for the lab, which the lab manual for the course describes as a "succinct condensation of the crucial steps, written so that a person familiar with laboratory procedures could do the experiment.” The undergraduates are expected to answer a set of pre-lab questions, which are questions designed to familiarize undergraduates with the calculations needed to complete the written lab report that they submit at the end of each lab. The teaching assistants assigned to each lab are responsible for grading these materials, though the undergraduates can consult with the faculty member or the other teaching assistants with questions regarding these materials.

After the undergraduates have completed this preliminary work, they attend the pre-lab lecture, which is delivered in a lecture hall with auditorium seating. There are approximately 100 undergraduates attending the pre-lab lecture on any given day of the week. In the pre-lab lecture, the instructor walks the undergraduates through the experiment: demonstrating setting up the equipment, offering suggestions and advice about time management, highlighting safety precautions, prioritizing work, guiding 
undergraduates’ lab report write up, and drawing undergraduates' attention to the theoretical concepts the experiments are designed to reinforce. As the week progresses, the professor also provides advice and suggestions for solving problems that undergraduates on previous days have encountered when carrying out the experiments. For most experiments, the pre-lab lecture lasts for approximately 30-40 minutes, during which time the undergraduates are free to ask questions. At the end of the demonstration, undergraduates are encouraged to ask the professor questions, if they have any.

The undergraduates then report to their assigned labs to begin the hands-on work of the lab experiment. These lab sections are conducted by a teaching assistant assigned to a lab for the entire semester. The structure of the lab, established by the faculty member, is consistent from teaching assistant to teaching assistant, with only slight variations in the presentation of information. When the undergraduates arrive to their lab room, they are seated in the classroom area and are free to ask the teaching assistant questions. Once the lab begins, the teaching assistant gives a brief overview of what the undergraduates will be doing and answers questions related to any of the materials undergraduates have prepared in advance or related to the pre-lab demonstration by the faculty member. The overview is brief and lasts approximately 10 minutes. The teaching assistant then distributes a lab quiz, which is designed to take only a few minutes. The quiz covers the material that the undergraduates should have prepared in their outlines. When an undergraduate has completed the quiz, the undergraduate turns in the quiz, the pre-lab questions, and the outline. The undergraduate then receives any special instructions or sample assignments for the current lab and moves to the assigned 
lab bench to begin the experiment. At this point, the undergraduate begins setting up the experiment.

The Physical Setting

The laboratories are identified by their room numbers, and in this introductory chemistry course, there are two laboratory sections that take place in a given laboratory room. The laboratories are large rooms with four main work areas: a classroom, a work area for undergraduates to obtain materials and to dispose of materials, and two undergraduate laboratories. The classroom area and the materials area are a central corridor in the room, with one laboratory on each side. The laboratory on the right of the room has 18 individual lab benches, and the laboratory on the left has an additional 18 individual benches, for a total of 36 lab benches in the larger laboratory room. Numbering of lab benches begins on the lab area on the right of the classroom area and continues to the lab area on the left. Physically, the laboratory sections within the larger laboratory room are mirror images of each other. Figures 1 and 2 below show the floor plans for the laboratory rooms in this study. 


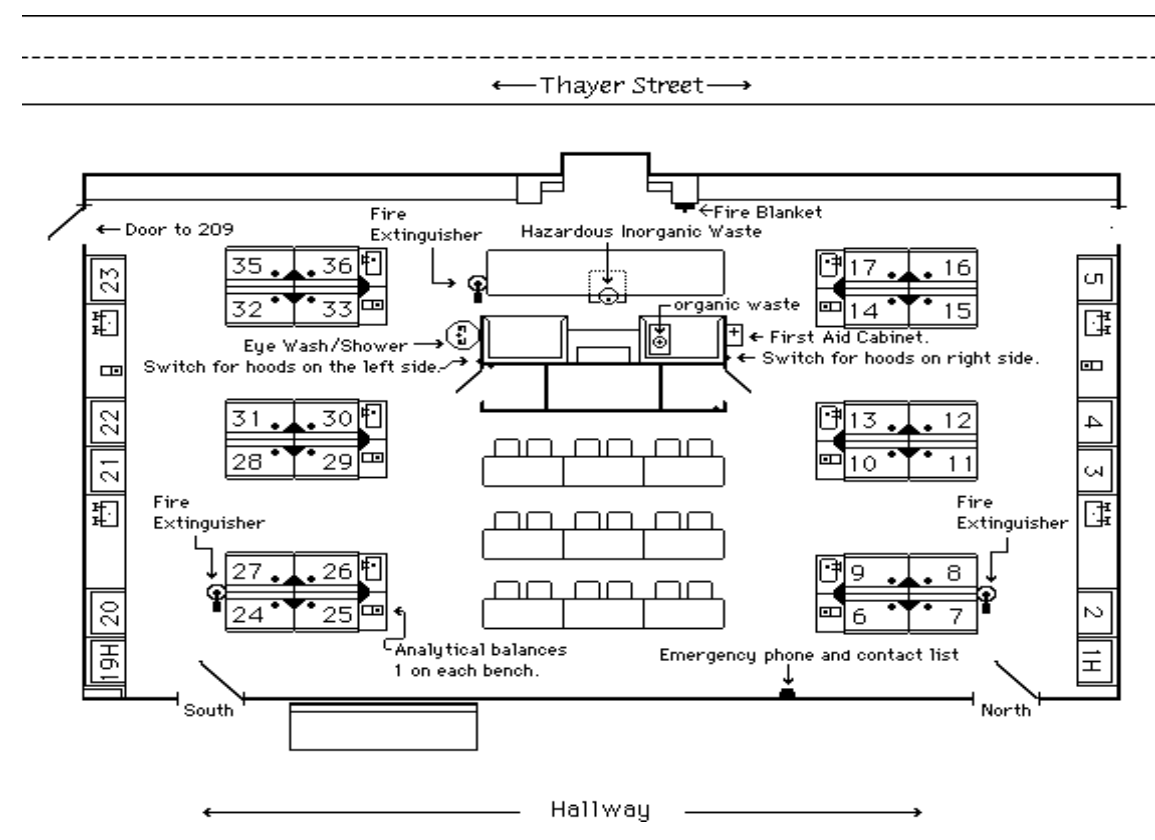

Laboratory 205

Figure 1: Floor Plan of Laboratory Room 205

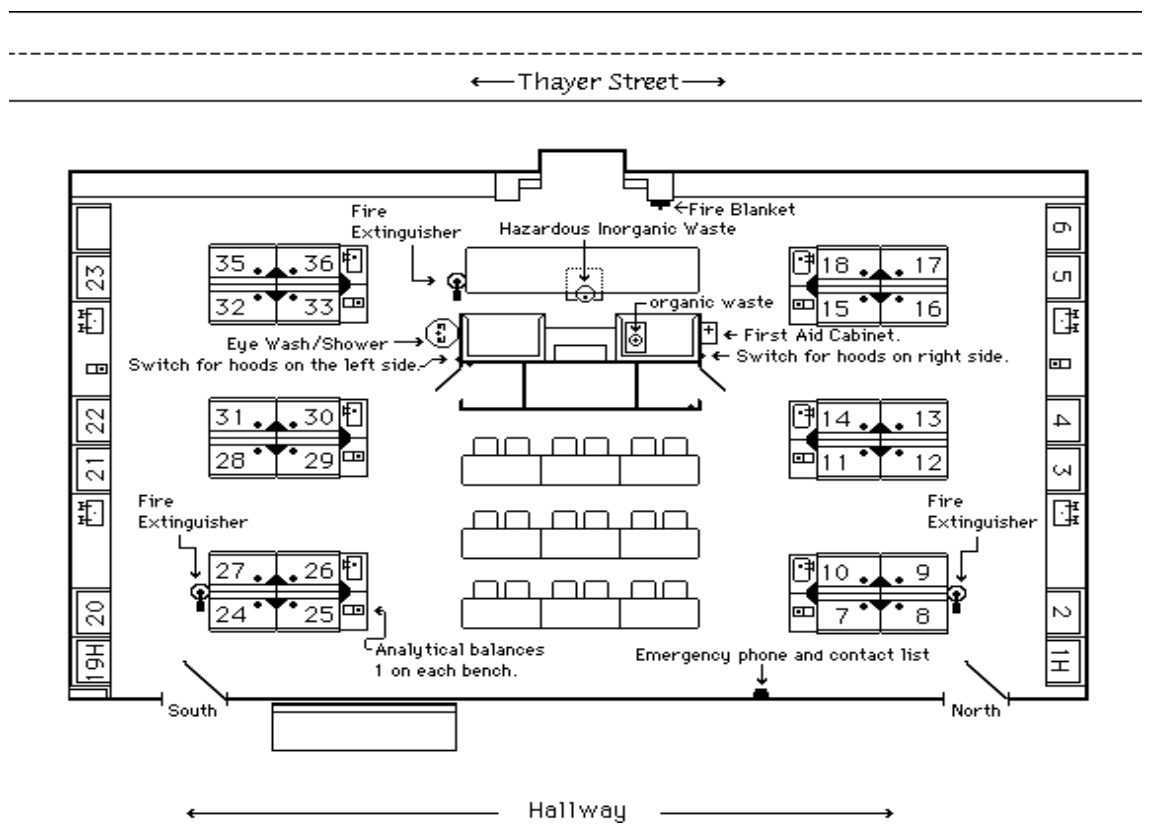

\section{Laboratory 209}

Figure 2: Floor Plan of Laboratory Room 209 
At the start of each lab session, the undergraduates enter the lab and go to the classroom area, the 18 seats between the two sets of laboratory benches in each laboratory room. The staggered start of the lab sections allows two groups of undergraduates to conveniently share the classroom space. Undergraduates begin the lab in the classroom area to complete the preliminary activities before they begin the actual lab, and when ready, they move to their assigned benches.

Each undergraduate has his or her own lab bench within each lab section. However, each day of the week, a different undergraduate uses the bench. The bottom half of the bench has five locked storage areas for each student assigned to a particular bench. The top portion of the lab bench includes a glass-enclosed work space, with a moveable sash that undergraduates can adjust for their protection. There are certain heights that the sash needs to be for undergraduates to maintain safety procedures. If an undergraduate raises the sash higher than the established limit, a buzzer goes off. Undergraduates carry out their experiments under the hoods of the lab benches.

Each week's lab experiment requires the undergraduates to use different materials. Each undergraduate has a set of standard equipment, which is located in a locked storage area immediately below the work bench, to be used throughout the semester. Undergraduates obtain all solutions and almost all additional supplies and equipment that are not part of the standard bench equipment from the area in the back of the room. There are also some items that undergraduates obtain from the stock room down the hall. This area at the back of the room also has facilities for the safe disposal of waste materials and safety equipment necessary in case of an accident, e.g., an eye wash/shower fountain. Undergraduates use this area as necessary during the course of 
their lab sessions, and they are free to move about the lab. Because of the staggered start of the labs, two lab sections share the classroom and materials area in a room with efficiency and limited overlap.

\section{Participants}

The participants in this study include three groups: the international teaching assistants, the undergraduates enrolled in the sections taught by these teaching assistants, and the faculty member teaching the course. Others who work in the labs, e.g., the manager of the labs and roving teaching assistants, provided me with additional background information related to the functioning of the chemistry labs on several occasions. After the teaching assistants were assigned to the various sections of the course, the instructor identified those sections taught by international teaching assistants. In this particular semester, there were three international teaching assistants assigned to the course to teach two sections each, for a total of 6 out of the approximately 30 sections taught by international teaching assistants. This was an unusually small number of international teaching assistants for this course, unique for the particular year that the study was conducted. All three international teaching assistants were invited to participated in the study, and all agreed.

Each teaching assistant taught two sections. Three of the six sections taught by international teaching assistants were selected on logistical considerations. Because some teaching assistants taught on the same days, the lab sections were selected to allow me to observe one section from each of the three teaching assistants. One teaching assistant (TA 1) oversaw a 2:00 lab on Tuesdays. The second teaching assistant (TA 2) was assigned to a 2:00 lab on Wednesdays, and the third teaching 
assistant (TA 3) to a lab at 1:00 on Thursdays. The undergraduates in these sections were then invited to participate in the study. Table 1 indicates the sections, day of the week, locations, benches, and start times for the three lab sections in this study.

Table 1

Lab Section Room Assignments

\begin{tabular}{cccccc}
$\begin{array}{c}\text { Teaching } \\
\text { Assistant }\end{array}$ & $\begin{array}{c}\text { Lab } \\
\text { Section }\end{array}$ & $\begin{array}{c}\text { Day of } \\
\text { Week }\end{array}$ & $\begin{array}{c}\text { Room } \\
\text { Number }\end{array}$ & $\begin{array}{c}\text { Bench } \\
\text { Numbers }\end{array}$ & $\begin{array}{c}\text { Start } \\
\text { Time }\end{array}$ \\
\hline TA 1 & 12 & Tuesday & 205 & $19-36$ & $2: 00$ \\
TA 2 & 20 & Wednesday & 209 & $19-36$ & $2: 00$ \\
TA 3 & 22 & Thursday & 205 & $1-18$ & $1: 00$ \\
\hline
\end{tabular}

The Professor

The professor for the laboratory component of the course was a female nativespeaker of English, with 19 years of university-level teaching experience in chemistry and 14 years experience of administration in the graduate school at the institution. In the fall semester of 2005, she was the sole faculty member for this laboratory course. She had taught and co-taught the course in previous years and contributed to writing the lab manual used by undergraduates in the course. The faculty member was responsible for all curricular and logistical aspects of the laboratory component of the course: designing and determining the lab experiments for the course, presenting the five pre-lab lectures each week, and overseeing all teaching assistants. 


\section{The Teaching Assistants}

In total, there were five international teaching assistants who agreed to participate in this study. Three of the international teaching assistants were selected for this project at the beginning of the semester. However, due to issues related to visa status, one of the international teaching assistants was required to leave the United States and return to his native country prior to the end of the semester. As a result, experienced international teaching assistants filled in for this teaching assistant in his final two lab sessions. The substitute teaching assistants also agreed to participate in this study. As a result, data gathered for this study includes data from all five teaching assistants: three primary teaching assistants and two substitute teaching assistants. A copy of the teaching assistant consent form is included in Appendix A.

Even though there were only a few international teaching assistants assigned to this course this semester, all efforts were made to include teaching assistants in this study with similar background characteristics, in order to minimize variations of the teaching assistant background variables of country of origin, native language, length of time in the United States, level of English proficiency, sex, and prior teaching experience. Only teaching assistants who had been in the United States at institutions of higher education for at least one year were included in order to minimize potential communication difficulties related to adjustments to a new educational environment. The three primary international teaching assistants invited to participate in the study were selected because of their similar background characteristics of native language, length of time in the United States, and teaching experience. The substitute teaching 
assistants were also matched for these characteristics before they were invited to participate.

All five of the international teaching assistants had similar backgrounds. All five were native speakers of Mandarin Chinese and had been in the United States for at least one year. All five had experience as teaching assistants in chemistry using English as the language of instruction, four of the five as teaching assistants at the university where the study took place. Four of the five were male and one was female. All were enrolled in a Ph.D. program in the Department of Chemistry. Table 2 provides an overview of the background characteristics of the teaching assistants in this study.

\section{Table 2}

Overview of Teaching Assistant Background Characteristics

\begin{tabular}{|c|c|c|c|c|c|}
\hline & \multicolumn{5}{|c|}{ Teaching Assistants } \\
\hline & \multirow{2}{*}{$\frac{\text { Tuesday }}{\text { TA } 1}$} & \multicolumn{3}{|c|}{ Wednesday } & \multirow{2}{*}{$\begin{array}{c}\text { Thursday } \\
\text { TA } 3\end{array}$} \\
\hline & & TA 2 & TA 2.1 & TA 2.2 & \\
\hline Lab Section & 12 & 20 & 20 & 20 & 22 \\
\hline $\begin{array}{l}\text { Native } \\
\text { Country }\end{array}$ & China & China & China & China & China \\
\hline $\begin{array}{c}\text { Native } \\
\text { Language }\end{array}$ & Chinese & Chinese & Chinese & Chinese & Chinese \\
\hline $\begin{array}{l}\text { Length of } \\
\text { Time in the } \\
\text { US }\end{array}$ & 27 months & 15 months & 15 months & 15 months & 15 months \\
\hline Sex & Male & Male & Male & Male & Female \\
\hline Age & 24 & 26 & 23 & 25 & 22 \\
\hline
\end{tabular}


The five international graduate students in the study were all advanced, nonnative speakers of English. All had a minimum score of 600 on the paper-based TOEFL for acceptance to the university. Further, all had demonstrated sufficient English language proficiency in the university’s local performance-based spoken English language proficiency evaluation for prospective international teaching assistants, required of all international teaching assistants prior to assuming their teaching duties. The spoken English evaluation procedure is a teaching simulation that requires the prospective international teaching assistants to present a topic from their discipline to a panel of ESL professionals, undergraduate students, and a departmental representative. Their English is evaluated on four linguistic measures (accuracy of pronunciation, overall fluency of speech, grammar/vocabulary use, listening comprehension for responding to questions) and three cultural/pedagogical measures (non-verbal communication, use of teaching resources, and overall organization of information). All five teaching assistants had passed the evaluation and were certified to assume their duties as teaching assistants. All spoke with some degree of accented English; however, their demonstrated skills and facility with spoken English were determined to be acceptable for them to assume the duties of teaching assistants in a lab at the University.

\section{The Undergraduates}

The undergraduates participating in this study attend a mid-sized, elite liberal arts institution in the Northeast, with a highly competitive admissions process. At the time that the study was conducted, information on the host university's website provided the following overview of undergraduates: the admission rate is approximately $16 \%$ of applicants. For a recent entering class, $94 \%$ of the undergraduates accepted 
were in the top $10 \%$ of their graduating class, and of those, $26 \%$ were valedictorians and $12 \%$ were salutatorians. Undergraduates represent all geographic regions, and the undergraduate international population is on average $10 \%$ of the undergraduate body. Undergraduate majors at the institution are fairly evenly distributed between the Sciences/Math/Engineering (46\%) and the Humanities/Social Sciences (42\%), with the remainder undecided (12\%).

All undergraduates enrolled in the laboratory sections of the selected teaching assistants were invited to participate in the research project. The faculty member teaching the lab course introduced me to the undergraduates. The teaching assistants were present when I described the project and invited the undergraduates to participate. In the announcement to the undergraduates, I identified that the research project was not concerned with individual performance, either the teaching assistant's or the undergraduate’s. Rather, this research project was interested in identifying what was important for successful communication for learning content material in a chemistry lab. As such, the undergraduate perspective of lab communication was a crucial part of this project. The goal of the research was identified as learning what was or was not helpful communication in the labs and what mattered to the undergraduates involved in communicative exchanges as they were learning the material of the course.

The undergraduates were informed that the perspectives of the teaching assistants and the faculty member would also be obtained of the communicative exchanges. I identified that the results of this study would be used to better prepare teaching assistants (native speaking and non-native speaking) and to develop an increased awareness of the communicative strategies that are helpful to undergraduates 
learning the content material. Initially, most of the undergraduates agreed to participate. Some undergraduates agreed to participate later in the semester after they were familiar with the activities and demands of the study. A copy of the undergraduate consent form is included in Appendix B. Table 3 identifies the participation for the study by section.

\section{Table 3}

Undergraduate Participation by Lab Section

\begin{tabular}{rccc} 
& \multicolumn{3}{c}{ Laboratory Section } \\
\cline { 2 - 4 } & 12 & 20 & 22 \\
\cline { 2 - 4 } & Tuesday & Wednesday & Thursday \\
\hline Total Undergraduates & 17 & 18 & 16 \\
Agreed to Participate & 14 & 15 & 16 \\
Declined to Participate & 3 & 3 & 0 \\
\hline
\end{tabular}

Procedures

\section{Observations}

Over the course of the semester, the first hour of all laboratory sections for all three teaching assistants were observed and documented. Observations of the chemistry laboratories provided the basis of the data collected for this study. Because the communication being investigated occurred in a science laboratory, I followed all safety precautions established for the setting: wearing goggles at all times and being restricted to certain locations in the laboratory. Observations included field notes and audio/video 
recordings of the laboratory sessions. Establishing accurate recording and replaying of interactions that occurred in the setting was a priority in designing the study because these recordings made the interview phase of this project possible. During the semester, additional data on background information of the participants was collected in the form of questionnaires.

Schedule of observations. The schedule of observations was determined in consultation with the faculty member. Each week, I observed the pre-lab lectures in order to become familiar with each week's experiment and to become familiar with the questions that undergraduates had related to each of the various labs. The first four lab experiences were documented by direct observation and field notes. Waiting to introduce recording technology until later in the semester provided me with the opportunity to become familiar with the activities of the labs and the participants in an unencumbered way. Movement around the labs was less restricted, and this process allowed the undergraduates and the teaching assistants opportunities to ask me questions about the project and increase their comfort level.

As the semester progressed, audio and video recordings were introduced at times that were not intrusive. Once the teaching assistants and the undergraduates became comfortable with my observing in the labs, digital audio recordings were made of labs four and five, and digital video recordings were made of the final three labs of the semester. Digital audio allowed me to capture the communicative exchanges in the lab, but required extensive field notes to document movements and activities. After the undergraduates became familiar with the less intrusive method of audio recordings, I 
introduced video recordings, which provided documentation of the activities of the lab and how the verbal and visual aspects of lab interactions coordinated.

Because of the constant movement of the teaching assistants throughout the lab, video recording presented many challenges. For safety reasons, when videotaping, I was restricted to being in either the classroom area or at the back wall of the lab. As a result, capturing all visual information was not possible because the lab benches obscured many parts of the room. When operating the video recording equipment, I could not easily take field notes. However, the greatest advantage of the video recordings was that they did provide greater context for understanding the activities and interactions in the lab. Table 4 provides a schedule for types of data collected in the labs.

Table 4

Schedule of Laboratory Experiments and Data Collection

\begin{tabular}{cccc} 
Lab & Lab Dates & Lab Topic & Types of Data Collected \\
\hline 0 & September 20-22 & $\begin{array}{c}\text { Lab Check-In \& } \\
\text { Measuring } \\
\text { Volumes }\end{array}$ & Field Notes \\
1 & September 27-29 & Complex Ions & Field Notes \\
2 & October 4-6 & Hess's Law & Field Notes \\
3 & October 18-20 & Unknowns & Field Notes \\
4 & October 25-27 & Second Law & Digital Audio Recordings \\
5 & November 1-3 & Cu Ore, Part 1 & Digital Audio Recordings \\
6 & November 8-10 & Cu Ore, Part 2 & Digital Video Recordings \\
7 & November 15-17 & The Sea & Digital Video Recordings \\
8 & November 29- & Kinetics & Digital Video Recordings \\
\hline
\end{tabular}


Equipment and procedures for audio and video recording. Each teaching assistant was fitted with a wireless transmitting and receiving system in order to record the teaching assistant-undergraduate interactions with digital audio recordings. Preliminary trials with the recording system resulted in clear audio recording of the teaching assistant's and undergraduate's voices in communicative exchanges. The microphone was sufficiently sensitive to allow the teaching assistants and undergraduates to be a comfortable distance apart. Furthermore, ambient noise did not obscure the recorded voices. On a few rare occasions, the voice of an undergraduate walking toward the teaching assistant or speaking to a teaching assistant from a distance was not picked-up by the recording system.

The teaching assistants wore an AKG PT 81 body pack transmitter in the pocket of their lab coats. Connected to the transmitter was an AKG C 417L lavalier microphone, an omni-directional microphone. An AKG PR 81, a portable receiver, was connected to the digital audio recorder, a Marantz professional portable solid state recorder, model PMD670. During the lab, I took notes and monitored the interactions from the back of the lab using Sony MDR-7506 professional folding headphones.

Digital video recording of the lab communication and activities used the same wireless transmitting and receiving system, with the microphone attached to the teaching assistants. However, for video recording, the AKG PR 81 portable receiver was mounted on the video camera, a Canon Optura Xi. In addition, a BeachTek DXA-4P microphone adapter was needed for the camera's audio feature to work accurately with the wireless transmitter/receiver. The video recordings were made on Sony Mini-DV 60-minute tapes. To videotape safely in the lab, I stood at the back of 
the classroom area, which was the middle of the lab area, and with the camera panned the room, following the teaching assistants’ movements in the lab.

Preparing the audio and video recordings. Once the digital audio and video recordings were made, they needed to be prepared so that the recordings could be used in the interview phase of this project. The audio was transferred from the digital audio recorder to a computer (Mac) workstation in the language lab facilities at the host university. The files were downloaded as MP3 files. The MP3 files were then converted to Audacity files for editing. Audacity is open-source software for recording and editing sound. It was selected because it is a free multi-platform program, available for Mac OS X, and Microsoft Windows. The audio files were then burned to CDs for transport and use on a personal computer, a Dell Dimension (Pentium 4 CPU 2.40GHz 2.39 GHz 512 MB of Ram).

After the audio files were transferred to the personal computer, the files were then edited for use in interviews. The digital audio files were reviewed in real time to mark the interactions for initial time codes. Silences were edited out, using a feature of Audacity that allows for maintaining the original time codes. Original versions of all recordings were maintained for back-up. The purpose of this editing was to make identifying interactions and speech easier in the interview process and analysis phase of this project. Time codes, monitored at the time of the original audio recording, were confirmed in this process, as well. For every hour of audio recording, this phase of preparing the digital audio took approximately two hours to complete.

The video files required similar processing, but due to the nature of video transfer, this was a more time-consuming process. After the video recordings were 
completed, the video was transferred to an e-Mac (Powermac 6.4, 1.42 Ghz PowerPC G4 Memory 1 GB DDR Ram) using the software application iMovie HD 5.0.2 (III). The transfer from mini-DV tape took one hour in real time. The digital video file was then compressed into a format that would allow the one-hour lab session to fit onto a CD. The time to compress one hour of video to fit onto a CD was approximately 50 minutes. The compressed versions of the labs were burned to CDs as QuickTime movies. QuickTime was selected because it is a common multi-platform video file format. The QuickTime movies were then downloaded to the same personal computer as the audio files were. There was no editing for the video files. The preparation time for transfer and compression was similar to the audio editing process: every hour of digitally recorded material required approximately two hours of preparation.

At this point the audio and video files were reviewed in final preparation for use in the interview process. The digital audio and video files were reviewed in real time to confirm time codes, complete information about identifying who was involved in the interactions, who initiated the interaction (teaching assistant, undergraduate, faculty, or other). This process took approximately two hours for each hour of digitally recorded lab. Information detailing the recorded interactions was then entered into an Excel workbook for use in the interviews and for later analysis. This preliminary preparation of files was necessary to locate the interactions accurately and efficiently in the recorded data in order to conduct the interviews. 
Interviews

Once the audio and video recordings and the accompanying Excel files documenting information in the recordings had been prepared, interviews were conducted. As mentioned previously, one of the main goals of this project was to look at communication in a real-world learning environment to find out from the participants engaged in the communicative exchanges whether they viewed the communication to be successful or not, based on their intentions and how the exchange unfolded. In order to complete this phase of the investigation, the participants needed to be invited to a one-on-one interview session in order to obtain their feedback through semi-structured interviews. Interviews were initiated as soon as possible after the interactions occurred to increase the likelihood that when reviewing the interactions the participants would remember clearly the details of the communicative exchange.

Interview procedures. All interviews were conducted in my office. The one-onone interviews were held at a building located on campus, a few buildings away from the building where the chemistry labs were conducted. All interviews were scheduled to be one-on-one interviews, conducted as soon as possible after the interaction occurred to increase participants’ recall of information about the interaction. The first participants to be interviewed were the undergraduates. After the undergraduates were interviewed, the teaching assistants were invited for one-on-one interviews. The faculty member was the last participant to be interviewed. For the convenience of the faculty member, the faculty interviews were conducted in the month after the course had finished. Interview invitations for undergraduates and teaching assistants were extended in face-to-face communication and later through e-mail. 
When an undergraduate arrived for an interview, I explained how the interview would proceed. First, an audio or a video clip would be played back for the undergraduate to hear or see. Playback of the communicative exchanges was on a desktop PC, using Audacity for playback of the audio files and QuickTime clips for the video files. The undergraduate was allowed to hear or see the recorded interaction as many times as he or she wanted to. When the undergraduate was comfortable with the exchange presented, I started the interview. Undergraduates were always free to ask questions or provide other information at any time during the interview.

After explaining the procedures for the interviews, I reviewed the the semistructured interview prompts with the participants to familiarize them with the topics that would be covered. The undergraduates were allowed to see the interview prompts and ask questions about them. I verbally stated the interview prompts to the undergraduates and took notes on their responses. I confirmed each response before writing it on the interview form. Additional comments were encouraged and documented. The undergraduates responded to a 10-item, 7-point Likert-scaled interview where 1 indicated strong disagreement and 7 strong agreement with the statement. At the end of the interview, the undergraduates were encouraged to add additional comments that they felt were important, but had not been addressed. Undergraduates were reassured that the teaching assistants and the faculty member would not have access to the interview information or the interview forms. They were encouraged to be open and honest about what they felt, either positive or negative, about the communicative exchanges. They were encouraged to add any information that they felt would improve communicative exchanges in the lab as they 
were learning the material. The undergraduates seemed comfortable and relaxed with the interview process. At the end of the interview, the undergraduates filled out background information questionnaires. The undergraduate background questionnaire is provided in Appendix C. Undergraduates who did not participate in the interview process completed background information later in the semester before the start of a lab session.

The interviews for the teaching assistants and for the faculty member were conducted in a similar manner. In one-on-one interviews, the teaching assistants or the faculty member heard the audio or viewed the video clip. The segment was replayed as many times as necessary. They then responded to a 10-item, 7-point Likert-scaled interview parallel to the one completed by the undergraduates, with a shift in focus to capture the perspective of the participant. They were invited to add additional comments whenever they felt that additional information was important to include. In addition, the teaching assistants completed background information questionnaires at the end of their first interview session. The teaching assistant background questionnaire is provided in Appendix D.

Initially, I invited undergraduates in for interviews in face-to-face conversations and scheduled the interviews via e-mail. Later, as the undergraduates became more comfortable with the interview process, undergraduates were contacted through e-mail. Because the undergraduates were eager to talk about the interactions, the interview process for each undergraduate took approximately 20-30 minutes. The interview process for the teaching assistants and the faculty sessions lasted approximately 10 minutes per interaction. 
Interview prompts. The interview prompts for all three groups of participants were similar, though each prompt was written to reflect the perspective of the constituency being interviewed. For example, the first prompt sought information on whether the participants felt that the teaching assistant understood the question the undergraduate asked. For the undergraduate interview, the prompt was framed as "The teaching assistant understood my question.” For the teaching assistant's interview, the prompt was framed as “I understood the undergraduate's question.” The faculty member’s interview prompted was framed as “I think the teaching assistant understood the question.” In a few of the interview items, the faculty member's prompts focused on the accuracy of the content information exchanged between the undergraduate and the teaching assistant.

The interview elicited information on ten different dimensions of the communicative interaction. The dimensions focused on whether the teaching assistant understood the question (Interview Item 1), how easy it was for the undergraduate to ask the question (Interview Items $2 \& 3$ ), what motivated the undergraduate to ask the question (Interview Items $4 \& 5$ ), whether the undergraduate understood and was satisfied with the response (Interview Items $6 \&$ 7), whether the response provided sufficient information (Interview Items 8 \& 9), and the overall impression of whether this was a successful communicative interaction (Interview Item 10). Table 5 summarizes the various dimensions examined. 
Table 5

Interview Item Dimensions

Interview Item

Dimension

\begin{tabular}{cl}
\hline 1 & Teaching assistant comprehension of the question \\
3 & Undergraduate comfort asking the question \\
4 & Undergraduate difficulty expressing the question \\
5 & Undergraduate requesting clarification of content information \\
6 & Undergraduate comprehension of the response \\
7 & Undergraduate satisfaction with the response \\
8 & Sufficient information included in the response \\
9 & Wish for another response \\
10 & Overall success of the interaction \\
\hline
\end{tabular}

When describing the interview process to the participants, I reviewed all prompts. Interview Items 4 and 5 were distinguished in the following way. For Item 4, I was interested in knowing whether the undergraduate was asking for specific information. In other words, was the undergraduate in need of content information that he or she did not have or did not know. For Item 5, I wanted to know if the undergraduate had some sense of what the answer was, but was checking to make sure (i.e., confirm) that he or she was doing the right thing before proceeding. The interview prompts for each participant are listed in Table 6. 
Table 6

Interview Prompts

\begin{tabular}{|c|c|c|c|}
\hline $\begin{array}{l}\text { Interview } \\
\text { Item }\end{array}$ & Undergraduate & Teaching Assistant & Faculty \\
\hline 1 & $\begin{array}{l}\text { The teaching assistant } \\
\text { understood my } \\
\text { question. }\end{array}$ & $\begin{array}{l}\text { I understood the } \\
\text { undergraduate's } \\
\text { question. }\end{array}$ & $\begin{array}{l}\text { I think the teaching } \\
\text { assistant understood the } \\
\text { question. }\end{array}$ \\
\hline 2 & $\begin{array}{l}\text { I was comfortable } \\
\text { approaching the TA } \\
\text { with my question. }\end{array}$ & $\begin{array}{l}\text { The undergraduate's } \\
\text { question was easy to } \\
\text { answer. }\end{array}$ & $\begin{array}{l}\text { The undergraduate’s } \\
\text { question was clearly } \\
\text { expressed. }\end{array}$ \\
\hline 3 & $\begin{array}{l}\text { I wasn’t sure how to } \\
\text { explain (or phrase) my } \\
\text { question. }\end{array}$ & $\begin{array}{l}\text { The undergraduate had } \\
\text { difficulty asking the } \\
\text { question. }\end{array}$ & $\begin{array}{l}\text { The undergraduate had } \\
\text { difficulty expressing } \\
\text { the question. }\end{array}$ \\
\hline 4 & $\begin{array}{l}\text { I needed to have } \\
\text { instructions or } \\
\text { information clarified. }\end{array}$ & $\begin{array}{l}\text { The undergraduate } \\
\text { wanted information } \\
\text { clarified. }\end{array}$ & $\begin{array}{l}\text { The undergraduate was } \\
\text { seeking clarification of } \\
\text { information. }\end{array}$ \\
\hline 5 & $\begin{array}{l}\text { I was checking to make } \\
\text { sure that I understood } \\
\text { what to do; i.e., I was } \\
\text { seeking confirmation. }\end{array}$ & $\begin{array}{l}\text { The undergraduate was } \\
\text { checking to make sure } \\
\text { that he/she understood } \\
\text { what to do. }\end{array}$ & $\begin{array}{l}\text { The undergraduate was } \\
\text { seeking confirmation } \\
\text { that what he/she was } \\
\text { doing was correct. }\end{array}$ \\
\hline 6 & $\begin{array}{l}\text { I understood the TA's } \\
\text { response. }\end{array}$ & $\begin{array}{l}\text { The undergraduate } \\
\text { understood my } \\
\text { response. }\end{array}$ & $\begin{array}{l}\text { The undergraduate } \\
\text { understood the } \\
\text { response. }\end{array}$ \\
\hline 7 & $\begin{array}{l}\text { I was satisfied with the } \\
\text { TA's response. }\end{array}$ & $\begin{array}{l}\text { The undergraduate was } \\
\text { satisfied with my } \\
\text { response. }\end{array}$ & $\begin{array}{l}\text { The TA responded } \\
\text { accurately. }\end{array}$ \\
\hline 8 & $\begin{array}{l}\text { The TA provided } \\
\text { sufficient information } \\
\text { for me to understand } \\
\text { the response. }\end{array}$ & $\begin{array}{l}\text { I was satisfied with my } \\
\text { response. }\end{array}$ & $\begin{array}{l}\text { The TA provided } \\
\text { sufficient information } \\
\text { in the response for the } \\
\text { undergraduate to } \\
\text { understand the } \\
\text { response. }\end{array}$ \\
\hline 9 & $\begin{array}{l}\text { I wish the TA had } \\
\text { responded differently. }\end{array}$ & $\begin{array}{l}\text { I now realize that } \\
\text { another response would } \\
\text { have been better. }\end{array}$ & $\begin{array}{l}\text { The TA should have } \\
\text { responded differently. }\end{array}$ \\
\hline 10 & $\begin{array}{l}\text { Overall this was a } \\
\text { successful } \\
\text { question/answer } \\
\text { exchange. }\end{array}$ & $\begin{array}{l}\text { Overall, this was a } \\
\text { successful } \\
\text { question/answer } \\
\text { exchange. }\end{array}$ & $\begin{array}{l}\text { Overall I think this was } \\
\text { a successful } \\
\text { question/answer } \\
\text { exchange. }\end{array}$ \\
\hline
\end{tabular}

All participants could provide additional explanations for each item. For example, in Interview Item 9, participants could describe what a different response should include. 


\section{Analysis}

The analysis phase of this project has three parts: analysis of the data collected during classroom observations and the background information gathered from questionnaires; analysis of the Likert-scaled responses and comments from the interviews; and analysis of the interactions the participants reviewed during the interview phase of this project. Each of these phases of the study presented different types of data and required different approaches to analyzing the data. However, central to all analysis was the construct of a communicative exchange or interaction, the unit of analysis for this project. For a spoken exchange to be considered as a unit for analysis, the interaction must be related to the course and be comprised of a sequence of two or more uninterrupted turns (Fairclough, 2003).

\section{Lab Communication}

Organizing the large amount of data generated in this research project was the first stage in analysis. Before beginning data collection, areas of potential research interest were established, and these were then used to classify and organize the material. For this project, the categories included the gender of the undergraduate participant; who initiated the communicative exchange; the topic, task or activity of the communicative exchange, and the length of interaction. These categories were the principal guides for segmenting and organizing the data in the preliminary stages of analysis. Analysis of data for the lab interactions and the background questionnaires is based on descriptive statistics (frequency counts and percentages) to provide an overall view of the interactions and activities of the labs, and chi-square analysis was used with the data from the lab interactions. 


\section{Organizing the Data}

The audio and video recordings, which also served as the source material for the interview phase of this project, were reviewed multiple times in real time to check for errors in the supporting documentation of the interactions. In this review process, additional information was added as necessary to the Excel files that accompanied the digital materials. During the spring 2006 semester, additional information related to the interactions was introduced into the Excel files containing the supporting documentation, including the length of the interactions, the interaction activity type, and transcriptions for selected interactions.

This review process was extremely time-consuming and tedious given the volume of data collected. Each new set of additional information added to the documentation files constituted a substantial amount of time. For each hour of digitally recorded material, identifying, coding, and checking for accuracy of the files for the interactions took approximately two-to-three hours for each new classification added. Transcriptions of interactions identified as being important took on average 20 minutes per interaction. However, this review process was an important foundation for the analysis and interpretation phases of this project because it provided me with the opportunity to develop increased familiarity with and a deeper understanding of the activities and interactions that occurred during the semester. This increased awareness of events in the lab contributed to the insights of themes and patterns in the data that emerged during the analysis and interpretation stages of this project. 
Each interaction recorded for this project includes documentation for the following information:

- Each interaction was coded by the lab session and lab section in which it occurred.

- Each interaction was numbered sequentially as it occurred in the lab session.

- Each interaction was identified by where it took place, in the classroom area or in the lab area.

- Each interaction was identified by the undergraduate involved. Undergraduates were identified by the number of their lab bench. For interactions that occurred in the classroom area, undergraduates were identified when possible.

- Start and stop times for each interaction were recorded and used to calculate the length of the interaction.

- Interactions were identified by who initiated an interaction, by who spoke first. No consistent way existed to document interactions initiated by non-verbal communication, though it did occur.

- For interactions that involved more than one undergraduate, the additional undergraduates were noted. The undergraduate who initiated the interaction was considered the primary participant.

- Interactions were documented by a key phrase or topic of the interaction, as a way to ensure the correct interaction was easily accessible in the digital format.

- Interactions were documented by the gender of the undergraduate participant(s).

- Interactions were identified by activity or task type in the lab experiment. 


\section{Coding the Data}

In the analysis phase of the project, the classification categories mentioned above presented different types of data and required different ways to approach coding the data and consequently different approaches to checking for accuracy and reliability of the coding. Multiple reviews of the material in the analysis phase of this project provided opportunities to check for accuracy and reliability.

The start and stop times for interactions were taken from the digital recordings and were reviewed multiple times for accuracy over the course of multiple semesters. From these time codes, interaction lengths were calculated.

Coding an interaction by who initiated it proved to be somewhat problematic in the science laboratory, even with supporting digital audio and video materials to review. In many cases, it is clear that the person speaking first is the one who initiates the interaction. However, in some instances, an interaction was initiated by non-verbal means. For example, an undergraduate might establish eye contact with the teaching assistant, and the teaching assistant would move to where the undergraduate was to talk with the undergraduate. In a case such as this, the undergraduate may speak first or the teaching assistant may speak first.

In the lab environment, undergraduates are spread out around the room and the teaching assistant is constantly moving around, so capturing all non-verbal activity of the undergraduates and teaching assistants was not possible. There were instances where an undergraduate used non-verbal communication to obtain the teaching assistant's attention. However, the physical layout of the lab, with floor-to-ceiling work benches, limited an undergraduate's ability to get a teaching assistant's attention by 
non-verbal means and increased the undergraduate’s tendency to initiate an interaction with the teaching assistant verbally. As such, for this study's results to be consistent, I chose to base initiation of the interaction on the first person to speak, the only way to reliably and systematically code the interactions. A research project that would investigate the non-verbal aspects of interaction initiation would require a different approach to data collection. Coding categories for interaction initiation were as follows: teaching assistant, undergraduate, and other (a faculty member, undergraduate from another section, roving teaching assistant, or lab manager).

Each interaction was coded for the sex of the undergraduate(s) involved. These coding categories were derived from the background questionnaires provided by the undergraduates. In some cases, multiple undergraduates were participating in an interaction. In these cases, although the sex of all the participants was documented, for purposes of analysis in this project, only the sex of the primary undergraduate participant was counted. Self-reported coding categories for gender were male or female.

Finally, the interactions were coded for activity or task involved in the interaction. Preliminary coding categories were determined in consultation with the faculty member at the start of the semester. However, eventually the coding categories evolved into the following categories: lab preparation, materials, equipment, procedures, safety, social, unassigned. Table 7 provides the definitions used in coding lab communication for activity types. 
Table 7

Coding Categories and Definitions for Activities Discussed in Lab Communication

\begin{tabular}{|c|c|}
\hline Category & Topics Discussed \\
\hline \multirow[t]{2}{*}{ Equipment } & Tools, devices, and equipment of the laboratory. \\
\hline & $\begin{array}{l}\text { Examples: standard equipment such as test tubes, beakers, funnels, } \\
\text { and stir bars were included in this category, as were specialized } \\
\text { equipment such as pH meters. }\end{array}$ \\
\hline \multirow[t]{2}{*}{ Lab Preparation } & Advance preparation for the lab. \\
\hline & $\begin{array}{l}\text { Examples: questions related to the pre-lab quiz, the pre-lab } \\
\text { questions, returned assignments, sample assignment, or } \\
\text { undergraduates being organized into working groups. }\end{array}$ \\
\hline \multirow[t]{2}{*}{ Materials } & $\begin{array}{l}\text { Solutions or samples used in an experiment, i.e., experimental } \\
\text { materials. }\end{array}$ \\
\hline & $\begin{array}{l}\text { Examples: } \mathrm{NaOH} \text { (sodium hydroxide), reagents, types of water } \\
\text { used, and samples to be analyzed. }\end{array}$ \\
\hline \multirow[t]{2}{*}{ Procedures } & $\begin{array}{l}\text { How to carry out the procedures of the experiment as directed by } \\
\text { the lab manual. }\end{array}$ \\
\hline & Examples: setting up vacuum filtration or titration. \\
\hline Safety & $\begin{array}{l}\text { Actions related to the health and well being of the those present in } \\
\text { the lab. } \\
\text { Examples: wearing goggles, cleaning up broken glassware, or } \\
\text { working appropriately under the hood with proper ventilation. }\end{array}$ \\
\hline Social & $\begin{array}{l}\text { Conversational exchanges that were carried out in the lab but were } \\
\text { not directly related to the experiment. Their function was } \\
\text { maintaining a sense of social cohesiveness in the lab. }\end{array}$ \\
\hline Unassigned & $\begin{array}{l}\text { Communicative exchanges where classification was not possible, } \\
\text { the result of part of the exchange being inaudible. }\end{array}$ \\
\hline
\end{tabular}




\section{Establishing Reliability}

Once the data collected had been organized into manageable classification systems, checking for reliability of the coding of data was the second step. Procedures for establishing reliability in the coding of data collected in the observations vary based on the types of categorized data. The main methods of organizing the data included the categories of who initiated an interaction, the gender of the participant(s) in the interaction, the length of an interaction, and the activity or task carried out in the interactions.

The data related to the categories of interaction initiation, interaction length, and gender of the undergraduates were checked for reliability in the same way. Interaction initiation was determined by who spoke first. Interaction length was calculated from the time codes generated by the digital recording equipment. Gender of undergraduates was obtained from self-reporting in the background questionnaires. For these categories, the supporting Excel files documenting information for each interaction were reviewed on multiple occasions over multiple semesters for accuracy.

The coding of data for activity or task topic of the interaction required external reliability coders. Initially, the faculty member consulted about possible categories for this area. These initial categories were refined and a final determination of activities or tasks was made after multiple observations and reviews of the interactions. To check reliability of coding for this category, two independent professionals were hired. One was a linguistic anthropologist and one a language specialist. In one-on-one sessions, I identified the categories that developed from working with the data and defined them to the reliability coders. I played the interactions for the reliability coders, who were 
allowed to review each interaction as many times as necessary for them to be comfortable assigning an activity or task type to an interaction.

Because of the volume of data to be checked and time constraints, it was impractical for one person to check for reliability in the coding of activity or task type, and it was impractical to check all interactions. I established a principled way to randomize interactions to be checked for reliability. Every fifth interaction initiated by a teaching assistant and every fifth interaction initiated by an undergraduate were checked for reliability. Approximately $18 \%$ of all interactions in the recorded data were checked in this way. In 9 of the 15 labs, the rate of agreement between the reliability coders' assignment and my assignment was $100 \%$. Overall the rate of agreement for all interactions checked was 94\%.

The main discrepancies in reliability coding occurred with one of the reliability coders. In a couple of lab sessions, this coder had a tendency to categorize some interactions as being a combined category of materials/equipment. In a few other instances, the discrepancy was related to the format in which an interaction was reviewed. An interaction that was recorded with audio only did not have the visual component available. In a few instances, it was not possible for the reliability coder to determine with sufficient certainty what the activity or task type was. For example, if an undergraduate asked the teaching assistant about a pre-lab question related to setting up an experiment, a reliability coder could not determine whether the undergraduate was working in the lab area with the equipment or was in the classroom area referring to print materials related to the lab unless there was visual information to provide contextual information. 
The reliability coders were able to use the categories supplied and did not need to expand on the categories. Further, the categories established provided meaningful distinctions to the reliability coders. It is concluded that the categories for activity or task demonstrate consistency across raters and completeness by sufficiently addressing all activities presented in interactions (Patton, 2002). The interview process also provided an additional measure of reliability check on a subset of the interactions, as the participants frequently indicated in their discussions what the type of activity or task they were engaged in was.

\section{Interviews}

The second method of data collection was the semi-structured interviews conducted with the participants involved in the interactions. The semi-structured interviews presented two types of data for analysis: the Likert-scaled responses and the comments expressed during the interviews. The interview process also identified a subset of interactions that were analyzed for their content. Analysis of the Likert-scaled responses consists of descriptive statistics, frequency counts, and percentages. From the comments during the interviews, themes and patterns emerged that were used in the analysis of the interactions.

\section{Likert-Scaled Responses}

For each interview interaction, the Likert-scaled responses from the participants were analyzed in item-by-item comparisons. All interview items for each interview interaction were compared for agreement and disagreement of opinion among the three participants, a three-way comparison of the undergraduate, teaching assistant, and faculty member. Opinions were also examined in two-way comparisons: 
undergraduate-teaching assistant (the instructional pair), undergraduate-faculty (the native speaker perspective), and teaching assistant-faculty (the content-area perspective).

Opinions of the participants for the interview items were classified as congruent opinion (of agreement and disagreement), divergent opinion, missing response, and insufficient degree of certainty. In this study, congruent opinions of agreement occur when participants responded with a sufficient degree of certainty to an interview item on the Likert scale. For example, if all three participants agreed with an interview item of an interaction with a 6 or 7 on the scale, the interview item was considered to have a congruent opinion of agreement. Similarly, congruent opinions of disagreement occurred when all three participants disagreed with an interview item for an interaction with a 1 or 2 on the scale. Divergent opinions occurred when the participants had differing opinions on an interview item. For example, if the teaching assistant disagreed with an interview item and selected a 1 or 2 on the Likert scale, and the undergraduate agreed with the interview item by selecting a 6 or 7 on the Likert scale, the interview item was classified as having divergent opinions. Missing responses were assigned when a participant could not respond to the interview item with a scaled response. For example, in some interactions, the audio recording did not provide sufficient information for the faculty member to respond to an interview item. Finally, when participants selected a response from the scale in the range of 3,4 , or 5 , the interview item was considered to have an insufficient degree of certainty.

Interview Item 10 of the semi-structured interview was used to determine whether an interaction was classified as successful or not by the participants. It states: 
“Overall, this was a successful interaction.” Based on the responses to this item, an interaction could be classified into one of three categories. Participants could agree with a sufficient degree of certainty that the interaction was successful. Participants could not agree on whether the interaction was successful or unsuccessful, i.e., the interactions were partially successful. Finally, participants could agree that the interaction was unsuccessful.

\section{Participant Comments}

Participant comments were documented for each of the interview items, and these were reviewed for themes and patterns. At the end of the interviews, the participants provided additional comments, ones not related to individual interview items but related to the interactions. These additional comments related to the interactions were also reviewed for themes and patterns. The themes that emerged in this phase of analysis guided the analysis of the subset of interview interactions.

\section{Analysis of Lab Communication and Interactions}

Analysis of the data obtained in the lab observations included a quantitative component. In addition to descriptive statistics related to the communicative interactions of each lab session and of the lab sections of each teaching assistant, statistical analysis using chi-square was used to assess the significance of features of the interactions that occurred in the labs. The software program used for statistical analysis was SAS (version 9.1.3). An alpha level of .05 was used for all statistical tests.

The interview process yielded a subset of interactions that the participants identified as successful, partially successful, and unsuccessful. These interactions were then analyzed for their content and characteristics. Information obtained in the interview 
process from the Likert-scaled responses and participant comments guided the analysis of the interview interactions. Broad transcription of the interview data provided sufficient detail for interaction analysis using a framework from Flowerdew and Miller (2005) of conversational listening, focusing on how interactions were opened, closed, and topics established. Additional analysis examined listener-centered features such as turn-taking, speaking style, and lexical selection (deixis). Topics identified from interaction analysis included the relationship of ambiguity and lexical choice and the coordination of verbal and visual information in real-world communication. 


\section{CHAPTER 4: FINDINGS}

This study investigates what constitutes successful communication and/or negotiation of information between non-native English speaking teaching assistants and their undergraduates students in introductory-level chemistry labs to better understand which features of those interactions contribute to successful communication between these two populations. This chapter, organized into three sections, presents findings obtained in the analysis of the data collected from observations and recordings of the labs (field notes, audio and video recordings), background questionnaires, interviews, and analysis of select interactions.

The first section presents summary data and descriptive statistics of the background characteristics of the undergraduate participants, information obtained through questionnaires, and of the lab communication, information collected from observations and digital audio and video recordings of the lab sessions. The second section examines data collected from the semi-structured interviews carried out with the participants, including quantitative data from the Likert-scaled responses and qualitative data from the comments provided by the participants during the interview process. The third section presents findings from an analysis of a subset of interactions that were identified through the interview process.

\section{Chemistry Laboratory Overview}

In this study, an examination of communication patterns between non-native speaking teaching assistants and their undergraduate students, the international teaching assistants were chosen by purposeful sampling. Briefly, the teaching assistants selected were native speakers of Mandarin Chinese who had been in the United States for at 
least one year prior to the start of the study and had teaching experience in the field at the university level in the United States. The undergraduates in this study were those undergraduates who were enrolled in the sections taught by the international teaching assistants. The undergraduates were enrolled at a prestigious, private university in the Northeast with a highly competitive selection process. The undergraduates in the sections of the participating teaching assistants chose the day of the week and the start time of the lab section they wanted to attend. However, they were randomly assigned to sections by the faculty member teaching the laboratory portion of the course. In effect, the undergraduates in this study were randomly selected, though there is no way of knowing whether other undergraduates had decided to transfer out of these sections because the sections were taught by international teaching assistants.

The undergraduates in the three sections were all invited to participant in the study, and participation was high for all sections. Overall, 45 of the 51 undergraduates enrolled in all three sections agreed to participate. The six undergraduates who did not consent to participate came from the Tuesday and Wednesday sections, three from each section. In the Tuesday section, one undergraduate did not attend any of the lab sessions that were recorded, and the other two undergraduates in the Tuesday section only attended some of the lab sessions, either two or three of the five labs sessions recorded. The Wednesday section also had three non-participants, one undergraduate younger than the age of consent to participate (18 years old), one international undergraduate who declined to participate, and one who attended only occasionally due to illness. The participation rate of the Thursday section was $100 \%$. However, it should be noted that four of the seven male undergraduates in this section did not initially consent to 
participate in the study. As the semester progressed and they became familiar with the activities of the study, they agreed to participate. In essence, all eligible, regularly attending undergraduates agreed to participate in the study.

In order to better understand the undergraduate population involved in the study, a background questionnaire was administered to establish a profile of the undergraduates. The background questionnaire asked for information related to the undergraduates' age, sex, year in college, major, experience or exposure to other languages and cultures, and academic preparation in chemistry and mathematics. In general, the undergraduates who completed the background questionnaires completed all questions. However, there were some instances in which undergraduates did not respond to all questions. Only one participant in the Tuesday section declined to complete the background questionnaire. The following is a summary of the various background characteristics of the undergraduates. Appendix E provides a summary table of response rates for each item, as well as frequency counts and percentages for the three sections.

\section{Undergraduate Participant Profile}

Of the 51 undergraduates assigned to these three lab sections, 45 agreed to participate in the study, a participation rate of $88 \%$. In the Tuesday section, 17 undergraduates enrolled and 14 agreed to participate. In the Wednesday section, 18 enrolled and 15 agreed to participate. In the Thursday section, all 16 undergraduates eventually agreed to participate. In general, all regularly attending undergraduates 18 years and older agreed to participate. 


\section{Gender}

Collectively, there were slightly more female participants than male, with 53\% female and $47 \%$ male. Of the 6 non-participants, 3 were male and 3 were female. Each section had an equal distribution of males and females, though the Thursday section had a slightly higher number of females. Each section had 7 male participants. There were 7 females in the Tuesday section, 8 in the Wednesday section and 9 in the Thursday section.

Age

The majority of the undergraduate participants, 87\%, were either 18 (47\%) or 19 (40\%) years old, with 3 undergraduates reporting slightly older ages, $20(n=2)$ and 31 $(n=1)$. Collectively, the balance between 18-year-olds and 19-year-olds was similar, with slightly more 18 -year-olds $(n=21)$ than 19-year-olds $(n=18)$. The three sections each had 7 undergraduates who were 18-year-olds, and 6 who were 19-year-olds. The three older undergraduates were in the Thursday section. The undergraduate in the Thursday section who reported his age as 31 was part of the host university’s resumed undergraduate education program, designed for older adults interested in returning to college to pursue an undergraduate degree.

\section{Year in College}

All of the 42 undergraduates who reported their year in college were in either their first $(n=23)$ or second $(n=19)$ year of college. The distribution of first- and second-year undergraduates was slightly different for the three sections. The Tuesday section had 6 first-year and 7 second-year undergraduates. The Thursday section had 8 
first- and 8 second-year undergraduates. However, the Wednesday section had almost twice as many first-year undergraduates $(n=9)$ as second-year $(n=4)$. Majors

While the distribution of undergraduates with decided $(n=24)$ and undecided ( $n=19$ ) majors was fairly even in all sections combined, the distribution within the sections was not. The Tuesday section had 8 undergraduates with decided majors and 5 with undecided majors. The Wednesday section had only 4 undergraduates with decided majors and 10 with undecided majors. In contrast, the Thursday section had 12 undergraduates with decided majors and only 4 who had not decided their majors.

While the distribution of decided versus undecided majors differed from section to section, there was more uniformity in the types of majors that the undergraduates had elected or were considering. Of the 24 undergraduates with decided majors, 22 were science majors, mostly bio-medical sciences, and 2 were non-science majors. Of the 19 undergraduates who had yet to decide a major, all stated that they were likely to major in science, with biomedical sciences being the primary major.

\section{Community Growing Up}

The undergraduate participants who responded to questions related to cultural and linguistic backgrounds self-reported that 41 grew up in the United States, with one undergraduate growing up abroad. The undergraduates identified 16 states, representing all geographic regions of the United States, as their home states, and the one undergraduate from abroad identified Japan as her home country. Of the undergraduates who responded, 31 classified the community in which they grew up as suburban, with 3 undergraduates identifying their communities as rural and 4 classifying their 
communities as urban. Each of the three sections had at least at least 1 undergraduate who reported growing up in a rural community and 1 who reported growing up in an urban community.

\section{Language Spoken at Home}

English was the predominate language spoken at home for the participants. For 29 undergraduates it was the only language spoken at home. However, it should be noted that that the undergraduates' spoken English demonstrated variations typical for English speakers from different regions of the United States. For 10 undergraduates English and another language were spoken at home, and for 2 undergraduates English and two other languages were spoken at home. Only 1 undergraduate identified that a language other than English was the only language spoken at home. For this undergraduate, it became clear in the interview process that he had lived for a significant amount of time in his early childhood in another country. The Tuesday section had the highest percentage of undergraduates who reported speaking only English at home, 76\%, compared with $61 \%$ for the Wednesday section, and $69 \%$ for the Thursday section.

\section{Languages Studied and Travel Abroad}

Only three of the undergraduates reported never studying a foreign language. Twenty-six undergraduates reported studying one foreign language, 11 studied two foreign languages, and 2 had studied three foreign languages. In addition, many of the undergraduates had experience living or traveling abroad. Three undergraduates reported living abroad; and an additional 26 reported having traveled abroad. Thirteen undergraduates reported that they had not traveled or lived abroad. In the three sections, 
the Tuesday and Wednesday sections had similar proportions of participants reporting living or traveling abroad, 77\%, and the Thursday section had the lowest proportion, $56 \%$.

\section{Chemistry Background}

All of the 42 undergraduate participants who responded in the background questionnaire reported having studied chemistry in high school, with 17 reporting that they had taken AP chemistry. Of the undergraduates who indicated that they had studied chemistry in high school, 5 reported that they had only studied chemistry for 1 semester, while 24 reported studying chemistry for 2 or more semesters. Thirteen undergraduates had studied chemistry in high school for 4 or more semesters. Only 1 undergraduate from the Tuesday section reported studying high school chemistry for 4 semesters or more, but 5 from the Wednesday section and 7 from the Thursday had. As for the distribution of undergraduates who had taken AP chemistry, 4 were in the Tuesday section, 5 in the Wednesday section, and 8 in the Thursday section. It was not clear the extent to which these high school chemistry classes included a laboratory component to the course.

\section{Mathematics Background}

Of the 42 undergraduates responding to the questions related to their preparation in mathematics, all reported that they had studied calculus in high school, with the majority of undergraduates having studied math in high school for all 4 years. Eight of the undergraduates reported that they had studied mathematics during high school for 2-3 years, and 31 undergraduates reported studying mathematics for 4 years. In addition, 3 undergraduates reported taking 9 and 10 semesters of mathematics in high 
school, by taking more than one math course in a semester. The undergraduates in the Tuesday and Wednesday sections all reported taking around 3-4 years of math classes, while the undergraduates in the Thursday section reported taking 2-4 years of high school mathematics.

Of the 36 undergraduates who responded to the questions about taking collegelevel mathematics, 7 reported that they had not taken a math class at the college level, and 29 reported that they had taken or were taking college-level math classes. Of those who reported taking college-level mathematics classes, 24 reported taking one course, 3 reported taking two courses, 1 reported taking three courses, and 1 reported taking four courses. The proportion of undergraduates who reported taking college-level mathematics courses was similar for all sections, Tuesday, 82\%; Wednesday, $80 \%$, and Thursday, $80 \%$.

Information obtained from the undergraduate background questionnaire provides a profile of the undergraduate participants. The summary percentage calculations here are based on the total number of participants $(N=45)$ and include only the counts of participants who responded. The undergraduates were almost equally divided between males (47\%) and females (53\%) and were predominately 18- and 19years-olds (87\%). There were nearly equal numbers of first-year (51\%) and second-year (42\%) undergraduates. While about half of the undergraduates had declared majors (53\%), nearly all undergraduates had either declared or were likely to major in the sciences (89\%), with the bio-medical sciences the most common major. The majority of undergraduates grew-up in suburban environments (69\%) with English as the only language spoken at home (64\%) or as one of the languages spoken at home (26\%). 
Nearly all undergraduates had studied a foreign language (87\%), and over half (64\%) had visited another country. All undergraduates had extensive high school preparation in chemistry and in mathematics. In total, 93\% had studied high school chemistry, with 38\% taking AP chemistry. In total, 91\% had studied calculus in high school, with 73\% studying math in high school for 4 or more years. At least $64 \%$ of the undergraduates had or were taking college level mathematics classes.

\section{Communication in the Chemistry Labs}

The chemistry labs of all three international teaching assistants were energetic classroom learning environments. As the undergraduates entered the labs, they sat in the classroom area of the laboratory. They conversed casually with each other and the teaching assistants prior to official start of the lab session, and they asked questions of the teaching assistants and each other. It was clear that in all three lab sections that the undergraduates were actively engaged in the course and that the international teaching assistants had established rapport with the undergraduates.

These mostly casual conversations and exchanges that occurred when the undergraduates were entering the classroom area of the laboratories were not part of the interactions considered in this study; however, these interactions prior to the start of the class indicate that the undergraduates and the teaching assistants were comfortable with each other. Interactions that occurred after the official the start of the lab were the ones that comprise the data in this study and form the basis of all analysis of the lab communication that follows. For the purposes of this study, the official start of the lab was when the teaching assistant began addressing the undergraduates in the lab section 
as a class. The observations and recordings ended one hour after the official start of the lab.

The activities for the first hour of the lab sections included two primary types of classroom communication, information delivered in a lecture format and questionanswer interactions. In general, the structure of the first hour of all three lab sections followed a standard format. To begin, the teaching assistants provided a brief overview of the experiment to orient the undergraduates. The overview was delivered as a brief lecture, and there were few interruptions by the undergraduates. This lab introduction by the teaching assistants differed from the pre-lab lecture delivered by the faculty member teaching this course, which provided a dry run of the main experimental procedures and demonstrated use of the experimental equipment to accompany the overview of the experiment. The teaching assistant's overview focused more on the main points of the experiment for the lab, and was brief, usually 5 to 10 minutes in length. The teaching assistants delivered their information without equipment to support their lab overviews. They did, however, rely on the chalkboard to supplement spoken information. Teaching assistants gave undergraduates suggestions for the experiment, highlighted the focus for the experiment of the day, and discussed logistical issues related to the lab. They also answered any spill-over questions from the pre-lab lecture.

Undergraduates were free to ask questions on any of the assignments or topics related to the experiments: the pre-lab questions, the lab outline, the write-up of a lab, or other aspects of the current or previous labs. Undergraduates then took the pre-lab quiz and were allowed as much or as little time as they needed to complete it. Because the labs lasted for 4 hours, the undergraduates were quick to begin the lab, and did not 
linger taking the quiz. In general, the pre-lab quizzes took between 5 to 10 minutes and were usually related to the calculations that undergraduates needed to use in the lab experiment or in the lab report write-up they were required to complete in the last half hour of the lab. Delays in starting the experiment meant that the undergraduates would need to stay longer than the scheduled 4 hours in the labs, so undergraduates were careful to balance efficiency with accuracy when taking the quiz.

Once an undergraduate passed in the pre-lab quiz, the undergraduate moved from the classroom area to begin the experiment. Often, the undergraduates took this opportunity to ask the teaching assistants any residual questions about their preparation for the lab. This meant that the teaching assistants were required to monitor and attend to the needs of undergraduates engaged in various stages of the lab activities simultaneously. For example, undergraduates still working on the quiz could ask the teaching assistant questions related to the quiz. At the same time, undergraduates engaged in the set-up of the experiment were also asking questions about the equipment, materials, and experimental procedures. Undergraduates were also noted asking questions about papers related to previous labs that had been graded and returned.

Initial analysis of the data collected through direct observation, audio-taping, and video-recordings demonstrates that the first hour of the chemistry laboratory sessions are fast-paced, vigorous classroom environments. While all three lab sections displayed their own rhythms and characteristics, the similarities in the activities and interactions outweighed the differences in the labs. Each lab experiment that the undergraduates had to complete also created different demands on the undergraduates 
and the teaching assistants. What follows is an overview of communication in the introductory-level chemistry labs, occurring in five different experimental lab sessions during the semester in three different lab sections. Lab communication was analyzed for the following characteristics: frequency of interactions, length of interactions, initiation of interactions, gender of undergraduates engaged in the interactions, and the activity topics of the interactions. (See Appendix F for summary tables of lab communication.) Interaction Frequency

In total, there were 877 identifiable interactions in the 15 hours (900 minutes) of recorded labs. As stated in the methodology section, a communicative exchange was considered an interaction if there were two alternating, uninterrupted turns. In general, there was approximately one interaction for each minute in the 15 recorded labs, 877 interactions in 900 minutes, $(N=15, M=58, S D=23)$. There were differences in the communicative activities in the five lab sessions. The most communicative exchanges occurred in Lab 6, with 218 interactions, ( $N=3 M=73$, $S D=27)$ and Lab 7, with 219 interactions, $(N=3, M=73$, $S D=19)$. The fewest interactions occurred in Lab 8, with 101 interactions, $(N=3, M=34, S D=14)$. The number of interactions in the remaining lab sessions fell in between, Lab 4, with 165 interactions, $(N=3, M=55, S D=22)$ and Lab 5, with 174 interactions, $(N=3, M=58$, $S D=18)$.

There were also differences in the amount of verbal interaction in the lab sessions of the three lab sections. Fewer interactions occurred in the Thursday section, with 198 interactions, $(N=5, M=40, S D=13)$ than in the Tuesday section, with 304 interactions, $(N=5, M=61, S D=10)$. Both the Tuesday and Thursday sections had 
fewer interactions than the Wednesday section, with 375 interactions ( $N=5, M=75$, $S D=27)$. Table 8 provides the frequency of interactions for each lab session and for each lab section, including breakdowns by participant consent.

Table 8

Frequency of Interactions by Lab Session and Lab Section

Lab Session

\begin{tabular}{rcccccc}
\multicolumn{1}{l}{ Lab Section } & Lab 4 & Lab 5 & Lab 6 & Lab 7 & Lab 8 & Total \\
\cline { 3 - 4 } Consent & 52 & 63 & 60 & 67 & 40 & 282 \\
Nuesday Consent & 0 & 3 & 6 & 5 & 8 & 22 \\
Section Totals & 52 & 66 & 66 & 72 & 48 & 304 \\
\hline Wednesday & & & & & & \\
Consent & 72 & 65 & 90 & 73 & 31 & 331 \\
No Consent & 6 & 6 & 12 & 19 & 1 & 44 \\
Section Totals & 78 & 71 & 102 & 92 & 32 & 375 \\
\hline Thursday & & & & & & \\
Consent & 35 & 36 & 47 & 55 & 21 & 194 \\
No Consent & 0 & 1 & 3 & 0 & 0 & 4 \\
Section Totals & 35 & 37 & 50 & 55 & 21 & 198 \\
\hline Totals & & & & & & \\
$\quad$ Consent & 159 & 164 & 197 & 195 & 92 & 807 \\
No Consent & 6 & 10 & 21 & 24 & 9 & 70 \\
All Interactions & 165 & 174 & 218 & 219 & 101 & 877 \\
\hline
\end{tabular}

Note. Frequency counts illustrate the communicative demand placed on international teaching assistants in the lab environment during the first hour of the labs. All data from non-participants have been excluded from student analysis. 
In terms of percentages of interactions as they occurred in the labs in relationship to the total number of interactions, Lab 4 comprised 19\% of all interactions, Lab 5, 20\%; Lab 6, 25\%; Lab 7, 25\% and Lab 8, 12\%. In terms of interactions distributed across the sections, the Tuesday section accounted for $35 \%$ of all interactions, the Wednesday section $43 \%$, and the Thursday section $23 \%$. A chi-square test of independence was performed to examine the relationship between lab session and lab section. There is not a significant association between the lab session in which an interaction occurs and the section, $\chi^{2}(8, N=877)=13.98, p=0.11$.

That the Thursday lab section had the smallest proportion of overall interactions may be related to the background in high school chemistry of these undergraduates, as the undergraduates in this section had strong backgrounds in high school chemistry. Over half of the undergraduates in the Thursday section (54\%) had 2 or more years of high school chemistry, and 8 of the 16 undergraduates (50\%) responded that they had taken AP chemistry. In addition, in conversations with the teaching assistant for this section, she remarked that the undergraduates in this section were academically very good students who worked well in the lab, performed well on the assignments, and tended to ask few questions. She based her evaluation of this section on comparisons with the other section she was teaching in the current semester and with other sections that she had overseen in previous semesters at this university.

Interactions of non-participants occurred more frequently in the Wednesday section, with $12 \%$ of interactions involving non-participating undergraduates, compared with 7\% in the Tuesday section, and none in the Thursday section. Excluding interactions from non-consenting participants, the proportions of interactions occurring 
in the three sections were almost identical to the proportions for all interactions that occurred in the labs. Proportions of interactions that involved undergraduates who consented to participate in this study: Tuesday (35\%), Wednesday (41\%), and Thursday (24\%).

Interaction Length

While the average number of interactions for the labs was approximately one per minute, a preliminary survey of the data revealed that in general interactions were brief. The length of interactions was calculated from the start and stop times in the digital recordings; however, documenting precise start and stop times of interactions was not always possible. As a result, accuracy was limited if seconds were used to examine interaction length, so time intervals were needed to ensure a more reliable measure (Kirk \& Miller, 1986). Categories of 10-second intervals were established for interactions of less than 1 minute. A category was established for interactions of 1-to-2 minutes and another category for interactions over 2 minutes.

Interactions that took less than 30 seconds $(n=641)$ occurred more frequently than interactions that took longer than 30 seconds $(n=236)$. Interactions of 30 seconds or less accounted for $73 \%$ of the lab interactions. In addition, $92 \%$ of all interactions in the labs were a minute or less in length. Only $8 \%$ of all interactions were over 1 minute in length. Of the interactions that were over 1 minute in length, two-thirds, or 14 out of 21, occurred in initial part of the lab, when the teaching assistants and undergraduates were located in the classroom area and were engaged in interactions related to the lab overview and preparing for the labs. Table 9 provides a summary of the frequency of lab interactions categorized in 10-second intervals, the percentage of the total 
interactions those units comprise, and a cumulative percentage for time intervals for all interactions.

Table 9

Frequency and Percentage of Interactions by Length of Interaction

\begin{tabular}{lccc}
$\begin{array}{l}\text { Interaction Length } \\
\text { in Seconds }\end{array}$ & Frequency & Percentage & $\begin{array}{c}\text { Cumulative } \\
\text { Percentage }\end{array}$ \\
\hline $1-10$ & 285 & $33 \%$ & $33 \%$ \\
$11-20$ & 223 & $25 \%$ & $58 \%$ \\
$21-30$ & 133 & $15 \%$ & $73 \%$ \\
$31-40$ & 81 & $9 \%$ & $82 \%$ \\
$41-50$ & 47 & $5 \%$ & $88 \%$ \\
$51-60$ & 38 & $4 \%$ & $92 \%$ \\
$61-120$ & 49 & $6 \%$ & $98 \%$ \\
$>120$ & 21 & $2 \%$ & $100 \%$ \\
\hline Total & 877 & $100 \%$ & \\
\hline
\end{tabular}

Note. Frequency counts and percentages illustrate the communicative demand placed on international teaching assistants in the lab environment during the first hour of the labs. All data from non-participants have been excluded from student analysis. 
Looking across the lab sessions as the semester developed, as seen in Table 10, interactions tended to be brief across all five labs, with the majority of interactions in all labs falling below the 30-second threshold. Interactions in Lab 4 tended to be slightly longer. This may be explained by the fact that this lab occurred early in the semester, when undergraduates were less familiar with the materials, and possibly less familiar with the teaching assistants. 
Table 10

Frequency and Percentage of Interactions by Lab Session and Length of Interaction

\begin{tabular}{|c|c|c|c|c|c|c|c|}
\hline \multirow{2}{*}{\multicolumn{2}{|c|}{$\begin{array}{l}\text { Interaction Length } \\
\text { (in Seconds) }\end{array}$}} & \multicolumn{5}{|c|}{ Lab Session } & \multirow{3}{*}{$\begin{array}{r}\text { Total } \\
285\end{array}$} \\
\hline & & \multirow{2}{*}{$\frac{\text { Lab } 4}{35}$} & \multirow{2}{*}{$\begin{array}{c}\text { Lab } 5 \\
66\end{array}$} & \multirow{2}{*}{$\begin{array}{c}\text { Lab } 6 \\
70\end{array}$} & \multirow{2}{*}{$\begin{array}{c}\text { Lab } 7 \\
74\end{array}$} & \multirow{2}{*}{$\begin{array}{c}\text { Lab } 8 \\
40\end{array}$} & \\
\hline $1-10$ & Frequency & & & & & & \\
\hline & Percentage & $21 \%$ & $38 \%$ & $32 \%$ & $34 \%$ & $40 \%$ & $32 \%$ \\
\hline \multirow[t]{2}{*}{$11-20$} & Frequency & 45 & 42 & 46 & 66 & 24 & 223 \\
\hline & Percentage & $27 \%$ & $24 \%$ & $21 \%$ & $30 \%$ & $24 \%$ & $25 \%$ \\
\hline \multicolumn{2}{|c|}{ Cumulative Percentage } & $48 \%$ & $62 \%$ & $53 \%$ & $64 \%$ & $63 \%$ & $58 \%$ \\
\hline \multirow[t]{2}{*}{$21-30$} & Frequency & 21 & 23 & 42 & 34 & 13 & 133 \\
\hline & Percentage & $13 \%$ & $13 \%$ & $19 \%$ & $16 \%$ & $13 \%$ & $15 \%$ \\
\hline \multicolumn{2}{|c|}{ Cumulative Percentage } & $61 \%$ & $75 \%$ & $73 \%$ & $80 \%$ & $76 \%$ & $73 \%$ \\
\hline \multirow[t]{2}{*}{$31-40$} & Frequency & 21 & 13 & 20 & 17 & 10 & 81 \\
\hline & Percentage & $13 \%$ & $7 \%$ & $9 \%$ & $8 \%$ & $10 \%$ & $9 \%$ \\
\hline \multicolumn{2}{|c|}{ Cumulative Percentage } & $74 \%$ & $83 \%$ & $82 \%$ & $87 \%$ & $86 \%$ & $82 \%$ \\
\hline \multirow[t]{2}{*}{$41-50$} & Frequency & 13 & 7 & 13 & 10 & 4 & 47 \\
\hline & Percentage & $8 \%$ & $4 \%$ & $6 \%$ & $5 \%$ & $4 \%$ & $5 \%$ \\
\hline \multicolumn{2}{|c|}{ Cumulative Percentage } & $82 \%$ & $87 \%$ & $88 \%$ & $92 \%$ & $90 \%$ & $88 \%$ \\
\hline \multirow[t]{2}{*}{$51-60$} & Frequency & 9 & 9 & 13 & 6 & 1 & 38 \\
\hline & Percentage & $5 \%$ & $5 \%$ & $6 \%$ & $3 \%$ & $1 \%$ & $4 \%$ \\
\hline \multicolumn{2}{|c|}{ Cumulative Percentage } & $87 \%$ & $92 \%$ & $94 \%$ & $95 \%$ & $91 \%$ & $92 \%$ \\
\hline \multirow[t]{2}{*}{$61-120$} & Frequency & 17 & 8 & 11 & 8 & 5 & 49 \\
\hline & Percentage & $10 \%$ & $5 \%$ & $5 \%$ & $4 \%$ & $5 \%$ & $6 \%$ \\
\hline \multicolumn{2}{|c|}{ Cumulative Percentage } & $98 \%$ & $97 \%$ & $99 \%$ & $98 \%$ & $96 \%$ & $98 \%$ \\
\hline \multirow[t]{2}{*}{$>120$} & Frequency & 4 & 6 & 3 & 4 & 4 & 21 \\
\hline & Percentage & $2 \%$ & $3 \%$ & $1 \%$ & $2 \%$ & $4 \%$ & $2 \%$ \\
\hline \multicolumn{2}{|c|}{ Cumulative Percentage } & $100 \%$ & $100 \%$ & $100 \%$ & $100 \%$ & $100 \%$ & $100 \%$ \\
\hline \multicolumn{2}{|l|}{ Total } & 165 & 174 & 218 & 219 & 101 & 877 \\
\hline
\end{tabular}

Note. Frequency counts and percentages illustrate the communicative demand placed on international teaching assistants in the lab environment during the first hour of the labs. All data from non-participants have been excluded from student analysis. 
As the semester progressed, interactions tended to be shorter. In general, over half of all interactions were completed in 30 seconds or less, with $61 \%$ of all interactions in Lab 4 being 30 seconds or less, and by Lab 8, 76\% of all interactions were 30 seconds or less. The trend for shorter interactions as the semester progressed was most evident in interactions in the 1-10 second interval. In Lab 4, 21\% of all interactions were 10 seconds or less and by Lab 8, 40\% of all interactions were 10 seconds or less. A chi-square test of independence was performed to examine the relationship between the lab session and length of interaction. Chi-square analysis supports that there is a significant association between interaction length and the lab in which it occurred, $\chi^{2}(28, N=877)=43.30, p=0.033$. In general, interactions were shorter as the semester progressed.

Table 11 also demonstrates that the tendency for interactions to be relatively short in duration was consistent across the three lab sections. In each of the three sections, a minimum of $65 \%$ of all interactions lasted less than 30 seconds. In terms of overall percentages, the Tuesday section had shorter interactions, with $81 \%$ of interactions in this section completed in 30 seconds or less. The Thursday section had slightly longer interactions, with $65 \%$ of its interactions completed in 30 seconds or less, and $80 \%$ of its interactions taking 50 seconds or less. The Wednesday section fell in between, with $71 \%$ of its interactions taking 30 seconds or less, and $80 \%$ of its interactions taking 40 seconds or less. The fact that the Thursday section had the longest interactions may have some relationship to the fact that this section also had the fewest interactions. 
Table 11

Frequency and Percentage of Interactions by Lab Section and Length of Interaction

\begin{tabular}{|c|c|c|c|c|c|}
\hline \multirow{2}{*}{\multicolumn{2}{|c|}{$\begin{array}{l}\text { Interaction Length } \\
\text { (in seconds) }\end{array}$}} & \multicolumn{3}{|c|}{ Lab Session } & \multirow{3}{*}{$\begin{array}{r}\text { Total } \\
285\end{array}$} \\
\hline & & \multirow{2}{*}{$\begin{array}{c}\text { Tuesday } \\
121\end{array}$} & \multirow{2}{*}{$\begin{array}{c}\text { Wednesday } \\
103\end{array}$} & \multirow{2}{*}{$\begin{array}{c}\text { Thursday } \\
61\end{array}$} & \\
\hline $1-10$ & Frequency & & & & \\
\hline & Percentage & $40 \%$ & $27 \%$ & $31 \%$ & $32 \%$ \\
\hline \multirow[t]{2}{*}{$11-20$} & Frequency & 79 & 105 & 39 & 223 \\
\hline & Percentage & $26 \%$ & $28 \%$ & $20 \%$ & $25 \%$ \\
\hline \multicolumn{2}{|c|}{ Cumulative Percentage } & $66 \%$ & $55 \%$ & $51 \%$ & $58 \%$ \\
\hline \multirow[t]{2}{*}{$21-30$} & Frequency & 46 & 58 & 29 & 133 \\
\hline & Percentage & $15 \%$ & $15 \%$ & $15 \%$ & $15 \%$ \\
\hline \multicolumn{2}{|c|}{ Cumulative Percentage } & $81 \%$ & $71 \%$ & $65 \%$ & $73 \%$ \\
\hline \multirow[t]{2}{*}{$31-40$} & Frequency & 20 & 38 & 23 & 81 \\
\hline & Percentage & $6 \%$ & $10 \%$ & $12 \%$ & $9 \%$ \\
\hline \multicolumn{2}{|c|}{ Cumulative Percentage } & $88 \%$ & $81 \%$ & $77 \%$ & $82 \%$ \\
\hline \multirow[t]{2}{*}{$41-50$} & Frequency & 11 & 22 & 14 & 47 \\
\hline & Percentage & $4 \%$ & $6 \%$ & $7 \%$ & $5 \%$ \\
\hline \multicolumn{2}{|c|}{ Cumulative Percentage } & $91 \%$ & $87 \%$ & $84 \%$ & $88 \%$ \\
\hline \multirow[t]{2}{*}{$51-60$} & Frequency & 10 & 16 & 12 & 38 \\
\hline & Percentage & $3 \%$ & $4 \%$ & $6 \%$ & $4 \%$ \\
\hline \multicolumn{2}{|c|}{ Cumulative Percentage } & $94 \%$ & $91 \%$ & $90 \%$ & $92 \%$ \\
\hline \multirow[t]{2}{*}{$61-120$} & Frequency & 12 & 22 & 15 & 49 \\
\hline & Percentage & $4 \%$ & $6 \%$ & $8 \%$ & $6 \%$ \\
\hline \multicolumn{2}{|c|}{ Cumulative Percentage } & $98 \%$ & $97 \%$ & $97 \%$ & $98 \%$ \\
\hline \multirow[t]{2}{*}{$>120$} & Frequency & 5 & 11 & 5 & 21 \\
\hline & Percentage & $2 \%$ & $3 \%$ & $3 \%$ & $2 \%$ \\
\hline \multicolumn{2}{|c|}{ Cumulative Percentage } & $100 \%$ & $100 \%$ & $100 \%$ & $100 \%$ \\
\hline \multicolumn{2}{|l|}{ Total } & 304 & 375 & 198 & 877 \\
\hline
\end{tabular}

Note. Frequency counts and percentages illustrate the communicative demand placed on international teaching assistants in the lab environment during the first hour of the labs. All data from non-participants have been excluded from student analysis. 
A chi-square test of independence was performed to examine the relationship between lab section and interaction length. Chi-square analysis supports that there is a significant association between lab section and length of interactions, $\chi^{2}(14, N=877)=$ 23.78, $p=0.0487$. In general, interactions occurring in the Tuesday section were shorter than in the Wednesday and Thursday lab sections.

\section{Interaction Initiation}

Interactions were examined by who initiated the communicative exchange, the teaching assistant or the undergraduate. In the 15 hours of labs that were recorded, 35\% of the 877 interactions were initiated by the teaching assistants $(n=308)$ and $56 \%$ by undergraduates $(n=491)$. The remaining $9 \%$ of all interactions included 78 interactions that were classified as no consent, interactions involving non-consenting undergraduates, or other, interactions involving others affiliated with the labs, such as the lab manager, other teaching assistants, or the faculty member. These interactions were removed from analysis for two reasons. First, the interactions in these categories overlapped with the categories of undergraduate or teaching assistant initiation. Second, and equally important, is that the purpose of this research study is to look at the interactions that occur between international teaching assistants and their undergraduate students. While the interactions of non-consenting undergraduates and others affiliated with the setting are an important part of the duties of these teaching assistants and the activities of the labs in general, they were not central to or available for use in this study and were therefore removed from analysis of interaction initiation.

Interactions that included only undergraduates who agreed to participate in the study and their teaching assistants totaled 799 interactions. Of the 799 interactions, the 
teaching assistants initiated 39\% and the undergraduates initiated 61\%. Table 12

provides an overview of the frequency and percentages of interaction initiation.

\section{Table 12}

Frequency and Percentage of Interactions by Interaction Initiation

\begin{tabular}{lcccc} 
& \multicolumn{2}{c}{ All Interactions } & \multicolumn{2}{c}{ Participant Interactions } \\
\cline { 2 - 5 } $\begin{array}{c}\text { Interaction } \\
\text { Initiation }\end{array}$ & Frequency & Percentage & Frequency & Percentage \\
\hline Teaching Assistant & 308 & $35 \%$ & 308 & $39 \%$ \\
Undergraduate & 491 & $56 \%$ & 491 & $61 \%$ \\
Other & 8 & $1 \%$ & -- & \\
No Consent & 70 & $8 \%$ & -- & \\
\hline Total & 877 & & 799 & \\
\hline
\end{tabular}

Note. Frequency counts and percentages of all interactions illustrate the communicative demand placed on international teaching assistants in the lab environment during the first hour of the labs. All data from non-participants have been excluded from student analysis.

When examining each of the lab sessions for how interaction initiation occurred, the data show that in all labs undergraduates initiated more of the interactions than the teaching assistants did. However, the distribution of who initiated interactions differed in the various labs. In the earlier labs, undergraduates initiated twice as many interactions as the teaching assistants. In Lab 4, undergraduates initiated 69\% of all 
interactions and the teaching assistants initiated 31\%. Undergraduate interaction initiation in Lab 5 (69\%) and Lab 6 (63\%) was still high, with undergraduates initiating almost two interactions for every one interaction the teaching assistants initiated.

However, in Labs 7 and 8, there appears to be a more equal distribution of who initiated the interactions. In Lab 7, only 52\% of interactions were undergraduate initiated, and in Lab 8, 53\% were. Table 13 provides a summary of the frequencies and percentages of interaction initiation by lab session.

Table 13

Frequency and Percentage of Interactions by Lab Session and Interaction Initiation

\begin{tabular}{ccccccc} 
& \multicolumn{5}{c}{ Lab Session } & \\
\cline { 2 - 5 } $\begin{array}{c}\text { Interaction } \\
\text { Initiation }\end{array}$ & Lab 4 & Lab 5 & Lab 6 & Lab 7 & Lab 8 & Total \\
\hline $\begin{array}{r}\text { Teaching Assistant } \\
\text { Frequency }\end{array}$ & 50 & 51 & 72 & 92 & 43 & 308 \\
Percentage & $31 \%$ & $31 \%$ & $37 \%$ & $48 \%$ & $47 \%$ & $38 \%$ \\
\hline Undergraduate & & & & & & \\
Frequency & 109 & 111 & 124 & 98 & 49 & 491 \\
Percentage & $69 \%$ & $69 \%$ & $63 \%$ & $52 \%$ & $53 \%$ & $62 \%$ \\
\hline Total & 159 & 162 & 196 & 190 & 92 & 799 \\
\hline
\end{tabular}

A chi-square test of independence was performed to examine the relationship between lab session and interaction initiation. Chi-square analysis supports that there is a significant association between a lab in which an interaction occurs and who is likely to initiate it, $\chi^{2}(4, N=799)=17.5, p=0.0015$. The proportion of interactions that were 
initiated in the earlier labs by undergraduates was in general greater than those initiated later in the semester. As the semester progressed, there was a shift in the proportion of interactions that were initiated by the teaching assistant and by the undergraduate. Toward the beginning of the semester in Lab 4, undergraduates initiated $69 \%$ of lab communication and by the end of the semester in Lab 8 that proportion dropped to 53\%. Teaching assistants initiated a higher proportion of interactions at the end of the semester (47\%) than earlier in the semester (31\%).

For reasons beyond anyone’s control, the Wednesday section's teaching assistant was not able to teach the last two lab sessions of the semester. As a result, the Wednesday section had three different teaching assistants over the course of the semester, the primary teaching assistant for Labs 4,5 , and 6, and substitute teaching assistants for Labs 7 and 8 . This change of teaching assistants may have influenced the way that interactions were initiated in the labs for the Wednesday section. For example, it may have been the case that with the substitute teaching assistants, undergraduates were hesitant to initiate interactions with teaching assistants they did not know very well.

To see if the greater proportion of teaching assistant-initiated interactions toward the end of the semester was the result of the substitute teaching assistants, the interactions from the Wednesday section were excluded for analysis. Table 14 provides the frequency and percentages for only the Tuesday and Thursday sections, excluding the interactions from the Wednesday section. 
Table 14

Frequency and Percentage of Interactions by Lab Session and Interaction Initiation for the Tuesday and Thursday Sections

\begin{tabular}{rcccccc} 
& \multicolumn{5}{c}{ Lab Session } & \\
\cline { 2 - 5 } $\begin{array}{c}\text { Interaction } \\
\text { Initiation }\end{array}$ & Lab 4 & Lab 5 & Lab 6 & Lab 7 & Lab 8 & Total \\
\hline $\begin{array}{r}\text { Teaching Assistant } \\
\text { Frequency }\end{array}$ & 23 & 19 & 27 & 46 & 24 & 139 \\
Percentage & $26 \%$ & $20 \%$ & $25 \%$ & $39 \%$ & $39 \%$ & $29 \%$ \\
\hline Undergraduate & & & & & & \\
Frequency & 64 & 78 & 79 & 71 & 37 & 329 \\
Percentage & $74 \%$ & $80 \%$ & $75 \%$ & $61 \%$ & $61 \%$ & $71 \%$ \\
\hline Total & 87 & 97 & 106 & 117 & 61 & 468 \\
\hline
\end{tabular}

Using only data collected from the Tuesday and Thursday sections, a chi-square test of independence was performed to see if the relationship between lab session and lab section was significant. Chi-square analysis supports that there is a significant association between the lab in which an interaction occurs and who initiates that interaction, $\chi^{2}(4, N=468)=14.00, p=0.0073$. In this analysis, the proportion of undergraduate-initiated interactions toward the beginning of the semester was higher (74\%) than at the end of the semester (61\%). For the teaching assistants, the proportion of interaction initiation at the beginning of the semester was lower (26\%) than at the end of the semester (39\%), the proportion increasing as the semester progressed.

Analysis of interaction initiation also looked for patterns across the lab sections. As indicated in Table 15, the overall percentage of interactions initiated by teaching 
assistants and undergraduates in the Tuesday and Thursday sections are similar. Even though their numbers differ, undergraduates are still initiating over $70 \%$ of the interactions. However, in the Wednesday section the teaching assistants and the undergraduates initiated interactions in similar proportions, at 51\% and 49\% respectively. The higher proportion of interactions initiated by the teaching assistant in the Wednesday section may be an artifact of the Wednesday section having substitute teaching assistants for two of the five lab sessions.

Table 15

Frequency and Percentage of Interactions by Lab Section and Interaction Initiation

Lab Section

$\begin{array}{lll}\text { Interaction } & \text { Tuesday } & \text { Wednesday } \\ \text { Initiation } & & \text { Thursday }\end{array}$

Teaching Assistant

\begin{tabular}{|c|c|c|c|c|c|}
\hline & Frequency & 82 & 169 & 57 & 308 \\
\hline & Percentage & $30 \%$ & $51 \%$ & $30 \%$ & $38 \%$ \\
\hline \multicolumn{6}{|c|}{ Undergraduate } \\
\hline & Frequency & 194 & 162 & 135 & 491 \\
\hline & Percentage & $70 \%$ & $49 \%$ & $70 \%$ & $62 \%$ \\
\hline Total & & 276 & 331 & 192 & 799 \\
\hline
\end{tabular}


Chi-square analysis supports that there is a significant association between the lab section in which an interaction occurs and who initiates that interaction $\chi^{2}(2, N=$ 799) $=37.33, p<0.0001$. In general, undergraduates initiated a higher proportion of interactions in the Tuesday (70\%) and Thursday (70\%) sections. In the Wednesday section, interactions were initiated in similar proportions, teaching assistant (51\%) and undergraduates (49\%).

Once again, to see if the substitute teaching assistants may have influenced the interaction patterns in the Wednesday section, only lab sessions taught by the primary teaching assistants were reviewed. Table 16 shows data from only the first three lab sessions (Labs 4, 5, \& 6) for all three teaching assistants. This data reveals that in all three sections, the undergraduates initiated a greater proportion of interactions; however, in the Wednesday section, there was a tendency for the teaching assistant to initiate a higher proportion of the interactions than the teaching assistants in the other sections. 
Table 16

Frequency and Percentage of Interactions for Labs 4, 5, \& 6 by Lab Section and Interaction Initiation

\begin{tabular}{ccccc} 
& \multicolumn{3}{c}{ Lab Section } & \\
\cline { 2 - 4 } $\begin{array}{c}\text { Interaction } \\
\text { Initiation }\end{array}$ & Tuesday & Wednesday & Thursday & Total \\
\hline $\begin{array}{c}\text { Teaching Assistant } \\
\text { Frequency }\end{array}$ & 48 & 104 & 21 & 173 \\
Percentage & $28 \%$ & $46 \%$ & $18 \%$ & $33 \%$ \\
\hline Undergraduate & & & & 344 \\
Frequency & 126 & 123 & 95 & $67 \%$ \\
\hline Percentage & $72 \%$ & $54 \%$ & $82 \%$ & 517 \\
\hline
\end{tabular}

Looking only at interactions for the first three lab sessions of the primary teaching assistants in this study, chi-square analysis supports that there is a significant relationship between the lab section in which an interaction occurs and who initiates that interaction, $\chi^{2}(2, N=517)=30.55, p<0.0001$. In general, undergraduates initiated a greater proportion of interactions in all lab sessions. However, interactions were initiated in greater proportions by undergraduates in the Tuesday (72\%) and Thursday (82\%) sections, while in the Wednesday section, undergraduates initiated only a slightly higher proportion of interactions (54\%) than the teaching assistant (46\%).

With this data indicating that perhaps teaching assistant rapport with the undergraduates may have influenced the patterns of interaction initiation, frequencies of interaction initiation by lab session and lab section were reviewed. Table 17 below 
shows the distribution of initiation for each lab and for each section. Of the 15 labs examined, 11 labs had more undergraduate-initiated interactions and 4 had either equal numbers of undergraduate and teaching assistant-initiated interactions or higher numbers of teaching assistant-initiated interactions. One for the four occurred in the Thursday section (Lab 8), but three of the four occurred in the Wednesday section (Labs 6, 7, \& 8).

Table 17

Frequency of Interaction Initiation by Lab Session and Lab Section

\begin{tabular}{lcccccc} 
& \multicolumn{6}{c}{ Lab Session } \\
\cline { 2 - 5 } Lab Section & Lab 4 & Lab 5 & Lab 6 & Lab 7 & Lab 8 & Total \\
\hline Tuesday & & & & & & \\
Teaching Assistant & 19 & 15 & 14 & 22 & 12 & 82 \\
$\quad$ Undergraduate & 33 & 48 & 45 & 40 & 28 & 194 \\
\hline Wednesday & & & & & & \\
Teaching Assistant & 27 & 32 & 45 & $46^{\text {a }}$ & $19^{\text {a }}$ & 169 \\
$\quad$ Undergraduate & 45 & 33 & 45 & 27 & 12 & 162 \\
\hline Thursday & & & & & & \\
Teaching Assistant & 4 & 4 & 13 & 24 & 12 & 57 \\
Undergraduate & 31 & 30 & 34 & 31 & 9 & 135 \\
\hline Total & 159 & 162 & 196 & 190 & 92 & 799 \\
\hline
\end{tabular}

${ }^{a}$ Teaching assistant interactions initiated by the substitute teaching assistants. 
Further scrutiny of these four labs provides possible explanation for why these four labs exhibit different patterns of interaction initiation from the other labs.

Of the four labs with higher numbers of interactions initiated by the teaching assistant, one occurred in Lab 8 of the Thursday section, the section which typically had the fewest overall number of interactions. The teaching assistant initiated 12 interactions and the undergraduates initiated 9. As the final lab of the semester, the decrease in the number of undergraduate-initiated interactions may be indicative of the undergraduates being more comfortable with the procedures and activities to conduct experiments, skills they had been developing over the course of the semester. In other words, the undergraduates may have developed more expertise and independence as chemists and therefore needed less assistance from the teaching assistant, a desired outcome in the final lab of the semester.

The remaining three labs where interaction initiation did not follow the pattern of undergraduates initiating more interactions, which was established in the majority of labs, occurred in the Wednesday section. These three labs were the last three labs of the semester. In the first of these three, Lab 6, which was taught by the regular teaching assistant, there were an equal number of interactions initiated by the undergraduates and the teaching assistant, 45 interactions for each. The remaining two labs in which there were more interactions initiated by the teaching assistant occurred in the final two labs of the semester. In these two labs, the substitute teaching assistants replaced the primary teaching assistant. The undergraduates in this section had not met or worked with either of these teaching assistants prior to their introductions at the start of labs that they were overseeing. 
From this analysis, it appears that the rapport undergraduates and teaching assistants establish contributes to undergraduate patterns of approaching their teaching assistants with their questions. Introducing substitute teaching assistants appears to have influenced the way that interactions were initiated in the Wednesday section. More interactions initiated by the teaching assistant in labs sessions taught by substitute teaching assistants may be associated with the undergraduates or with the substitute teaching assistants. One possibility is that undergraduates may not have established sufficient rapport and were not as comfortable approaching the substitute teaching assistants with their questions. A second possibility is that the substitute teaching assistants, not being familiar with the undergraduates and their expertise with the lab procedures, felt that it was important for them to actively check with the undergraduates to see if they needed assistance. A third possibility may be that toward the end of the semester, the undergraduates were more comfortable with and adept at carrying out the experimental procedures and protocols, and therefore had fewer reasons to initiate interactions with the teaching assistant. This pattern of interaction initiation with the substitute teaching assistants could also be a combination of all three factors, or something else.

\section{Gender of Undergraduate Participants}

In the early stages of this study, gender issues were considered to be an important area for investigation. However, it became clear early on in the data collection phase that to better understand issues related to gender in classroom communication patterns between these two populations a study with a different design would be required. A study examining issues related to gender would need to take a 
more focused, in-depth approach. For example, rather than looking at only a portion of the labs, i.e., the first hour in this study, a study looking at gender-related issues would need to look at communicative interactions over the course of the entire length of the lab experiment (4 hours). This became apparent when one of the teaching assistants indicated that the males in his section tended to ask questions later in the lab session, and the females tended to ask questions earlier.

Another consideration when establishing a study that explores issues of gender is that such a study would need to take into account early on the dynamics of the labs and how undergraduates are organized into lab partners. The current study was designed to look at individual interactions between an undergraduate and a teaching assistant. However, much of the work done in the labs is with the undergraduates working together in pairs to share equipment and to work collaboratively, as many experimental procedures require more than one person to carry it out. The working pairs in the labs can be male-male, female-female, or male-female. Preliminary observations indicate that the gender composition of undergraduate pairs may be important for understanding how gender influences communication patterns. A study that examines issues related to gender would need to be structured in a way that would account for the way that undergraduates were paired. In such a study, purposeful sampling of the classroom(s) would need to evaluate characteristics related to the undergraduates in a section and their assignment to lab partners.

Although it was apparent early on in this study that there are important issues related to gender in this educational environment and that this is a fruitful area of investigation for future studies, the current study was not set up to adequately examine 
gender-related issues. However, even though this study could not more completely explore gender-related issues, there are some important insights into issues of gender in the interactions that the current study could explore.

As indicated in Table 18, there is a difference in the frequency and distribution of interactions that involve males and females. In the table, other interactions are composed of interactions with the faculty member, lab manager, other teaching assistants, and multiple undergraduates. The no consent category includes interactions of undergraduates who did not agree to participate in the study. As in the case with interaction initiation, interactions classified as other and no consent were removed from analysis. From this analysis, a slightly higher proportion of interactions with participating undergraduates occurred with females (54\%) than with males (46\%). These proportions reflect the gender composition of the labs, females (53\%) and males (47\%). 
Table 18

Frequency and Percentage of Interactions by Gender of Undergraduate Participants

\begin{tabular}{lcccc} 
& \multicolumn{2}{c}{ All Interactions } & \multicolumn{2}{c}{$\begin{array}{c}\text { Interactions with } \\
\text { Assignable Gender }\end{array}$} \\
\cline { 2 - 5 } $\begin{array}{c}\text { Gender of } \\
\text { Undergraduate } \\
\text { Participants }\end{array}$ & Frequency & Percentage & Frequency & Percentage \\
\hline Male & 339 & $39 \%$ & 339 & $46 \%$ \\
Female & 399 & $45 \%$ & 399 & $54 \%$ \\
Other & 69 & $8 \%$ & & -- \\
No Consent & 70 & $8 \%$ & & -- \\
\hline Total & 877 & $100 \%$ & 738 & $100 \%$ \\
\hline
\end{tabular}

Note. Frequency counts and percentages of all interactions illustrate the communicative demand placed on international teaching assistants in the lab environment during the first hour of the labs. All data from non-participants have been excluded from student analysis.

Looking at the frequency and percentage of interactions that involve males and females in interactions, as indicated in Table 19, there is a shift in the balance of interactions involving males and females. While females are involved in $61 \%$ of the interactions in the early part of the semester, by the end of the semester they are involved in $44 \%$ of the interactions. On the other hand, there is a slight increase in the percentage of interactions that involve males over the course of the semester, from $39 \%$ to $56 \%$ at the end of the semester. Chi-square analysis revealed that this was not a 
statistically significant association between the gender of a participant in an interaction and the lab in which the interaction occurred, $\chi^{2}(4, N=738)=6.82, p=0.146$.

Table 19

Frequency and Percentage of Interactions by Lab Session and Gender of Undergraduate Participants

\section{Lab Session}

Gender of

$\begin{array}{lllllll}\text { Undergraduate } & \text { Lab } 4 & \text { Lab } 5 & \text { Lab } 6 & \text { Lab 7 } & \text { Lab } 8 & \text { Total }\end{array}$
Participants

Male

\begin{tabular}{rcccccc} 
Frequency & 59 & 67 & 86 & 83 & 44 & 339 \\
Percentage & $39 \%$ & $44 \%$ & $47 \%$ & $48 \%$ & $56 \%$ & $46 \%$ \\
\hline Female & & & & & & \\
Frequency & 91 & 87 & 97 & 90 & 34 & 399 \\
Percentage & $61 \%$ & $56 \%$ & $53 \%$ & $52 \%$ & $44 \%$ & $54 \%$ \\
\hline Total & 150 & 154 & 183 & 173 & 78 & 738 \\
\hline
\end{tabular}

The gender of undergraduate participants in interactions was examined in the three lab sections. As seen in Table 20, the Tuesday and Thursday sections have a similar proportion of interactions involving males and females. In both of these sections, about half of the interactions involved males and half involved females. The Tuesday section had slightly more interactions with males (51\%), and the Thursday section had slightly more interactions with females (51\%). In contrast, the Wednesday section has a wider disparity between interactions involving males (40\%) and those involving females (60\%). 
Table 20

Frequency and Percentage of Interactions by Lab Section and Gender of Undergraduate Participants

Lab Section

\begin{tabular}{|c|c|c|c|c|}
\hline $\begin{array}{l}\text { Gender of } \\
\text { Undergraduate } \\
\text { Participants }\end{array}$ & Tuesday & Wednesday & Thursday & Total \\
\hline \multicolumn{5}{|l|}{ Male } \\
\hline Frequency & 132 & 118 & 89 & 339 \\
\hline Percentage & $51 \%$ & $40 \%$ & $49 \%$ & $46 \%$ \\
\hline \multicolumn{5}{|l|}{ Female } \\
\hline Frequency & 128 & 177 & 94 & 399 \\
\hline Percentage & $49 \%$ & $60 \%$ & $51 \%$ & $54 \%$ \\
\hline Total & 260 & 295 & 183 & 738 \\
\hline
\end{tabular}

A chi-square test of independence was performed to examine the relationship between gender of the participant and lab section. Chi-square analysis revealed that there is a significant association between the lab section in which an interaction occurs and the gender of the undergraduate participating in the interaction, $\chi^{2}(2, N=738)=$ 7.168, $p=0.0278$. In general, a higher proportion of females were involved in interactions in the Wednesday sections (60\%) than in the Tuesday (49\%) or Thursday (51\%) sections. However, as mentioned previously, the teaching assistant in the Wednesday section indicated that the males in his section tended to ask questions later in the lab. In the Tuesday section, the participation rate for males (51\%) and females (49\%) is almost identical to their proportions in the section, males (50\%) and females 
(50\%). In the Thursday section, males participated in interactions in a slightly higher proportion (49\%) than their proportion of the class (44\%), and females participated in slightly lower proportions (51\%) than their proportion in the class (56\%).

To see if the substitute teaching assistants in the Wednesday section influenced the patterns of interactions, the lab interactions for the labs sessions that had the primary teaching assistants (Labs 4, 5, \& 6) were examined. Table 21 shows the frequencies and percentages of male and female participants in interactions of the three lab sections for the first three recorded labs. A similar trend appeared: females were involved in higher proportions of the interactions in all sections, Tuesday (53\%), Wednesday (62\%), and Thursday, (52\%). Chi-square analysis revealed that this was not statistically significant, $\chi^{2}(2, N=487)=4.69, p=0.096$. 
Table 21

Frequency and Percentage of Interactions for Labs 4, 5, \& 6 by Lab Section and Gender of Undergraduate Participants

Lab Section

\begin{tabular}{|c|c|c|c|c|}
\hline $\begin{array}{c}\text { Gender of } \\
\text { Undergraduate } \\
\text { Participants }\end{array}$ & Tuesday & Wednesday & Thursday & Total \\
\hline \multicolumn{5}{|l|}{ Male } \\
\hline Frequency & 79 & 78 & 55 & 212 \\
\hline Percentage & $47 \%$ & $38 \%$ & $48 \%$ & $44 \%$ \\
\hline \multicolumn{5}{|l|}{ Female } \\
\hline Frequency & 88 & 128 & 59 & 275 \\
\hline Percentage & $53 \%$ & $62 \%$ & $52 \%$ & $57 \%$ \\
\hline Total & 167 & 206 & 114 & 487 \\
\hline
\end{tabular}

Interaction Activities

Lab communication was examined for the types of lab activities discussed in the interactions. Prior to the analysis of actual interactions, the faculty member of the course identified topics of interactions that were likely to appear: procedures, safety, and equipment. When examining the interactions based on the types of information actually discussed, six primary categories of interactions emerged: equipment, lab preparation, materials, procedures, safety, and social. The following are definitions for the various topics of discussion of lab activity categories: 
- Equipment: Interactions related to the equipment necessary to conduct lab experiments. Some equipment is standard to each work bench, e.g., hood, vent, test tubes and flasks; other equipment is specialized for a particular experiment, e.g., $\mathrm{pH}$ meter.

- Lab Preparation: Interactions related to activities in the labs that are designed to ensure all undergraduates in all sections have a uniform educational experience and are adequately prepared to effectively and efficiently engage in the lab experiment, e.g., pre-lab questions and quizzes.

- Materials: Interactions related to the materials that are used in the labs and lab experiments, e.g., solvents, solutions, reagents, chemical samples.

- Procedures: Interactions related to carrying out the actual experiment, e.g., setting up the apparatus or how materials and equipment are used together for the purposes of the experiment.

- Safety: Interactions related to maintaining precautionary measures for undergraduates to be safe and to maintaining a safe environment in the labs, e.g., wearing goggles, keeping the hood sash at an appropriate height, cleaning up or handling broken glassware.

- Social: Interactions in the lab setting that are not directly related to the lab experiment but that are part of maintaining social cohesion between members of the labs.

There were some interactions that could not be assigned to a particular category. Sometimes this inability to assign an interaction to an activity category was the result of portions of the audio track being inaudible at crucial points. In other cases, insufficient 
information was captured in the recording process to assign a category accurately. In the case of audio recordings, the visual information needed to complete the understanding of what was going on was not available, and in the case of the video recordings the necessary visual information was obscured due the physical layout of the laboratory and the location of the camera.

The categories that emerged as having the highest frequency of occurrence were the categories of lab preparation ( $n=283)$, procedures $(n=303)$ equipment $(n=127)$, and materials $(n=48)$. Interactions discussing safety $(n=24)$ and social $(n=18)$ aspects of the labs occurred less often. There were four interactions that were unassignable and 70 interactions involving non-consenting undergraduates. Table 22 shows the frequencies and percentages for the activity types of the interactions. 
Table 22

Frequency and Percentage of Lab Interactions by Topic of Activity

\begin{tabular}{lcccc} 
& \multicolumn{2}{c}{ All Interactions } & $\begin{array}{c}\text { Interaction with Assignable } \\
\text { Activity Topics }\end{array}$ \\
\cline { 2 - 5 } Activity & Frequency & Percentage & Frequency & Percentage \\
\hline Equipment & 127 & $14.5 \%$ & 127 & $16 \%$ \\
Lab Preparation & 283 & $32 \%$ & 283 & $35 \%$ \\
Materials & 48 & $5 \%$ & 48 & $6 \%$ \\
Procedures & 303 & $35 \%$ & 303 & $38 \%$ \\
Safety & 24 & $3 \%$ & 24 & $2 \%$ \\
Social & 18 & $2 \%$ & 18 & \\
Unassigned & 4 & $0.5 \%$ & -- & \\
No Consent & 70 & $8 \%$ & -- & \\
\hline Total & 877 & $100 \%$ & 803 & \\
\hline
\end{tabular}

Note. Frequency counts and percentages of all interactions illustrate the communicative demand placed on international teaching assistants in the lab environment during the first hour of the labs. All data from non-participants have been excluded from student analysis.

The lab preparation interactions were a substantial number of the interactions, second only in frequency to interactions related to procedures. However, the lab preparation interactions differed from the other types of interactions in this study. As mentioned previously, the interactions relating to lab preparation are interactions that in many cases originate in conversations and activities that occur prior to the hands-on 
portion of the lab experiment. Undergraduates involved in these interactions were frequently asking questions about pre-lab preparations: the pre-lab questions, the prelab lecture, or the information provided in the lab manual. The teaching assistants were frequently repeating instructions from the faculty member or carrying out routine activities related to classroom maintenance. In other words, these interactions were more often interactions that were based in texts (written or spoken) of other speakers. When the teaching assistants were involved in interactions related to lab preparation, they were frequently engaged in either planned discourse (e.g., giving a recap of the lab at the start), were communicating information from the faculty member (e.g., making announcements), or were engaged in communicative exchanges about the logistics of the lab.

The interactions related to the other activity types were those that occurred primarily while the undergraduates were engaged in the experiment for that week. As such, these interactions were based on questions, conflicts, and dilemmas the undergraduates faced when attempting to carry out the experiment. These interactions tended to be ones that required teaching assistants and undergraduates to communicate spontaneously, negotiating and responding to issues, concerns, and topics that arose while the undergraduates and the teaching assistants were participating in the lab experiment. However, some of these interactions were the result of the undergraduates being confronted with experiences in the real-world lab experiments that differed from what they had anticipated happening based on their preparations for the lab. Table 23 shows the frequency and percentage of interactions for each lab by the topic of activity discussed. 
Table 23

Frequency and Percentage of Interactions by Lab Session and Topic of Activity

\begin{tabular}{|c|c|c|c|c|c|c|}
\hline \multirow[b]{2}{*}{ Activity } & \multicolumn{5}{|c|}{ Lab Session } & \multirow[b]{2}{*}{ Total } \\
\hline & Lab 4 & Lab 5 & Lab 6 & Lab 7 & Lab 8 & \\
\hline \multicolumn{7}{|l|}{ Equipment } \\
\hline Frequency & 38 & 23 & 17 & 34 & 15 & 127 \\
\hline Percentage & $24 \%$ & $14 \%$ & $9 \%$ & $18 \%$ & $17 \%$ & $16 \%$ \\
\hline \multicolumn{7}{|l|}{ Lab Preparation } \\
\hline Frequency & 39 & 61 & 60 & 76 & 47 & 283 \\
\hline Percentage & $25 \%$ & $37 \%$ & $31 \%$ & $39 \%$ & $52 \%$ & $35 \%$ \\
\hline \multicolumn{7}{|l|}{ Materials } \\
\hline Frequency & 12 & 2 & 9 & 18 & 7 & 48 \\
\hline Percentage & $8 \%$ & $1 \%$ & $5 \%$ & $9 \%$ & $8 \%$ & $6 \%$ \\
\hline \multicolumn{7}{|l|}{ Procedures } \\
\hline Frequency & 62 & 62 & 98 & 65 & 16 & 303 \\
\hline Percentage & $39 \%$ & $38 \%$ & $50 \%$ & $34 \%$ & $18 \%$ & $38 \%$ \\
\hline \multicolumn{7}{|l|}{ Safety } \\
\hline Frequency & 6 & 11 & 5 & 1 & 1 & 24 \\
\hline Percentage & $4 \%$ & $7 \%$ & $3 \%$ & $1 \%$ & $1 \%$ & $3 \%$ \\
\hline \multicolumn{7}{|l|}{ Social } \\
\hline Frequency & 2 & 5 & 7 & 0 & 4 & 18 \\
\hline Percentage & $1 \%$ & $3 \%$ & $4 \%$ & $0 \%$ & $4 \%$ & $2 \%$ \\
\hline Total & 159 & 164 & 196 & 194 & 90 & 803 \\
\hline
\end{tabular}


A chi-square test of independence was performed to examine the relationship between the lab session and activity of an interaction. Chi-square analysis supports that this is significant, $\chi^{2}(20, N=803)=80.29, p<0.0001$. However, it appears that the patterns seen in the activity topic of the interactions are related to the content of the lab in which the interactions occurs, rather than a progression over time. Lab 8 had the highest proportion of lab preparation interactions, 52\%. Lab 6, had the highest proportion of interactions related to procedures, $50 \%$.

Analysis of interactions based on the lab section in which they occurred, as shown in Table 24, show that general proportions of interactions by activity types for the Tuesday and Wednesday sections are more similar than those in the Thursday section, most specifically in the percentage of interactions related to lab preparation and procedures. The Thursday section has a much smaller occurrence of lab preparation interactions, 23\%, compared with the Tuesday and Wednesday sections, with percentages of $39 \%$ and $40 \%$ respectively. The overall percentage of procedure-related interactions in the Thursday section (53\%) is much greater than for the Tuesday (34\%) and Wednesday (32\%) sections. 
Table 24

Frequency and Percentage of Interactions by Lab Section and Topic of Activity

\begin{tabular}{|c|c|c|c|c|c|}
\hline \multirow{2}{*}{\multicolumn{2}{|c|}{ Activity }} & \multicolumn{3}{|c|}{ Lab Section } & \multirow[b]{2}{*}{ Total } \\
\hline & & Tuesday & Wednesday & Thursday & \\
\hline \multicolumn{6}{|c|}{ Equipment } \\
\hline & Frequency & 50 & 50 & 27 & 127 \\
\hline & Percentage & $18 \%$ & $15 \%$ & $14 \%$ & $16 \%$ \\
\hline \multicolumn{6}{|c|}{ Lab Preparation } \\
\hline & Frequency & 108 & 131 & 44 & 283 \\
\hline & Percentage & $39 \%$ & $40 \%$ & $23 \%$ & $35 \%$ \\
\hline \multicolumn{6}{|c|}{ Materials } \\
\hline & Frequency & 12 & 22 & 14 & 48 \\
\hline & Percentage & $4 \%$ & $7 \%$ & $7 \%$ & $6 \%$ \\
\hline \multicolumn{6}{|c|}{ Procedures } \\
\hline & Frequency & 96 & 105 & 102 & 303 \\
\hline & Percentage & $34 \%$ & $32 \%$ & $53 \%$ & $38 \%$ \\
\hline \multicolumn{6}{|c|}{ Safety } \\
\hline & Frequency & 9 & 10 & 5 & 24 \\
\hline & Percentage & $3 \%$ & $3 \%$ & $3 \%$ & $3 \%$ \\
\hline \multicolumn{6}{|l|}{ Social } \\
\hline & Frequency & 5 & 12 & 1 & 18 \\
\hline & Percentage & $2 \%$ & $2 \%$ & $1 \%$ & $2 \%$ \\
\hline Total & & 280 & 330 & 193 & 803 \\
\hline
\end{tabular}


A chi-square test for independence was performed to examine the association between the lab section and the activity discussed in the interaction. Chi-square analysis revealed that this was a statistically significant association, $\chi^{2}(10, N=803)=36.048$, $p<0.0001$. In general, the proportion of interactions discussing lab preparation was higher for the Tuesday (39\%) and Wednesday (40\%) sections than for the Thursday section (23\%). The proportion of interactions discussing procedures was higher for the Thursday section (53\%) than for the Tuesday (34\%) and Wednesday (32\%) sections. Interaction Initiation and Gender of Undergraduate Participants

As mentioned previously, the current study's approach to data collection does not allow for issues of gender to be fully explored. However, interactions that could be categorized by both initiation and gender were examined to see if there were any patterns related to whether teaching assistants initiated more interactions with males or with females or whether there was a tendency for male or female undergraduates to initiate in great proportions interactions with the teaching assistant. Table 25 provides an overview of the frequency and percentages of interactions by their initiation, teaching assistant or undergraduate, and the gender of the undergraduate participant. 
Table 25

Lab Interactions by Initiation and Gender of Undergraduate Participants

\begin{tabular}{cccc} 
& \multicolumn{2}{c}{ Interaction Initiation } & \\
\cline { 2 - 3 } $\begin{array}{c}\text { Gender of } \\
\text { Undergraduate } \\
\text { Participants }\end{array}$ & $\begin{array}{c}\text { Teaching } \\
\text { Assistant }\end{array}$ & Undergraduate & Total \\
\hline $\begin{array}{c}\text { Male } \\
\text { Frequency }\end{array}$ & 117 & 222 & 339 \\
Percentage & $47 \%$ & $45 \%$ & $46 \%$ \\
\hline Female & 130 & 269 & 399 \\
Frequency & $53 \%$ & $54 \%$ & $54 \%$ \\
Percentage & 247 & 491 & 738 \\
\hline Total & & & \\
\hline
\end{tabular}

A chi-square test of independence was performed to examine the relationship between interaction initiation and gender of the undergraduate participant. Chi-square analysis indicates the relationship between the gender of the undergraduate involved in an interaction and who initiated the interaction is not statistically significant, $\chi^{2}(1, N=$ 738) $=0.307, p=0.58$

A second area of investigation was to examine the interactions undergraduates initiated to see if there were patterns related to gender in the first hour of the labs. Interactions for the Tuesday and Thursday sections were the only undergraduateinitiated interactions included in this analysis. Interactions from the Wednesday section were excluded for two reasons. First, there are indications that the substitute teaching assistants influenced the pattern of undergraduate interaction initiation. Second, while it would have been possible to look at the interactions with the primary teaching assistant 
for the Wednesday section for Labs 4, 5, and 6, trends or patterns for the entire semester would not have had time to develop. The proportion of males and females in the Tuesday and Thursday sections were similar and evenly divided between males and females. The Tuesday section was 50\% male and 50\% female, and the Thursday section was $44 \%$ male and $56 \%$ female. The gender distribution of the two sections together, reflected the gender proportions for the study, $47 \%$ males and $53 \%$ females.

As shown in Table 26, undergraduates in the Tuesday and Thursday sections initiated interactions in similar proportions. In the Tuesday section, with the male teaching assistant, the male undergraduates initiated a slightly higher proportion of the interactions (54\%) than the females (46\%) did. In the Thursday section, with the female teaching assistant, the proportions were reversed. The female undergraduates initiated a higher proportion of interactions (54\%) than the male undergraduates (46\%), though these proportions differ slightly from the gender composition of the section. 
Table 26

Frequency and Percentage of Undergraduate-Initiated Interactions by Lab Section and Gender Undergraduate Participants

\begin{tabular}{ccccc} 
& & \multicolumn{2}{c}{ Lab Section } & \\
\cline { 3 - 4 } $\begin{array}{c}\text { Gender of } \\
\text { Undergraduate } \\
\text { Participants }\end{array}$ & Tuesday & Thursday & Total \\
\hline Male & & & \\
& Frequency & 104 & 62 & 166 \\
& Percentage & $54 \%$ & $46 \%$ & $50 \%$ \\
\hline Female & & & 73 & 163 \\
& Frequency & 90 & $54 \%$ & $50 \%$ \\
\hline Total & Percentage & $46 \%$ & 135 & 329 \\
\hline
\end{tabular}

A chi-square test of independence indicates that there is no statistically significant association between lab sections for the Tuesday and Thursday sections and the gender for undergraduate-initiated interactions, $\chi^{2}(1, N=329)=1.88, p=0.17$.

The next investigation for gender-related patterns of undergraduate-initiated interactions examined interactions across the various lab sessions for these two sections. As shown in Table 27, overall, males and females in the Tuesday and Thursday sections initiated interactions in equal proportions, $50 \%$ initiated by the males and $50 \%$ by the females. In the early labs, females initiated higher proportions of interactions (66\%) compared to males (34\%), but by the end of the semester, the proportions were reversed: males initiated a greater proportion of interactions (62\%) than the females $(38 \%)$. 
Table 27

Frequency and Percentage of Undergraduate-Initiated Interactions by Lab Session and Gender of Undergraduate Participants

\begin{tabular}{cccccccc} 
& & \multicolumn{5}{c}{ Lab Session } & \\
\cline { 3 - 6 } $\begin{array}{c}\text { Gender of } \\
\text { Undergraduate } \\
\text { Participant }\end{array}$ & Lab 4 & Lab 5 & Lab 6 & Lab 7 & Lab 8 & Total \\
\hline Male & & & & & & \\
& Frequency & 22 & 36 & 45 & 40 & 23 & 166 \\
& Percentage & $34 \%$ & $46 \%$ & $57 \%$ & $56 \%$ & $62 \%$ & $50 \%$ \\
\hline Female & & & & & & 14 & 163 \\
& Frequency & 42 & 42 & 34 & 31 & 14 & $50 \%$ \\
\hline Total & Percentage & $66 \%$ & $54 \%$ & $43 \%$ & $44 \%$ & $38 \%$ & 329 \\
\hline
\end{tabular}

A chi-square test for independence indicates there is a significant association for undergraduate-initiated interactions between the lab session in which an interaction occurs and the gender of the undergraduate participants, $\chi^{2}(4, N=329)=11.55$, $p=0.021$. Earlier in the semester, females initiate interactions in greater proportions than males, but by the end of the semester those proportions are reversed. As the semester progresses, males gradually initiate a higher proportion of interactions and females a lower proportion. 
Interaction Initiation and Activity

Interactions were analyzed looking at interaction initiation and the activity of the interaction. As the data in Table 28 show, undergraduates tended to initiate interactions related to equipment, materials, and procedures more often than the teaching assistants initiated these types of interactions. The teaching assistants initiated a greater proportion of the interactions that discussed lab preparation and safety. 
Table 28

Frequency and Percentage of Interactions by Interaction Initiation and Topic of Activity

\begin{tabular}{|c|c|c|c|}
\hline \multirow[b]{2}{*}{ Activity } & \multicolumn{2}{|c|}{ Interaction Initiation } & \multirow[b]{2}{*}{ Total } \\
\hline & $\begin{array}{l}\text { Teaching } \\
\text { Assistant }\end{array}$ & Undergraduate & \\
\hline \multicolumn{4}{|l|}{ Equipment } \\
\hline Frequency & 27 & 100 & 127 \\
\hline Percentage & $9 \%$ & $20 \%$ & $16 \%$ \\
\hline \multicolumn{4}{|l|}{ Lab Preparation } \\
\hline Frequency & 152 & 125 & 277 \\
\hline Percentage & $50 \%$ & $25 \%$ & $29 \%$ \\
\hline \multicolumn{4}{|l|}{ Materials } \\
\hline Frequency & 9 & 39 & 48 \\
\hline Percentage & $3 \%$ & $8 \%$ & $6 \%$ \\
\hline \multicolumn{4}{|l|}{ Procedures } \\
\hline Frequency & 88 & 215 & 303 \\
\hline Percentage & $29 \%$ & $44 \%$ & $38 \%$ \\
\hline \multicolumn{4}{|l|}{ Safety } \\
\hline Frequency & 20 & 4 & 24 \\
\hline Percentage & $7 \%$ & $1 \%$ & $3 \%$ \\
\hline \multicolumn{4}{|l|}{ Social } \\
\hline Frequency & 9 & 8 & 17 \\
\hline Percentage & $3 \%$ & $2 \%$ & $2 \%$ \\
\hline Total & 305 & 491 & 796 \\
\hline
\end{tabular}


A chi-square test of independence was performed to examine the relationship between interaction initiation and the activity discussed in the interactions. Chi-square analysis indicates that there is a significant association between who initiates the interaction and the activity of that interaction, $\chi^{2}(5, N=796)=88.69, \mathrm{p}<0.0001$. In general, for the interactions initiated by the teaching assistants, a greater proportion discussed lab preparation (50\%) and safety (7\%). The undergraduates initiated higher proportions of interactions related to equipment (20\%), materials (8\%), and procedures (44\%).

Interactions Activity and Gender of Undergraduate Participants

Interactions were analyzed by looking at both the activity type and gender of the undergraduate participant. As shown in Table 29, in terms of frequency and percentages, females tended to be involved in a higher proportion of interactions related to procedures and social interactions, whereas males showed a tendency to be involved in slightly higher proportions of interactions that were related to lab preparation and slightly higher for interactions related to equipment. 
Table 29

Frequency and Percentage of Interactions by Gender of Undergraduate Participant and Topic of Activity

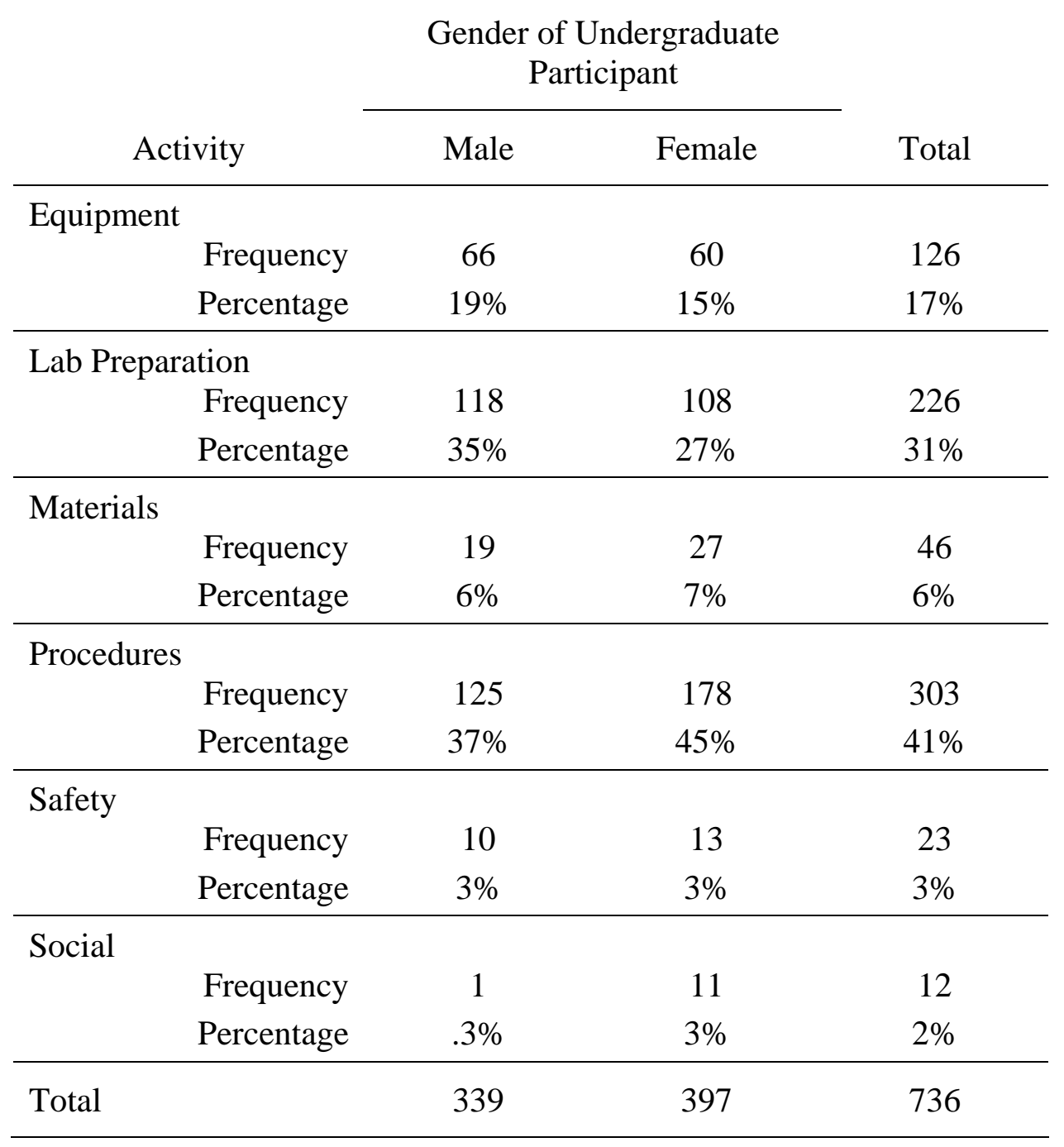


A chi-square test of independence was performed to examine the relationship between gender of the undergraduate participant and the activity discussed in an interaction. Chi-square analysis indicates that there is a significant association between who initiates the interaction and the activity of that interaction, $\chi^{2}(5, N=736)=$ 15.6412, $\mathrm{p}=0.0079$. Males were involved in higher proportions of interactions related to lab preparation (35\%). Females were involved in interactions in higher proportions of interactions related to procedures (45\%). Females were also more likely to participate in higher proportions (3\%) of social interactions than males (0.3\%). Females participated in $93 \%$ of all of the social interactions, whereas males only participated in $8 \%$. 


\section{Interviews}

The second section of this chapter reports on research findings from the semistructured interviews. The interview phase of this research project was designed to obtain the participants' perspectives of the interactions and identify interactions that were and were not successful for later analysis. Using a semi-structured interview format, the participants, in one-on-one sessions with the researcher, reviewed interactions in either audio or video format, and then responded to a 10-item, 7-point Likert-scaled interview. At any time during the interview, participants were allowed to add comments and express their opinions about the lab interactions. This section presents a discussion of participant involvement in the interview process and information on participant responses, both Likert-scaled responses and comments, for each interview item.

\section{Interview Participation}

The interview process occurred in three-stages. For any interaction that occurred in the lab setting, the researcher needed to gain three perspectives. The two primary participants in the interactions were the undergraduate and the teaching assistant, the people actually engaged in the face-to-face interactions. The third perspective was that of the faculty member overseeing the course, the content-area expert. The content-area specialist perspective was crucial to this research project as a check on the accuracy of information in the interactions. Even though the primary participants may perceive an interaction to be successful, if the interaction included inaccurate information, then the interaction was not an example of successful classroom communication. The faculty member of the course, with her expertise and teaching experience in the discipline, was 
the most reliable source to comment on the accuracy of information in the chemistry lab communicative exchanges.

Because of the large number of interactions that could possibly be part of the interview process, the interviews needed to be conducted in stages. The undergraduates were the first participants to be invited in for interviews, and these interviews were conducted as soon as possible after the interactions occurred in order to ensure undergraduate recall of the events surrounding the interaction. Once an undergraduate had been interviewed, the teaching assistant for that section was interviewed. After interviews were completed with all undergraduates and teaching assistants, the faculty member came in for interviews. The faculty member interviews took place after the end of the semester.

Interview participation rates for the faculty member and teaching assistants were excellent. They came in for interviews for every interaction that the researcher requested. The participation rate for the undergraduates was lower. All undergraduates who agreed to participate in the research project were invited to participate in the interview process. However, not all undergraduates responded to the invitations, which were extended individually in person and through e-mail communication, a standard method for communicating on this campus. Of the 45 undergraduate participants, 16 participated in interviews, a rate of $36 \%$ of all participants.

While not all undergraduates responded to the interview invitations, undergraduates from all three sections participated in the interviews. In the Tuesday section six undergraduates participated, three male and three female. From the Wednesday section, only two females participated. The Thursday section had the most 
undergraduates participating in interviews with a total of eight, two male and six female. Undergraduates who took part in the interview process participated in only one interview session each. Even though the undergraduates were invited to participate in interviews on multiple occasions, no undergraduate interview participant came in more than once for an interview.

The undergraduates had busy and demanding schedules. In many cases, it was difficult to schedule an interview time when they were available. The interview sessions varied in length, depending on how much information about the interaction the undergraduates were interested in discussing. In general, undergraduate interviews lasted from 10 to 30 minutes per interaction examined. All the participants who came in for interviews participated on their own, with no compensation and no additional benefit for their time spent. They contributed their time for this project and shared their thoughts and feelings about the interactions with great care and sincerity.

With an undergraduate participation rate of $36 \%$ in the interview process, undergraduate participation is a limitation to this study. The information collected from the undergraduates was limited to those undergraduates who were willing to come in and be interviewed, a subset of the larger population of undergraduates. These undergraduates shared their views and opinions, but they may not represent the range of opinions and interactions of the larger group of undergraduates enrolled in the sections observed. The interview participants were the undergraduates who were comfortable and willing to give time to discussing with an outside observer the interactions that they had with their teaching assistants. They were comfortable discussing their experiences even before the semester was over and they had received their final grades. From 
comments during the interviews, the undergraduates' level of satisfaction with the course was generally favorable. However, with only $36 \%$ of the undergraduates participating in the interview process, this research project may have missed collecting information from those undergraduates in the course whose experiences in this educational environment were less positive.

One can only speculate why some undergraduates came in for interviews and others did not. It may have been that undergraduates were uncomfortable commenting on their interactions with their teaching assistants for reasons related to the undergraduates themselves, the teaching assistants, the course, or the researcher. The undergraduates who did not participate in the interviews may not have been comfortable discussing their classroom interactions, their performance, or the material. However, from the onset, the goal of this research project was to examine successful communication, so while the research findings may not reflect the range of opinions and beliefs from the entire class, they do represent the opinions and beliefs of a portion of the undergraduates in the three sections, i.e., undergraduates willing to discuss communication in the labs. As a subset of the larger population, their views are an important contribution to understanding successful communication between undergraduates and international teaching assistants.

Undergraduate Interview Participants

Overall, the participation rate for the undergraduates in the study was very high, $88 \%$. The only undergraduates who did not participate in the study $(n=6)$ were undergraduates below the age of consent, non-native speakers, or those who were frequently absent. From the three sections, a total of 16 undergraduates participated in 
the interview process. Two more undergraduates, a male and a female from the Wednesday section, responded to the invitations for interviews by sending e-mail comments indicating that they were in general satisfied with their experiences in the labs. Both expressed satisfaction with the course and their communicative interactions with their teaching assistant, but they did participate in interviews.

In general, the background characteristics of the undergraduates who participated in the interviews were representative of the larger undergraduate population of participants. Appendix G provides a summary comparison of the background characteristics of the undergraduate participants and the subset of undergraduates who participated in interviews. The most notable difference between the composition of the interview undergraduates and all participating undergraduates is related to gender. In the larger population, there were slightly more females than males, overall 24 females (53\%) and 21 males (47\%). However, in the interview participants, there were more females $(n=11,69 \%)$ than males ( $n=5,31 \%)$. Table 30 shows frequencies of undergraduate participants of the study and in interviews by gender. 
Table 30

Frequency and Percentage of Undergraduate Participants by Gender and Interview Participation

\begin{tabular}{cccc} 
& \multicolumn{2}{c}{ Gender of Undergraduate Participants } & \\
\cline { 2 - 3 } Interview Participation & Male & Female & Total \\
\hline $\begin{array}{c}\text { Participation } \\
\text { Frequency }\end{array}$ & 5 & 11 & 16 \\
Percentage & $24 \%$ & $46 \%$ & $36 \%$ \\
\hline $\begin{array}{c}\text { No Participation } \\
\text { Frequency } \\
\text { Percentage }\end{array}$ & 16 & 13 & 29 \\
\hline Totals & $76 \%$ & $54 \%$ & $64 \%$ \\
\hline
\end{tabular}

A chi-square test of independence was preformed to see if there was a relationship between interview participation and gender. Chi-square analysis indicates that there is not a statistically significant association between the gender of the undergraduates who participated in interviews and those who did not, $\chi^{2}(1, N=45)=$ $2.371, p=0.124$.

A further examination of the gender of participants reveals different levels of undergraduate participation among the sections. In the Tuesday section, equal numbers of males ( $n=3)$ and females ( $n=3)$ participated, reflecting the gender composition of that section. In the Wednesday section, only two undergraduates participated in interviews, both were female and both were lab partners. In the Thursday section, eight undergraduates participated, two males and six females. 
Many of the males in the Thursday section did not initially agree to participate in the study, and it appears that they were also hesitant to participate in the interview process. It is unclear why this happened; however, the gender of the instructors may have influenced male participation in this section. The gender of the teaching assistant, the faculty of the course, and the researcher were all female, which may have contributed to reluctance of the male undergraduates to participant, initially in the study and later on in the interview process.

In the group of study participants, $47 \%$ of the undergraduates were 18 -years-old, and $40 \%$ were 19 -years old. Roughly the same proportion exists in the interview participation of undergraduates: 18-year-olds (44\%) and 19-year-olds (44\%). Two of the three older students were also part of the interview undergraduates, one 20-year-old and the 31-year-old.

Similar proportions of first-year and second-year undergraduates occurred in both groups. Among the study undergraduates, 51\% were first-year students, compared with $56 \%$ in the interviews. In the study, $42 \%$ were second-years and in the interviews, $44 \%$ were second-years.

The proportion of decided and undecided majors was also similar. The proportion of the interview participants with decided majors was 56\% compared with the study undergraduate proportion of 53\%. The proportion of undecided majors for the interview undergraduates was $44 \%$ compared with the study undergraduates at $42 \%$. All interview undergraduates had either declared science majors or were inclined to declare science majors. In the study undergraduates, there were three undergraduates who were either declared or possible non-science majors. 
As for the cultural and linguistic background characteristics, the interview undergraduates were represented in proportions similar to the study undergraduates. In the study participants, $91 \%$ grew up in the U.S., compared to $94 \%$ of the interview undergraduates. The one undergraduate who grew up in another country participated in the interviews. Three out of the four study undergraduates from urban areas participated in the interviews. The proportion of interview undergraduates from suburban areas (63\%) was similar to the study undergraduates (69\%).

The background characteristics of language spoken at home, languages studied, and travel abroad in the interview undergraduates reflected the study population. For languages spoken at home, the study undergraduate proportion was $64 \%$ compared with the interview undergraduate percentage of 63\%. For English and one other language, the percentages were $22 \%$ for the study undergraduates and $19 \%$ for the interview undergraduates. Both undergraduates who spoke English and two other languages at home and the undergraduate who spoke only another language at home participated in the interviews.

The proportions of undergraduates who had not studied a language were similar in both groups: $7 \%$ for the study undergraduates and $6 \%$ for the interview undergraduates. The proportion of undergraduates in the study who had studied one or more languages was slightly higher (94\%) than the study undergraduates (87\%). The undergraduates who participated in the interviews who had lived abroad occurred in slightly higher proportions than in the study population. All three of the undergraduates who had lived abroad participated in the interviews. The proportion of undergraduates who had not traveled abroad was smaller in the interview undergraduates (19\%) than in 
the study undergraduates (29\%). However, the proportions of undergraduates who had traveled abroad were similar among interview participants (56\%) and study participants (58\%).

The chemistry backgrounds of the interview undergraduates also reflected the study undergraduates. Ninety-three percent of the undergraduates had studied chemistry in high school, with all of the interview participants having studied chemistry in high school. However, in the interview undergraduates, a higher proportion had studied AP chemistry, interview undergraduates (50\%) and study undergraduates (38\%).

As for background in mathematics, 91\% of the study undergraduates reported having studied calculus in high school, compared to $94 \%$ of the study undergraduates. Similarly, 73\% of the study undergraduates had studied 4 years of math in high school compared to $69 \%$ of the interview undergraduates. A slightly higher proportion of study undergraduates (64\%) reported studying mathematics in college than the interview undergraduates (56\%) had.

While the background characteristics for the interview participants closely matched the characteristics of the larger population of undergraduates in the sections studied, the undergraduates who participated in the interview process varied in one important area: their willingness to discuss their interactions. It must be reiterated that undergraduate participation in the interview process is a limitation of this study.

Preliminary comparisons of undergraduates who came in for interviews and those who did not indicate that undergraduates may have been motivated to participate in the interview process for reasons related to gender and to overall frequency of participation in the first hour of the labs. Since higher proportions of females 
participated in the interview process, the first stage of analysis was to see if there were patterns of interview participation based on gender. It appears that gender may have played a role in whether an undergraduate participated in the interview process.

Of the 10 undergraduates who commented on interactions from Lab 4, the lab with the largest number of undergraduate interview participation, two were male and eight were female. As discussed in the analysis of interaction participation and initiation in the five lab sessions in the previous section, females tended to participate in interactions earlier in the semester, with males participating in greater proportions later in the semester. As indicated in Table 31, the proportion of males participating in the interview process increased as the semester progressed and the proportion of females decreased, reflecting the overall patterns of participation seen in all lab interactions.

Table 31

Frequency and Percentage of Undergraduate Interview Participants by Lab Session and by Gender

Lab Session

Gender of

Undergraduate Interview

Lab 4 Lab $5 \quad$ Lab $6 \quad$ Lab $7 \quad$ Lab 8

Participants

Male

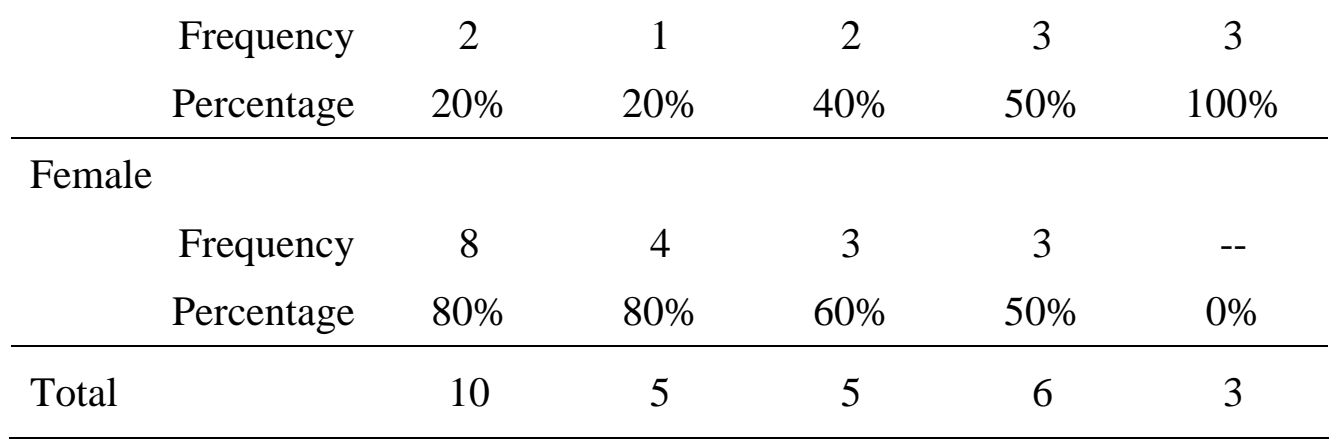


This initial analysis of interview participation based on gender pointed to the possibility that undergraduate participation in the interview process may be related to the frequency of their participation in the first hour of the labs. Lab 4 had the greatest number of undergraduates who commented on their interactions. Furthermore, undergraduates from all lab sections participated in the interviews for this lab. Comparing the number of interactions each participant engaged in during the first hour of the lab session for all undergraduates in the three lab sections, it appears that undergraduates who participated in more lab interactions came in for interviews. As shown in Table 32, in Lab 4, of the 45 undergraduates in this study, seven did not participate in any interactions. For the undergraduates who participated in one to five interactions $(\mathrm{n}=31), 87 \%$ did not come in for interviews and 13\% did. However, $86 \%$ of the undergraduates who participated in six or more interactions $(n=7)$ came in for interviews. 
Table 32

Frequency and Percentage of Undergraduate Interview Participation for Lab 4

\begin{tabular}{|c|c|c|c|}
\hline \multirow[b]{2}{*}{$\begin{array}{l}\text { Frequency of } \\
\text { Interaction } \\
\text { Participation }\end{array}$} & \multicolumn{3}{|c|}{ Lab 4} \\
\hline & $\begin{array}{l}\text { Interview } \\
\text { Participants }^{\mathrm{a}} \\
\quad(\mathrm{n}=10)\end{array}$ & $\begin{array}{c}\text { Interview } \\
\text { Non-Participants } \\
(\mathrm{n}=35)\end{array}$ & Total \\
\hline \multicolumn{4}{|c|}{ 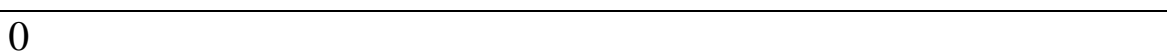 } \\
\hline Frequency & -- & 7 & 7 \\
\hline Row Percentage & & $100 \%$ & \\
\hline Column Percentage & & $20 \%$ & $16 \%$ \\
\hline \multicolumn{4}{|l|}{$1-5$} \\
\hline Frequency & 4 & 27 & 31 \\
\hline Row Percentage & $13 \%$ & $87 \%$ & \\
\hline Column Percentage & $40 \%$ & $77 \%$ & $68 \%$ \\
\hline \multicolumn{4}{|l|}{$>5$} \\
\hline Frequency & 6 & 1 & 7 \\
\hline Row Percentage & $86 \%$ & $14 \%$ & \\
\hline Column Percentage & $60 \%$ & $3 \%$ & $16 \%$ \\
\hline Total & 10 & 35 & 45 \\
\hline
\end{tabular}

${ }^{\text {a }}$ Only interview participants who commented on interactions for Lab 4 are included in this comparison.

Analyzing interview participation by the number of interactions in which undergraduates participated in Lab 4 indicates that undergraduates who had more frequent interactions in the lab were more likely to participate in the interview process. As shown in Table 33, this pattern was also seen when examining the number of interactions for all documented lab sessions. In this comparison, only undergraduates from the Tuesday and Thursday sections $(n=30)$ were analyzed. The Wednesday section was excluded because only two undergraduates participated in interviews in 
Lab 4, and no undergraduates from this section participated in the interview process for Labs 5, 6, 7, and 8. For the Tuesday and Thursday sections, undergraduates who tended to participate more frequently in interactions were more likely to participate in the interview process. For the undergraduates who participated in fewer than 20 interactions ( $n=21$ ) in the five lab sessions, 62\% did not come in for interviews and 38\% did. However, $67 \%$ of the undergraduates who participated in 20 or more interactions $(\mathrm{n}=9)$ came in for interviews.

\section{Table 33}

Frequency and Percentage of Interactions for All Lab Sessions of Undergraduates by Interview Participation for the Tuesday and Thursday Sections

\begin{tabular}{cccc} 
& \multicolumn{3}{c}{ All Lab Interactions } \\
\cline { 2 - 4 } $\begin{array}{c}\text { Frequency of } \\
\text { Interaction } \\
\text { Participation }\end{array}$ & $\begin{array}{c}\text { Interview } \\
\text { Participants } \\
(\mathrm{n}=14)\end{array}$ & $\begin{array}{c}\text { Interview } \\
\text { Non-Participants } \\
(\mathrm{n}=16)\end{array}$ & Total \\
\hline $1-19 \quad$ Frequency & 8 & 13 & 21 \\
Row Percentage & $38 \%$ & $62 \%$ & $70 \%$ \\
Column Percentage & $57 \%$ & $81 \%$ & 9 \\
\hline $20-39 \quad$ Frequency & 6 & $33 \%$ & $30 \%$ \\
Row Percentage & $67 \%$ & $19 \%$ & 30 \\
Column Percentage & $43 \%$ & 16 & 9 \\
\hline Total & 14 & $33 \%$ & \\
\hline
\end{tabular}




\section{Interview Interactions}

The interviews explored a subset of all interactions that occurred in the labs. Of the 877 interactions, the subset of interactions for which there is interview data from all three participants (undergraduate, teaching assistant, and faculty member) in this study totals 51 . One of the interactions was an interaction that was initiated by the teaching assistant, rather than the undergraduate. Because the focus of this investigation is on student-initiated interactions, the teaching assistant-initiated interaction was excluded from analysis.

Interactions from all five lab experiments are included in this portion of the analysis; however, not all sections have all labs represented. For the Wednesday lab section, only two undergraduates participated in the interviews, and their interactions were in Lab 4. Table 34 shows the distribution of interview interactions for all labs sessions and lab sections. 
Table 34

Frequency and Distribution of Interview Interactions by Lab Session and Lab Section

\begin{tabular}{|c|c|c|c|c|c|c|}
\hline \multirow{2}{*}{ Lab Section } & \multicolumn{5}{|c|}{ Lab Session } & \multirow[b]{2}{*}{ Totals } \\
\hline & Lab 4 & Lab 5 & Lab 6 & Lab 7 & Lab 8 & \\
\hline \multicolumn{7}{|l|}{ Tuesday } \\
\hline Total Interactions & 52 & 66 & 66 & 72 & 48 & 304 \\
\hline Consent & 52 & 63 & 60 & 67 & 40 & 282 \\
\hline Interview Interactions & 2 & 2 & 5 & 12 & 4 & 25 \\
\hline \multicolumn{7}{|l|}{ Wednesday } \\
\hline Total Interactions & 78 & 71 & 102 & 92 & 32 & 375 \\
\hline Consent & 72 & 65 & 90 & 73 & 31 & 331 \\
\hline Interview Interactions & 5 & 0 & 0 & 0 & 0 & 5 \\
\hline \multicolumn{7}{|l|}{ Thursday } \\
\hline Total Interactions & 35 & 37 & 50 & 55 & 21 & 198 \\
\hline Consent & 35 & 36 & 47 & 55 & 21 & 194 \\
\hline Interview Interactions & 8 & 8 & 1 & 2 & 1 & 20 \\
\hline \multicolumn{7}{|l|}{ Totals } \\
\hline Total Interactions & 165 & 174 & 218 & 219 & 101 & 877 \\
\hline Consent & 159 & 164 & 197 & 195 & 92 & 807 \\
\hline Interview Interactions & 15 & 10 & 6 & 15 & 5 & 50 \\
\hline
\end{tabular}

Note. Frequency counts of total interactions illustrate the communicative demand placed on international teaching assistants in the lab environment during the first hour of the labs. All data from non-participants have been excluded from student analysis.

The subset of interview interactions examined consisted of 50 interactions out of the total number of interactions of 877 , resulting in $6 \%$ of all interactions. Excluding the interactions of the non-participants, the percentage is also $6 \%$. Because there were only two undergraduates in the Wednesday section who participated in the interviews, this 
section only has interactions from Lab 4 represented in the subset of interview data. Looking at the interactions from only the labs in which undergraduates participated in the interview process, that is, excluding data from Labs 5, 6, 7, and 8 from the Wednesday section, the interaction interview rate was slightly higher 9\%, 50 interactions out of a total of 548. Because of the focus of the study, all interactions in the interview subset were initiated by undergraduates. Looking at only undergraduateinitiated interactions for lab sessions from which interview data is available (Lab 4 for all sections and Labs 5, 6, 7, and 8 for the Tuesday and Thursday sections) the interactions in the interview subset constitute $13 \%$ of these interactions $(n=374)$.

The characteristics of the interview interactions differ slightly from the characteristics of all possible interactions documented in this study in terms of gender (see Table 35). Males initiated 21 interactions or $42 \%$ of the interview subset and females initiated 29 interactions or 58\%. In all labs, males participated in $46 \%$ and females in $54 \%$ of interactions. In the undergraduate-initiated interactions of all labs, males initiated $45 \%$ and females initiated $55 \%$. 
Table 35

Comparison of Frequency and Percentage of Study Interactions and Interview Interactions by Gender of Undergraduate Participants

\begin{tabular}{ccc} 
& \multicolumn{2}{c}{ Interactions } \\
\cline { 2 - 3 } $\begin{array}{c}\text { Gender of } \\
\text { Undergraduate } \\
\text { Participants }\end{array}$ & All Labs & $\begin{array}{c}\text { Interview } \\
\text { Interactions }\end{array}$ \\
\hline Male & 339 & 21 \\
Frequency & $46 \%$ & $42 \%$ \\
Percentage & 399 & 29 \\
\hline Female & $54 \%$ & $58 \%$ \\
Frequency & 738 & 50 \\
\hline Percentage & & \\
\hline
\end{tabular}

The length of the interview interactions reflected the general tendency of interactions to be brief. As shown in Table 36, the interview interactions are distributed across all time intervals. However, the interview interactions were slightly more evenly distributed across the 10-second interval categories than the study interactions were. 
Table 36

Comparison of Frequency and Percentage of Study Interactions and Interview Interactions by Length of Interaction

\begin{tabular}{|c|c|c|}
\hline \multirow[b]{2}{*}{$\begin{array}{l}\text { Interaction Length } \\
\text { (in seconds) }\end{array}$} & \multicolumn{2}{|c|}{ Interactions } \\
\hline & All Labs & Interview Subset \\
\hline \multicolumn{3}{|l|}{$1-10$} \\
\hline Frequency & 285 & 7 \\
\hline Percentage & $33 \%$ & $14 \%$ \\
\hline \multicolumn{3}{|l|}{$11-20$} \\
\hline Frequency & 223 & 9 \\
\hline Percentage & $25 \%$ & $18 \%$ \\
\hline Cumulative Percentage & $58 \%$ & $32 \%$ \\
\hline \multicolumn{3}{|l|}{$21-30$} \\
\hline Frequency & 133 & 8 \\
\hline Percentage & $15 \%$ & $16 \%$ \\
\hline Cumulative Percentage & $73 \%$ & $48 \%$ \\
\hline \multicolumn{3}{|l|}{$31-40$} \\
\hline Frequency & 81 & 7 \\
\hline Percentage & $9 \%$ & $12 \%$ \\
\hline Cumulative Percentage & $82 \%$ & $62 \%$ \\
\hline \multicolumn{3}{|l|}{$41-50$} \\
\hline Frequency & 47 & 6 \\
\hline Percentage & $5 \%$ & $12 \%$ \\
\hline Cumulative Percentage & $88 \%$ & $74 \%$ \\
\hline \multicolumn{3}{|l|}{$51-60$} \\
\hline Frequency & 38 & 1 \\
\hline Percentage & $4 \%$ & $12 \%$ \\
\hline Cumulative Percentage & $92 \%$ & $74 \%$ \\
\hline \multicolumn{3}{|l|}{$61-120$} \\
\hline Frequency & 49 & 9 \\
\hline Percentage & $6 \%$ & $18 \%$ \\
\hline Cumulative Percentage & $98 \%$ & $94 \%$ \\
\hline \multicolumn{3}{|l|}{$>120$} \\
\hline Frequency & 21 & 3 \\
\hline Percentage & $2 \%$ & $6 \%$ \\
\hline Cumulative Percentage & $100 \%$ & $100 \%$ \\
\hline Total & 877 & 50 \\
\hline
\end{tabular}

Note. Frequency counts and percentages illustrate the communicative demand placed on international teaching assistants in the lab environment during the first hour of the labs. All data from non-participants have been excluded from student analysis. 
The activities associated with the interview interactions also reflect the overall patterns of all lab interactions. Since the emphasis for this study is on undergraduateinitiated interactions, the categories that had higher frequencies of interactions initiated by the teaching assistants are under-represented in the interview interaction subset, e.g., lab preparation $(n=2)$. The majority of interview interactions discussed activities related to equipment $(n=14)$, materials $(n=7)$, and procedures $(n=28)$. No safety or social interactions were represented in the interactions of the interview subset. Table 37 compares the frequency and percentages of the interview interactions and all lab interactions based on activity types. 
Table 37

Comparison of Frequency and Percentage of Study Interactions, UndergraduateInitiated Interactions, and Interview Interactions by Activity

\begin{tabular}{|c|c|c|c|}
\hline \multirow[b]{2}{*}{ Activity } & \multicolumn{3}{|c|}{ Interactions } \\
\hline & Study & $\begin{array}{l}\text { Undergraduate- } \\
\text { Initiated }\end{array}$ & Interview \\
\hline \multicolumn{4}{|l|}{ Equipment } \\
\hline Frequency & 127 & 100 & 13 \\
\hline Percentage & $16 \%$ & $20 \%$ & $26 \%$ \\
\hline \multicolumn{4}{|l|}{ Lab Preparation } \\
\hline Frequency & 283 & 125 & 2 \\
\hline Percentage & $35 \%$ & $25 \%$ & $4 \%$ \\
\hline \multicolumn{4}{|l|}{ Materials } \\
\hline Frequency & 48 & 39 & 7 \\
\hline Percentage & $6 \%$ & $8 \%$ & $14 \%$ \\
\hline \multicolumn{4}{|l|}{ Procedures } \\
\hline Frequency & 303 & 215 & 28 \\
\hline Percentage & $38 \%$ & $44 \%$ & $56 \%$ \\
\hline \multicolumn{4}{|l|}{ Safety } \\
\hline Frequency & 24 & 4 & Not Represented \\
\hline Percentage & $3 \%$ & $1 \%$ & -- \\
\hline \multicolumn{4}{|l|}{ Social } \\
\hline Frequency & 18 & 8 & Not Represented \\
\hline Percentage & $2 \%$ & $2 \%$ & -- \\
\hline Total & 803 & 491 & 50 \\
\hline
\end{tabular}




\section{Participant Responses and Comments to the Interview Items}

\section{Obtaining Participant Opinions}

In the interview process participants in the interactions (undergraduates, teaching assistants, and faculty member) met with the researcher in one-on-one sessions to review interactions. All participants were given the opportunity to review an interaction as many times as was necessary for them to recall what was happening during the interaction. In general, the undergraduates and the teaching assistants had no difficulty remembering where the interactions were occurring in the labs. The participants easily recognized the interactions, often supplying additional information about why a question arose or the problem the undergraduate was having at the time.

The faculty member, who was not physically present when the interactions occurred, had greater difficulty contextualizing some of the interactions. In part, this was related to limitations of viewing the interactions through audio and video recordings. In some cases, the recorded interactions did not provide the contextual information necessary for the faculty member to clearly understand what was happening in the interaction. Nevertheless, for most of the interview interactions, the faculty member was able to review an interaction and respond to the Likert-scaled interview form without difficulty. Whenever the faculty member could not reliably determine what was happening in an interaction or accurately place an interaction in an experiment, she declined to respond to an interview item, rather than give a neutral response.

At the start of each interview, I explained how the interview session would proceed. First, an audio or a video clip would be played back. Playback of the 
communicative exchanges was on a desktop PC, using Audacity for playback of the audio files and QuickTime clips for the video files. The interview participant was allowed to hear or see the recorded interaction as many times as he or she wanted. When the interview participant was comfortable with the exchange presented, I started the interview. Interview participants were always free to ask questions or provide other information at any time during the interview.

After explaining the procedures for the interviews, I reviewed the semistructured interview prompts with the participants to familiarize them with the topics that would be covered. Interview participants were allowed to see the interview prompts and ask questions about them. I verbally stated the interview prompts to the participants and took notes on their responses. I confirmed each response before writing it on the interview form.

In the interview process, once the participants were familiar with the interaction, they then responded to a series of 10 interview item prompts to which they rated their responses using a 7-point Likert scale, ranging from 1 for strongly disagree to 7 for strongly agree. Responses to each item in the range of 1 (strongly disagree) or 2 (disagree) were categorized as a participant disagreeing with the item. A response of 6 (agree) or 7 (strongly agree) was categorized as a participant agreeing with the item. When participants rated an item as 3 (slightly disagree), 4 (neutral/no opinion), or 5 (slightly agree), the item was classified as insufficient degree of certainty. In the interview process, the participants were usually very quick to respond using the ends of the scale when they were sure of their responses. When the participants seemed to be 
unsure of their opinions, they were more hesitant and chose ratings from the middle ranges.

At any point during the semi-structured interviews, the participants were free to add comments and suggestions to any of the items. In many cases, especially with the undergraduates, even though the comments and suggestions were attached to particular interactions, the undergraduates spoke about interactions in the labs more generally, indicating that what was happening in the interaction under scrutiny was in fact typical of other interactions or types of interactions in the labs.

To reiterate, this subset of interactions, although representative in many ways of all interactions that occurred, was established by the undergraduates who agreed to be part of the interview process and who were willing and able to participate in the interviews. These interactions are ones that involve the undergraduates who were able to dedicate time to the interview process and who were comfortable participating in the interview process. 


\section{Triangulating Participant Opinions}

To ensure that an interaction was accurately classified as successful or unsuccessful from the point of view of the participants, it was first essential to obtain the perspectives of the participants in the interactions, as discussed above. The next step was to compare the opinions of the participants to identify the interactions that were successful and those which were not. In this study, an interaction was identified as successful or unsuccessful if there was agreement among the participants. This level of participant corroboration was necessary to establish prior to examining the interactions for characteristics and patterns.

In the interview process, it quickly became apparent that participants wanted to discuss the interactions presented, but they also wanted to talk more generally about communication patterns in the lab interactions, focusing on what they thought were positive features of communication as well as what hesitations and reservations they had. The interactions reviewed reflected specific instances of communicative interactions and at the same time represented types of interactions. Each of the interview items on the interview form provoked comments that centered on the dimensions addressed. What became of interest in looking at the Likert-scaled responses was where people agreed and where people disagreed. Agreement did not always come easily.

Participants did not always have the same opinions about whether a given interaction was successful or not in the Likert-scaled responses. In order to identify those interactions for which there was unanimous agreement that an interaction was successful, the opinions needed to be reviewed and a classification scheme needed to be 
developed. The participant opinions for each interview item were classified into four categories: congruent opinions, divergent opinions, insufficient degree of dertainty, and missing response.

If participants demonstrated agreement of opinion for an item, that is, responding to an item with 1 (strongly agree) or 2 (agree) for agreement and 7 (strongly disagree) or 6 (disagree) for disagreement, the opinions were classified as congruent opinion. Congruent opinions could either be opinions in which the participants agreed with the interview item or the participants disagreed with the interview item. What is important for this category is that the participants all held the same opinion of an item. If, on the other hand, one participant agreed with an item to a sufficient degree, e.g., 1 or 2, and another participant's opinion was on the opposite end of the scale, e.g., 6 or 7, then the opinions of the participants were classified as divergent opinions. If one of the participants selected a response that was in the range of slightly agree (3), neutral (4), slightly disagree (5), then the item was classified as insufficient degree of certainty. Finally, in some instances, items were classified as a missing response because a participant was unable to provide an opinion. In most cases, it was the content-area specialist who was not able to provide a response.

In reviewing opinions for the interview items, missing responses were first identified, and the item was classified as missing response. If the item had responses from all three participants, but one participant did not specify a sufficient degree of certainty for the item, it was classified as insufficient degree of certainty. If the item had opinions from all three participants to a sufficient degree of certainty, and there was agreement, the item was categorized as congruent opinion, with an indication of the 
direction of agreement or disagreement. If the participants opinions differed, that is they were on opposite ends of the scale, then the item was classified as divergent opinion.

Two-way comparisons were also made for undergraduates and teaching assistants (the instructional pair), the undergraduate and the faculty member (the nativespeaker perspective) and the teaching assistant and the faculty member (the content-area perspective). The three-way comparison was the most important comparison for this study. However, in some cases, when the faculty member could not rate an item, the two-way comparison of undergraduate-teaching assistant perspective provided a useful comparison.

Interview Items and Dimensions

The 10-item semi-structured interview was designed to elicit information from the participants on various dimensions related to the undergraduate-initiated interactions under examination. In general, an undergraduate-initiated interaction involved a question posed by the undergraduate to the teaching assistant and a response from the teaching assistant. Some of the interview items focused on the undergraduate-initiated question and other interview items focused on the teaching assistant's response.

Interview items 1-5 emphasized the undergraduate’s question. Item 1 addressed the teaching assistant's understanding of the undergraduate's question. Items 2 and 3 addressed issues related to an undergraduate's comfort asking and ability to express the question. Items 4 and 5 investigated what was motivating the undergraduate's question, i.e., did the undergraduate ask the question to obtain content information or was the undergraduate seeking confirmation and support. 
Interview Items 6-9 emphasized the teaching assistant's response. Item 6 addressed the undergraduate's understanding of the teaching assistant's response. Item 7 investigated satisfaction with the response, from the perspective of the undergraduate. Items 8 and 9 examined whether the information in the response was sufficient and whether there was a preference for another answer.

Finally, Interview Item 10 asked participants to evaluate the interaction holistically by rendering an opinion on the overall success of an interaction. Responses to this item determined whether an interaction was classified as successful or unsuccessful, and this classification was used for analyzing the interactions.

In the following discussion of participant opinions, responses to the Likertscaled interview items are examined in two ways. The primary method was to compare the responses of all three participants for agreement, a three-way comparison: the undergraduate, the teaching assistant, and the faculty member (the content-area expert). However, in cases where the faculty member was not able to reliably or accurately respond to an item, a comparison was made with just the teaching assistant's and the undergraduate's responses. Comparisons were also made to examine undergraduatefaculty consensus (native-speaker consensus) and teaching assistant-faculty consensus (content-area specialist consensus). However, for this study, findings related to the undergraduate-teaching assistant consensus emerged as the most important for communication patterns. Appendix H provides summary counts and percentages of participant opinion agreement for each interview item. 
Interview Item 1: Comprehension of the question.

\begin{tabular}{|c|l|}
\hline UG & The teaching assistant understood my question. \\
\hline TA & I understood the undergraduate's question. \\
\hline Faculty & I think the teaching assistant understood the question. \\
\hline
\end{tabular}

Interview Item 1 asked whether the teaching assistant understood the question presented by the undergraduate. Of the 50 interactions examined, participant agreement was high for this item, with 70\% congruent opinions for all 3 participants, and a slightly higher rate of $78 \%$ for the teaching assistant-undergraduate comparison. In all cases, the congruent opinions were in agreement with the interview item. Divergent opinions occurred in only two cases, both occurring in Lab 6. In both cases, the undergraduates reported different opinions from the teaching assistant and the faculty member. The undergraduates in both interactions felt that the teaching assistant did not understand the question, while the teaching assistant and the faculty were of the opinion that the teaching assistant had understood the question. However, in both instances, the undergraduates felt that the interactions were successful overall. Insufficient degrees of certainty occurred in $18 \%$ of the responses, the lowest rate of all interview items.

Participant comments for this interview item were more frequent from the faculty member, with a few comments from the undergraduates. The teaching assistants did not elaborate on this item. The undergraduates and the faculty member commented in several interactions that it took some clarification for the undergraduate and teaching assistant to achieve success in understanding the question. A common comment from both the undergraduates and the faculty member was of the type: "On the second try they got it right” or "On the second time around the teaching assistant understood. At 
first the teaching assistant didn’t understand what I was misunderstanding, but we eventually worked it out.”

In one of the early undergraduate interviews, the undergraduate took issue with the phrasing of the interview item, pointing out that for her it was not about the teaching assistant "understanding the questions"; rather it was more important for the teaching assistant to "understand her situation.” In subsequent interviews with the undergraduates, this distinction proved to be meaningful and was reinforced in many other ways: in the discussions with the undergraduates it became clear that they needed their teaching assistants to understand what the undergraduates were saying, what the undergraduates were doing, and where the undergraduates were in the experiment to make sense of the undergraduate's question.

It was also important to the undergraduates that the teaching assistants understood what the problem was that the undergraduates were experiencing and what prompted them to seek help from the teaching assistants. This undergraduate's comment, focusing on "the situation” rather than "the question," shifted the meaning of the teaching assistant's understanding by expanding the notion of understanding an undergraduate's question from the purely linguistic level to a broader level of understanding the context and situation in which the verbal interaction was embedded. Other undergraduates used this terminology "in my situation,” as well.

The faculty member's comments confirmed that more than just the verbal interaction was involved in understanding the undergraduates' questions. First, there were instances in which the faculty member, who had designed and carried out the experiments on multiple occasions, had difficulty placing an interaction in an 
experiment because as she phrased it, “more visual information was needed to determine what was going on.” In the audio recordings, the faculty member only had access to what was said. With the video recordings, complexities of recording in the lab did not always provide suitable images for review.

On several occasions, the faculty member pointed out that it took some clarification for the teaching assistant to understand a question an undergraduate was asking. In some cases, she identified that what appeared to be a simple question from the perspective of an outside observer was in fact a complex and compound question that the teaching assistant needed to pull apart before being able to respond to the question accurately. Not only could a question expressed by an undergraduate have multiple parts, but the question's meaning and consequently an appropriate response to it depended on when in the experiment the question was occurring. It was important for the undergraduate or the teaching assistant to provide some orientation to where and when in an experiment a question was occurring.

The faculty member also discussed that the ways the undergraduates expressed some of the questions made understanding a question difficult, which will be discussed in greater detail in Interview Item 3. From the participant comments from this interview item, the most important idea that emerged was that the participants did not expect the interaction to proceed without some negotiation and that the demands of the situation required effort on all parts for success to be achieved in an interaction. A key concept that was expressed by an undergraduate was that it was the teaching assistant's ability to understand the undergraduate's "situation" that was crucial, and sometimes, 
understanding the "situation” involved verbal information, visual information, clarifying, and negotiating.

Interview Item 2: Comfort with the question.

\begin{tabular}{|c|l|}
\hline UG & I was comfortable approaching the TA with my question. \\
\hline TA & The undergraduate's question was easy to answer. \\
\hline Faculty & The undergraduate's question was clearly expressed. \\
\hline
\end{tabular}

Interview Item 2, examining the dimension of comfort with a question, reflected slightly different perspectives of what comfort with the question was. The undergraduate perspective emphasized how the undergraduate felt about approaching the teaching assistant with the question. The teaching assistant perspective emphasized how comfortable and confident the teaching assistant was with knowing the information to answer the question. The content-area specialist was asked to comment on whether the content requested in the question was clearly expressed. In two instances, the faculty member was not able to respond to this item.

This interview item had higher levels of insufficient degree of certainty, 34\% for the three-way comparison of opinions and $28 \%$ for the undergraduate-teaching assistant comparison. Congruent opinions, all for agreement, occurred at a rate of $50 \%$ for all three perspectives, but for the undergraduate-teaching assistant comparison, the rate was higher, 66\%. There were five divergent opinions for this item. In all five instances, the undergraduates were of the opinion that they were comfortable asking the teaching assistant the question. In three of these instances, the teaching assistants felt that the questions were not easy to answer, with the faculty member identifying that the undergraduates' questions were clearly expressed. In two instances, the faculty member did not think that the undergraduates clearly expressed their questions, though in these 
interactions the undergraduates were comfortable asking the question and the teaching assistants were comfortable answering the question.

Comments from all three participants were elicited with this interview item. From the undergraduate perspective two main themes emerged. The first was that the undergraduates were comfortable asking questions of their teaching assistants because the teaching assistants were supportive and helpful. Some undergraduates indicated that it was sometimes easier to ask questions when they were in groups. Later, undergraduates expressed appreciation for the lab work being structured for them to work in pairs. They liked being able to work with their partner to resolve issues, but felt comfortable approaching the teaching assistant when they could not resolve the problem as a group.

The second major theme that emerged was that the undergraduates felt that some of their questions were, in their words, "stupid" and that they should know the answers to their questions. One undergraduate explained that in her previous experiences in science classes before college, she was encouraged to work independently and was supposed to solve problems on her own. She therefore felt she should not ask questions of the teaching assistant because it was not how she was taught to learn in the sciences. She did, however, find that the question-answer interactions she had with the teaching assistant were a positive and productive part of her learning experience in the class.

The teaching assistant comments also had two primary themes. The first was related to their not being quite sure what the undergraduate was having problems with, which made answering some questions difficult. The second theme related to pedagogy of the discipline: the question that the undergraduate was asking had a complicated or 
"complex" answer. The difficulties the teaching assistants experienced in responding to these types of questions related to how they could best meet the undergraduate's immediate needs without providing more information than the undergraduate was prepared for or wanted.

The faculty member identified that sometimes undergraduate questions were not clearly expressed. In some instances, the undergraduates were collapsing multiple questions into one question, which made the teaching assistant's job of teasing apart the questions more complicated. In other cases, the undergraduate did not express the question completely. Finally, the faculty member identified that some of the questions were "information dense," meaning that questions were expressed clearly and precisely, while others required supplemental, e.g., visual, information for understanding or interpretation. As in the previous interview item, the faculty member identified frequently that the undergraduates and the teaching assistants needed to work together to understand the question and the situation, which often took two attempts.

Interview Item 3: Difficulty expressing the question.

\begin{tabular}{|c|l|}
\hline UG & I wasn't sure how to explain (or phrase) my question. \\
\hline TA & The undergraduate had difficulty asking the question. \\
\hline Faculty & The undergraduate had difficulty expressing the question. \\
\hline
\end{tabular}

Interview Item 3, examining the dimension of the degree to which an undergraduate had difficulty expressing the question, had similar prompts for all participants. This item had one of the lowest degrees of congruent opinions among the three participants, at $48 \%$ disagreeing that the undergraduate had difficulty expressing or phrasing the question. Congruent opinions of disagreement with the statements of this item between the undergraduates and the teaching assistants were only slightly 
higher, 58\%. Divergent opinions occurred in 10\% of interactions for all three participants, and $12 \%$ for undergraduate-teaching assistant participants.

In two of the six interactions where the undergraduates and the teaching assistants had differing opinions, the undergraduates felt that they did not have difficulty expressing the question, but the teaching assistants thought that the undergraduates had difficulty expressing the questions. In the other four instances of disagreement, the teaching assistants thought that the undergraduates did not have difficulty expressing the question, but the undergraduates thought that they had difficulty expressing their questions. In instances of disagreement, the faculty member's opinions agreed with the undergraduate's in three of the six instances. In the remaining three instances, the faculty member's opinion fell in the range of insufficient degree of certainty. Overall, the rate of insufficient degrees of certainty for this item was 36\% for the three-way comparison and 30\% for undergraduate-teaching assistant comparison.

Comments on this interview item came from the undergraduates and the faculty member. There was one theme that emerged from these comments that was consistent for both: the undergraduates had difficulties expressing what they wanted to say primarily because they did not have or were not sure of the vocabulary to express what they wanted to. As one undergraduate indicated: “I know what I wanted. I didn’t know what it was.” Another undergraduate commented: "I ended up phrasing it okay, but I didn’t specify things clearly, but he [the teaching assistant] understood.” Finally, one undergraduate reported: “Using the word 'electrode’ would have helped make this clearer, rather than just 'this.'” In this instance, the meaning was conveyed by the undergraduate showing the teaching assistant what "this" was. 
The faculty member confirmed the undergraduate-identified difficulties with expressing the question. In one instance, she indicated that the undergraduate "was not using words very well.” In another interaction, she pointed out that the undergraduate “didn’t have the terminology to clearly express his question.” Finally, in this interview item and elsewhere, the faculty member identified that the undergraduates depended heavily on the use of "this," which required the teaching assistant to see and understand what "this" was referring to.

Interview Item 4: Requesting clarification.

\begin{tabular}{|c|l|}
\hline UG & I needed to have instructions or information clarified. \\
\hline TA & The undergraduate wanted information clarified. \\
\hline Faculty & The undergraduate was seeking clarification of information. \\
\hline
\end{tabular}

Interview Item 4 examined the dimension of whether the undergraduate was asking for specific information that he or she did not know. This item had one of the highest rates of divergent opinions, $14 \%$ for both the three-way comparison and the undergraduate-teaching assistant comparison. In all instances except one, the teaching assistant agreed with the statement that the undergraduate was asking for information to be clarified, and the undergraduate disagreed with the item. The rates for insufficient degree of certainty were also the same for both comparisons, 24\%. Congruent opinions were in the direction of agreement with the interview prompt, 56\% for the three-way comparison and $62 \%$ for the undergraduate-teaching assistant comparison.

There were few comments from the participants for this interview item. One undergraduate comment was "I just needed help." The teaching assistant reported that the undergraduates just wanted to know the answer. The faculty member identified that 
in some cases, the undergraduates needed information that had been inadvertently omitted from the lab manual.

What was most interesting about the comments for this interview item and the following item related to confirming information was that undergraduates identified that they were simultaneously seeking confirmation and clarification. They wanted both information and support for what they were doing when they approached the teaching assistant. From the undergraduates' perspective, their questions were multi-functional.

Interview Item 5: Requesting confirmation.

\begin{tabular}{|c|l|}
\hline UG & $\begin{array}{l}\text { I was checking to make sure that I understood what to do; i.e., I was } \\
\text { seeking confirmation. }\end{array}$ \\
\hline TA & $\begin{array}{l}\text { The undergraduate was checking to make sure that he/she understood what } \\
\text { to do. }\end{array}$ \\
\hline Faculty & $\begin{array}{l}\text { The undergraduate was seeking confirmation that what he/she was doing } \\
\text { was correct. }\end{array}$ \\
\hline
\end{tabular}

Interview Item 5 was a companion item to Interview Item 4. Whereas Interview Item 4 asked whether the undergraduate was seeking information that he or she did not know, Item 5 asked participants if the undergraduate was merely seeking confirmation or reassurance about what they were doing. This item had the highest rate of divergent opinions, with $16 \%$ disagreeing in the three-way comparison and $12 \%$ in the undergraduate-teaching assistant comparison.

Of the six interactions where there were divergent opinions between the teaching assistants and the undergraduates, three interactions occurred in the Thursday section in Lab 5 and three in the Tuesday section, two in Lab 7 and one in Lab 8. The divergent opinions in Lab 5 were all of the same type: the undergraduates agreed that they were asking for confirmation, but the teaching assistant disagreed. The faculty member's opinion agreed with the undergraduate's opinion in all three of these 
instances. In the interactions in Labs 7 and 8 with the Tuesday teaching assistant, the reverse was true, the undergraduates disagreed that they wanted confirmation, but the teaching assistant thought that the undergraduates were seeking confirmation. The faculty member's opinions in Lab 7 were congruent with the undergraduates' opinions, but in Lab 8 the faculty member's opinion was congruent with the teaching assistant's. In the three-way comparison, $36 \%$ of opinions of the interactions were of insufficient degree of certainty and 32\% in the undergraduate-teaching assistant comparison. As for congruent opinions, in the direction of agreement with the interview item, only $40 \%$ occurred in the three-way comparison, and 54\% for the undergraduate-teaching assistant opinions.

As identified in the previous item, there were few comments from any of the participants for Interview Items 4 and 5. The main theme from the comments was related to the undergraduates' intention for their questions to be multi-functional. The undergraduates express what Kearsley (1976) states about question functions: the undergraduates intend for their questions to be have multiple purposes simultaneously. At the same time that they were asking for discrete information, they were also asking that the teaching assistant confirm that what they were doing was right. The undergraduates always appreciated it when they teaching assistant provided reassurance. 
Interview Item 6: Comprehension of the response.

\begin{tabular}{|c|l|}
\hline UG & I understood the TA's response. \\
\hline TA & The undergraduate understood my response. \\
\hline Faculty & The undergraduate understood the response. \\
\hline
\end{tabular}

Interview Item 6 asked participants their opinions of whether the undergraduate understand the teaching assistant's response. For this item, there were no divergent opinions, and congruent opinions were high at 70\% agreement for the three-way comparisons, and $76 \%$ for the undergraduate-teaching assistant comparisons. For the three-way comparison, this interview item was identical in agreement to Interview Item 1, the dimension exploring whether the participants thought that the teaching assistant understood the undergraduate's questions. For insufficient degree of certainty, the percentages were $22 \%$ for the three-way comparison, and $24 \%$ for the undergraduateteaching assistant comparison.

Comments related to this interview item came from all three participants, with most comments coming from the undergraduates. The most significant comment from the undergraduates was that in addition to the verbal information in the teaching assistant's response, the visual information that accompanied the verbal information was crucial to the undergraduates' understanding of the response. In some cases, undergraduates understood the response through the teaching assistant's demonstration. The faculty member's comments echoed the importance of demonstrations in the chemistry labs, i.e., using both visual and verbal channels for conveying information. The teaching assistants' main comment for this interview item related to their hesitations in responding. The teaching assistants thought that hesitating to think about 
the response before saying it was potentially distracting or confusing for the undergraduates.

Interview Item 7: Satisfaction with the response.

\begin{tabular}{|c|l|}
\hline UG & I was satisfied with the TA's response. \\
\hline TA & The undergraduate was satisfied with my response. \\
\hline Faculty & The TA responded accurately. \\
\hline
\end{tabular}

Interview Item 7 asked participants their views on whether the undergraduate was satisfied with the teaching assistant's response. The content-area specialist perspective identified whether the teaching assistant's response was accurate and therefore a satisfactory response to the question. The congruent opinions of agreement with this item were higher for the undergraduate-teaching assistant comparison, 62\%, than for the three-way comparison, 50\%. While there were no divergent opinions between the undergraduates and the teaching assistants, the faculty member diverged in $4 \%$ of the interactions, citing the accuracy of the responses. The rate of insufficient degree of certainty was 38\% for both comparisons.

The undergraduates had more comments for this interview item than the other participants. One teaching assistant indicated some dissatisfaction when the undergraduate did not do what the teaching assistant had instructed. The faculty member's comments were reiterations of comments from other interview items.

The consistent comments from the undergraduates were that while they were in general satisfied with the response, they wanted more elaboration. In some instances, the undergraduate was satisfied that the teaching assistant gave him just enough information, not too much and not too little. He appreciated that the teaching assistant gauged the amount of information to the undergraduate's specific need. 
Interview Item 8: Sufficient information in the response.

\begin{tabular}{|c|l|}
\hline UG & The TA provided sufficient information for me to understand the response. \\
\hline TA & I was satisfied with my response. \\
\hline Faculty & $\begin{array}{l}\text { The TA provided sufficient information in the response for the } \\
\text { undergraduate to understand the response. }\end{array}$ \\
\hline
\end{tabular}

Interview Item 8 explored whether the teaching assistant's response to the undergraduate's question included sufficient information for the undergraduate to understand it. The teaching assistant's statement was phrased to capture whether the teaching assistant was satisfied with the response. While there were no divergent opinions for this item in either of the comparisons, the rates of congruent opinions of agreement differed, with the undergraduate-teaching assistant comparison higher at $62 \%$ than the three-way comparison of 50\%. In a three-way comparison, this item had the highest rate of insufficient degree of certainty, at $42 \%$. Uncertainty in the undergraduate-teaching assistant comparison was also high, at 38\%.

Comments from the faculty member on this interview item reinforced that the visual information and demonstrations were necessary for a response to have sufficient information. Undergraduate comments also indicated that sufficient information in the response meant that verbal information was supported with visual information. The undergraduates needed and wanted to see what to do in addition to hearing what they needed to do. The faculty member and the undergraduates agreed that "both the verbal and visual information" are essential for communication to be successful in a chemistry lab.

For Interview Item 8, the teaching assistants' comments were critical of their teaching skills. In one instance, the teaching assistant felt that he had given the 
undergraduate too much information, reflecting that a briefer answer would have been better for the undergraduate. In another instance, the teaching assistant was unhappy with pauses and hesitations before answering. This teaching assistant wanted to respond more quickly with verbal information.

Interview Item 9: Preference for another response.

\begin{tabular}{|c|l|}
\hline UG & I wish the TA had responded differently. \\
\hline TA & I now realize that another response would have been better. \\
\hline Faculty & The TA should have responded differently. \\
\hline
\end{tabular}

Interview Item 9 was related to Interview Items 7 and 8, exploring satisfaction with the response. However, Interview Item 9 asked the participants whether they preferred a different response. This item had the highest rates of divergent responses at $18 \%$ in the three-way comparison, and $12 \%$ in the undergraduate-teaching assistant comparison. In the undergraduate-teaching assistant comparison, all three teaching assistants were represented. More of these divergent responses occurred early in the semester, with four instances occurring in Lab 4. In three of the four interactions from Lab 4, the teaching assistants wished that they had answered the question differently. The undergraduates in these interactions did not want a different response. However, for the remaining interactions with divergent responses, from Lab 4, Lab 6, Lab 7, and Lab 8 , the undergraduates responded that they would have preferred another response, while the teaching assistants were satisfied with the responses they gave. It should be noted that when the faculty member's opinion was available, her opinion was congruent with the teaching assistants' opinions in the later part of the semester, but congruent with the undergraduate opinions in the early part of the semester. 
Congruent opinions of disagreement with this interview item, which indicated satisfaction with the teaching assistant's response, were $38 \%$ in the three-way comparison and 56\% for the undergraduate-teaching assistant comparison. The rate of insufficient degree of certainty was slightly higher in the three-way comparison, 36\%, than in the undergraduate-teaching assistant comparison, 32\%.

All three participant groups commented on this interview item. The teaching assistants had more varied comments about how they would have responded differently, such as guiding undergraduates to appropriate places in the lab manual, telling rather than showing undergraduates what to do for a quicker response, and responding more quickly. One teaching assistant identified that the difficulties in responding were related to teaching in this discipline, a common problem for native and non-native teaching assistants alike.

The comments from the undergraduates and the faculty member were consistent and overlapped. The undergraduates wanted more elaboration. Undergraduates wanted the teaching assistant to let them know when they were right. Further, they wanted the teaching assistant to reiterate why they were right. Similarly, the undergraduates wanted explanations about why they were wrong when they were wrong. In some cases, the undergraduates thought that the visual channels of information were sufficient, but wanted the verbal information to supplement what they were seeing. In cases where the teaching assistant used only verbal explanations, the undergraduates expressed an interest in seeing what to do in addition to hearing about what they should do. As one undergraduate stated: “I’ve never been in a chem lab and I haven't used the equipment before. They [faculty member and teaching assistants] assume that we are familiar with 
it [the equipment], but we aren't. Reading the chapter [in the lab manual] doesn't show you how to use the equipment.”

The faculty member's comments were centered on issues related to pedagogical considerations and reflected the undergraduates' desires for more elaboration. The faculty member in some instances thought that the undergraduates needed more elaboration with the responses and that the teaching assistants should spend a little more time explaining why something happened or why something should be done in a particular way.

Interview Item 10: Overall success of the interaction.

\begin{tabular}{|c|l|}
\hline UG & Overall, this was a successful question/answer exchange. \\
\hline TA & Overall, this was a successful question/answer exchange. \\
\hline Faculty & Overall I think this was a successful question/answer exchange. \\
\hline
\end{tabular}

Interview Item 10 asked the participants to think about the interaction holistically and render an opinion of whether overall the interaction was successful or not. In this interview item, there were no divergent responses. Congruent opinions of agreement with this item were higher for the undergraduate-teaching assistant comparison at $62 \%$ than for the three-way comparison at $56 \%$. There were no congruent opinions of disagreement for this item either, which means that no interaction could be identified as unsuccessful. The rates of insufficient degree of certainty for this item were at 36\% for the three-way comparison and 38\% for the undergraduate-teaching assistant comparison.

There were few comments from the participants for this final interview item. One undergraduate commented on the length of time it took for an interaction to be successful, but that eventually the exchange was successful because both the teaching 
assistant and the undergraduate worked together to resolve the undergraduate's question or problem. The faculty member's comments related to the accuracy or approach to a response, stating that some interactions were structurally (linguistically) accurate but the faculty member had some concerns related to the content of the response. The teaching assistants did not elaborate on this interview item.

Successful, Partially Successful, and Unsuccessful Interactions

The purpose of Interview Item 10 was for the participants to identify which interactions were successful and which interactions were not. As discussed previously, it was also important for participants to concur that an interaction was successful in order for it to be defined as being successful. Similarly, for an interaction to be identified as unsuccessful, it needed to be unsuccessful for all participants. No undergraduate and no teaching assistant ever identified an interaction as unsuccessful.

The faculty member only rated one interaction as unsuccessful due to the content of the response supplied by the teaching assistant, with the teaching assistant and undergraduate agreeing in their rating of the interaction. Because there were no interactions that could be classified as unsuccessful, interactions that were not identified as successful were classified as partially successful, meaning that one of the participants viewed the interaction with a sufficient degree of certainty as successful and that one or more of the participants rated the interaction with an insufficient degree of certainty ( 3,4 , or 5 on the Likert-scale).

Of the 50 interactions, undergraduates identified 39 interactions that were successful; the teaching assistants identified 39 successful interactions, and the faculty member identified 39 successful interactions. However, in only 28 of the interactions 
did the three participants agree that the interactions were successful. Within each group of participants, satisfaction was high for many of the interactions; that is, each participant group identified $78 \%$ of the interactions as successful. However, finding consensus of opinion among the participants on interactions was challenging, as only $56 \%$ of the interactions were classified as successful by all three participant groups.

In total, there were 28 interactions that were identified as successful by all three participants and 22 interactions that were classified as partially successful. Looking at the interactions from just the undergraduate and the teaching assistant perspectives, 31 interactions were identified as successful. When examining the faculty member's perspective on these three additional interactions, the faculty member took issue with some aspect of the content of the response in two interactions. The faculty member acknowledged that the communicative exchanges had been successful linguistically, i.e., the participants "seemed to have succeeded in communicating something"; however, the information exchanged was not entirely accurate, and therefore, from her perspective, she could not agree that it was a successful exchange. In the third interaction, the faculty member could not rate the overall success of the interaction because there was insufficient contextual information in the recording for her to do so. The undergraduate-faculty member perspective had 33 successful interactions, and the teaching assistant-faculty member perspective identified 34 successful interactions. Appendix I provides an overview of characteristics of the subset of the interview interactions by success category.

When looking at the opinions for complete consensus on all interview items, only one interaction was found for the three-way comparison, a successful interaction 
from Lab 7. For the undergraduate-teaching assistant comparison of opinions there were three interactions with complete agreement on all interview items, one in Lab 6 and two in Lab 7. For the undergraduate-faculty member comparison, there were three interactions of consensus on all interview items, two in Lab 7 and one in Lab 8. Finally, the faculty member-teaching assistant comparison had the most agreement: there were 10 interactions in which there was complete consensus for all interview items, one in Lab 6, six in Lab 7, and three in Lab 8. All of these interactions with faculty memberteaching assistant consensus on all interview items occurred in the Tuesday section.

At the end of the series of interview items, participants were encouraged to add any comments or bring up any topics that they felt were relevant, but had not been addressed in the interview items. There was a great variety of comments that the participants, especially the undergraduates and the faculty member wanted to add. Many of these comments reinforced and expanded on information addressed in the comments about the individual items. Comments that occurred at the end of the interview provided additional perspectives that were not captured by the interview items; frequently these comments were more global about the class, the people, the places, and the content as they related to learning in the discipline, where all of these interactions were embedded.

Because the additional participant comments at the end of the interview were not tied to a particular interview item, they were first examined together as additional comments. Various themes began to emerge during this initial survey of comments. Because the interactions had been classified as successful or partially successful, the additional comments were reviewed using this distinction to classify and analyze them. 
This distinction proved to be a useful and appropriate way to approach analyzing the additional comments of the participants, and the themes identified in the preliminary review of these comments occurred in patterns based on the success category of an interaction.

In general, the teaching assistants' additional comments supplied information on how the undergraduates behaved as a group. There were no apparent patterns in the comments related to the success of an interaction. The teaching assistants never singled out individual undergraduates to comment on. They focused on the undergraduates as a group. The faculty member's comments covered a wide variety of topics, ranging from pedagogical to linguistic to logistical. For any interaction, her comments were often a combination of these three aspects and usually related to larger patterns or trends from the entire class. The undergraduates' comments were the ones in which the most distinct patterns emerged based on whether an interaction was classified as successful or partially successful.

Teaching assistant comments. The teaching assistants took the opportunity at the end of the interviews to comment on the undergraduates. They did not elaborate on any interactions in particular, nor did they comment on particular undergraduates; rather, they discussed the undergraduates as a class. The teaching assistant in the Thursday section commented that her section was very good academically: the undergraduates were well prepared for the labs and performed very well on the pre-lab quizzes. She also contrasted the section that was part of this study with the other section that she was overseeing and mentioned that the observed section was a quieter section. She 
mentioned that in the observed section the undergraduates did not ask very many questions, and they did not talk much when carrying out the experiment.

The teaching assistant for the Wednesday section commented on the behavior of the undergraduates in his section. His generalization was based on gender. He reported that the females in the section asked more questions at the beginning of the lab sessions and the males tended to ask more questions toward the end of the session, especially as the undergraduates were closer to the write-up phase of the experiment. His comments were based on observations from both of the sections he was overseeing.

The teaching assistant for the Tuesday section commented that the undergraduates in his section were good undergraduates who worked efficiently in the labs. All three teaching assistants expressed pride in the work of their undergraduates, and stated that they enjoyed serving as teaching assistants for their undergraduates.

Faculty member comments. The faculty member took the opportunity to comment on various topics: the pedagogical skills of the teaching assistants, the quality of work by the undergraduates, the relationship of the activities to the lab materials and the lab preparation, the dynamics of interactions between the teaching assistants and the undergraduates, and the content information from the course.

After the faculty member reviewed a number of interactions, she was able to make generalizations related to various undergraduates. For example, for one undergraduate, she remarked that the undergraduate always asked very good questions. For other undergraduates she observed that they did not have control of the vocabulary necessary for talking about the material, which was sometimes problematic for the teaching assistants. 
For a cluster of other undergraduates, the faculty member was able to characterize their difficulties in carrying out the instructions presented in the lab manual: they were taking the instructions too literally, when it was not necessary. For example, at times undergraduates wanted a degree of precision that did not match the precision required of the task. In some instances, undergraduates thought that they needed to be more precise with their work than the task actually called for, and at other times where greater precision was required, they were not demonstrating sufficient concern for precision. In short, she identified that these were common issues to many undergraduates in introductory chemistry labs as the undergraduates are developing their judgments and establishing their priorities to think and act like chemists.

As for comments related to the content of the course, the faculty member often referred to the particular apparatus or techniques in an experiment. Since the faculty member was working with all the teaching assistants and undergraduates in all of the laboratory sections, she had dealt with many of the questions and situations during the semester and was familiar with the questions and concerns that the undergraduates were bringing up in the interactions in this study. As such, she was able to make generalizations about the particular interactions and identify what many of the issues were. For example, in some of the interactions, she was able to identify that the undergraduate was having difficulties due to the way that information in the lab manual had been presented. For other interactions, she was able to identify that the technique that the undergraduates were using was a similar though distinct procedure from what they were used to performing. Finally, she was able to comment on the variations in differing types of equipment. For example, one brand of $\mathrm{pH}$ meter required one type of 
calibration, and another brand required a slightly different approach to calibration, which was confusing to both the teaching assistants and the undergraduates.

The faculty member provided valuable insight into how the teaching assistants performed as instructors, contrasting what they were presented with and what they achieved. For example, the faculty member identified when the undergraduates had not provided sufficient information for the teaching assistant to be able to respond to the questions and how the teaching assistant needed to rely on visual inspection of the equipment or experiment for the teaching assistant to understand the question, e.g. "is this right?” She was also able to comment on assumptions that the teaching assistant had about what an undergraduate had completed correctly, but in fact had not completed. She was also able to describe how an undergraduate's limited grasp of terminology had directed the teaching assistant's attention away from the real problem, e.g., referring to a burette as the problem when the issue was related to a flask. Finally, she was able to identify that in some cases an undergraduate would ask a question that the teaching assistant had not thought of, but was able to work through with the undergraduate, modeling for the undergraduate how a chemist would resolve a problem.

The comments mentioned above were connected to interactions that were classified as successful and partially successful. In both types of interactions, from the content-area specialist's perspective, there were many instances in which the undergraduates could have expressed themselves with more precision or where the teaching assistants needed to understand what problems the undergraduates were having by paying attention to what the undergraduates were doing in relationship to what they were saying. 
In both types of interactions (successful and partially successful), the faculty member explained that the teaching assistants could have provided a little more explanation to provide more information to the undergraduates. However, the faculty member commended the teaching assistants for doing a great job of teaching, one aspect of which was communicating information by demonstrating what needed to be done for the undergraduates. In general, the faculty member had praise for the work of the teaching assistants and the undergraduates, acknowledging that often it took some negotiating between the undergraduates and the teaching assistants to make sure that they were talking about the same thing.

Undergraduate comments. The additional comments from the undergraduates were wide ranging, discussing all aspects of the lab component of this introductory class - the teaching assistants, the faculty, the other undergraduates, the content, the workload, their concerns, their frustrations, and their worries. However, throughout all of the discussions, the undergraduates were positive about the course and their experiences, and felt that even though the course was difficult, it was a valuable learning experience. While none of the undergraduates ever discussed that they saw chemistry as their major or profession, they understood that chemistry was an essential foundation to their futures in related sciences.

The undergraduates were also enthusiastic about offering suggestions that would improve the educational experiences for undergraduates taking the course in the future. However, unlike the comments from the teaching assistants and the faculty member, the comments from the undergraduates took on a different tenor when they were made in connection with an interaction categorized as successful and when the interaction was 
classified as having an insufficient degree of certainty as to the interaction's success.

The comments related to the successful interactions focused on what was positive about classroom communication and how it supported their learning in the laboratory. Comments related to the interactions that were classified as partially successful tended to emphasize what could have been done differently to improve the communication in the classroom to facilitate their understanding of the material and what they were doing in the labs. The undergraduates never identified failures of the course or the instructors; rather they focused on what was positive about the course and what would be a change for the better. The undergraduates focused their comments on what they needed to succeed in the chemistry labs.

For interactions that were classified as successful, three major themes emerged. The first theme centered on the undergraduates' expectations for communication in the labs: the undergraduates reiterated how important it was for their teaching assistants to understand them. The second theme related to undergraduate comfort in the classroom and the sense of trust they had developed with their teaching assistants. The third theme emphasized what facilitated their learning and understanding of the content material: much information is communicated through visual channels of communication.

One of the first things that many, though not all, of the undergraduates mentioned, was that at the beginning of the semester, they had concerns about the communication skills of their teaching assistants and to understanding what the teaching assistant was saying. Undergraduates from all three sections agreed that the production of spoken English by their teaching assistants during the first part of the labs, when the teaching assistants were delivering information to the entire class, was sometimes 
difficult to understand, especially the production of the specialized terminology of chemistry. As the semester progressed, the undergraduates adjusted to the speaking patterns of their teaching assistants.

Though pronunciation was cited as being important for communication, the undergraduates clearly distinguished between the expectations they had for lecture-style delivery of information and the interactive communication patterns in the hands-on lab portion of the lab where question-answer interactions were the priority when carrying out the experiments. In brief, the undergraduates thought that precise pronunciation of their teaching assistants was more important in the lecture-style delivery of information than in the question-answer based interactions in the labs. As a couple of undergraduates pointed out, pronunciation is always important but it is not as much of an issue, i.e., barrier to successful communication, when communicating with the teaching assistants in question-and-answer interactions during the labs.

Many of the undergraduates also expressed the opinion that the pre-lab review, the lecture-style delivery of information by the teaching assistants at the beginning of the lab, was not really necessary or helpful. They felt satisfied with the pre-lab lecture given by the faculty member and thought that having the teaching assistants provide another summary was too repetitive. The undergraduates felt that the pre-lab lecture was sufficient preparation, and they did not think that it was necessary to listen to the teaching assistants cover the same points again. Once the undergraduates were in the laboratories, they were eager to begin the work of the experiments: engaging in the hands-on experience of the lab and asking questions. 
For the undergraduates in the chemistry lab, the successful interactions centered on the teaching assistant's ability to respond to their questions. From the undergraduates' perspective, it was crucial that the teaching assistant understood their questions, and even more importantly that the teaching assistant understood what the undergraduates were doing or trying to do. Undergraduates noted that in many instances when they approached the teaching assistant, they themselves knew that something was wrong or that something was not working, but they were not quite sure what was wrong or how to approach resolving the problem. The undergraduates needed the teaching assistant to understand their situations in order for successful communication and problem resolution to occur. For the undergraduates, teaching assistant understanding of their questions and needs, i.e., comprehending their situation, was vital to the successful interactions and communication. Undergraduates gauged the teaching assistant's comprehension of their problems from the responses the teaching assistant provided.

The second theme that emerged from the undergraduates' interview comments related to the trust and comfort they felt when asking their teaching assistant questions. In all three of the sections, the undergraduates thought the teaching assistants were working with them to communicate successfully. All three teaching assistants had established early on in the semester classroom environments that demonstrated to the undergraduates that they were receptive to questions, that they were patient with the undergraduates when they were asking questions, and that they were supportive and encouraging of undergraduates asking questions.

When undergraduates were conducting the experiments, the simple act of the teaching assistant walking around the lab communicated to the undergraduates that the 
teaching assistant was available and interested in helping the undergraduates. However, the undergraduates had mixed opinions about whether they wanted the teaching assistant to interrupt them with questions. Most undergraduates appreciated that the teaching assistants made themselves available, but the undergraduates did not want to be interrupted from their work by questions from the teaching assistant. The undergraduates wanted to work independently and ask for help when they needed it.

The supportive atmosphere of the labs helped the undergraduates pursue questions. While there were initial concerns from the undergraduates about being able to communicate with their teaching assistant, they all felt that after an initial adjustment period of becoming familiar with their teaching assistant and the teaching assistant's communication style, the undergraduates did not really see language as a barrier to communication, even though they acknowledged that sometimes there were languagerelated differences in communication. The undergraduates indicated that as they worked with the teaching assistant, they were able to work though those differences and did not see these language differences as a distraction. One group of undergraduates indicated that they thought of their teaching assistant as their friend and that the language, i.e., pronunciation, differences were viewed in an accepting way.

The undergraduates felt that it was as much their responsibility to make communication work as it was of their teaching assistant, and they felt comfortable doing so. This undergraduate view supports an observation from the faculty member: successful understanding of the undergraduate's question or problem did not occur at first. It frequently took two tries for the undergraduate and the teaching assistant to understand each other. Sometimes the undergraduates felt that they had to persist to 
have the teaching assistant understand them and that when they did, the teaching assistant understood them. These undergraduates did not view the fact that the teaching assistant did not understand them on the first attempt as particularly problematic. They understand the process of negotiating where they were having problems was part of the communication pattern for asking their questions. The undergraduates persisted because they were comfortable with their teaching assistants and trusted that the teaching assistants were interested in helping them.

Undergraduate comfort with and trust of the teaching assistant was a prominent theme in undergraduate comments. Undergraduates from one of the lab sections commented that other undergraduates in their section were not as comfortable asking the teaching assistant questions. This observation may explain why some undergraduates did not participate in the interview process. An examination of questioning patterns of the undergraduates in the section indicated that all undergraduates asked the teaching assistant questions. Undergraduates who participated in the interviews clearly viewed comfort with and trust in the teaching assistant as important for successful communication. However, interview data from all other undergraduates in the section would be needed to provide a more complete understanding of how undergraduate comfort related to communication with their teaching assistant. As indicated previously, undergraduate interview participation was a limitation of the present study.

The third theme that emerged from the undergraduate comments emphasizes how the teaching assistants responded to undergraduate questions. Successful communication in the chemistry labs included information that was expressed both 
verbally and visually. Undergraduates agreed that the teaching assistants needed to show them what to do with the equipment or in the experiment in order for communication to be successful. The undergraduates greatly appreciated seeing the teaching assistants demonstrate using the equipment and setting up the experiment. For the undergraduates, much of their understanding of the material and learning in the labs depended on the visual information. In many instances, the information that teaching assistants communicated visually was just as important, if not more important, than the verbal information.

While undergraduates commented that the combination of verbal and visual information was important for success, there were instances where the visual information was preferred over the verbal. One undergraduate mentioned that in the demonstrations, the teaching assistant was not depending on "science speak.” As a result, when the teaching assistant was demonstrating how to do something in the lab, the undergraduate did not feel that the teaching assistant was "talking over my head." Teaching assistant demonstrations, i.e., showing the undergraduates what to do, was essential for successful communication in the chemistry labs for these undergraduates.

For the interactions in the labs that were classified as partially successful, one theme emerged with great consistency: the undergraduates wanted more elaboration. Interestingly, this is one of the major comments that the faculty member also suggested would improve communication. In some situations where the teaching assistants demonstrated what the undergraduates needed to do, they did not provide, from the undergraduates' perspective, a sufficient amount of verbal information for the undergraduates. Undergraduates also wanted the teaching assistant to articulate for them 
why what the undergraduates were doing incorrectly was incorrect. Furthermore, undergraduates wanted the teaching assistant to articulate what the undergraduates were doing correctly, and state why it was correct.

Working together in lab pairs allowed the undergraduates to talk about and solve problems in the labs together. The undergraduates agreed that working with partners was a positive aspect of the lab experience. They appreciated trying to resolve their issues and concerns together, but when they could not resolve problems, they went to the teaching assistant for help. This allowed the undergraduates the opportunity to clarify what they understood and what they did not. However, when the undergraduates approached the teaching assistants with problems and questions, they were not always confident that they knew what the problem was or even how to express it. If the teaching assistants articulated the problem, i.e., demonstrated how to verbally express the information, the undergraduates would have been more satisfied with the interaction.

Undergraduates were also worried about making mistakes. They expressed concerns about needing to identify the types of problems that were significant and those that were more trivial. One undergraduate commented that when the teaching assistant responded with "yeah or sure, like it was no big deal," she still worried because she did not know if it was important or not. For the teaching assistant to follow-up with a little more information would have helped this undergraduate develop a deeper understanding of the priorities of the discipline and contributed to a more successful interaction. 
One undergraduate clearly identified the conflict she often felt when communicating with the teaching assistants and faculty member of the course. She identified that the instructional staff assumed that the undergraduates were familiar with the equipment and apparatus of the labs, but in fact, since the undergraduates had not had experience in the labs before, they did not know how to work with or handle the equipment and materials. While the lab materials provided pictures and explanations of what to do, this undergraduate felt that in the labs she needed more help transferring the lab manual information to the hands-on work. Having the teaching assistants and other instructional staff demonstrate and express information simultaneously was important. As this undergraduate was developing her skills in the chemistry lab, she wanted verbal information about what she "was doing right or doing wrong" to accompany demonstrations. 


\section{Interaction Analysis}

The final phase of this research project is an analysis of interactions reviewed in the semi-structured interviews. These interactions were selected for analysis because the participants had identified which interactions were successful and had described what facilitated and what limited communication in them. Interactions analyzed in this section are classified as either successful or partially successful. No interactions could be classified as unsuccessful.

As discussed the previous section, the interview process yielded 50 undergraduate-initiated interactions, of which 28 were rated as successful by all three participants in the interactions. The remaining 22 interactions were classified as partially successful. In the partially successful interactions, at least one of the participants rated the interaction as successful and at least one participant rated it with an insufficient degree of certainty as to whether or not the interaction was successful. As a consequence, these interactions could not be categorized as unsuccessful and were classified as partially successful. Because the partially successful interactions exhibit some degree of success, they have been included in the interactions analyzed here. For clarity, interactions discussed below are always identified by the success category to which they belong, with further explanation about participants' views of the interactions included when appropriate.

\section{Approach to Analysis}

\section{Transcriptions}

The participant comments and perspectives obtained in the interview process guided the direction of interaction analysis and the selection of a theoretical framework 
with which to approach analysis. Interview interactions were first transcribed using “normal orthographic conventions” (Brown \& Yule, 1982, p. 9). That is, dialogue of the speakers was transcribed as the words that were spoken, with common reductions such as "cuz" for "because” indicated when used by the speakers. More detailed phonological features of spoken English, e. g., phonetic transcription or intonation contours, were not added to the transcriptions at this point because in the interview process participants did not identify that these features were related to the success of the interactions. Though the teaching assistants spoke with varying degrees of nonnative accent, in the question-and-answer interactions of the lab sessions the teaching assistants were comprehensible and intelligible to the undergraduates.

Interview comments from all participants indicated that the coordination of visual and verbal channels of communication contributed to successful communication. However, the digital recordings of communication in the labs presented some limitations to reliably coding the transcripts for non-verbal or visual information. In 6 of the 15 lab sessions only audio information was recorded, and although 9 of the 15 lab sessions had video information recorded, the visual data was limited. In the labs, safety procedures had to be observed at all times, requiring the video camera to be stationed in one of two locations. This restriction limited the consistency with which the images were captured and as a result consistent visual information for many interview interactions was not available for inspection. As a result, no additional refinements could be consistently and reliably made in the transcripts for non-verbal or visual aspects of the communication. This is a limitation of this study, but an important area for future investigations. 
Interview data from the participants indicated that comfort and rapport with their teaching assistants contributed to the success of the interactions. However, many of the characteristics of the teaching assistant-undergraduate relationship were established at the beginning of the semester, before recording of the lab sessions occurred. Further, with the limitations of image documentation in the digital recordings of the interactions, these features could not be explored with sufficient reliability either. A research study investigating participant rapport would need a different methodological approach, with interactions documented much earlier in the semester and all types of undergraduate-teaching assistant interactions monitored, including office hours.

The third theme in the undergraduates' interview comments indicated that teaching assistant understanding of undergraduate questions (and situations) contributed to successful communication, even though the faculty member observed that frequently it took the undergraduate and the teaching assistant two attempts to reach mutual understanding of the questions being asked. The receptive skills of listening comprehension have been mentioned in the literature as "important for ITA effectiveness,” (Hoekje \& Williams, 1992, p. 252). However, the research literature of in-context interactive classroom communication involving international teaching assistants and undergraduates (Myers, 1994; Tanner, 1991; Williams et al., 1997) has looked only at the ways that teaching assistants use questions for instructional purposes and has not examined undergraduate-initiated questions or how teaching assistants understand and respond to undergraduate questions. As Rounds (1994) identifies "viewing classroom interactivity 
from the point of view of students' questions is by and large uncharted territory” (p. 105).

The undergraduate participants' in this study identified that teaching assistant comprehension of their questions is important for successful communication. The lack of research in the area of teaching assistant understanding and listening comprehension of undergraduate questions points to the need to understand this aspect of communication between undergraduates and their teaching assistants. Thus, the interactions in this study are examined using a theoretical framework related to second language listening comprehension as an approach to understanding successful communication between these two populations. For this type of analysis, the normal orthographic transcripts, which document what the participants say without phonetic transcription, were sufficient, and no additional refinements were made to them. (See Appendix $\mathrm{J}$ for the transcription key to example interactions.)

\section{Theoretical Framework}

Research in listening comprehension involving non-native speakers of English in academic environments has centered on academic lectures (Flowerdew, 1994); the function of language and communication in these contexts is transactional, where "the speaker has primarily in mind the efficient transfer of information” (Brown \& Yule, 1983, p. 2). The question-and-answer interactions of the chemistry lab have a transactional function, but unlike the monologue of a chemistry lecture, interactive communication in the labs is less formal and more spontaneous communication. The question-and-answer interactions in the chemistry labs are carried out in one-on-one 
interactions more closely structured like casual conversation, where the speakers alternate turns.

Flowerdew and Miller (2005) discuss that conversational listening in the context of spoken conversations differs in substantial ways from the monologue typical of an academic lecture and "is a social activity requiring that both speaker and hearer affect the message and how it is interpreted” (p. 52). In the labs, both the teaching assistants and the undergraduates can originate and guide the direction of the interactions and either can be the initiator (speaker) or the responder (listener). Flowerdew and Miller further identify the complexity of the distinctions between listeners and speakers in analyzing conversation in that both participants can take on both roles of speaker and listener in the course of the conversation.

The three major stages of conversation that Flowerdew and Miller (2005) identify as deserving attention for conversational listeners are openings, closings, and topics. In openings, the role of the listener is to respond to the summons of the initiator of the conversation. In this way, the listener's response guides the direction the conversation takes. Closings are also important in conversations, as the listener (responder) needs to recognize when the speaker (initiator) is ready to close the conversation. Finally, topics are the core of the conversational exchange, and the listener has a role in influencing the conversation, for example, moving the conversation from one topic to another, topic shift.

In addition to these three primary landmarks of conversation where listener influence is evident, Flowerdew and Miller (2005) identify other features of conversations that are listener activities. Some features are related to the structure of 
the conversation, such as turn-taking, recognizing and employing the boundaries of spoken turns and switch in conversational roles. Other listener activities are internal to the communicative exchange and are related to the way the exchange unfolds: backchanneling, verbal and non-verbal signals from the listener that they are attending; reformulation, clarifying that the listener understands; repair, correcting misunderstandings and negotiating meaning, and exploiting ambiguity. In this project Flowerdew and Miller’s framework for conversational listening guided the analysis of undergraduate-initiated interactions and provided the basic approach for understanding successful communication between international teaching assistants and the undergraduates in their sections.

Speaking Styles

Analysis of lab communication from earlier in this chapter pointed to the possibility that there were differences in communication patterns of the three lab sections. For example, the Wednesday section had more frequent interactions. The Tuesday section had a tendency for shorter interactions. The Thursday section had fewer, but longer interactions. These findings indicate the possibility that the undergraduates and the teaching assistants in the three sections had established different styles of speaking or interacting. The first level of interaction analysis was to determine if successful interactions occurred with greater frequency in any of the three lab sections, which would provide a starting point for interaction analysis. The question was to see if successful interactions were in some way connected with a particular teaching assistant or a particular section of undergraduates. If so, then 
aspects of the speaking styles of those undergraduates and teaching assistants could provide a focus for analysis of what features contribute to successful communication.

Because the Wednesday section provided only a small percentage of the total number of interview interactions (10\%) and those interactions were from one lab early in the semester with two undergraduates who were lab partners, data from this section was limited and successful communication may have been the result of idiosyncrasies of the undergraduate participants. The Tuesday and Thursday sections had a greater number of undergraduate participants and more interactions to examine. Therefore, these two sections were compared to see if speaking styles might be associated with successful interactions.

Analysis of the two sections (see Table 38) revealed that numerically successful interactions occurred more often in the Tuesday section $(n=18)$ than in the Thursday section $(n=9)$ and there were more partially successful interactions in the Thursday section ( $n=11)$ than in the Tuesday section $(n=7)$. Proportionally, $72 \%$ of the Tuesday interactions were successful and $28 \%$ were partially successful. For the Thursday section, $45 \%$ of the interactions were successful and $55 \%$ were partially successful. However, chi-square analysis of the interactions based on success type for the Tuesday and Thursday sections revealed that there was no statistical significance of whether a successful interaction was likely to occur in one section over another, $\chi^{2}(1$, $N=45)=3.38, p=0.0662$. However, this result indicates trend-level significance. With this finding, analysis of the interactions proceeded to examine structural features of the interactions, using all of the interview interactions. 
Table 38

Distribution of Successful and Partially Successful Interactions in the Tuesday and Thursday Sections

\begin{tabular}{rccc} 
& \multicolumn{2}{c}{ Section } & \multirow{2}{*}{ Total } \\
\cline { 2 - 3 } Interactions & Tuesday & Thursday & 18 \\
Fuccessful & 18 & 9 & $60 \%$ \\
Percentage & $72 \%$ & $45 \%$ & 18 \\
Frequency & 7 & 11 & $40 \%$ \\
Percentage & $28 \%$ & $55 \%$ & 45 \\
\hline Partially Successful & 25 & 20 & \\
\hline Totals & & & \\
\hline
\end{tabular}

Conversational Listening

\section{Turn Taking}

Interactions in the labs are usually not simple two-turn communicative exchanges of one question followed by one answer. Contrary to some observations about classroom communication being short exchanges involving initiation-replyevaluation/feedback (Mehan, 1985), in this setting, the majority of interactions were made up of a more complex series of questions and answers, with two-turn communicative exchanges in the minority. In the 50 interview interactions, only two (4\%) were two-turn sequences. The average number of turns for all 50 interview interactions was 11 turns, the median 10 turns, and the mode 7 turns. Examining interactions by the success categories, the successful interactions on average had fewer 
turns, averaging 10 turns, than the partially successful interactions, which averaged 13 turns. In general, the partially successful interactions demonstrated a slightly wider range in the number of turns required for interaction completion, from 4 to 42 turns. The successful interactions demonstrated a range that was slightly narrower, 2 to 33 turns. As a general rule, participants in the interactions alternated turns, as demonstrated in Example 1 with 10 turns.

\section{Example 1: 5 Th 11 Successful}

UG And do we need to elevate them?

TA Elevate?

UG Yeah like

TA Oh, uh. No it's better clamp it

UG This one?

TA Clamp, yeah.

UG Just so it doesn't move.

UG2 Yeah, cuz it was falling.

TA Yeah, and this one too.

UG We'll probably need another one.

In Example 1, the undergraduate (UG) initiates and concludes the interaction, and has a total of five speaking turns. The teaching assistant (TA) has four turns, which alternate between the undergraduate's turns. In this example, a pair of undergraduates 
are working together, and the second undergraduate (UG2) is following along with the conversation, interjecting an observation for an additional undergraduate speaking turn.

The majority of interactions followed the pattern for turn taking as shown in Example 1. However, there were instances for which using the notion of turn to examine and describe interactions proved to be slightly problematic in this setting, as Example 2 illustrates. Example 2 was classified as partially successful, but was identified as successful by both the undergraduate and the faculty member. The teaching assistant rated the interaction as neutral, commenting that her response included too many hesitations and delays, and she wished that it were more fluently expressed.

\section{Example 2: 4 Th 29 Partially Successful}

UG Well, I don't know I'm having trouble.

TA Hold this down. The tips to the... ahh... This is... Yeah, You adjust the height of the burette and then put the tips into the uhh...uhhh.

UG Student carries out instruction.

TA A little lower.

UG Student carries out instruction.

TA Yeah. Now press the bottle and let it go. The solution will go up.

UG Student carries out instruction.

TA Yeah. Now you can close this.

UG Close this?

TA Yeah, this one is closed when it is vertical. 
UG So, it's closed.

TA Yeah, Yeah.

In this interaction of 12 turns, the undergraduate and teaching assistant alternate speaking turns with six turns each. However, for the undergraduate's participation in the interaction, three of the six turns do not include language. The undergraduate comprehends and carries out the instructions of the teaching assistant. When the undergraduate has carried out the teaching assistant's instruction, the teaching assistant sees that the undergraduate has completed his turn, and appropriately adds her next spoken turn. As the interaction progresses, the undergraduate coordinates his language and his actions, and his turns become speaking turns.

In Example 2, the undergraduate completes some turns with an action and in other turns combines language and an action together. The turns in which the undergraduate carries out the instruction of the teaching assistant are technically not speaking or conversational turns because they do not include spoken language. However, they are functioning in the same way that spoken turns do. As demonstrated in Example 2, defining a turn as a speaking event exclusively is not adequate or appropriate in this setting. The participants are clearly taking turns in the interaction, with the same fluidity of well coordinated turns of conversation. Sometimes, the turns are completely verbal. Sometimes, the turns are the actions carried out by the undergraduate and monitored by the teaching assistant. Finally, the turns can be a coordinated event that is a verbal expression accompanied with a physical or gestural action. The physical action or activity of the turn is monitored visually in the same 
way that a verbal turn is monitored auditorily. In other words, the teaching assistant depends on both what she sees and what she hears in order to respond appropriately to the undergraduate.

Example 2 and others like it challenge us to see communication in the labs as more than just verbal communication. While language is an important part of the interaction and communication, the visual and gestural information also contributes substantially to the interaction. The interaction is a coordination of two channels of communicated information: verbal and visual. For this interaction, both of the native English speaking participants, the undergraduate and the faculty member, agreed that this was a successful interaction, which supports the importance of the visual information contributing significantly to the success of the interaction. The teaching assistant, who was the non-native speaker, was neutral about the success of the interaction for reasons related to her abilities with spoken English, her self-identified hesitancy and perceived lack of fluent speaking, on which the native speakers did not comment.

\section{Opening Interactions}

Flowerdew and Miller (2005) identify that conversation openings are one of the three main stages of an interaction, one in which the listener's role can decide the direction of the conversation by the way the listener responds to the summons (p. 53). In the interview interactions, the undergraduates initiated the interaction and opened the interactions by either calling out the teaching assistant's name or using some vocalization to indicate that they were opening an interaction. When using a teaching

assistant's name to open an interaction, a common pattern was for the undergraduate to 
say the teaching assistant's name, the teaching assistant would respond verbally or vocally with "yeah"or "uhm," indicating that the opening summons was successful, and the undergraduate would proceed to ask the question. In some cases the undergraduate would address the teaching assistant directly and begin the question before the teaching assistant could respond. Example 3 and Example 4 demonstrate the pattern of undergraduates using direct address to begin an interaction.

Example 3: From Interaction from 4 Th 5 Partially Successful

UG "Thursday teaching assistant's name."

TA Uhm.

UG Where do we get the two grams of borax? Is it in the back?

Example 4: From Interaction from 8 T 45 Successful

UG “Tuesday teaching assistant’s name.”

TA Yep.

UG Ah, what do we do if all the thermometers are giving us different readings?

In 15 of the 50 interactions ( 10 successful and 5 partially successful), the undergraduates used a teaching assistant's name, to open the interaction. In 28 of the 50 interactions (18 successful, 10 partially successful), undergraduates used either the teaching assistant’s name or a vocalization, such as “uhm.” When undergraduates spoke the teaching assistants' names, they did so with confidence and without hesitation, even though the names were Chinese names. 
Obtaining the teaching assistant’s attention by direct address or a vocalization was a common pattern that appeared in interview interactions. However, it should be noted that in one interview with an undergraduate, the undergraduate commented that it was apparent on the video how comfortable he was with his teaching assistant by the fact that he did not need to use the teaching assistant's name when he asked his teaching assistant a question. His comfort with the teaching assistant was demonstrated by the fact that he just asked the question with no direct address used to get the teaching assistant's attention. For this undergraduate, there was no need to open the interaction because he was comfortable enough and trusted that in the lab the conversation was already open with this teaching assistant. The undergraduate opened the interaction with his question, the topic to be discussed.

Other undergraduates employed this same pattern to open the interaction. In the interactions where the undergraduate did not use direct address or "uhm," the undergraduate just asked the question, going directly to the topic of the interaction. In two instances, both partially successful, the undergraduates initiated an interaction by using an explicit statement of the intention to ask a question. The overt signaling of the undergraduate questions used discourse marking (Williams, 1992), such as "I have a question” or “my second question is.” However, when undergraduates did not use direct address, the typical undergraduate approach was simply to ask the question. Undergraduates opened interactions directly with their questions in 22 interactions (10 successful and 12 partially successful). Examples of how questions are expressed will be discussed later in the section related to interaction topics. 


\section{Closing Interactions}

Just as there were common ways of opening the interactions, there were common patterns of how the interactions were closed. In the majority of interactions, the communicative exchange is concluded with one of the participants verbalizing or vocalizing some type of conclusion. Often the teaching assistants provided the final verbal or vocal signal of approval; however, in many instances the teaching assistant provides some type of confirmation and the undergraduate follows with a confirmation that the interaction is complete. In 32 interactions (19 successful and 13 partially successful) out of the 50 interactions, the teaching assistants spoke the final confirmation, usually “yeah,” “uh hum,” or the one negative response, “I don’t think so.” In 18 interactions (9 successful and 9 partially successful), the undergraduates closed the interaction with “okay," "thank you,” alright," “good idea,” and in a few instances a statement indicating the next action to be carried out. Examples 5 and 6 illustrate how teaching assistants closed the interactions.

\section{Example 5: From Interaction 5 T 48 Successful}

UG Should we dump it out or it can stay there?

TA It can stay there. Yeah, yeah.

\section{Example 6: From Interaction 4 W 38 Partially Successful}

UG How much is enough?

TA Maybe 5, 5 grams. 5 grams, yeah. 
In Example 5 and 6, the undergraduates ask final questions; the teaching assistants answer the questions and conclude with "yeah.” In the first example, there was unanimous agreement that the interaction was successful. The second example was classified as partially successful. In this example, the teaching assistant and the faculty member rated the interaction as successful. The undergraduate rated the interaction with an indefinite degree of certainty. She felt that the teaching assistant's response was slightly vague, and she thought that more elaboration in the response would have helped to make the interaction more successful. Examples 7 and 8 demonstrate undergraduate turns that close the interactions.

\section{Example 7: From Interaction 5 Th 6 Successful}

UG The filtrate's going in here, so but it won't be like won't have any gas coming out, so it'll be ok?

TA Uhm, Yeah.

UG Okay.

Example 8: From Interaction 4 T 51 Partially Successful

UG It's broken. Should we get another one?

TA Yeah, get another one.

UG Okay.

Examples 7 and 8 illustrate the pattern of undergraduates closing the interactions. The undergraduates state an observation about some aspect of the 
experiment and then ask a final question. The teaching assistants respond to the questions, and the undergraduates follow up with "Okay" to signal the end of the interaction. In Example 7, all participants rated the interaction as successful.

The interaction in Example 8, was partially successful. This interaction, lasting for 1 minute and 56 seconds, involved the teaching assistant working with the undergraduate to figure out what was not working in the set-up of the apparatus. The teaching assistant was the only participant who rated the interaction as successful. The undergraduate and the faculty member both rated the interaction with insufficient degrees of certainty. The faculty member's comments related to issues of both the undergraduate's and the teaching assistant's performance. The undergraduate expressed a desire for more elaboration. In her words, "when the teaching assistant says 'yeah,' 'okay,' and ‘sure,' it comes off casually, like it's no big deal.” However, she indicated that the undergraduates "worry about what's important and what isn't." From her perspective, more elaboration is always important.

\section{Interaction Topic}

After interactions were examined for features related to the turn taking, openings and closings, the interactions were examined for Flowerdew and Miller's (2005) third major component of conversation: topic. Analysis of interaction topic was approached on two levels. The first examined the syntactic form undergraduates used to identify the topic, focusing on the first question undergraduates expressed in an interaction. The second examined what undergraduate questions were about, using the categories established earlier in this project of activity type of the interaction: equipment, lab preparation, materials, procedures, safety, and social. 


\section{Phrasing of Undergraduate Questions}

A survey of interview interactions identified typical question patterns that undergraduates used when expressing their initial question in the interaction: whquestions, yes/no questions, questions with alternatives signaled by or, a brief statement of the problem, and a statement of the situation followed by a question. An initial undergraduate question in an interaction may also consist of a combination of these question forms. While the focus of this analysis was on the first question in the interaction, usually initiated in the first undergraduate turn, these patterns of question forms reappeared in other parts of the interactions as well.

Syntactic forms. In all of the initial questions asked by the undergraduates, 40 out of the 50 were stated in one complete, syntactically well-formed turn (22 of the successful interactions and 18 of the partially successful). These questions were expressed as grammatically complete questions. In the remaining 10 interactions (6 successful and 4 partially successful) the undergraduate expressed a part of the question. At a pausing point the teaching assistant provided a back channel cue, a vocalization acknowledging he or she was following the question. The undergraduate completed the question in the undergraduate's next turn. There were also a few instances where the undergraduate asked two related questions in the first turn. The examples below, Examples 9-13, illustrate the principal ways undergraduates asked the initial question in the interview interactions, in both the successful and partially successful interactions. 


\section{Example 9: Wh-questions}

UG How much $\mathrm{NaOH}$ and $\mathrm{HCl}$ should we pick up? (Successful $7 \mathrm{~T}$ 26)

UG Uh...How do we do this? Just put it here? (Partially Successful 4 Th 26)

Example 10: $\underline{\text { Yes/No questions }}$

UG Is that the right way to set it up? (Successful 5 Th 7)

UG Is this a Hirsch funnel? (Partially Successful 6 Th 34)

Example 11: Question with alternatives signaled by or

UG Do we actually have to clamp this in or can I just put it in so it rests on the bottom? (Successful 7 T 39)

UG Is that good enough or do we have to put iodine in? (Partially Successful 8 T 19)

Example 12: $\underline{\text { Statement of a problem }}$

UG It still isn't working. (Successful 7 T 65)

UG It won't go out. (Partially Successful 4 T 51)

Example 13: Statement of a situation followed by a question

UG Um... On the actual bottle it says .019 molarity. Is that okay for the $\mathrm{NaOH}$ ? (Successful 7 Th 66)

UG When I measure the $\mathrm{pH}$ of the seawater and it's not 8.2, do I adjust it to 8.2 or do I leave it like that? (Partially Successful 7 T 64) 


\section{Lexical choices and ambiguity. From a survey of the syntactic forms}

undergraduates use to express the topics of the interactions, it becomes evident that in addition to the variety of syntactic structures that undergraduates use to identify the topic, they also use a range of lexical choices when expressing the topic. Some questions are clearly, completely, and precisely expressed, with little chance for misinterpretation because the undergraduates are using precise terminology. In other words, some questions are relatively unambiguous. However, in other questions undergraduates are using less precise, less specific lexical choices. These questions allow for multiple interpretations and are ambiguous. For example, the uses of the pronoun it in the statements of Example 12 are ambiguous. To respond to these questions, both interlocutors need to agree on what "it" refers to. These examples require additional information for the teaching assistant, i.e., the listener, to accurately interpret the undergraduate’s question.

This observation reinforces the faculty member's remarks during the interview process, in which she described some interactions as being "information dense." The information dense undergraduate questions were concisely and unambiguously expressed, which made interpreting and responding to them fairly straightforward, even for someone not engaged in the interactions. There were other interactions that were unclear, ones the faculty member could not rate because the question did not provide sufficient information for unequivocal interpretation. To interpret and understand what was happening in the interaction, she needed additional information. Even for the faculty member teaching the course, when reviewing an interaction from the course, she identified that some undergraduate interactions were stated clearly, 
concisely, and unambiguously, while other interactions were ambiguous, and she could not, with reasonable certainty, interpret the question or understand the interaction, and could therefore not respond. Examples 14 and 15 illustrate two types of undergraduate questions expressed with the different lexical choices.

Example 14: Information dense and unambiguous

UG “Wednesday teaching assistant's name,” do you know how much solid sodium borate we're supposed to put in this thing to heat over the Bunsen flame? (Partially Successful, 4 W 38)

Example 15: $\underline{\text { Context dependent and ambiguous }}$

UG “Thursday teaching assistant's name,” Should I pour this in there? (Successful, 5 Th 8)

Examples 14 and 15 demonstrate the range of lexical specificity with which the undergraduates asked the initial questions in the interactions. The faculty member identified the question in Example 14 as an "information dense question," which was unambiguous and easily interpreted. In Example 15, the faculty member had difficulty interpreting and reconstructing what was happening in the interaction. The second example is ambiguous and can only be understood when additional information is supplied.

In Example 14, the undergraduate clearly specifies what her needs are: quantity of sodium borate to place in a container for heating. While the use of "this thing" for 
the container is ambiguous and requires that the teaching assistant see what the undergraduate is referring to, the majority of the question is explicitly and concisely expressed. In Example 15, the undergraduate uses a precise verb pour, but the use of "this," "in,” and "there” cannot be interpreted unless additional information is provided.

In Example 15, the undergraduate's lexical choices of “this" and "there” are ambiguous and are examples of what is called deixis or deictic forms. Deictic forms can refer to time (now or then) to locations (here or there) to objects (this, that, these, those), and to people (him, her) or things (it) and are part of the referential system of English in which the function of the word is to refer the listener to some other part of the text (spoken or written) or to some contextual aspect for interpretation (Brown \& Yule, 1983, p. 50).

Halliday \& Hasan (1976) identify that these “co-referential forms” (p. 31), such as this or that, are forms that instead of being interpreted semantically on their own make reference to something else for interpretation. Exploring the concept of deictic reference in greater detail, they identify that deictic forms can be classified in one of two ways, both of which require the retrieval of information from elsewhere to interpret the information expressed: endophoric (or textual), in which the deictic form refers to something identified in a spoken or written text and exophoric (or situational), in which reference must be made to the context of the situation (p. 33). While in some instances deictic pronouns and deictic reference may have interpretations embedded in a text, for example a previous utterance, they may also have no possible interpretation without a physical object provided in the context, in which case they are exophoric 
reference. This type of language and usage is “context-bound language” (Halliday \& Hasan, 1976, p. 35).

Examples 14 and 15 illustrate a range of lexical choices that undergraduates make to express questions: sometimes their questions are explicitly expressed with precise control of vocabulary and key terminology from the discipline, and at other times the questions are expressed with ambiguity, depending on deictic reference, which creates a syntactically complete but ambiguous question that needs to be interpreted before it can be responded to. Both examples occur in the context of the lab and require certain contextual information for the teaching assistant to respond: the teaching assistant needs to know which step in the procedure of a given lab the undergraduate is working on.

In Example 14, identified by the faculty member as being "information dense," the undergraduate provides sufficient contextual detail using specific noun forms and clearly identifies that she is asking the teaching assistant to provide her with a response that includes a quantity. As long as the undergraduate and the teaching assistant mutually understand what part of the experiment the undergraduate is working on, the question can essentially stand on its own. It can be answered without information external to the verbal information. With the exception of the undergraduate's use of "this thing" for the container she is using, the undergraduate articulates precisely what information she needs.

The question in Example 15, while syntactically well-formed and complete, can only be understood and responded to with information external to the linguistic information. The ambiguity in this example comes from what the undergraduate means 
when she uses the forms "this" and "there.” The undergraduate substitutes the demonstrative pronoun this for the full noun form. Because this is the initial question in the interaction, the meaning of "this" cannot be recovered from previously expressed textual information and is an example of exophoric or situational reference. The meaning of "this" must be recovered from environmental information. Similarly, the place adverb there substitutes for the more complete identifier of the place the undergraduate refers to. However, the referent has not been established in a previous verbal turn. The meaning of "there" can only be determined with additional information from the physical environment. In this instance, the question is bound to the context and can only be interpreted with information supplied from the context. In Example 15, the teaching assistant must depend on the visual information that accompanies the verbal information presented by the undergraduate's question in order to disambiguate what is being expressed and complete the interaction with an appropriate reply. The meaning of this undergraduate question is completely embedded in the context and can only be interpreted with additional information provided by the context.

In the Example 14, the teaching assistant and the faculty member both rated the interaction as successful. The faculty member commented that the undergraduate "asked a great question,” and the information that she was requesting was information that had been omitted from the lab manual. The undergraduate rated this interaction with an insufficient degree of certainty. She thought that this interaction could be improved if the teaching assistant had elaborated more in the response. This undergraduate wanted to receive a response that also "information dense," one that 
included information framed as a scientific discourse (Gee, 2005). Example 15, which was ambiguous, was rated as successful by all three participants.

Contrary to what might be expected, the question that is explicitly and completely expressed and essentially unambiguous, Example 14, was only partially successful, while the question that was ambiguously expressed, Example 15, ended up being a successful interaction. This observation that a precisely and relatively unambiguously expressed question would evolve into an interaction that was partially successful while a completely ambiguous and contextually based question would develop into a successful interaction is important to understanding successful communication in the chemistry labs. Teaching assistants need to disambiguate undergraduate questions, which can be expressed using exophoric reference and which depend on the physical resources of the chemistry lab for their meaning. To do this, teaching assistants must simultaneously interpret what the undergraduates express verbally and interpret visually information from the environment. The physical resources of the labs and the verbal expressions are coordinated for successful communication to occur.

In Example 15, in order for the teaching assistant to disambiguate the question, she needed to simultaneously see and comprehend the visual information that was present in the communicative exchange and hear and understand what was being expressed verbally. Both the verbal and the visual information needed to be integrated for the teaching assistant to understand the question and then respond to it in a meaningful way, which in this situation led to a successful interaction for the undergraduate, as well as for the teaching assistant and the faculty member. At this 
point, it became apparent that the successfulness of the communicative exchanges in this setting are dependent on aspects of communication and interaction that extend beyond what is said, the purely linguistic considerations.

The physical context and objects in the real world provide information that is essential for deriving meaning from what the undergraduates are expressing. As Lynch (1994) identifies, elements beyond the text are important in determining the listener's degree of success in understanding the speaker's meaning (p. 270). The visual information is not just redundant information. The verbal and the visual information are coordinated to provide the meaning of the questions that the undergraduates pose to their teaching assistants and to which the teaching assistants must respond. As the undergraduate in an interview deftly and succinctly expressed, "the teaching assistant understood my situation, not just my question.”

This undergraduate provided key information to understanding successful communication in the chemistry labs. Successful communication requires that the teaching assistants be able to go beyond the verbal information undergraduates provide. For the teaching assistants to understand the questions and respond appropriately, they must be able to make sense of the undergraduates' questions and accompanying physical circumstances. Undergraduates' use of deictic reference and deictic pronouns create ambiguity that can only be resolved by combining both the linguistic and the contextual information in this real-world setting. Meanings are not derived exclusively from verbal expressions or from contextual information observed through visual inspection. Both visual and verbal information are necessary and must be synthesized and interpreted for interactions in the lab to be successful. 


\section{Topics of Undergraduate Questions}

Understanding how undergraduate questions that begin an interaction are phrased syntactically and lexically contribute to a teaching assistant's comprehension of the questions. However, teaching assistants also need to understand what types of information the undergraduates are seeking to respond in meaningful ways. The second level of topic analysis of the undergraduate questions looked at what information or types of information the undergraduates were asking about. At this stage of analysis, the complete interactions were reviewed. (See Appendix K for an overview of interview interaction examples used in this discussion of the topic of interactions.)

Earlier in this research project, interactions were categorized based on the types of activities that each interaction discussed. These categories of lab activities were used to examine the interactions for topics of undergraduate questions and interactions. Six activity categories were observed in the first hour of the chemistry labs: equipment, lab preparation, materials, procedures, safety, and social. In the subset of interview interactions, there were no interactions that were categorized as safety or social activities. The interview interactions included examples of four categories: procedures (56\%), equipment (26\%), materials (14\%), and lab preparation (4\%). Table 39

provides an overview of the interview interactions by category type and compares their occurrence with all interactions. 
Table 39

Comparison of Frequency and Percentage of Interaction Initiation for Study

Interactions and Interview Interactions by Activity

\begin{tabular}{|c|c|c|c|c|}
\hline \multirow[b]{2}{*}{ Activity } & \multicolumn{4}{|c|}{ Interactions } \\
\hline & $\begin{array}{c}\text { All } \\
\text { Interactions }\end{array}$ & $\begin{array}{l}\text { Teaching } \\
\text { Assistant } \\
\text { Initiated }^{\text {a }} \\
\end{array}$ & $\begin{array}{l}\text { Undergraduate } \\
\text { Initiated }^{\mathrm{a}}\end{array}$ & $\begin{array}{l}\text { Interview } \\
\text { Subset }^{\mathrm{b}}\end{array}$ \\
\hline \multicolumn{5}{|l|}{ Equipment } \\
\hline Frequency & 127 & 27 & 100 & 13 \\
\hline Percentage & $16 \%$ & $20 \%$ & $80 \%$ & $26 \%$ \\
\hline \multicolumn{5}{|l|}{ Lab Preparation } \\
\hline Frequency & 283 & 152 & 125 & 2 \\
\hline Percentage & $35 \%$ & $55 \%$ & $45 \%$ & $4 \%$ \\
\hline \multicolumn{5}{|l|}{ Materials } \\
\hline Frequency & 48 & 9 & 39 & 2 \\
\hline Percentage & $6 \%$ & $19 \%$ & $81 \%$ & $14 \%$ \\
\hline \multicolumn{5}{|l|}{ Procedures } \\
\hline Frequency & 303 & 88 & 215 & 7 \\
\hline Percentage & $38 \%$ & $29 \%$ & $71 \%$ & $56 \%$ \\
\hline \multicolumn{5}{|l|}{ Safety } \\
\hline Frequency & 24 & 20 & 4 & Not Represented \\
\hline Percentage & $3 \%$ & $83 \%$ & $17 \%$ & -- \\
\hline \multicolumn{5}{|l|}{ Social } \\
\hline Frequency & $18^{\mathrm{C}}$ & 9 & 8 & Not Represented \\
\hline Percentage & $2 \%$ & $53 \%$ & $47 \%$ & -- \\
\hline Totals & 803 & 305 & 491 & 50 \\
\hline
\end{tabular}

${ }^{a}$ Percentages of interaction initiated by the teaching assistants and the undergraduates are for within each activity type. That is, for equipment, $20 \%$ were initiated by the teaching assistant and $80 \%$ were initiated by the undergraduates.

${ }^{\mathrm{b}}$ All interview interactions were initiated by undergraduates.

${ }^{\mathrm{c}}$ One social interaction was initiated by the faculty member. 
Table 40 below provides the frequencies and percentages of the success categories for the activity topics of the interview interaction subsets. In the subset of interview interactions, the proportion of successful interactions occurring in the activities of equipment (77\%) and materials (71\%) was higher than for the procedure types (46\%). The interactions related to lab preparation in the interview interactions subset were only partially successful.

Table 40

Frequency and Percentage of Successful and Partially Successful Interview Interactions by Activity

\begin{tabular}{|c|c|c|c|}
\hline \multirow[b]{2}{*}{ Activity } & \multicolumn{2}{|c|}{ Interview Interactions } & \multirow[b]{2}{*}{ Total } \\
\hline & Successful & $\begin{array}{c}\text { Partially } \\
\text { Successful }\end{array}$ & \\
\hline \multicolumn{4}{|l|}{ Lab Preparation } \\
\hline Frequency & -- & 2 & 2 \\
\hline Row Percentage & -- & $100 \%$ & \\
\hline Column Percentage & -- & $9 \%$ & $4 \%$ \\
\hline \multicolumn{4}{|l|}{ Equipment } \\
\hline Frequency & 10 & 3 & 13 \\
\hline Row Percentage & $77 \%$ & $23 \%$ & \\
\hline Column Percentage & $36 \%$ & $14 \%$ & $46 \%$ \\
\hline \multicolumn{4}{|l|}{ Material } \\
\hline Frequency & 5 & 2 & 7 \\
\hline Row Percentage & $71 \%$ & $29 \%$ & \\
\hline Column Percentage & $18 \%$ & $9 \%$ & 14 \\
\hline \multicolumn{4}{|l|}{ Procedure } \\
\hline Frequency & 13 & 15 & 28 \\
\hline Row Percentage & $46 \%$ & $54 \%$ & \\
\hline Column Percentage & $28 \%$ & $68 \%$ & $56 \%$ \\
\hline \multicolumn{4}{|l|}{ Total } \\
\hline Frequency & 28 & 22 & 50 \\
\hline Percentage & $56 \%$ & $44 \%$ & \\
\hline
\end{tabular}


Lab preparation. The interactions classified as lab preparation were the fewest in number in this subset of interactions $(n=2)$. The proportion of this type of interaction, 4\%, is smaller than their occurrence in all documented interactions (35\%). As a category, lab preparation interactions were frequently related to assignments from the lab manual, pre-lab questions, and pre-lab quizzes. Lab preparation interactions were related to the activities established by the faculty member of the course to ensure that the undergraduates were provided with a uniform educational experience across all sections and that the undergraduates were prepared to engage in the lab experiment effectively and efficiently. While lab preparation interactions were more likely to be initiated by the teaching assistants (55\%), they were initiated with high frequency (45\%) by the undergraduates. The two interactions from the subset of data interactions categorized as lab preparation consisted of a pre-lab question (Example 16) and a quiz question (Example 17).

\section{Example 16: 8 T 19 Partially Successful}

UG Is that good enough or do we have to put iodine in?

TA I, you can write down that equation. It's a It's a

UG It's [inaudible]. Cuz if you do it with the iodine in it, it cancels out in both sides anyway.

TA That's right.

UG So that's good enough?

TA Yeah, it's good enough. 
In Example 16, the interaction is carried out with well-formed and fairly complete sentences. There is some interruption by the undergraduate of the teaching assistant's first turn. Although the undergraduate’s question is well-formed structurally, it is ambiguous. The undergraduate uses "that" to guide the teaching assistant to the problem the undergraduate is trying to solve on the paper. The teaching assistant is required to attend to the remainder of the question that the undergraduate is expressing verbally, but the teaching assistant must also simultaneously gather from the print material information to make sense of the undergraduate's question, and then respond to it. Even though the undergraduate understood the response, he wanted more explanation to develop a fuller understanding of why his answer on this quiz item was sufficiently accurate. The undergraduate reported that he was hesitant to ask the question initially because he was not sure if the teaching assistant was allowed to answer it.

\section{Example 17: $\underline{8 \text { Th } 5 \text { Partially Successful }}$}

UG Did I understand that question correctly?

TA Uh...You need to change the concentration of the catalyst.

UG Uhum

TA Like...um...uh.

UG Like this one...wait wait wait wait...Like this one compared to this one?

TA No. This the same concentration so.

UG So it's like 4 compared to 7, right?

TA 4 and 7 . But 7 has no catalyst. 
UG um hum

TA So mainly to

UG Which would change the catalyst concentration. Right?

TA make uh double it or half

UG The concentration of the catalyst. You mean the catalyst you add? Like how much you add would change this. Right?

TA Ah, how much you add.

UG It's like I understood that correctly, I think.

TA uh. (Laugh)

In Example 17, the undergraduate is asking a question related to a problem on the pre-lab quiz. The teaching assistant has not had prior access to the quiz questions and has not had the opportunity to think about the problem the undergraduate is asking about. The teaching assistant has to think and respond spontaneously to help the undergraduate. While the first two turns of the interaction are well-formed and syntactically complete, the majority of the dialogue of the interaction is fragmented and incomplete, with the participants thinking through the problem together and building on what the other is saying. They are walking through the problem together, comparing it to other problems in the quiz and working together to express the ideas and reach a conclusion.

In the undergraduate’s first turn, he expresses his question in a structurally correct statement; however, the teaching assistant is required to disambiguate the question. Not only is the undergraduate asking the teaching assistant to judge whether 
the undergraduate understood a quiz question, the teaching assistant has to determine from the context what "that question" refers to, read the question, and understand what the question is asking the undergraduate to do.

In Examples 16 and 17, the undergraduates use the demonstrative pronoun that, which requires the teaching assistants to understand the undergraduates and their questions by using information that only the context can provide. In this case, the context is provided by the written materials that the undergraduates are working with. In Example 17, the deictic form of the demonstrative determiner that guides the teaching assistant to the paper that contains the textual information that the teaching assistant must see and understand prior to responding to the undergraduate’s questions.

Both of the examples from the lab preparation questions illustrate a key point in what undergraduates are asking of their teaching assistants. Both questions are in essence asking for the teaching assistants’ assessment of the undergraduates’ understanding of the material that the undergraduates are learning. As the undergraduates are developing understanding and mastery of the content material, they are seeking advice and confirmation from their teaching assistants as to whether their judgments are accurate and appropriate from a chemist’s perspective.

Both examples illustrate how the undergraduates are developing judgments of how to interpret information, not only the information that they are presented with in the quiz and the pre-lab questions, but also in the responses that they are expected to provide to their instructors. The undergraduates are learning how to prioritize information and what degree of precision is necessary. Further, the undergraduates are learning to compare and relate situations they are confronted with and compare the 
new information with their other experiences: what the similarities are, what the differences are, and what the appropriate application for the current situation is.

These interactions occurred in the classroom area of the labs and relate to conceptual and theoretical understanding, preparation prior to the hands-on lab experience. Neither of these interactions was identified as successful, though the faculty member rated both as successful. In Example 16, the teaching assistant rated it as successful, but the undergraduate indicated that he wanted more elaboration as to “why” what he was doing "was right.” In Example 17, the undergraduate rated it as successful, but the teaching assistant felt that she could have done a better job of walking the undergraduate through the problem. As she acknowledged, she knew the answer, but could not give it directly to the undergraduate, so she worked with the undergraduate by walking him through the problem and how to approach it.

Both interactions ask a similar type of question: the undergraduate is seeking the advice of the teaching assistant on whether the undergraduate understands the material correctly and is approaching the problem appropriately. In both instances, the undergraduates seem to be developing judgments about the material and their understanding of the material. In both questions, the undergraduates present the teaching assistants with questions that are syntactically well formed, but with questions that are ambiguous. That ambiguity is resolved by the teaching assistants using the contextual information from the papers that the undergraduates are working with. These interactions coordinate the verbal exchange and the textual resources that exist in the lab preparation type of interaction. In both cases, the teaching assistants 
disambiguate the undergraduates' questions, but with different degrees of satisfaction for the participants.

Equipment. The next category of interactions based on activities in the lab relates to equipment. Interactions in this group include organizational and instructional activities that pertain to the equipment needed to conduct lab experiments. Equipment includes those items that are standard to each work bench, e.g. hood, vents, gas nozzles, test tubes, flasks, burettes, pipettes, beakers, wash bottles, etc. It also includes electronic equipment that may be unique to a particular experiment, but that chemists use in the process of experimentation, e.g., $\mathrm{pH}$ meter. Out of the 50 interview interactions, 13 were identified as focusing on questions or concerns related to lab equipment (10 successful and 3 partially successful). Of the $16 \%$ of equipment-related interactions of the study interactions, $80 \%$ are initiated by the undergraduates.

A survey of the undergraduate questions related to equipment in the subset of interview interactions found three primary topics. The first type included questions undergraduates had about how to locate or acquire a particular piece of equipment. In these questions the undergraduates knew what they needed; they just did not know where it was or how to find it. The second type of question undergraduates asked related to equipment in the lab were questions in which the undergraduates needed to identify the type or sub-type of equipment they were to use. In these interactions, undergraduates were looking for the appropriate equipment to use or an appropriate substitute. Sometimes, undergraduates had some doubt about what was needed, what they had or what was an acceptable alternative. The third group of undergraduate questions about equipment related to how the equipment worked. In some cases, the 
undergraduates had questions about the proper functioning of a piece of equipment, and in other cases the questions were related to whether a piece of equipment was functioning properly or not.

The undergraduate-initiated interactions that relate to equipment from the interview subset do not ask questions that are theoretical in nature. Rather, they are practical questions of where equipment can be found, what equipment is most appropriate, and how equipment functions. In most instances, the undergraduates are developing familiarity with the equipment and resources in the lab, learning how to use the resources that chemists depend on. In the examples here, there is a range of verbal dexterity that undergraduates demonstrate when asking for help with equipment in the chemistry lab. In most cases, the undergraduates can articulate what their needs are and identify what information they are requesting from their teaching assistants. However, the examples do provide insight that the undergraduates are developing verbal dexterity of the terminology and expressions of the lab, coordinating their speaking with the objects in the physical environment.

In addition to demonstrating that the undergraduates are developing familiarity with and control of the vocabulary of the discipline, these examples also demonstrate that the undergraduates are developing their understanding of how to approach and understand situations that arise in the chemistry labs. By talking and working with their teaching assistants, the undergraduates are developing how to judge information and read situations in the way more experienced chemists do. 
Locating and acquiring equipment. The questions that undergraduates ask to locate and acquire a piece of equipment are expressed in syntactically complete utterances. The undergraduates can articulate what it is that they are searching for with a fair amount of accuracy, as seen in Example 18. The lab manual describes in detail the requirements for the lab procedures, so what the undergraduates need has been specified for them.

\section{Example 18: 7 T 56 Successful}

\section{UG “Tuesday section TA’s Name”}

TA Yep.

UG We don't have a pH meter in our thing.

TA You, You can I I think that one one. Use that one. You can just take it.

UG Can we just take it over?

TA Yeah.

In Example 18, the undergraduate identifies that she and her lab partner do not have a pH meter as part of the standard equipment in their lab bench. The undergraduate identifies what she needs in statement form, indicating that the $\mathrm{pH}$ meter is missing from "our thing." As occurred in the example interactions for lab preparation, this interaction requires that the teaching assistant interpret what "thing" the undergraduates are referring to, information that can only be retrieved from the physical context in which the interaction is occurring. In his response, the teaching assistant suggests that they use "that one," an instance of situational reference that the 
undergraduates can interpret accurately when the physical object is present. The teaching assistant identifies what the undergraduates should do to acquire "it," and the undergraduate echoes the teaching assistant's response, which the teaching assistant then affirms and closes the interaction. Example 18 also demonstrates that the ambiguity of the interaction originates with both the undergraduate and the teaching assistant and that both participants resolve the ambiguity of the interaction. Example 19 is another example of an undergraduate locating equipment.

\section{Example 19: 8 T 36 Successful}

UG “Tuesday teaching assistant's name,” Are there are there wash bottles we can use to rinse these?

TA Yeah. There you should have a wash bottle in your locker.

UG We I don't.

TA You don't?

UG No, neither does my lab partner.

TA You can maybe yeah or you can check “undergraduate’s name.” Maybe you can just borrow.

UG Do you have a wash bottle?

UG2 Yeah.

In Example 19, the undergraduate knows what she needs and identifies for the teaching assistant the intended use for the wash bottles. In her question, "these” can only be understood when the physical object is actually present and available for visual 
inspection by the teaching assistant. Because the undergraduate has specified that he is looking for a wash bottle, the teaching assistant proceeds to guide the undergraduate to locating one, in this case, suggesting that the undergraduate borrow the piece of equipment from a neighboring undergraduate. However, it is only through the context that the teaching assistant can provide the appropriate response. In this interaction, he understands what "these" refers to in the context and that the wash bottle is the appropriate piece of equipment to be used by the undergraduate. Example 20, a slightly longer interaction, also illustrates an undergraduate trying to locate equipment.

Example 20: 4 Th 22 Successful

UG Uhm. Where might I find

TA Uhm.

UG the largest stirring bar and a magnetic stirrer?

TA Uhhha. The stir bar?

UG Should I just use a thermometer?

TA Uhm....The stir bar is the little white thing ah in that box.

UG This box?

TA This one.

UG These things?

TA And the stir plate is in fact that hot plate.

UG Okay....So this?

TA Uhm...This is a plate.

UG Okay, so...we should put this in here?

TA Yeah. 
Example 20 begins as an interaction to locate standard lab equipment, but quickly turns into an interaction in which the teaching assistant is helping the undergraduate learn the precise terminology of the equipment that she needs and information about what the equipment is. The undergraduate begins the question, but does not express it completely in the first turn. On her second turn, she has identified explicitly two pieces of equipment that she is looking for: "the largest stirring bar and a magnetic stirrer.” When the teaching assistant responds with the more accurately expressed "stir bar," the undergraduate jumps in with a follow-up question redirecting the teaching assistant to a possible alternative piece of equipment to stir the solution with, shifting the question from where to find a piece of equipment to what is an appropriate or acceptable piece of equipment to use.

At this point, the teaching assistant refocuses the undergraduate by clearly expressing the name of the piece of equipment that the undergraduate first identified and telling her where she will find it. The teaching assistant does this by directing the undergraduate to the appropriate location with "in that box.” At this point, the interaction becomes an interaction dependant on deictic references that both the undergraduate and the teaching assistant use and one in which they communicate successfully. Their communication can only be understood with the coordination of verbal information with the physical objects in the environment being visible and recognized simultaneously by both participants.

By the end of the interaction, the undergraduate concludes with a final question relating to what to do, "Okay, so...we should put this in here?” This final question is only understood by the teaching assistant because of the understanding she has of what 
the undergraduate is referring to when she uses “this,” “in,” and "here.” What started out as a simple question about where to locate a piece of equipment has developed into a longer interaction involving the undergraduate asking multiple questions. Throughout the interaction, the teaching assistant provides the undergraduate with support about what the proper names of the equipment are and how these items work. The interaction evolves into one in which the undergraduate learns about how the equipment functions. She was also informed what equipment was not appropriate to use, in this case the thermometer.

Example 20 illustrates that while the undergraduate has some grasp of the vocabulary she needed to talk about the activities in the lab, she is still not using the vocabulary with the needed precision. In fact, the teaching assistant needed to be able to read the situation and coordinate what she saw with what she heard from the undergraduate in order to supply the appropriate terminology. Both the undergraduate and the teaching assistant demonstrate extensive use of deictic pronouns and reference. This example also illustrates that the undergraduate, while starting to use the specialized vocabulary of the discipline is also starting to develop an understanding of what to do in the lab and how to use the equipment. She is developing judgments of how to approach activities of the lab experiment as a chemist.

Identifying appropriate equipment. Some undergraduate questions related to equipment are fairly straightforward and brief. The undergraduates seek help from the teaching assistants to determine the appropriate equipment to use, as in Example 21. 


\section{Example 21: 7 T 52 Successful}

UG Can we use a beaker of this size to...?

TA Yeah, sure.

In Example 21, the undergraduate asks the teaching assistant a question about an appropriate size of beaker to use, and before the undergraduate can finish the question, the teaching assistant provides the answer. In this example, the undergraduate uses "this size" rather than a more precise identifier for the size of beaker. Here, once again, the teaching assistant is required to coordinate the verbal information that the undergraduate is providing with the visual information that the undergraduate provides, showing the teaching assistant the object in question for reference. In this case the undergraduate is developing a sense of precision, what is an acceptable piece of equipment to use for a particular purpose. Example 22 shows a similar situation.

\section{Example 22: 4 W 56 Partially Successful}

UG And my second question was that we're gonna be taking aliquots of this stuff into glass beakers

TA That's right.

UG We don't have that many glass beakers, do we? Just those things.

TA Yeah, that's right.

UG They don't say glass beakers, though.

TA Yeah, yeah. You can use these.

UG Just use these? Ok. 
In Example 22, the undergraduate is trying to determine which type of container is acceptable for her purpose. In this example, the undergraduate provides a clear introduction in her first turn describing her intended use of the equipment. In her second turn, she completes it with more deictic reference, “just those things,” which can only be understood if the teaching assistant is monitoring both the verbal and visual information in this context. In closing the interaction, there is echoing of the teaching assistant's words, “use these.” Interpreting “these” requires the coordination of visual and verbal information, before an appropriate response can be expressed.

The undergraduate rated the interaction in Example 22 as successful. The faculty member also agreed that it was a successful interaction. In this case, the faculty member could intuit what "these” the undergraduate was referring to. The teaching assistant was not sufficiently satisfied with his response. Upon reflection, he indicated that he probably should have had the undergraduate use the glass beakers. The next example, Example 23, also illustrates an undergraduate trying to determine the appropriate equipment to use.

Example 23: 4 W 23 Successful

UG: “Wednesday teaching assistant's name,” Undergraduate gets TA's attention from a distance. Teaching assistant moves to undergraduate.

TA Yeah.

UG We don't have 600 mil beakers, do we?

TA What?

UG 600 milliliter beakers 
TA You don't?

UG I don't think so. I only have 500 mils.

TA Oh, that's doesn't matter. 500 works well.

UG But it says to heat 500 mils in a $600 \mathrm{ml}$ beaker.

TA Well, I...I...I...I ...I think it works well. Oh yeah, come on man. This is 600 . Is this yours?

UG That's “undergraduate's name,” but ok. Oh..

TA Is that 500 or 600 ?

UG Oh...Oh... “Wednesday teaching assistant's name.”

TA I'm genius

UG You are a genius. How was I supposed to know that. Come on.

In Example 23, the undergraduate is searching for a particular piece of equipment and needs help from the teaching assistant to find and identify the appropriate size of beaker. She specifically identifies the piece of equipment that she is searching for, “a 600 milliliter beaker,” the type specified in the lab manual. After a few turns of clarification, the undergraduate makes it clear that she only has a 500 milliliter beaker. The teaching assistant in the next turn reassures the undergraduate that the beaker she has, the beaker calibrated to 500 milliliters, would "work well," but the undergraduate persists in trying to acquire the 600 milliliter beaker. At this point the undergraduate is trying to be as precise as the lab manual specifies so as not to deviate from the instructions and is cautious to avoid making a mistake that may have consequences later on. It is only when the teaching assistant inspects the actual beaker 
that it becomes clear to him why the undergraduate has questions about the size of beaker. In fact, she has the appropriate beaker. The beaker has a capacity of 600 milliliters and is therefore called a 600 milliliter beaker, but it is only calibrated to measure 500 milliliters.

There are two issues here. First, the undergraduate is unfamiliar with the naming system for the equipment. Beakers are identified by their capacity but are calibrated to hold a slightly smaller amount. In the introductory lab check-in, where the undergraduates make sure that they have all of the standard equipment, this size of beaker is identified as a 600 milliliter beaker. In the interaction, the teaching assistant indicates to the undergraduate the source of her confusion, which she recognizes as being an error of misreading on her part.

What had contributed to the undergraduate's confusion was her desire to be as precise as possible, knowing that sometimes deviations from the instructions would lead to problems later on. In this case, her misunderstanding was related to her wanting to be as precise as possible when it was not necessary. While on the surface this interaction is about an undergraduate learning the appropriate naming system for beakers, on another level it may be an example of an undergraduate developing a sense of proportion: when is precision necessary and when is it not.

Even though this undergraduate did not depend on deictic reference in the interaction, it took more than one attempt for the teaching assistant and the undergraduate to resolve the question of what the appropriate type of beaker was. The friendly joking that closes the interaction, where the teaching assistant calls himself a “genius,” refers back to another interaction in the lab where the same undergraduate 
called the teaching assistant "a genius," in an interaction similar to this one: the teaching assistant pointed out to the undergraduate something that she should have known, but had temporarily forgotten because she was paying attention to another feature of the experiment. This ability to joke around was an important part of the relationship between the teaching assistant and his undergraduates. This interaction points to the friendly atmosphere and non-threatening environment in which the undergraduate felt comfortable asking and persisting with questions that she eventually realized she already knew the answer to. However, these questions were important for her to ask as she develops her sense of precision and judgments when working in the labs. Example 24 shows another instance of an undergraduate needing help identifying appropriate equipment.

\section{Example 24: 4 T 21 Successful}

UG “Tuesday teaching assistant’s name.”

TA Yep.

UG Uhm, I need something to rinse out the burette with.

TA Ah, you should have a brush in your holder.. uh in your locker.

UG No, something you don't. You rinse the $\mathrm{HCl}$ through it.

TA Yeah. Uh, You can use the just use the transfer pipette... or the a normal

UG Where do I have...I don't have one of those.

TA Ok. I...I... Let me see. Oh, You can use the automatic pipette, that's fine.

UG The automatic pipette?

TA Yeah, that's fine. 
In Example 24 the undergraduate needs help from the teaching assistant to identify a piece of equipment. In this example, like the previous example, it takes more than one turn for the teaching assistant and the undergraduate to resolve the question. In this interaction, the undergraduate approaches the teaching assistant and asks for "something to rinse out the burette with." Here the term "something" is ambiguous. The teaching assistant assumes that the undergraduate is requesting a piece of equipment, such as a brush, and he proceeds to direct the undergraduate to where to find the brush. In this situation, "something” could also have referred to a solution.

Without more specific information, the teaching assistant assigns a meaning that he thinks best meets her situation, given the experiment and his knowledge of what should be done at this point in the experiment. In fact, this was not the piece of equipment that she has in mind. She still does not know, or at least is not articulating, the name of the piece of equipment that she needs, so she attempts to describe it with "You rinse the $\mathrm{HCl}$ through it." This additional information related to how the piece of equipment functions is sufficient information for the teaching assistant to name the piece of equipment, a transfer pipette, that the undergraduate needs, and later in the interaction, he provides her with an alternative piece of equipment, an automatic pipette, that would also work for her purposes.

Example 24 points out that the undergraduates are developing their familiarity with the equipment and their control of the vocabulary needed to talk about the equipment in the chemistry lab. In the final turn, the undergraduate is seen echoing the name of the item. As in Example 23, the interaction in Example 24 was not successful on the first try, but with negotiation and clarification when the undergraduate persisted, 
the undergraduate and the teaching assistant were able to achieve success in the interaction. In Example 23, the object itself was required to resolve the confusion. In Example 24, the undergraduate, while unable to name the item she needed, was able to describe the equipment's function to communicate to her teaching assistant what she was searching for. The undergraduates in these two examples persisted, and the teaching assistants eventually understood and were able to respond with the appropriate information, modeling for the undergraduates the language of the discipline and helping the undergraduates develop the dexterity to talk about the equipment, as well as how to use and think about the equipment.

Equipment function. The third major topic of concern for undergraduates for questions related to equipment had to do with equipment function. Undergraduate questions of this type dealt with how to handle or use a piece of equipment properly and what to do if a piece of equipment was broken or malfunctioning. Example 25 is the one interaction all three participants rated identically on all 10 dimensions of the Likert-scaled interviews.

Example 25: 7 T 53 Successful (three-way consensus on all interview items)

UG Should I turn it on higher?

TA Ah, It's okay.

UG Alright.

This initial question in Example 25 is expressed in a syntactically well-formed question. However, it is ambiguous. This question can only be interpreted and 
understood if one understands what "it" is. This meaning can only be derived by seeing the object in the context or the situation in which the interaction occurs. In this case, the undergraduate was referring to the gas valve of a Bunsen burner. In this interaction, the flame was on, but the undergraduate was unsure if the flame was sufficient for the functioning of the Bunsen burner in this experiment. The undergraduate was developing his judgment of how to adjust and modify the equipment so that it was functioning properly for the intended purpose. The teaching assistant could only respond to this interaction by reading both the situation and comprehending the question. Example 26 is another example of an interaction related to equipment function.

\section{Example 26: 7 T 66 Successful}

UG Uhm. Is there a different one that we can get? This one's like broken.

TA Oh, it's. I don't think so. You can maybe you can just use a clamp to to hold the electrode. Teaching assistant moves to student's bench.

TA This is too big. The with three-finger. The three-finger three-finger stuff.

In Example 26, the undergraduate has a question about a piece of equipment that he thinks is broken. In fact, the equipment is not broken; however, the undergraduate would achieve greater success with a slightly different piece of equipment. The teaching assistant was not exactly sure of the name of the equipment, but did identify part of the name of the type of clamp that the undergraduate needed, "a three-finger clamp," which the undergraduate pieces together from the teaching 
assistant's second turn with "clamp" and third turn with "three-finger stuff.” This is another instance in which the undergraduate is developing understanding of and judgments about the equipment in a chemistry lab, how equipment is used and what equipment works best in a particular situation. Example 27 also addresses equipment function.

Example 27: 8 T 45 Successful

UG “Tuesday teaching assistant’s name.”

TA Yep.

UG Ah, what do we do if all the thermometers are giving us different readings?

TA I think ah these two are really close. And maybe this is not so good.

UG Okay.

TA Uh yeah, I think you can use either either of these two.

In the last example for this section on interactions related to equipment, Example 27, the undergraduate is able to explicitly state the problem: what to do in a situation where they are getting different readings from some thermometers that they need for the experiment. The teaching assistant can only respond to this question by examining the thermometers to determine which one or ones are functioning properly and which ones are not. While the teaching assistant is informed by the verbal information that the undergraduate provides, to understand and respond to the question, he must examine the thermometers and identify ones that are functioning properly. In his final turn, he draws the undergraduate's attention to the equipment with his use of 
"these two," which is made clear by his physical action of directing the undergraduate's attention to the appropriate thermometers. In this example, the undergraduate is developing a chemist's judgment and approach in order to respond to a situation arising from equipment not functioning as expected.

The interactions from the subset of interview interactions that deal with equipment are not of deep theoretical understanding of chemistry. They are practical and important questions for the undergraduates as they are learning to find, to identify, and to use the equipment essential to the chemistry lab. They are very practical questions in the lab, where the undergraduates are learning how to use the resources that chemists depend on. In essence, with these questions the undergraduates demonstrate that they are learning to understand how the hands-on work of chemistry is accomplished. The questions range from where to locate or acquire items, to selecting the appropriate items, and finally to how a piece of equipment works. The topic expressed by an undergraduate may start on one topic and evolve into another one.

In the examples here, there is a range of verbal dexterity that undergraduates demonstrate when asking for help with the chemistry equipment: from complete control of the terminology of and expressions used in the lab to imprecise, ambiguous or even inaccurate use of the terminology. Questions from the undergraduates and responses from the teaching assistants require that the language be coordinated with the objects from the physical environment for successful communication to exist. The teaching assistants need to hear and understand what the undergraduates are saying and see and understand what the undergraduates are holding and using. The teaching 
assistants need to disambiguate what the undergraduates say by depending on comprehending what they see the undergraduates have and what they are doing. The undergraduates need to do the same when they are the listeners.

In addition to demonstrating that the undergraduates are developing familiarity with and control of the vocabulary of the discipline, the examples also demonstrate that the undergraduates are developing their understanding of how to handle, approach, and understand situations that arise in the chemistry labs. In the lab environment by talking with (speaking and listening) and watching their teaching assistants, the undergraduates are developing their understanding and skills of how to judge information and read situations in the way that more experienced chemists do, as well as speak like chemists. The language and the activities of the chemistry lab are inextricably connected.

Materials. In the labs, undergraduates also asked their teaching assistants about the materials used in the experiments: chemicals, reagents, solvents, solutions, and experimental samples. While these questions only accounted for $6 \%$ of the interactions in the labs, the majority of these interactions (81\%) were initiated by the undergraduates, with the remainder (19\%) initiated by the teaching assistants. In the subset of interview interactions, $14 \%$ of the interactions discussed materials in the experiments, 7 out of the 50 interactions. For these questions, there were 5 successful interactions and 2 partially successful interactions. In one case, a partially successful materials interaction was rated as successful by the undergraduate and the teaching assistant. The faculty member only had access to the audio recording of the interaction, and without the visual information, she was could not commit to some of the 
Likert-scaled questions. The second partially successful materials interaction was rated as successful by the teaching assistant and the faculty member, but the undergraduate wanted more explanation and elaboration in the response.

Interactions of this type share some similarity to the types of questions that undergraduates ask about lab equipment, with one difference. For materials, undergraduates asked three primary types of questions. Like the equipment-based questions, undergraduates asked questions about where to find and how to acquire the materials. They also ask their teaching assistant's advice about identifying an appropriate type of material, where they know the general material they need, they just need some clarification of the appropriate type of material to use. However, unlike the third type of question that undergraduates ask about the function of the equipment, the undergraduate questions for materials are concerned about precision: how much of an item do they need.

Like the undergraduate questions and interactions where the topic was equipment, the undergraduate questions on materials were practical rather than theoretical questions. The undergraduate questions were where to find the material, which sub-type of material is needed in a particular experiment, and how much is an adequate amount for an intended purpose. These interactions tended to be rather brief, no more than nine turns in total in the interview subset.

Locating and acquiring materials. Example 28 is a materials question in which an undergraduate is trying to locate a material when she is in the process of collecting materials before she starts setting up the experiment. 


\section{Example 28: 4 Th 5 Partially Successful}

UG “Thursday teaching assistant's name.”

TA Uhm,

UG Where do we get the two grams of borax? Is it in the back?

TA Uh, the borax Uh (moving to the back of the room to the supply table)

TA Yeah.

UG There?

TA Yeah.

This interaction occurred earlier in the semester at a time when the undergraduates were becoming familiar with the physical set-up of the lab. The undergraduate labs are set up so that when undergraduates need materials for experiments, those materials are set out in the back of the room on a special table. In this example, the undergraduate has a sense of where the material she needs for the experiment is; she is checking with the teaching assistant to be sure.

While this interaction is classified as partially successful, it was rated as successful by both the undergraduate and the teaching assistant. The teaching assistant commented that she thought that the interaction could be improved if she just told the undergraduate where to obtain the borax rather than showing her. Her concern was that by showing the undergraduate where to find the borax, she was taking too much time. The undergraduate, however, appreciated that the teaching assistant was showing her were to obtain the borax. The faculty member, who only had access to the audio 
recording, felt that she needed more information about the interaction in order to rate all dimensions of the Likert-scaled interview items.

In the exchange between the teaching assistant and the undergraduate, the undergraduate expresses her question as two syntactically complete questions. In the second question of her first turn, the referent for "it" is easily recovered from the first question, "the borax.” The response is primarily achieved by the teaching assistant showing the undergraduate where to find the borax, at the back of the room. The teaching assistant achieves success in ways that are not necessarily dependent on what she says, but by what she does: demonstrating where to look for the materials. While the teaching assistant, upon reflection, thought that both the verbal and the visual were important when communicating information to the undergraduate, when she was engaged in the spontaneous interaction in the lab, her initial reaction was to help the undergraduate with a demonstrative act of showing the undergraduate. The teaching assistant demonstrated through her actions that she understood the undergraduate's question. The undergraduate was entirely satisfied and indicated that this was the response that she was looking for.

Selecting and identifying the appropriate material. The next two examples of materials-related questions, Examples 29 and 30, are of undergraduates asking for support when selecting an appropriate type of material for an experiment. 


\section{Example 29: 7 T 24 Successful}

UG Uhm.

TA Yep.

UG For part 4 do we use natural seawater?

TA Natural seawater, yeah.

\section{Example 30: $\underline{6}$ T 34 Successful}

UG When we do the sample B, we we use that with deionized water, right?

TA Yeah, Yeah.

UG Ok.

TA Uhum.

In both examples, the undergraduates need to determine the appropriate type of water to use in an experiment. In both cases, the undergraduates clearly identify and situate the question as to where in the experiment they are, with "for part 4 " in Example 29 and "when we do the sample B" in Example 30, contextualizing their questions with verbal rather than visual information. Both of these questions are precisely stated and do not require reference to items in the environment. These interactions can stand alone with just the verbal information. These questions reflect that the undergraduates are in control of the vocabulary of the materials they need, information that has been specified for them in the lab manual. These two interactions also demonstrate that the undergraduates are sensitive to issues of precision, as they ask about specific types of a material that is needed to successfully complete the 
experiment. Example 31 also illustrates an undergraduate trying to ensure that she is working with the appropriate material.

\section{Example 31: 7 Th 15 Successful}

UG Um. On the actual bottle it says .019 molarity. Is that okay for the $\mathrm{NaOH}$ ?

TA $0.019 ?$

UG It says .019.

TA Which one? (TA and undergraduate move to supply area.)

TA Oh...uh... . No, this is point 1.

TA Yeah, this one. Yeah.

In Example 31, the undergraduate is seeking to make sure that she is precise and accurate in her judgment about which material she is selecting. In this example, the undergraduate confronts a situation in which she is expecting one degree of a concentration for the sodium hydroxide $(\mathrm{NaOH})$ but is not finding the appropriate bottle. What she is finding in the real world of the lab does not match what she has expected to find based on the information that she has been supplied in the lab manual. She seeks help from the teaching assistant to reconcile this difference. This interaction is resolved successfully when the teaching assistant can see the container the undergraduate is referring to and can clear up the confusion about the concentration of the sodium hydroxide. The teaching assistant coordinates the visual information from the environment with the verbal information for this interaction to be successful. 
Measurement precision. Undergraduates also asked the teaching assistants questions related to the quantity of a material that was needed. In general, with these questions, undergraduates were asking the teaching assistants to help them understand how precise they needed to be when using materials in the experiment, as shown in Example 32.

Example 32: 7 T 26 Successful

UG How much $\mathrm{NaOH}$ and $\mathrm{HCl}$ should we pick up?

TA I (prolonged)

UG2 For part 4.

UG For aeration. Like how much should I take so we don't waste any?

TA Uhm.

UG About how much.

TA I think 10 milliliters should be enough.

UG 10 milliliters.

TA Yeah.

In the first example, Example 32, the undergraduate's question is syntactically well-formed and complete. However, the teaching assistant cannot respond until the undergraduate contextualizes the question for the teaching assistant. The undergraduate provides two additional pieces of information. First, the undergraduate orients the teaching assistant to where he is in the experiment, with "for part 4." The second piece of information he provides is what is motivating him to ask the question, i.e., he does not want to waste the materials. With this additional contextual information, the 
teaching assistant can respond. This interaction requires two attempts for the interaction to be completed because of the additional contextual information the undergraduate needs to supply verbally for the teaching assistant. Example 33 shows another undergraduate’s need for assistance with measurement precision.

\section{Example 33: 4 W 38 Partially Successful}

UG “Thursday teaching assistant's name,” do you know how much solid sodium borate we're supposed to put in this thing to heat over the Bunsen flame?

TA How much?

UG2 Uh...I don't think it matters.

UG It doesn't matter at all?

UG2 No, no.

UG How much is enough?

TA Maybe 5, 5 grams. 5 grams, yeah.

In Example 33, the undergraduate asks a question that is precisely expressed. In this interaction, the lab partners are working together, and one approaches the teaching assistant with a question. The other undergraduate participates in this interaction, providing her opinion of what the answer should be. The teaching assistant then provides a specific amount after allowing the undergraduates to talk through their question. The undergraduate who initially asked the question presses the teaching assistant to respond, and he provides her with a specific amount, though it is not expressed with the definiteness that the undergraduate had hoped for. 
Both the teaching assistant and the faculty member agree that this interaction in Example 33 was successful; however, the undergraduate who asked the question expressed the need for more information that would further explain why this particular amount was appropriate. She was slightly concerned about what she perceives as a lack of precision in the response of "Maybe 5, 5 grams. 5 grams, yeah," which communicated to her indefiniteness in the response. This undergraduate was looking for precise numbers and was concerned about what she considered the imprecision of the response.

In this interaction, the undergraduate was seeking two pieces of information from her teaching assistant. First, she was looking for a high degree of precision in the response, i.e., a more scientific response. Second, when there was no definite answer, she was looking for information about why precision was not needed. She needed more information to help her understand and develop her judgments when approaching the chemistry experiment. Developing a sense of precision and wanting to understand why choices are made are indications that the undergraduates are developing their understanding of how to approach the material, judge the activities of the lab, think about what they are doing, and interpret information.

The interactions that discuss the materials of the lab experiments are similar in ways to the interactions that address equipment. Undergraduates need help to acquire or locate the equipment and the materials they need to carryout the experiments. Undergraduates are aware that in the labs there are choices they need to make, and selecting an appropriate piece of equipment or selecting a specific material from multiple varieties of a given material can be important decisions. They also want to be 
precise and determine the appropriate piece of equipment or material for their purpose. Equipment- and materials-related questions also differ slightly. While the equipment interactions focus on the functioning of the equipment, proper function and malfunction, the materials interactions emphasize the quantity needed, precision in measurement.

These questions reflect concerns the undergraduates have about being precise and following carefully the instructions in the lab manual. They also demonstrate that the undergraduates are developing their understanding of how to approach problems in the hands-on work of the lab and control of the vocabulary and expression of the discipline. When asking these questions of their teaching assistants, they are developing judgments of how to behave and think like chemists. To respond appropriately to these undergraduate questions, teaching assistants frequently need to disambiguate the undergraduates' questions by reading the visual information that accompanies the verbal information.

Procedures. The last group of interactions focused on the procedures of the experiments: questions that arise when the undergraduates are carrying out the steps as outlined in the procedure section of the lab manual for the experiment. Procedurerelated interactions discuss various ways pieces of equipment fit together in an apparatus or how materials and equipment are used together for the purposes of the experiment. In short, these interactions focus on what the undergraduates are doing to complete an experiment. These interactions were the most frequent of all types of interactions. In the study interactions, procedure interactions accounted for $38 \%$ of all 
interactions, and $71 \%$ were initiated by undergraduates. In the interview interactions, procedure interactions accounted for $56 \%$ of all interactions.

In general, there were three primary types of questions undergraduates asked that were classified as procedural questions. First, undergraduates were seeking information and advice on what to do in an experiment. Second, undergraduates wanted to know how to perform some part of an experiment. Finally, undergraduates asked questions that focused on procedures after they had completed them but found that they were confronted with a situation that differed from their expectation or their work did not produce the expected result or outcome. In this last type of procedures question, teaching assistants were troubleshooting.

The majority of questions in this topic are practical, rather than theoretical, questions that arise from the hands-on use of materials and equipment to carry out the experiment. The undergraduates are well prepared to carry out the lab experiments: the lab manual describes what undergraduates are supposed to do, in addition to providing pre-lab questions, and the faculty member has demonstrated many of the procedures. However, the questions about procedures surface when the undergraduates themselves carry out the experiment. Questions often are related to getting the experiment to work and to making sure that the undergraduates are adhering to the requirements spelled out in the lab manual.

Establishing what to do. The first type of procedure-related question that undergraduates asked related to establishing what to do. This type of question accounted for over half of interview interaction related to procedures. The procedurerelated questions where undergraduates were deciding what to do tended to take fewer 
turns, usually 12 turns or fewer, than the other types of procedure interactions.

Example 34 illustrates a brief interaction of an undergraduate determining what to do.

\section{Example 34: $\underline{5 \text { Th } 30 \text { Successful }}$}

UG So, after the first like five minutes we have to like cover it?

TA Um, yeah.

Example 34 is a brief interaction of two turns. The undergraduate's use of "it" directs the teaching assistant to attend to the undergraduate's apparatus and interpret what "it" refers to. The question is well-formed and syntactically complete, and it requires no negotiation for either participant. The teaching assistant sees what "it" refers to and responds quickly and appropriately. Example 35 provides a slightly longer exchange.

Example 35: $\underline{6 \mathrm{~T} 22 \text { Successful }}$

UG Uhm. It says adjust volume to 100. If ours is like at 97

TA Ok.

UG Does that mean, do we add water or do we just

TA Add water.

UG Add water.

TA Add 3 milliliters.

UG Ok 
In Example 35, the undergraduate opens his question with “it," which requires the teaching assistant to understand that the reference is to the lab manual. The remainder of the question is complete, though spread out over two turns. The undergraduate's taking two turns to express his question is related to the undergraduate's contextualizing the primary question of what to do, which he phrases as a choice in his second turn. The teaching assistant interrupts the undergraduate's first turn with a back channel cue to signal to the undergraduate that he is following the information the undergraduate provides to contextualize his question. In the coordination of alternative choices, the undergraduate expresses "does that mean, do we just add water or do we” and before he can complete the second possibility, the teaching assistant responds, repeating the undergraduate's words, which the undergraduate echoes in the next turn. The teaching assistant then supplies an appropriate quantity of material to add at this stage of the procedure.

Example 35 demonstrates an interaction in which the undergraduate is expressing his information in a relatively clear way. The undergraduate provides the teaching assistant with background information about why he has a question. He knows that the manual has given him an instruction, “adjust the volume to 100," and he is not sure if the "97" is close enough or if additional precision is needed. When expressing his question he leaves off the unit of measure, which appears to be understood by both the teaching assistant and the undergraduate. However, at this point in his experiment his volume is "97," and he needs to know what to do: what steps does he need to take to make sure that his procedure matches the instructions in the lab manual, if any. The teaching assistant understands that the undergraduate is developing 
his judgment and understanding of what to do in his situation, and responds with additional precision on the amount the undergraduate needs, even though the undergraduate does not explicitly ask how much water. While the question is unspoken on the part of the undergraduate, the teaching assistant interprets the undergraduate's echoing “add water,” to require a response for more precision and elaboration, which the teaching assistant supplies with a specific quantity.

The next example of a procedure question, Example 36, has a similar syntactic form in that the undergraduate is presenting the teaching assistant with a question offering two possibilities of what to do, using two syntactically complete independent clauses coordinated by or.

Example 36: 7 T 39 Successful

UG Do we actually have to clamp this in or can I just put it in so it rests on the bottom?

TA Yep.

UG I can just put it in?

TA Yep.

UG Alright.

In Example 36, both clause alternatives are yes/no questions. Unlike Example 35, the undergraduate does not express information that would contextualize where the undergraduate is working in the experiment. The undergraduate just asks the question. The teaching assistant's response to the coordinated yes/no questions is a "Yep." The 
undergraduate is unsure of which option the teaching assistant is approving and checks with the teaching assistant about the second option, to which the teaching assistant responds affirmatively. The undergraduate then concludes the interaction with

\section{“Alright.”}

In Example 36, the teaching assistant comprehends and interprets correctly what "it" refers to from the visual information provided in the context to respond appropriately to the undergraduate's question and situation. The teaching assistant does not interrupt the undergraduate's coordinated question after the first alternative is expressed, but rather, waits until the undergraduate expresses the second alternative, which is the correct course of action for the undergraduate to pursue. The undergraduate is unsure what the teaching assistant’s indefinite "Yep” refers to, as the undergraduate has coordinated two yes/no questions. The undergraduate then restates what he thinks the teaching assistant is saying is the right thing to do, to which the teaching assistant confirms that the undergraduate understands. The undergraduate persists and clears up the uncertainty.

This interaction is ambiguous for many reasons, but it is successful overall, in part because the undergraduate persists to make sure he understands what the teaching assistant is saying. The teaching assistant clearly understands what the undergraduate is asking, even though the undergraduate's question includes many instances of situational and textual references, e.g., "this,” "it,” and "put it in.” At first, the undergraduate is not clear about the teaching assistant's response: is the teaching assistant referring to the first or the second alternative expressed? The undergraduate assumes that it is the second of his two alternatives and persists with his follow up 
question, which is his second alternative choice expressed as a statement, but intended as a yes/no question. The teaching assistant replies with a simple "Yep." Example 37 shows another instance of an undergraduate seeking clarification of what to do procedurally.

Example 37: $\underline{5 \text { Th } 7 \text { Successful }}$

UG Is that the right way to set it up?

TA The vacuum? Uh. Yeah, that that one is good.

UG So...

TA That's for the uhh fil...

UG For filtering. That's for after. Uhm. Ours like isn't quite boiling and we put it in yet. Should we start over and wait till it's like...

TA to boil

UG super boiling. Wait till it's really boiling and then put it in.

TA I I don't think so.

Example 37 demonstrates a successful interaction, but one in which negotiation is required to resolve the ambiguities created by the undergraduate's use of "it" in the initial question. The teaching assistant cannot determine what the undergraduate is referring to from the spoken or the visual information. The teaching assistant quickly responds to the undergraduate with what she thinks "it" refers to, "the vacuum," and continues her assessment of what should be done. 
While much of the interaction is expressed by both the teaching assistant and the undergraduate using fragmented speech, incomplete utterances, and frequent use of deictic reference (e.g., "that one”), they are both working together to express the information. In the teaching assistant's second turn, she begins to express, “filter," but before she can finish, the undergraduate completes the word, and develops the thought further by providing information that contextualizes when the apparatus will be used: "that's for after."

In Example 37 and in Example 36, the sparse language expressed by both teaching assistants allows or requires the undergraduates to articulate more precisely what it is that they are doing and asking for in order for the interaction to be successful. In each of these examples, the undergraduate and the teaching assistant are working together to achieve successful communication. The teaching assistants understand what is happening and where the undergraduates are having difficulties; however, in these instances, the undergraduates are articulating the ideas in the interactions, and expressing their needs relatively clearly to the teaching assistants. Example 38 is similar.

\section{Example 38: 5 Th 8 Successful}

UG “Thursday teaching assistant's name,” Should I pour this in there?

TA This is the... Why, why?

UG This is the ore and ...

TA yeah

UG ...the nitric acid and we don't want to use this one, and we want to start over. 
TA Oh, Oh.

UG So should I pour it in there or over there?

TA Oh, no. A waste of....

UG It's getting there.

TA Uh huh (laugh)

In Example 38, the undergraduate presents the teaching assistant with an ambiguous question: “Should I pour this in there?” The teaching assistant's immediate response is to locate what “this” is and the purpose of the undergraduate's proposed action. The teaching assistant's response to the question is sparse and incomplete, requiring the undergraduate to articulate more precisely what she is referring to. The teaching assistant continues to provide short and brief acknowledgements of what the undergraduate is proposing to do. In providing these brief responses, the teaching assistant is prompting the undergraduate to be explicit in describing what her intentions are.

In Example 38, the teaching assistant by using limited language to respond forces the undergraduate to articulate her thoughts about what her actions are and what she is about to do. The teaching assistant clearly understands what the undergraduate is attempting to do and responds appropriately throughout, prompting the undergraduate along the way. The teaching assistant recognizes the ambiguity of the undergraduate's question, and before she can respond to the undergraduate's question of what to do, the teaching assistant must disambiguate the question and understand the situation, which she does, in brief, fragmented turns. The teaching assistant and the undergraduate work 
together to determine what the undergraduate should be doing for this part of the experiment. Example 39 is another instance of the undergraduate and teaching assistant negotiating what to do.

Example 39: 7 T 72 Partially Successful

UG Uhm, We don't keep that in there while we titrate it do we?

TA The what?

UG The...uhm...pH meter.

TA The electrode uhh

UG Do we keep it in there while we add

TA I would say you don't have to, but uh, I don't think there are any problems if you

UG Oh, we can just keep it in there?

TA Yeah,

UG2 So then we just leave it. It's easier then we don't have to go clean it out.

Example 39 is a partially successful interaction. The two undergraduates working together both participated in this interaction, and both reviewed this interaction during the interview process. The teaching assistant, faculty member, and the undergraduate who did not ask the question all rated this interaction as successful. The undergraduate who asked the question rated this interaction with an insufficient degree of certainty. Those who already understood the information in this interaction 
saw it as successful. However, the undergraduate who was still developing his understanding needed more from the interaction.

In Example 39, the undergraduate approaches the teaching assistant with a procedure question about what to do. His question is phrased in a skeptical way, "We don't keep that in there while we titrate it do we?” The question as phrased has a significant amount of ambiguity, with "that," “in,” "there,” and "it.” The "we” refers to the undergraduate and his lab partner and is understood in the context of this particular lab where the undergraduates are working in pairs. However, the teaching assistant is unsure what "that" refers to in the undergraduate's first turn. The teaching assistant recognizes the ambiguity and quickly follows up with a question to identify what “that” the undergraduate is talking about in the undergraduate's first turn. The undergraduate replies first with a pause, “uhm," and then with "pH meter.” The teaching assistant recognizes that "pH meter” does not make sense and supplies the undergraduate with the proper word “electrode.” The undergraduate proceeds to ask the question once the undergraduate and the teaching assistant are clear that they are talking about the same thing. The teaching assistant and undergraduate negotiate the information. The teaching assistant replies to the undergraduate's final question of “Oh, we can just leave it in there?” with a positive "Yeah.” At this point the undergraduate's partner adds a comment explaining a benefit of just leaving the electrode in.

The undergraduate who asked the question and who rated the interaction with an insufficient degree of certainty wanted the teaching assistant to provide more elaboration on why the undergraduates could leave the electrode in. As he explained in 
the interview, he was not sure if the electrode should be left in or taken out. He thought that he understood what to do from the pre-lab lecture, but was not prepared for what he was confronted with when he was carrying out the experiment. This undergraduate was trying to reconcile what he thought he should be doing with the situation that confronted him.

This interaction is unique in the pool of interview interactions in that both of the undergraduates who were engaged and participating in the interaction responded to the interview items for this interaction. In the interviews with the second undergraduate (UG2) and the faculty member, it became clear that the undergraduate lab partner (UG2) knew how to approach this question to work efficiently on this part of the experiment. He knew what he and his lab partner should do. However, the undergraduate who asked the question was not sure. The undergraduate who was sure of what should be done thought the interaction was successful. The undergraduate who was not sure, the one developing control of the vocabulary to ask his question and developing judgments about how to approach the experiment, needed more explicit information from the teaching assistant. He needed and wanted the teaching assistant to elaborate on the reason "why" what he was told to do was "the right thing" to do.

In Example 39, the undergraduate partner supplied the reason in the final turn of the interaction. However, the undergraduate who asked the question needed to have the information articulated from the teaching assistant. As he expressed: "In principle, I understood, but I didn't understand why we were doing it differently.” The last example of this type of a procedure-related question in which the undergraduate is asking the teaching assistant what she should do, Example 40, is one in which both the 
undergraduate and the teaching assistant are expressing themselves with less dependence on situational reference.

\section{Example 40: $\underline{6 \mathrm{~T} 54 \text { Successful }}$}

UG Uhm. When we're. Like when we rinse out the kerosene.

TA Yep.

UG Do we rinse it into the same beaker that this phase is in or do we just rinse it into a different beaker that we can throw away?

TA Ah, It doesn't matter.

UG It doesn't matter? So but should it be added to this part that we're gonna use for electrowinning of the water?

TA Ah, I think that's that's for the uh if if you you use the sulfuric acid you get the copper solution, the blue copper solution.

UG Right.

TA That's That's for the for the ah for the electrowinning part.

UG And then afterward we rinse it out

TA That's that's just trash.

UG So that's just in another beaker.

TA Right.

In this example, the undergraduate establishes in her first turn contextual information of where she is working in the experiment and completes her question in her second turn. The teaching assistant responds quickly. The undergraduate's question 
is expressed as an alternative choice question (two independent yes/no questions coordinated by or). The teaching assistant's reply that “it doesn't matter” means that she could choose either alternative. However, the undergraduate recognizes that she is not quite sure of the response and pursues the question with more elaboration, providing the teaching assistant with information about what the use of the liquid should be.

It is through persistence that the undergraduate and teaching assistant work together in the remainder of the interaction. To clarify information during this interaction, the teaching assistant refers to the instructions in the lab manual to walk through the steps in the procedure to determine which solution the undergraduate is talking about. In this interaction, there were two possible solutions that the undergraduate could be asking about. At first, the teaching assistant understood the undergraduate to be asking about one solution, but then because the undergraduate persisted, they were able to work through the interaction, depending on the lab manual to ensure that they were both clear about which solution they were talking about.

The teaching assistant and the undergraduate both contribute to the success of the interaction. The undergraduate orients the teaching assistant at the beginning of the interaction. When the undergraduate senses that the teaching assistant does not quite understand her question, she pursues the question and provides additional contextual information. At this point, the teaching assistant recognizes that to resolve the undergraduate's problem and respond to her question, they must resolve the ambiguity in the interaction. To do so, the teaching assistant works with the undergraduate and 
the lab manual to clarify the steps in the procedures to determine which solutions are important and which solutions are "trash.”

In the interview process, the undergraduate indicated that the teaching assistant did not understand her question, at first. From her perspective, she thought that the answer did not make sense. In her words, "It was a vague answer, when I wanted more precision in the answer. This is important because if you make a mistake, it can mess you up later on." She persisted with her question, and by the end it was a successful interaction. She understood that the teaching assistant did not understand her original question, and she persisted until he did. At first, the teaching assistant did not understand which solution the undergraduate was proposing to discard, but through negotiation they resolved the undergraduate's problem.

The faculty member's comments provide further background on what is going on in this interaction. The faculty member identifies that this was a difficult question for the undergraduate to ask. The difficulty arose from the complexity of the situation. There were two phases in the experiment that the undergraduate could have been talking about. The faculty member saw that the undergraduate needed to orient the teaching assistant to the question and whether or not she was washing with the first extract. The teaching assistant had to make sure he was in the right place. His reaction as a chemist was to review the specified steps of the procedure in the lab manual and to clarify things in his own mind. This question required a lot of negotiation and consultation with the manual to ensure they were talking about the same thing and coming up with the appropriate response. 
How to carry out a procedure. The second type of undergraduate question related to procedures is a request for the teaching assistants to explain or demonstrate how to carry out a procedure. Examples 41 and 42 illustrate typical questions from undergraduates who are unsure of how to carry out a procedure in the lab experiment. These interactions take more turns than the procedure questions where undergraduates ask what to do. In Examples 41 and 42, where undergraduates ask the teaching assistants to help them understand how to carry out a procedure, there is greater dependence on situational reference. The teaching assistants must depend on visual information from the context to understand the questions and situations. Understanding for the teaching assistant has to come from both the visual and the verbal information.

\section{Example 41: $\underline{5 \text { Th } 6 \text { Successful }}$}

UG Uhm, Are we going about setting up the vacuum right?

TA Umm

UG How do we set up the vacuum?

TA You need another flask and yeah put the funnel in.

UG Another flask just like that?

TA Yeah....And you have a an adapter for the funnel to seal to the flask....

UG2 Do we have one?

TA Um... no.

UG2 I don't have anything in here.

TA It's not here. No. Do you have one?

TA Do you have one?

UG2 Kinda like this. 
UG Have one what?

TA An adapter

UG Adapter? Oh.

UG2 Kind of like a stopper.

TA Yeah, Yeah, Yeah, this one.

UG2 Put it underneath here.

UG Like underneath, like that?

TA Yeah.... hum... it's too small?

UG Yeah.

TA Wait. Just try this one. It should be ok.

UG Would it be okay like that?

TA Yeah, I think so.

UG Cool.

TA I'm not sure. (laugh)

UG I hope so.

TA Umm

UG The filtrate.

TA Uhm.

UG The filtrate's going in here, so but it won't be like won't have any gas coming out, so it'll be ok.

TA Uhm, Yeah.

UG Okay. 
In Example 41, the undergraduate asks for confirmation and is trying to gauge whether he and his lab partner are approaching the procedure accurately. In the first turn, the undergraduate expresses the question in a yes/no question. The question is asking for the teaching assistant’s judgment: “Are we going about setting up the vacuum right?” When the teaching assistant provides a positive back channel cue of “umm,” which can be interpreted as “yes” or "I’m following, please continue," the undergraduate uses his second turn to be more precise and direct in expressing his question, which is actually a request for the teaching assistant to show him and his partner "how to set up the vacuum." With this more directly expressed question, the teaching assistant can more accurately address the undergraduate’s concerns.

At the beginning of this interaction, the undergraduate recognizes when the teaching assistant is not interpreting his question in the way that he wants, which he determines from her response in her first turn. He then more articulately expresses what he really wants: the teaching assistant to help him set up the equipment. He does not want simple confirmation that he should proceed to work through the experiment. He needs more specific help at this juncture of the experiment. At this point the teaching assistant, understanding what the undergraduate now wants and needs, supplies him with more specific information about what equipment the undergraduate needs and how to set the vacuum up. The negotiation develops into a more complex interaction. In the process of setting up the vacuum, the teaching assistant provides the undergraduate with information about the appropriate equipment he needs, "an adapter," and where he can acquire it. The brief turns include many examples of deictic reference and situational reference throughout. 
As the interaction opens and the topic is being established, both the undergraduate and the teaching assistant as listeners interpret what the other has said. They then adjust what they say in the following turns. The undergraduate reads the teaching assistant's first turn "umm,” as the signal for him to begin to describe what he is doing. At this point, he then identifies that he is not asking for confirmation, but rather he is asking for information. With the more direct expression from the undergraduate asking for explicit information about how to set up the equipment, the teaching assistant can provide the undergraduate with the information and more elaborate support that he needs.

While the interaction in Example 41 starts out as a procedures question on how to set up the vacuum, it evolves to include additional information: the undergraduate is developing his understanding of the equipment necessary to carry out the experiment: what it is, where to find it, and how to use it. How to set up the apparatus depends on the undergraduates' having a clear understanding of the equipment and materials necessary for the chemistry labs. In this example, the undergraduate is developing his understanding of and use of the resources needed to complete the experiment, in addition to how to carry out the experiment. Example 42 is similar.

\section{Example 42: 5 T 44 Successful}

UG “Tuesday teaching assistant's name.”

TA Yep.

UG Could you show me how to uhm...sorry...How to like.

TA Oh, You need a adapter. 
UG Where do I get ... I was just looking for one of those.

TA Ah

UG Those in there?

TA (TA looks for an adapter). Adapter...Adapter...Oh, it's a stopper....It looks almost the same except the the adapter is hollow.

UG So I just look through for one of those. Can I look in yours

TA Yeah, You should have...Oh. Here's a. You can use this.

UG Instead of this?

TA Yeah, Yeah. Well. I...I...It's up to you. I...I mean uh you can use also use

UG2 I think we. Are you looking for this?

TA Yeah, Yeah, that kind of stuff. Yeah.

UG Oh, so that's. Is that good [inaudible]?

TA Yeah, that's good enough.

Example 42, from the same experiment with a different teaching assistant, is similar. The undergraduate does not state as directly her needs, which are similar to those of the undergraduates in Example 41. The undergraduate in Example 42 is asking the teaching assistant to help her set up the vacuum. However, the undergraduate is having difficulty expressing her question. The teaching assistant coordinates the undergraduate's spoken information with visual information of what she is doing to understand her question. The teaching assistant is able to jump in and respond to the undergraduate with the necessary information: she needs the correct piece of 
equipment, an adapter, to have the vacuum set up properly. The undergraduate can then ask the follow up questions of what the adapter is and how to acquire it.

Example 42 is a good companion to Example 41 because it demonstrates slightly different styles of interacting and teaching that both lead to successful interactions. In the first example (Example 41), the teaching assistant responds to the questions as they are asked, which means that the undergraduates are more responsible for articulating information. In the second example (Example 42), the teaching assistant sees the situation and jumps in, expressing what the undergraduate has difficulty articulating. The interaction in Example 42 is resolved more quickly in 16 turns compared with the example in Example 41, which took 33 turns.

The teaching assistant in Example 41, while giving the impression of producing less language, is as a teacher allowing the undergraduates time to express the information and develop the skills of expressing the information as a chemist would while working on the apparatus. The teaching assistant in the Example 42 responds using a slightly different approach and style. He expresses the information that the undergraduate is having difficulty expressing, thereby modeling for the undergraduate how to talk about the situation.

Both styles of communication and teaching are successful, though different. The first, having the undergraduates express the information, takes more turns and more time. The second is more efficient in terms of time. It provides a shorter explanation and models the discourse for the undergraduate. This different approach to responding to undergraduate questions may explain why in the first section of this chapter the Thursday teaching assistant’s (Example 41) interactions tended to be longer 
than the Tuesday teaching assistant's (Example 42) interactions. The difference in length of interactions may be related to teaching style, which is reflected in the ways the teaching assistants respond to undergraduate questions and speak to their undergraduates. The issue of undergraduate-teaching assistant communication may not be as much about speaking style as it is about teaching style, reflected by how teaching assistants respond to undergraduate questions.

Problem solving. The last type of question that undergraduates present to their teaching assistants related to procedures occurs in situations where undergraduates have completed some aspect of the experiment, but the outcome of their work is not what they expect and they are not sure why. The undergraduates are seeking help from the teaching assistants to troubleshoot and problem solve. The teaching assistants are called upon to review the steps that the undergraduates have taken and go through them step-by-step to problem solve. Undergraduates usually approach their teaching assistants with a declaration of "It's not working”; "I did this, but it’s not working”; “Nothing’s happening.” In general, these interactions tend to take longer in time and have more turns. The next three examples (Examples 43, 44, and 45) illustrate teaching assistant-undergraduate problem-solving interactions.

\section{Example 43: 7 T 54 Successful}

UG Uhm, “Tuesday teaching assistant's name.”

TA Yep.

UG I plugged this in, but I don't think it's on.

TA Okay....Is this on? .... Maybe this?...Yeah, it's on now. 
UG Hum.

TA I mean I mean the the power is on. The power supply is on.

UG Okay. Shouldn't that be at 7 though?

TA I...yeah. It should be 7 because you are using the $\mathrm{pH} 7$ buffer. Yeah.

UG But it's not.

TA Slope.... Pitch, that's fine....Set the function....

UG Oh, this was supposed to be..

TA Oh..it's Accument

UG Hum.

TA There, there are two two models. This or this one.

UG So, I have to. This goes to a hundred. This goes to standby.

TA Yeah.

UG And then... this goes to 100 .

TA Yeah, just just follow procedure.

UG It's still not....still not $7 \ldots$

TA Hum... Ah...[mumbles words walking through steps to adjust equipment] And set the temperature. Oh. Oh. That's fine. And And (mumbles words walking through steps to adjust equipment)

UG [inaudible]

TA Ah, yeah. The that's alright. You can just just leave it there. The $\mathrm{pH} 7$ buffer....Use the standard standard...This use this just. Oh, there's no response.

UG Oh, It moved a little.

TA Oh, it should be....here. $\mathrm{pH}$ position... It's kind of weird.... 
TA Take a look at others. See if they... the meter is broken or not. Take a look at others. TA goes to talk with other undergraduates. And addresses other question.

Example 43 is an example of a procedural problem-solving interaction. The undergraduates are following the lab manual procedures to measure $\mathrm{pH}$, and the first step involves the procedure of calibration. The undergraduate's initial statement focuses the teaching assistant's attention on the $\mathrm{pH}$ meter, identified as "this," which the teaching assistant disambiguates from the context by seeing what the undergraduate is working with. The teaching assistant walks the undergraduate through the steps for calibrating the $\mathrm{pH}$ meter. Together, they work through the steps. Eventually they determine that the problem lies with the equipment not functioning properly.

\section{Example 44: 4 Th 29 Partially Successful}

UG Well, I don't know I'm having trouble.

TA Hold this down. The tips to the... ahh... This is... Yeah, You adjust the height of the burette and then put the tips into the uhh...uhhh .

UG Student carries out instruction.

TA A little lower.

UG Student carries out instruction.

TA Yeah, Now press the bottle and let it go. The solution will go up.

UG Student carries out instruction.

TA Yeah. Now you can close this. 
UG Close this?

TA Yeah, this one is closed when it is vertical.

UG So, it's closed.

TA Yeah, Yeah.

Example 44 was a partially successful interaction. This example was discussed previously to indicate that interactions are frequently coordinated events of verbal and visual information. The undergraduate is having difficulty with a procedure that involves working with a burette. Both the native speakers of this interaction, the undergraduate and the faculty member, rated this interaction as successful. The teaching assistant rated the interaction with an insufficient degree or certainty because she wanted her response to be quicker; she was critical of her linguistic abilities of producing English. Even though the undergraduate rated this as a successful interaction, he indicated that he would have liked to have had more verbal interaction to support the demonstration.

Example 45: 4 T 51 Partially Successful

UG Uhm... Wha Ours. Something won't go out. It can't

TA Okay. So...

UG It won't go out.

TA Let me see. The container is not good enough.

UG No. I mean...I can't get the. It's not the container. It's that I can't get the liquid out of here. I can't get the liquid up or out. 
TA That's not enough

UG No, No. It won't come out.

TA Right. because of this part. Because of this part. ... You just use a big beaker and uh ah so so the the bottom the burette can reach the bottom the beaker. So it's it'll be much easier for you to get a.

UG No. It's. It's. I'm pressing this and nothing's happening.

TA Because there's no liquid. Because there's

UG This is. This is liquid.

TA Oh, Okay. Turn this on. If you want to suck it up, turn this on.

TA Okay...Come on....

TA Umm....That's weird.

TA I think the connection the connection here is broke.

UG It's broken. Should we get another one?

TA Yeah, get another one.

UG Okay.

In Example 45, the undergraduate states what the problem is to the teaching assistant: “Something won’t go out. It can’t.” The teaching assistant needs to disambiguate the question by coordinating the verbal information with the visual information. In the teaching assistant's response, he needs to go through the experiment in a methodical, step-by-step approach to troubleshoot. He takes himself through the various parts of the experiment, walking through what he thinks the problems is. The undergraduate thinks that the teaching assistant has misunderstood 
what she thinks the problem is and what is going wrong with the procedure. She persists in her third turn with, "No, I mean...," which helps reorient her question. As the teaching assistant and the undergraduate are walking through the steps in the procedure together, they finally determine that one piece is broken.

This interaction is only partially successful, but it underscores many of the aspects of communication seen in other interactions. First, the undergraduate expresses what the problem is but does so with language that depends on situational reference, i.e., "it won’t go out." To respond appropriately to the undergraduate, the teaching assistant disambiguates the question, depending on the visual information presented along with the undergraduate's verbal information. The interaction develops because the undergraduate persists when she recognizes that there may be a misunderstanding. Both the undergraduate and the teaching assistant modify their speaking and actions in response to what is said and done in the interaction.

The undergraduate and the faculty member both rated this interaction with an insufficient degree of certainty. The undergraduate indicated that "the burette wasn't working and we didn’t know why." The undergraduate expressed an interest for more elaboration in the response, explanations of why things were happening in the way they were. Similarly, the faculty member thought that the teaching assistant could have explained more in the course of the interaction. The faculty member also pointed out that this interaction was a complicated interaction for the teaching assistant and the undergraduate because of information that was not clearly expressed in their exchange. Ultimately, the teaching assistant and undergraduate reached a conclusion, but it took persistence on the part of both participants to redirect the focus of the interaction. For 
this interaction, the teaching assistant commented that in situations similar to this one that "even native speakers have problems with this," explaining that the complexity of responding to the question is related to the experimental details and figuring out onthe-spot what is going on-reading the situation in order to respond.

The interactions related to procedures demonstrate that undergraduates are concerned about the precision with which they approach the material, and they are dedicated to following the instructions to carry out the experimental procedures as outlined in the lab manual. These examples also demonstrate that when undergraduates are presenting their concerns to their teaching assistants, they express their information in ways that require the teaching assistants to attend to visual information in coordination with the verbal information undergraduates express. Often, the teaching assistants need to support undergraduate expression of information by providing them with the terminology to describe the activities of the lab experiments. 


\section{Summary of Findings}

Analysis of data gathered in this project provided findings on chemistry lab communication, participant perspectives on lab communication, and successful communication between teaching assistants and their undergraduate students. Background questionnaires provided a profile of the undergraduate participants, and observations of the labs (audio and video recordings) provided information about the communicative activities of the first hour of lab sessions in this introductory-level chemistry lab. Analysis of data collected in the semi-structured interviews provided Likert-scaled opinions and comments from the participants on 10 dimensions related to both the questions undergraduates ask and the responses teaching assistants give in interactions. The interview process yielded a subset of 50 interactions, which were classified into successful and partially successful interactions from the participants' perspective, with no interactions identified as unsuccessful. Analysis of the interview interactions, using Flowerdew and Miller's (2005) framework of conversational listening, revealed features of the interactions that could be seen as limitations to successful communication but that the participants overcame to achieve successful communication.

\section{Chemistry Lab Communication}

Undergraduate participation for this study was high: all regularly attending native-English speaking undergraduates of eligible age participated. Undergraduates were interested in and receptive to contributing to a study that was intended to improve communication and facilitate learning in the labs. The undergraduates who participated in this study were aware of the challenges that the course and the subject matter 
presented and were committed to succeeding in the course. Those who agreed to participate in this research project completed all labs for the course.

The undergraduates attended an elite, mid-sized, university in the Northeast, with a highly competitive selection process and demonstrated themselves to being intelligent, engaged in, and dedicated to learning in the course. Undergraduate characteristics obtained from a background questionnaire provided a profile of the undergraduate participants. In the lab sections, there were nearly equal numbers of males and females, with slightly more females. There was a slightly higher proportion of first-year students enrolled in the course than second-year students. In the interview process, many of the second-year students reported that they knew that the course was demanding and had deferred taking it until their second year to ensure that they could dedicate the time the course demanded, which explains why this introductory-level course had almost as many second-year students as first-year students. Almost all undergraduates were either 18 or 19 years old. Two-thirds of the undergraduates were from suburban areas with English being the exclusive language spoken at home.

Almost all undergraduates had studied at least one foreign language, and over half had traveled or lived abroad.

With only a few exceptions, the undergraduates had elected or were considering science majors, mostly biological sciences. Nearly all undergraduates had studied chemistry in high school, with over half reporting a minimum of 2 semesters of high school chemistry and almost half reported taking AP chemistry. In addition, almost all of the undergraduates had studied calculus in high school, the majority 
reporting 4 years of high school mathematics. Furthermore, over half reported taking at least one university-level mathematics course.

Communication during the first hour of five lab sessions in three different lab sections was documented in digital audio (6 hours) and video (9 hours) formats, resulting if 15 hours (or 900 minutes) of recorded laboratory communication. The unit of analysis for examining communication in the labs was an interaction, defined as two or more uninterrupted alternating turns. Analysis of communication that occurred in the labs provided insight into patterns of how communication in the labs occurred: how frequently interactions occurred, how long the interactions were, who initiated the interactions, the gender of the participants of the interactions, and the activities discussed in the interactions.

Communication between the teaching assistants and the undergraduates was frequent, 877 interactions were identified, averaging approximately one interaction per minute. Fewer than 1 in 10 interactions lasted more than 1 minute. Interactions were brief, with three-fourths 30 seconds or less. There were variations in the length of interactions based on the lab sessions and lab sections in which they occurred. In general, interactions were shorter as the semester progressed; Chi-square analysis supports a significant association. Chi-square analysis also supports a significant association between lab section and length of interaction. In general, interactions occurring in the Tuesday section tended to be shorter than interactions occurring in the Wednesday and Thursday lab sections. The Thursday sections tended to have slightly longer interactions. 
Overall, communication in the labs was more likely to be initiated by the undergraduates than the teaching assistants, with two undergraduate-initiated interactions for every one initiated by the teaching assistant. Patterns of interaction initiation demonstrated that there were changes over the course of the semester of who initiated interactions. At the beginning of the semester, undergraduates initiated nearly three-fourths of interactions; however, by the end of the semester, undergraduates and teaching assistants were initiating nearly equal numbers of interactions. Chi-square analysis supports that there is a significant relationship between the lab session in which an interaction occurs and who initiates the interaction. In this study, there were also indications that undergraduates initiated interactions more readily when they had established rapport with their teaching assistant.

It became apparent during the interview stage of this project that issues related to gender would not be adequately captured in this research project. One of the teaching assistants indicated that gender differences were likely to appear by examining the entire four-hour lab session, rather than just a segment of the lab. Furthermore, a study looking at gender-related issues would need a methodology that could accommodate and account for the ways in which undergraduates were paired to carry out the lab experiments: male-male, female-female, or male-female.

Overall, females participated in interactions at a slightly higher rate than the males. The participation rate of males and females in interactions is nearly identical to the gender composition of the male and female participants in the study. Examining male and female participation in interactions over the semester, it appeared that females participated in interactions at a rate of two female interactions for every one 
male interaction. By the end of the semester, males were participating in over half of the interactions. However, chi-square analysis did not support that this was a significant association.

Differing patterns of undergraduate participation in interactions by gender appeared across the three sections. The Tuesday and Thursday sections had similar rates of participation for males and females, with a slightly higher proportion of interactions being of the same gender as the teaching assistant. The male-female participation rates for the Tuesday section (male teaching assistant) showed slightly higher proportions of male participation. The Thursday section (female teaching assistant) had a slightly higher proportion of female participation. The Wednesday section (male teaching assistant), however, had a higher proportion of female participation than male participation. Chi-square analysis supports that this is a significant association between the sections in which an interaction occurred and the gender of the undergraduate participant.

Interactions were examined for the types of information discussed. The activities discussed in the interactions were classified into six categories: equipment, lab preparation, materials, procedures, safety, and social. Procedure-related interactions comprised one-third of all interactions, as did interactions related to lab preparation. Equipment- and materials-related questions accounted for one-fifth of all interactions, with safety and social interactions occurring with much less frequency. Comparisons of the activities in the labs over the course of the semester revealed differences in occurrence for some types of interaction activity. Interactions related to lab preparation occurred in the highest proportion in Lab 8. Interactions related to procedures occurred 
in highest proportions in Lab 6. The highest proportion of equipment-related interactions occurred in Lab 4. Interactions related to materials occurred in the lowest proportion in Lab 5, which also included the highest proportion of safety-related interactions.

Chi-square analysis supports that there is a significant association of the lab in which an interaction occurs and the type of activity. However, it appears that the patterns seen in the activity topic of the interactions is related to the content of the lab in which the interactions occurs, rather than a progression over time. Chi-square analysis also supports a significant association between the activity discussed in an interaction and the lab section in which it occurred. The Thursday section had the highest proportion of procedure-related interactions and lower proportions of interactions related to equipment and lab preparation. In general, the Tuesday and Wednesday sections were similar in the activities discussed in the interactions, i.e., higher proportions of lab preparation and equipment questions. The Wednesday section also had a higher proportion of social interactions.

An examination of interaction initiation (undergraduate and teaching assistant) by gender of the undergraduate participants pointed to approximately the same proportion of teaching assistant-initiated interactions occurring with males and females, and these proportions reflected the gender composition of the combined lab sections. Undergraduate-initiated interactions by males and females occurred in similar rates as well. Chi-square analysis revealed that there is no significant relationship between the gender of the undergraduates involved in an interaction and who initiates the interaction. 
Looking only at the undergraduate-initiated interactions in the Tuesday and Thursday sections (the sections without the substitute teaching assistants), there were differences in gender patterns over the course of the semester. Earlier in the semester, females were more likely to initiate interactions with the teaching assistants at a rate of two questions for every one that a male would initiate. By the end of the semester, this relationship was reversed and males were initiating two interactions with the teaching assistant for every one that females did. Chi-square analysis revealed a statistically significant association.

Analysis of interactions by who initiated the interactions and the activity of the interaction revealed that interactions for certain activities are more likely to be initiated by the teaching assistants and other types of interactions by the undergraduates. Nearly four-fifths of all safety-related interactions were initiated by teaching assistants. Teaching assistants initiated slightly more than half of the interactions related to lab preparation and almost all of the social interactions. Undergraduates initiated fourfifths of all interactions related to equipment and materials, and almost three-fourths of interactions related to procedures. Chi-square analysis supports that there is a significant association between who initiates an interaction and the activity discussed in the interaction.

Interactions were examined by the gender of the undergraduate participants and the activity discussed in the interaction. There were differences here, as well. In most instances, the proportion of males and females engaged in interactions related to various activities in the labs were very similar, except in the case of social interactions. Males were involved in slightly more than half of the interactions related to lab 
preparation and equipment. Females were involved in interactions in a slightly higher proportion of interactions related to materials, procedures, and safety. However, in the first hour of the labs, females were involved in 9 out of 10 interactions that were social in nature. There was a significant association between the gender of the undergraduate participant involved in an interaction and the activity discussed in the interaction.

\section{Interviews}

From the set of all lab interactions, a subset of interactions was identified through the interview process for discussion and analysis. Participation in the interview process varied. The teaching assistants and faculty member complied with all requests to examine and comment on the interview interactions and were available to review interactions on multiple occasions. The undergraduate participation rate was lower, a third of participating undergraduates participated in the interview process, with indications that undergraduates who participated in more interactions came in for interviews. Undergraduates who did participate in the interviews participated in only one interview session each, although they were invited to participate in multiple interview sessions. The undergraduate participation rate was a limitation of this study.

Even though the participation rate of undergraduates was lower than hoped, the background characteristics of the undergraduate participants who were interviewed were representative of all undergraduate participants in all areas. Although the interview sub-group had a slightly higher proportion of females compared to the larger group, the difference was not statistically significant.

The characteristics of the subset of interview interactions $(n=50)$ reflected the interactions from the larger collection of interactions in many important ways. Because 
of the focus of this investigation, the subset of interview interactions were from the proportion of undergraduate-initiated interactions and excluded the teaching assistantinitiated interactions of the larger set of interactions. The interview interaction subset included all lengths of interactions, with nearly two-thirds less then 40 seconds long. Males initiated slightly fewer of the interview interactions than females, but in rates similar to the larger sample of undergraduate-initiated interactions. For the activities discussed in the interview interactions, procedure-related interactions accounted for more than half of the interactions, equipment and materials two-fifths, and lab preparation the remainder. No interview interactions discussed topics related to social and safety activities.

The semi-structured interview asked participants to rate an interaction, using a 7-point Likert scale, on a total of 10 interview items. The interview items covered 10 dimensions, five related to the undergraduate's question that began the interaction, four related to the teaching assistant's response, and one asking the participants to rate the interaction for its overall success. Participants were encouraged to include additional comments at any point during the interview.

Opinions from the Likert-scaled portion of the interview process resulted in four categories for each interview item, according to how the three participant responses occurred: 1) congruent opinions, in the direction of agreement or disagreement with the interview item, participants having the same opinions to a sufficient degree of certainty; 2) divergent opinions, participants having opposite opinions with a sufficient degree of certainty; 3) insufficient degree of certainty, one or more of the participants rated the interview item on the Likert scale responding with a 
rating of an insufficient degree of certainty, and 4) missing response, one or more participants not being able to respond to the interview item.

In an item-by-item comparison of the interview items on the 10 dimensions covered, agreement among the three participants on the interview items occurred at a rate slightly higher than two-thirds on the items asking for opinions on comprehension: teaching assistant comprehension of the question and undergraduate comprehension of the response. The rate of agreement was slightly higher for the two-way comparison of undergraduates and teaching assistants for teaching assistant comprehension of the question and for undergraduate comprehension of the response. On all other interview dimensions, participants agreed about half of the time in the three-way comparisons. Once again, rates for the undergraduate-teaching assistant comparisons were slightly higher. Divergent opinions occurred most often when gauging what was motivating the undergraduate's question, i.e., was the undergraduate asking for content information or was the undergraduate asking for confirmation. Comments from the undergraduates indicated that their questions were multi-functional, simultaneously asking for content information and confirmation that what they were doing was right.

Interview Item 10 was used to determine whether an interaction was successful or unsuccessful. Each participant group identified slightly more than three-fourths of the interactions as successful. However, in this study for an interaction to be classified as successful, there needed to consensus, with a sufficient degree of certainty, among all three participants. Agreement among all three participants that interactions were successful occurred in over half of the interview interactions. No interactions were identified as unsuccessful, which could be related to the undergraduates who 
participated in the interview process. That is, undergraduates who were not satisfied and did not think that their interactions were successful with the teaching assistants may have not chosen to participate in the interview process. As a result, all 50 of the subset of interview interactions were classified as either successful or partially successful.

The different dimensions explored in the interview process elicited comments from the various participants. For the dimensions that examined the undergraduate questions, the undergraduates and the faculty member commented more often than the teaching assistants. Undergraduates commented for Interview Item 1 (teaching assistant understanding of the question) that comprehension of the question was more than the teaching assistant understanding the question. The teaching assistant understood the undergraduate's situation. While the undergraduates expressed that they were always comfortable asking the teaching assistant questions, they sometimes saw their own questions as “stupid.” The undergraduates also indicated that other undergraduates may not have been as comfortable asking the teaching assistants questions. Undergraduates also indicated in comments related to Interview Items 4 and 5 that they intended for their questions to simultaneously request discrete, content information and ask for reassurance. In other words, undergraduates saw their questions as multi-functional requests for clarification of information and confirmation that they were understanding the content and the activities of the lab correctly.

The teaching assistants gave few comments about the undergraduate questions. Their comments related to pedagogical issues of how to approach answering undergraduate questions. However, the faculty member provided much background 
information on the questions undergraduates asked, indicating when questions were not clearly expressed and where undergraduates were having difficulties explaining their questions. In some instances, the faculty member was able to provide insight into the source of undergraduate questions, e.g., information omitted from the lab manual or undergraduates not being sufficiently specific in their choice of terminology. As the faculty member indicated, and undergraduate comments supported, in many cases it took two tries for the undergraduate and the teaching assistant to negotiate and agree on what question the undergraduate was asking and what information the undergraduate needed to solve his or her problem.

Comments from the participants that related to the teaching assistants’ responses differed based on their perspectives. The teaching assistants were most critical of their language skills, feeling that quicker responses with less hesitancy would have been better. The teaching assistants wanted their language and their responses to be more efficient. On the other hand, the undergraduates in general appreciated that the teaching assistants demonstrated what they should be doing in addition to providing explanations. The undergraduates also indicated that they wanted the teaching assistants to explain why what the undergraduates were doing was right and why what they were doing was wrong, when it was wrong. In general, the main suggestion that undergraduates had was for the teaching assistants to include more elaboration in the verbal responses.

The faculty member's comments covered a wider range of topics, including undergraduate performance, teaching assistant performance, and issues related to teaching in the chemistry lab in general. The faculty member indicated the importance 
of teaching assistants' simultaneously demonstrating and expressing information. She echoed the undergraduates' comments that the use of demonstration coordinated with a verbal description of what needed to be done was essential for successful communication in this learning environment. She also indicated that both the undergraduates and the teaching assistants needed to take steps to ensure that they were both talking about the same place in an experiment for the interaction to be successful. In many instances, the interaction took more than one try for the undergraduate and the teaching assistant to be talking about the same point.

During the interview, the participants often provided comments directly related to each of the 10 interview items. However, at the end of the interview, the participants provided additional information about interactions in the labs. The additional comments were more global in nature and were usually inspired by the type of interaction that had just been reviewed. Additional comments from the participants were examined in relationship to the categories of success for the interactions, and various themes emerged from undergraduates’ comments in the additional comments and discussions.

Teaching assistants focused their additional comments on the skills and abilities of the undergraduates as a class. All teaching assistants were very positive about their undergraduates. The teaching assistants thought that the undergraduates were capable, well prepared, and dedicated to learning the material. All three teaching assistants enjoyed teaching the undergraduates. One teaching assistant identified differing patterns between males and females in his section: males ask questions later in the lab 
session and females earlier. Another teaching assistant commented on issues related to teaching chemistry in general.

The faculty member discussed both teaching assistant and undergraduate communication and interaction. The teaching assistants demonstrated and discussed what needed to be done, both of which are essential for teaching in the chemistry labs. In some cases, teaching assistants could have provided more explanation and elaboration for improved communication. Frequent negotiation was required by the teaching assistants and the undergraduates so that they were communicating on the same point in the experiment. The faculty member stated that the undergraduates were sometimes too precise when it was not necessary, but were not precise enough in other situations. The undergraduates sometimes had difficulties expressing their questions and using the appropriate terminology. In general, the faculty member's comments were positive about the work of both the teaching assistants and the undergraduates. The teaching assistants supported and guided student learning, and the undergraduates were committed to developing their skills in the chemistry lab to understand chemistry.

Undergraduate comments tended to be aligned with the interactions based on the success category of an interaction, successful or partially successful. Three themes emerged in the undergraduate comments related to interactions that were classified as successful. One theme emerged for the partially successful interview interactions.

First, undergraduates clearly had different expectations for the communication skills, especially pronunciation, of their teaching assistants based on the type of teaching. In a lecture format, typical of the pre-lab overview, clear pronunciation was a priority. However, in the question-answer format of the lab situation, pronunciation, 
while still important, was not seen as problematic in the lab and was not seen as a barrier to communication. In the interactive lab interactions, undergraduates prioritized teaching assistants’ understanding and comprehension skills.

A second theme that emerged was that the undergraduates were comfortable communicating with their teaching assistants and trusted that the teaching assistants were committed to helping them learn the material. The teaching assistants had established rapport with their students and provided a learning environment that supported student questions. The undergraduates viewed their teaching assistants as friendly and enjoyed interacting with them, though they did not want to ask "stupid" questions. Furthermore, undergraduates were comfortable pursuing questions and did not expect communication to be successful immediately. They recognized that successful communication required negotiation to achieve mutual understanding of the question or problem to be resolved.

The third theme that emerged from the undergraduate comments emphasized how the teaching assistants responded to undergraduate questions. Undergraduates wanted and needed the teaching assistants to demonstrate what to do, in addition to expressing the information verbally. For the undergraduates, much of their understanding of the material and learning in the labs depended on the coordination of the visual information, the demonstration, with the verbal expression of the information. In many instances, the information that teaching assistants communicated visually was just as important, if not more important, than the verbal information. The undergraduates depended on visual demonstration as an important constituent to successful communication and learning in the chemistry labs 
In the partially successful interactions, the one consistent theme that emerged from the undergraduate comments was that even though the teaching assistant's response included the verbal expression of information to accompany the visual demonstration, the undergraduates felt that they needed more verbal elaboration of information. Specifically, undergraduates wanted additional explanations related to why. The undergraduates wanted the teaching assistants to express why what the undergraduates were doing correctly was correct and why what the undergraduates were doing incorrectly was incorrect. The undergraduates wanted to hear both positive and negative comments expressed and explained by the teaching assistants.

\section{Interaction Analysis}

Analysis of the subset of 50 interactions from the interview process was guided by a framework of conversational listening (Flowerdew and Miller, 2005) and examined structural and functional features of the interactions from the listener's perspective: opening an interaction; closing an interaction; and topic, as established in the question presented in the undergraduate's initial question. Turn-taking, syntactic structures of initial questions, lexical choices, and the types of information discussed were also analyzed.

Analysis of chemistry lab communication during observations of the lab sessions indicated that differing styles of communication existed in the lab sections, which may have contribute to increased success in the interactions. It appeared that a higher proportion of successful interactions appeared in the Tuesday section than in the Thursday section. However, chi-square analysis does not support a significant 
association between lab section and success of interactions, though the association was trend level.

Turn-taking behavior within the interactions was usually a pattern of alternating turns between the undergraduates and the teaching assistants, with successful interactions having slightly fewer turns than the partially successful interactions. However, some communicative exchanges challenged the definition of what constitutes a communicative turn in this setting. In some interactions, actions and language were coordinated in a turn. In some instances, a turn was only a verbal expression. However, in some interactions, a participant's turn was the action or activity alone. These activity turns could not be monitored by the other participant by listening; rather, they had to be monitored visually.

Interactions were opened by undergraduates, who initiated the interactions in the subset of interview interactions. To gain the attention of the teaching assistant, undergraduates used the teaching assistant's name or some other vocalization, e.g. “uhm.” However, undergraduates also signaled their questions, with no introduction, by just asking the question. Rarely, did an undergraduate explicitly indicate intention to introduce a question with overt discourse marking, such as "I have a question.”

Closing interactions also had identifiable patterns. One of the participants, either the undergraduate or the teaching assistant, would close an interaction with "Okay" or some confirmation that the interaction was over. In the subset of interview interactions, the teaching assistants closed the interactions two-thirds of the time.

Topics of the interactions were established by the undergraduates through their questions, expressed in their first or second speaking turn. The syntactic forms of these 
questions were primarily of five different syntactic patterns: wh-questions, yes/no questions, questions with alternatives signaled by or, statement of a problem, statement of a situation followed by a question.

Analysis of question forms revealed that when asking their question, the undergraduates expressed their questions using a range of lexical choices or lexical precision. In some instances, undergraduate questions were clearly stated, syntactically well-formed, expressed using precise terminology, and easily understood from the information available in the question itself. In other instances, questions were expressed with heavy dependence on deictic reference and were ambiguous. For the ambiguously expressed questions, it was often impossible to adequately or appropriately respond to the question as it was stated, depending only on the language of the question.

In an examination of the ambiguously expressed questions, ambiguity was tied to the use of deictic reference; reference was most often situational (exophoric) reference rather than textual (endophoric) reference. In order for the teaching assistants to disambiguate the question, they needed additional information provided by the context. In other words, the simple act of hearing and responding to a question required that the teaching assistant understand the visual information that accompanied the verbal expression of the question. As one undergraduate expressed, the need was not so much for the teaching assistant to understand the question as it was for the teaching assistant to understand the situation.

Teaching assistants and undergraduates both depended on visual and verbal information for mutual understanding and successful communication. Undergraduates 
were also specific about identifying how for them the demonstrations that the teaching assistants provided were crucial to their understanding information about the chemistry labs and the experiments. The undergraduates appreciated both the verbal and the visual information that teaching assistants provided and expressed that both types of information were necessary for successful communication and to facilitate their learning in the labs.

After the interview interactions were analyzed for how interactions were syntactically and lexically formed, the interview interactions were analyzed to see what topics the undergraduates’ questions initiated. Teaching assistants must recognize the form of a question to understand it, and they must also understand what the question is about in order to respond appropriately and accurately. The activity categories that emerged in the analysis of lab communication earlier in the study provided a structure for examining the questions undergraduates initiated. The interview interactions only included examples of interactions that were related to equipment, lab preparation, material, and procedures. The interview interactions did not focus on safety- or socialrelated interactions.

There were only two interview interactions for the topic of lab preparation. Both of these interactions were instances in which the undergraduates were asking the teaching assistants to assess their understanding and approach to solving problems as presented in a pre-lab question and a pre-lab quiz. In both instances, the undergraduates were seeking support and information from the teaching assistants about the undergraduates’ judgments when approaching a problem. The undergraduates were simultaneously seeking information and confirmation that they 
were approaching the situation properly. They were soliciting the opinions of the teaching assistant, a more experienced chemist, to monitor their own understanding of the course material.

Interactions that focused on equipment and materials shared similarities in the types of questions that were asked of the teaching assistants. Questions related to equipment and materials could be categorized into one of three types of information that undergraduates were asking for help with: locating and acquiring equipment or material, identifying an appropriate piece of equipment or material for a particular purpose, and understanding the function of a piece of equipment or precise measurement of a material. All three types of questions for equipment and materials centered on the undergraduates developing familiarity and dexterity with the resources of a chemistry lab, using the resources and talking about them. As the undergraduates became more familiar with the labs and the equipment and materials used to carryout the experiments, they were also developing a sense of precision.

First, the undergraduates needed to develop familiarity with the physical environment of the labs and understand how to acquire the equipment and materials that they needed for the experiments. For these types of questions, the undergraduates knew what they needed. They did not know where or how to acquire it. In other words, they were not sufficiently familiar with the labs and resources for obtaining the items they needed.

The second type of equipment and materials questions were ones in which the undergraduates needed help determining what equipment or material they needed. The undergraduates needed support and assistance from their teaching assistants about what 
they should use. In some cases, the undergraduates were aware that they needed a special type of equipment or material; however, they were unsure what the appropriate choice or item was. The undergraduates were developing judgments for their work as chemists, which required that the teaching assistants provide supporting explanations to the undergraduates. In some cases, the undergraduates had a clear sense of what they needed, but in other instances, the undergraduates needed more support and information from the teaching assistant.

The third type of equipment and materials questions were expressed differently when the topic was related to materials or equipment. However, questions in these categories shared a similarity: undergraduates were developing a sense of precision for how to understand the function of an object or use of a material. The questions related to materials were more consistent and asked specifically about the quantity of a material that was needed. In these cases, undergraduates were developing their sense of what type of precision was needed in measuring and using the materials. The equipment questions were related to how a piece of equipment functioned. The undergraduate needed an explanation on how to use a piece of equipment, how it worked, or if it was functioning properly.

The interactions that were related to questions about procedures were also of three different types. The procedure-related interactions were the most frequently occurring types of all interview interactions, and in many respects were more complex questions because these interactions included not only issues and concerns related to equipment and materials but also to how things work together. For the procedure- 
related questions, undergraduates were asking three main types of questions: what to do, how to carry out a procedure, and how to problem-solve.

The first type of question related to procedures was the most common: asking the teaching assistant what should be done. Often, these questions were situations in which the undergraduates were reading the instructions in the lab manual and were double-checking with the teaching assistants about what they should be doing.

The second type of question related to procedures were questions in which the undergraduates needed the help of the teaching assistants to explain and demonstrate how to complete a step in an experiment. For example, in setting up a vacuum properly, the information that was provided in the lab manual described the procedure, but when the undergraduates where confronted with the hands-on experience of setting up a vacuum, they needed additional support and information from the teaching assistants to make the set-up match the instructions.

The last type of procedure-related question occurred in situations where the undergraduates had completed the steps in an experiment as detailed in the lab manual, but for some reason the outcome was not successful or it was not as anticipated. The undergraduates needed the teaching assistants to help troubleshoot. These interactions were usually longer and more complicated, and the teaching assistant was called on to walk through the steps of the experimental procedure using the apparatus that the undergraduates had constructed to locate the problem and then offer a solution.

In the procedure-related questions, undergraduates were seeking the advice, support, and help from their teaching assistants as the undergraduates worked through the chemistry experiments. The procedure-related questions demonstrated that the 
undergraduates were developing their understanding of and judgments about how to approach the work in the chemistry laboratory, as well as their abilities to discuss the activities of the experiment and lab. The teaching assistants had different teaching and communication styles of working through the procedure-related questions, especially when they were troubleshooting. One teaching assistant tended to be more expressive verbally, modeling for the undergraduates how chemists talked. Another teaching assistant tended to use less language modeling, requiring the undergraduates to express the information for themselves. Both styles were seen as successful by the participants, though the interactions in the labs in which the teaching assistant allowed the undergraduates to express the information tended to take slightly longer. 


\section{CHAPTER 5: DISCUSSION OF FINDINGS}

\section{Review of Research}

Three main assumptions have guided the research on international teaching assistant communication. First, research on international teaching assistant communication has assumed that international teaching assistants will be successful classroom communicators in American universities when their speech approaches that of native-English speakers. Conversely, the more international teaching assistant speech deviates from native-speaker norms the less successful they will be as communicators. Second, the research has also assumed that when evaluating the speech and communication of non-native speaking teaching assistants, the opinions of people external to the communicative exchange can provide sufficient understanding of where communication is and where communication is not successful. Finally, the research has focused on understanding classroom communication from the perspective that the significant language in the classroom is the language that originates with the instructor in the class.

Research on international teaching assistant communication has examined the speaking and discourse patterns of international teaching assistants from many perspectives. Much research (Field, 2005; Hahn, 2004, Leather, 1999; Munro \& Derwing, 2005, Pickering 2001, 2004; Riggenbach, 2000) has examined the mechanics of producing spoken English (consonant and vowel production, stress patterns, intonation patterns, rate and rhythm of speech, and overall fluency) with the goal of understanding how deviations in the speech produced by non-native speakers interfere with communication. Comparing how closely non-native speech approaches native- 
speaker norms, researchers have been interested in examining what non-native speakers produce and how that speech is perceived by listeners in order to characterize what comprehensible and intelligible speech is for this population. As this research base has grown, listener perceptions and listener background characteristics have been shown to influence perceptions of non-native speaker speech (Bresnahan et al., 2002) and have become important considerations when discussing communication between native and non-native speakers of English.

More contextualized research of international teaching assistant communication patterns (Jenkins \& Parra, 2003; Tyler, 1995; Williams, 1992) has expanded the scope of international teaching assistant communication research to include discourse-level phenomena. Methodologically, these investigations focus primarily on how the speech patterns of non-native speaking and native speaking teaching assistants differ in terms of communication patterns and strategies in classrooms or classroom-simulated environments. This body of research has identified that cultural, non-verbal, and discourse structure differences in communication patterns can contribute to communication breakdowns between international teaching assistants and American undergraduates in face-to-face communication.

A few research studies examining in-context communication of international teaching assistants in actual classrooms (McChesney, 1994; Myers, 1994, Rounds, 1987, 1994; Tanner, 1991; Williams et al., 1997) have looked at typical interactive communication during office hours, in recitation sections, and in laboratory sessions. While these studies have examined interactive communication in real-world learning environments between international teaching assistants and their undergraduate 
students, they have focused exclusively on the language produced by the non-native speaking teaching assistants. Mostly, these studies compare the in-context speech of international teaching assistants with that of native-speaking teaching assistants to understand why non-native speakers have difficulties communicating.

The research literature examining international teaching assistant communication in actual classrooms has focused primarily on question-answer interactions, examining exclusively the questions that teaching assistants initiate and use in guiding classroom instruction. Prior research has not examined communication that originates with the undergraduates, that is, the questions that undergraduates ask of their teaching assistants. The sparse references in the research literature to undergraduate-initiated communication in classrooms taught by international teaching assistants has largely dismissed undergraduate-initiated communication, often referring to undergraduate language use in the classroom as consisting of ill-formed questions (Myers, 1994; Rounds, 1994).

To date research has not examined classroom communication between undergraduates and international teaching assistants by looking at all communication that occurs in these classrooms, undergraduate and teaching assistant. Furthermore, the research literature has not examined classroom communication between these populations from the perspectives of those actually involved in the communication, but there are indications that obtaining their perspectives is crucial to clearly understanding the communicative exchanges that occur in these educational settings.

In an effort to know more about the communication and interaction patterns between international teaching assistants and their undergraduate students, this study 
investigates the language use and communication strategies between non-native speaking teaching assistants and native English speaking undergraduates and their approaches to negotiating information in the interactive setting of an introductory-level university chemistry laboratory, a learning environment where a high number of international students are placed in teaching positions. The focus of this investigation is to better understand how successful communication in academic environments can be encouraged and supported.

Research Questions: The research questions guiding this project were as follows:

- In university-level chemistry laboratories, what constitutes successful communication and/or successful negotiation of information between nativeEnglish speaking students and their teaching assistants who are advanced nonnative speakers of English?

- What communication skills (i.e., linguistic, paralinguistic, non-verbal, cultural, pedagogical) contribute to successful classroom interactions between non-native English speaking teaching assistants and their native-speaking undergraduate students?

The current research project builds and expands on the research investigating international teaching assistants in American university classrooms by looking at interactive classroom communication in a real-world setting, a chemistry lab, taking advantage of the collaborative nature of the communication this setting provides. However, it differs from previous research on international teaching assistants in significant ways, conceptually and methodologically. 
First, this study takes the unit of analysis as the interaction, defined as two or more alternating uninterrupted turns, that occurs between international teaching assistants and their undergraduate students in real-world communication situated in a classroom environment. This approach differs from previous research in that it does not look exclusively at the spoken language international teaching assistants produce nor does it attempt to understand how undergraduates evaluate the mechanical aspects of non-native spoken English in a classroom context. One consequence of using an interaction as the unit of analysis is that interactive classroom communication and the interactions that occur are seen as a process of collaborative communication, where both the teaching assistant and undergraduate contribute to the communicative event and must work together to create the interaction and negotiate understanding. In other words, interactive communication in the labs is seen as a spontaneous, meaningful, twoway negotiation and exchange of ideas and information.

To date, research on international teaching assistant communication has focused on and examined the language produced in classroom environments of the teaching assistant delivering course content. This point of view presupposes that the significant language used in classroom environments originates with the teaching assistant. While previous research has placed the speech of the teaching assistant as the most important speech in classroom discourse, this research project has taken a complementary and previously unrepresented view of classroom communication of international teaching assistants: classroom communication also includes communication that originates with the undergraduates. 
This view recognizes the contributions undergraduate language use and communication make in the instructional discourse of the classroom and it sees undergraduate-initiated classroom communication as an essential element of the communicative and interactive nature of American classrooms. In brief, this study adopts a broader understanding of a teaching assistant's language use in a classroom, one that includes two perspectives: the language the teaching assistant initiates and directs to undergraduates and the language undergraduates initiate and direct to the teaching assistant. The primary focus of analysis of this study has been on the language initiated by the undergraduates that teaching assistants respond to, and this study also examines the teaching assistants' language as spontaneous reactions and responses to the undergraduate-initiated communication.

This study found that that the interactions were more often initiated by the undergraduates: almost two thirds of lab interactions were initiated by the undergraduates. The sparseness of teaching assistant initiated interactions, one third of the interactions in this study, may have occurred for many reasons. It is possible that it is typical for this type of learning environment for teaching assistants to initiate fewer communicative interactions. The pattern of interaction initiation could also have been related to differing cultural assumptions about classroom behaviors. For example, the international teaching assistants in this study may have limited their interaction initiation in response their perception that in this learning environment undergraduates are responsible for interaction initiation. Issues related to gender may have also influenced the pattern of interaction initiations. 
Second, this research project differs methodologically from previous research on international teaching assistant classroom communication in that it seeks to gain the perspective of the actual participants engaged in and invested in the interactions in order to understand and interpret what motivates the interactions and how the participants view the interactions as they unfold. In this study, the participants determine what is successful and what is unsuccessful communication, rather than having a researcher or external observers detached from the actual experience of meaningful, interactive communicative determine what is or is not successful communication. The listener perspectives in this study are the listeners in the interactions, both the undergraduates and the teaching assistants, and not the researcher. In this study, semi-structured interviews were used to obtain the perspective of participants involved in the interactions: the undergraduates, the teaching assistants, and the faculty member guiding instruction in the course. The innovative methodology employed in this research project, with the objective of obtaining the participants perspectives, led to the significant findings of this study.

\section{Implications}

This exploratory study into what constitutes successful communication and/or successful negotiation of information between native-English speaking undergraduates and their teaching assistants who are advanced non-native speakers of English in university-level chemistry labs generated large amounts of data for analysis. The information, derived from three primary sources, included findings from observations of actual chemistry lab sessions, interviews with the participants in the classroom interactions, and analysis of actual interactions that occurred in the labs. Taken together, 
the findings obtained from these multiple data sources make important contributions to our understanding of communication between non-native speakers placed in instructional positions and their native speaking students in two primary ways. First, discourse guiding communication in interactive chemistry labs frequently originates with and is directed by undergraduates rather than teaching assistants; second, research investigating communication between these two populations benefits from the perspectives of the participants involved in the communicative exchanges.

From the data collected in classroom observations, the key finding of this study is that undergraduate-initiated interactions constituted a high proportion (two-thirds) of the classroom communication, highlighting the prevalence of undergraduate-directed classroom discourse in this setting. In an interactive classroom environment, such as a university-level chemistry laboratory, classroom communication originates at times with the teaching assistant, but more frequently with the undergraduates. This means that the communication skills necessary for teaching assistants to be effective in this educational environment include not just the language and discourse that is motivated and presented by the teaching assistant but also the language and the communication skills of responding to language and discourse generated by undergraduates. The assumption that the important speech in the classroom is what the teaching assistant produces when instructing undergraduates is challenged by the findings of this study as being too restrictive and excluding the majority of communication that occurred in this study: teaching assistants responding to undergraduate-initiated questions.

This brings to the forefront that in these educational environments in order for the teaching assistants to effectively and efficiently function, they need to be in 
command of two skills: their production skills of spoken English and their comprehension skills of understanding undergraduates engaged in meaningful learning activities. In interactions in which the discourse originates with the undergraduates, the skills of comprehension are a pre-requisite for appropriate teaching assistant responses.

Findings of this study reveal that in the context of a chemistry lab, language use is not a one-way delivery of information from teaching assistant to undergraduate, in which the success of the communicative exchange depends on the production skills of the speaker, though those skills are important. Rather, in this interactive setting, classroom communication is very much two-way communication, with undergraduates guiding the direction of the communicative exchange of the educational experience through their questions and requests. The teaching assistants need to understand the language and the needs of the undergraduates before they can respond to them, and this occurs with high frequency, sometimes as much as one question every minute.

Extrapolating from the interview data, the indications are that over the course of the semester, the undergraduates and teaching assistants were developing their skills of how to successfully negotiate information. In the two lab sessions for which undergraduates provided the most feedback through the interviews, Lab 4 and Lab 7 , interactions averaged one per minute and were initiated by the undergraduates most frequently on topics related to equipment, materials, and procedures. Half of these interactions were considered successful, and the other half were seen as partially successful, with the tendency for successful interactions to occur in the lab that occurred later in the semester. 
The finding that undergraduate-initiated discourse is the predominate discourse in the labs suggests that when evaluating the linguistic competencies of non-native speakers who will function in instructional capacities in this educational setting, skills at producing comprehensible and intelligible speech are only one part of the set of communication skills that need to be assessed. Comprehension skills also play a significant role in the abilities for non-native speakers to succeed in interactive educational environments and need to be assessed. In brief, while a teaching assistant's skills of pronunciation matter to undergraduates, i.e., the undergraduates need to be able to understand the speech of their teaching assistants, the teaching assistant's comprehension of the speech and discourse of their undergraduate students contributes substantially to how successfully the teaching assistant can communicate in an interactive classroom. Similarly, preparation programs that emphasize production skills of English at the expense of comprehension skills are not providing adequate instruction to the non-native speakers.

Understanding that a significant amount of classroom discourse originates with undergraduate discourse means that teaching assistant understanding of undergraduate language is critical for successful classroom communication and effective instruction. In order for teaching assistants to respond accurately and effectively to undergraduategenerated discourse requires that teaching assistants understand what questions undergraduates are asking. In addition to the basic listening comprehension skills of decoding speech in face-to face communication, teaching assistants need to be aware of the types of information that undergraduates need in order to support their learning the material. 
This study underscores the importance of listening comprehension skills in successful communication of international teaching assistants and their undergraduates in the interactive setting of science labs. At the same time it draws attention to the discourse generated by the undergraduates in this learning environment. The findings from this study of undergraduate discourse are that in many instances, undergraduate control of the discourse of the discipline is still developing. Even though the undergraduates are native speakers of English, they are not always in command of the discourse of the discipline they are learning, as evidenced by heavy dependence on deictic reference and by imprecise or inaccurate use of chemistry terminology in the labs. This observation also points out the importance of the spoken production skills of the international teaching assistants: to facilitate undergraduate mastery of the language of the discipline, the teaching assistants need to clearly articulate and accurately use the key terminology from chemistry.

This study revealed that undergraduates learning the course material express themselves using a range of lexical specificity, frequently depending on the deictic (situational) reference. In the questions generated by the undergraduates, there is a range of information expressed. Sometimes the questions are completely expressed verbally and can be responded to based on general contextual information, while other undergraduate-generated questions are completely embedded in the context and cannot be understood without information from the context—-seeing where and what the undergraduate is referring to and where the undergraduate's activities are situated in the lab experiment. 
One of the complexities of understanding undergraduate-generated questions for international teaching assistants is that often undergraduates are developing their skills of using the terminology and the expressions of the discipline, and when they ask their questions, the questions are not always expressed with enough lexical specificity for easy comprehension. Undergraduate questions in this study were not ill-formed; rather, the undergraduate questions were syntactically well formed but ambiguously expressed and required that the teaching assistants disambiguate the undergraduates' questions. Disambiguation of spoken information often requires accompanying visual and contextual information, especially in relation to the equipment and materials of the chemistry labs. The participants were using words, gestures, and physical resources to construct their discourse (Roth, 2000)

To clearly communicate, undergraduates and teaching assistants depended on physical resources, using visual channels to communicate information. Communication in this learning environment is not always verbal. Successful communication in the chemistry labs required communicating information through both verbal and visual channels of communication. Understanding other speakers in this discourse community requires more than skills of decoding the information presented. Comprehension skills require monitoring both verbal and visual information, which includes both the resources of chemistry and gestures. Language alone is not sufficient for successful communication; rather, interpreting what is heard and what is seen is the foundation for responding to questions and successful communication.

Other research on learning in the sciences (Roth, 2000; Roth, 2003) has found that gesture is an important resource for communication as students are developing the 
discourse of classroom communication and that gestures help connect the learner to the setting. In the setting of the chemistry lab, the physical resources of chemistry emerged as being particularly important in the communication between undergraduates and their teaching assistants. Using the physical resources of chemistry and the accompanying gestures facilitated the interactions by providing important avenues for the undergraduates and the teaching assistants to express themselves and to understand what others were trying to communicate. This dependence on physical resources is apparent in chemistry, but communication patterns between international teaching assistants and undergraduates may unfold in vastly different ways in disciplines such as mathematics or economics, disciplines that do not depend to such a large extent on manipulating materials and equipment and where the interactions depend more on verbal communication and gestures. Not all disciplines depend on a large array of resources and artifacts in the way that chemistry does.

In this study, the questions that undergraduates asked were not complex, theoretical questions. The undergraduate-generated questions were much more practical, focusing on the undergraduates becoming familiar with the chemistry lab environment and its resources. The undergraduates were developing judgments about how to function in the chemistry lab in the way that chemists do: how to read situations and respond appropriately. The undergraduates were asking questions in which they were clearly learning how to talk like chemists, act like chemists, and think like chemists in a laboratory.

Undergraduate-generated questions demonstrate that the undergraduates are becoming familiar with what the resources of the discipline are and how to use them, 
both understanding what they are, how they function, and how they are handled. The undergraduates are developing physical dexterity with the equipment, materials, and procedures of the discipline—-the concrete aspects of being a chemist, supporting their theoretical understanding of chemistry. They, therefore, need the support of the teaching assistants, who provide both the verbal explanations and the "hands-on" demonstrations.

This implies that while the previous research on classroom communication of international teaching assistants and their undergraduate students, which has focused to a large extent on the production skills of spoken English, is important, it has not begun to address an even larger area of research: how non-native speaking teaching assistants understand speech in real-world classroom contexts. As the results of this study reveal, the labs are interactive environments in which the language, the resources, the gestures, and the activities are coordinated and intertwined for successful communication.

In the interview stage of this research project, undergraduate participants identified that the visual information and the demonstrations that teaching assistants provided in the labs were crucial to successful communication. This finding supports the view that physical resources (or artifacts) and physical setting can influence discursive practices (Roth, McGinn, Woszyna, Boutonné, 1999). This significant finding surfaced because the research methodology of this study solicited participant input.

In the interview process, it became apparent that the perspectives of the teaching assistants, undergraduates, and faculty member did not always match. What also emerged in the interview process was how the differing perspectives viewed successful 
communication. Even though each participant group found four out of five interactions to be successful, when looking at the perspectives of all participants in an interaction, only half of the interactions could be considered successful. This finding strongly suggests that research methodologies that seek the perspectives of the participants deserve more attention.

The findings of this research project have implications for the practices of evaluating, instructing, and supporting international teaching assistants and instructing and supporting undergraduates who are in courses taught by non-native speaking teaching assistants. Without a doubt, the findings of this study indicate that the comprehension skills of non-native speakers contribute to their abilities to communicate successfully in interactive classroom environments. Furthermore, comprehension is more than just skills of decoding. As seen in this study, the language of the discourse generated by the undergraduates contained varying degrees of precision. Not only were teaching assistants required to be able to comprehend the speech of the undergraduates, the teaching assistants were often required to disambiguate the speech of the undergraduates. Disambiguating was a process that depended to a great extent on the visual information of the context and strategies of verbal negotiation, depending on the teaching skills and expertise in the discipline that the international teaching assistants possessed.

Furthermore, because much of the language generated in this learning environment was ambiguous, it was not unusual for successful communication to require more than one attempt before communication was successful. Both participants in the communicative exchanges needed to pursue questions when they felt that they 
were unresolved on the first attempt. That all participants persisted in the interactions to achieve successful communication was also essential. This is another important finding of this study.

\section{Limitations}

This study is not without limitations that influence the findings and the degree to which the findings can be generalized. This study is primarily a qualitative research project with a goal of understanding from the participants' perspective what is and what facilitates successful communication in this setting. As such, generalizing from the findings of this study may be limited by the setting in which this study was carried out: the institution was a private university with a highly selective admissions process (a non-representative institution) and all undergraduates in this study had extensive preparation in mathematics and chemistry at the high school level (non-representative students). Generalizing from the study's findings is also limited by the fact that the investigation took place in one course in one subject area, an introductory-level course in chemistry.

Additional limitations to this study's findings relate to the methodology employed to collect data. First, there are limitations associated with the researcher and the influence an outsider in the classroom may have had on this study's findings. The faculty member teaching the course introduced me to the undergraduates in all sections. While on one level this communicated to the undergraduates that this research project was approved of and supported by the faculty member of the course, it may have also communicated to the undergraduates that I was not sufficiently distanced from the instructional staff of the course. This association may have influenced how comfortable 
undergraduates were expressing their opinions, especially negative opinions about the course.

A second limitation of this study was related to undergraduate participation in the interview process. As described in the chapter on findings, the undergraduates who agreed to participate in the study were not always available or interested in participating in the interviews. The participation rate for the interviews was only one-third of the undergraduates who agreed to participate in the study, with some indications that undergraduates who participated in interactions with greater frequency were more likely to participate in the interview process. This participation rate means that a large proportion of undergraduates did not provide their perspectives on classroom communication. Given the positive nature of the comments of the undergraduates who came in for the interview phase of this project, it is possible that undergraduates who were not satisfied with the course or the interactions with their teaching assistants did not participate in the interviews. Obtaining their perspective is important.

The undergraduate participation rate in the interview process was further limited by the gender of the undergraduates who came in for interviews. Only one quarter of male undergraduates in the study participated in the interview process. The participation rate of females in the interview process was much higher; almost half of the study's female undergraduates participated in interviews. Analysis of participation in classroom interactions indicated that there were gender differences in interaction participation and initiation. However, the findings of this study are limited by the small proportion of males who participated in the interviews. Once again, obtaining the perspective of both male and female undergraduates is important. 
Further, the interactions analyzed depended on the interview process. These interactions only represented the communication and interaction styles of the subset of undergraduate participants who were interviewed. The range of interactions examined in the interaction analysis phase of this project may not be representative of all types of interactions. For example, the gender composition of the undergraduates who participated in the interviews included more females than males, which may mean that the interactions analyzed in this study are not representative of patterns of male interactions. Greater undergraduate participation in the interview process could have provided more varied opinions about interactive communication in the chemistry labs and also a greater variety of communicative exchanges.

Finally, the third major limitation of the study relates to documenting and recording the communication in the labs. Although the use of audio and video recording did not appear to bother the undergraduates, it may have had some impact on the interactions of the participants. For example, participants may have been less likely to engage in social interactions that are important for building rapport and strengthening social ties in the environment, or undergraduates may have refrained from asking the teaching assistant questions because they did not want their interactions documented.

Even though the recordings proved invaluable to documenting the activities and communication in the labs and made the interview process and interaction analysis possible, the recordings in the labs missed valuable data. The priority in the labs for safety meant that documenting the activities of the labs had to be conducted in a way that did not interfere with activities in the labs. Video recording was restricted to certain 
areas of the labs, which meant that not all activity was recorded. This restriction limited the images that could be captured and used later in the analysis of interactions.

\section{Future Research}

As a primarily qualitative research project with the objective of understanding chemistry lab communication from the participants' perspectives, the initial questions guiding this study were broad in nature, allowing for this research to reflect the views of the participants in the setting. As this project evolved, some areas identified in the research questions emerged as being more important for the participants, and other areas of investigation originally thought to be avenues of investigation did not sufficiently emerge from the participants' comments and information. It also became clear once in the setting that methods for capturing certain data limited the direction of the investigation and analysis. This is the nature of qualitative research.

This research project has demonstrated that an important area of classroom communication between international teaching assistants and their undergraduate students has not been explored: communication and language initiated by the undergraduates and directed at the teaching assistants. This unexplored area opens up many possibilities for future research of many types. Findings from this research project directs future research projects to examine the contributions of both participants in a communicative exchange and for the analysis of this communication to utilize a theoretical framework that accommodates verbal and visual (physical resources and gestures) information, coordinated for communication. Further, this study points out the importance of future research employing methodologies that allow researchers to gain the perspectives of the participants actually engaged and invested in the communication. 
Understanding communication between international teaching assistants and their undergraduate students using frameworks that depend exclusively on the language being communicated without including gesture and context will not be able to account for how communication occurs and miscommunication is resolved in this setting. Similarly, theoretical frameworks that examine non-verbal communication without incorporating the physical resources and artifacts of this setting will not capture the rich ways that members of this setting communicate not only with their voices and bodies, but also the environmental resources. Language, gesture, activity, and the setting are coordinated for successful communication.

Research into the role that listening comprehension plays in successful communication is another topic of future research in classroom communication. This research project was broad in its approach. Further research in the domain of chemistry could take a more-in depth research approach, for example, looking at only one chemistry lab for longer periods of time rather than looking at multiple lab sections as was done in this study. While Flowerdew and Miller's (2005) theoretical framework for conversational listening was employed in the analysis of this study's interactions, as mentioned previously, to understand the communicative exchanges in this setting will require theoretical frameworks that account for the resources of the setting and gesture in communication.

As mentioned previously, the broad approach to data collection of this project was not able to capture issues related to gender and its relationship to communication patterns between groups in this setting. There are strong indications that gender plays a role in the communication patterns. A more in-depth approach, e.g., examining one lab 
section for the duration of each session and over the semester may result in more informative findings related to gender. Future studies that examine gender-related issues will also need to account for the ways that undergraduates are paired and work with partners in the labs: male-male, female-female, and female-male. One area of great interest related to understanding how gender influences communication in the labs is to examine the gender pairings of undergraduates to examine more closely the ways in which undergraduates move from working together to resolve questions and problems in carrying out the work in the labs. It was clear from observations that undergraduates work together to resolve many of their problems and answer their own questions by working collaboratively in the undergraduate pairings. One important area of investigation would be to examine when and why undergraduates escalate asking their questions to the teaching assistant.

A broader approach to studying communication in real-world learning environments involving international teaching assistants and their undergraduate students would be to examine a greater variety of communication patterns in other types of interactive classrooms that involve international teaching assistants. For example, research questions should address learning and communicating in laboratories in other science disciplines, such as in physics or in the biological sciences. One important question is how the differing demands placed on teaching assistants and learners in these disciplines influence classroom communication patterns and strategies.

Finally, one of the most interesting findings of this study was that communication was not defined exclusively by language, and that in this real-world learning environment of chemistry, communication occurs through visual and verbal 
channels of communication. The resources and artifacts of the chemistry lab are important for lab communication to occur. However, international teaching assistants also teach in classrooms that are less dependent on physical resources for learning, such as in mathematics or economics. In these disciplines, one question to ask is how do the undergraduates and the teaching assistants disambiguate language. Not all educational contexts have the support of the physical resources that the chemistry lab provides. For these disciplines, research questions addressing what facilitates and what limits successful communication would contribute to our understanding of classroom communication, with a particular focus on the coordinated verbal and visual pathways for communicating information.

While the important findings of this research project point out new areas of research for international teaching assistant-undergraduate classroom communication, the methodological innovations of this project also have implications for future research project methodologies. As pointed out previously, the significant findings of this project were possible because of the methodology of obtaining the participants' perspectives through semi-structured interviews. A research project that did not involve obtaining participant opinions about the communicative exchanges would have resulted in significantly different findings. This points to the need to expand and extend the new methodologies created in this study.

Future research projects employing methodological approaches similar to this research project need to have adequate personnel to assist in the collecting, coding, and analyzing of data. To obtain the participants' perspectives, documenting lab activities and communication was essential to providing the contextual information that the 
participants needed for commenting on specific interactions. This process of accurately documenting lab communication depended to a great extent on technologies for recording and replaying the events and activities in this educational environment. To do so requires not only appropriate equipment but also personnel. In addition to the technical support needed to assist researchers documenting lab communication, the importance of having content-area experts to understanding communication cannot be underestimated. To ensure the accuracy and reliability in studies employing similar methodologies to those used in this project, researchers will need to collaborate with content-area specialists and technology specialists.

Participant recall of contextual information of the activities and events of lab communication was crucial to their ability to comment on the events and activities in this educational environment. Providing participants with video, and to a lesser extent audio, reproductions of the communicative exchanges was a very effective way to elicit their views of the exchanges. With this documentation, participants were able to identify and remember the exchange under investigation. Furthermore, the undergraduates in particular were able to remember large amounts of information surrounding the exchange, often times describing an extensive series of events leading up to the question. Undergraduates were able to explicitly describe what difficulties they were experiencing and what motivated them to ask the teaching assistant their questions. While every attempt was made to have participants interviewed as close as possible to when an exchange took place, even when participants viewed an interaction that occurred much earlier in the semester, they were able to recall many details 
surrounding the interactions. The audio and video documentation were essential to establishing reliable recall and comment on lab communication.

\section{Conclusion}

This research project began as a study to examine how international teaching assistants and their undergraduates expressed themselves in classroom communication and what facilitated successful communicative interactions. It ended up looking at how the participants understand each other and at their efforts to understand each other. The successful communication that occurred in these chemistry labs was not about what one participant group did; rather, it was what individuals of both groups did together.

Previous research on classroom interactions between undergraduates and international teaching assistants in classroom settings has focused almost exclusively on communication initiated by the teaching assistants. The data from this research project show that in a science lab, a sizeable amount of communication originates with the undergraduates. In this interactive educational context, classroom discourse takes two forms, discourse originating with the teaching assistant and discourse originating with the undergraduates. The successful communication in this chemistry lab was in part due to the teaching assistants' abilities to understand the language and classroom discourse of the undergraduates - a pre-requisite for any type of response. Only when the teaching assistants understood the needs of the undergraduates and the source of their questions could they supply responses that address the concerns of the undergraduates.

Undergraduates had to do the same, and when they thought that communication was not working, they had to persist by monitoring their understanding of the teaching assistant's information and redirecting the exchange. 
This research project challenges us to rethink the questions that we ask in research related to undergraduates and their international teaching assistants. International teaching assistants and undergraduates do collaborate to make communication successful. Facilitating and improving communication between these two populations requires research methodologies that allow us to obtain the perspectives of those actually engaged in the educational experience.

To provide undergraduates with answers to questions that they ask, teaching assistants must understand what undergraduates need when they ask their questions. Promoting and supporting successful communication between these two groups needs to be understood through the activity in which they are engaged, teaching and learning. While non-native speaking teaching assistants need to have the language skills necessary to interact and communicate using intelligible English, they also need to have the teaching skills to support undergraduate learning, which is to understand undergraduate needs when learning content material. In this study, all three teaching assistants demonstrated good teaching skills by having a clear understanding of the demands of the discipline, by being sensitive to the problems the undergraduates faced when learning the material, and by responding to those needs. 


\section{Appendix A}

\section{Teaching Assistant Participant Informed Consent Form}

1. I understand that I have been asked to participate in a study of communication patterns between teaching assistants and undergraduate students in university-level science labs that will involve my interactions with my students being observed and recorded on audiotape and/or videotape. I understand that I will also be contacted by the researcher to participate in follow-up, confidential interviews to obtain my perspective on the communicative exchanges and interactions I have with my students. I understand that these follow-up interviews will take approximately 10-20 minutes of my time and will occur outside of the regularly scheduled class. I understand that the purpose of this research is to investigate those communication and interaction strategies between graduate student teaching assistants and undergraduate students that facilitate undergraduate learning in the academic environment of a science laboratory.

2. I understand that the risks could include: additional time outside of class to participate in follow-up interviews with the researcher and that I could reasonably expect benefits from my participation in the study. These could include improved support for teaching assistants working with undergraduate students. Research findings from this study may be shared at academic conferences. Conversations recorded and collected in the course of this research project may be used solely for improving the instructional practices of teaching assistants with their undergraduate students. Only positive examples of successful interactions will be used for instructional purposes.

3. I understand that the possible alternative procedures or course of treatment that may be advantageous to me could include not participating in this research study.

4. I understand that my responses will be kept confidential to the extent permitted by law and that I may request an interpretation of the results once the study is complete. The records of this research will be kept private. In any sort of report we might publish, we will not include any information that will make it possible to identify a participant. Research records, audio recordings, and video recordings will be kept in a locked file, and access will be limited to the researchers, the College Human Participants in Research Committee, and regulatory agencies. Audio and video recordings will be archived in a locked file cabinet for a period of 5 years. At the end of this time, they will be destroyed.

5. I understand that if I have any questions about the study or if I experience any discomfort or have any concerns that I would like to express I may contact:

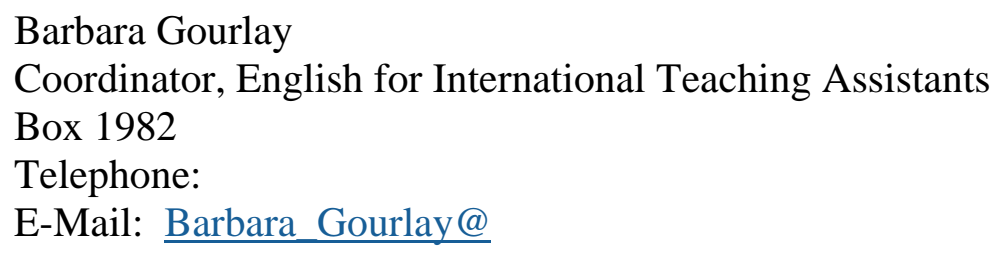




\section{Appendix A (Continued)}

Teaching Assistant Participant Informed Consent Form

If the researcher cannot be reached, or if you would like to talk to someone other than the researcher about concerns regarding the study, please contact Professor Carolyn Panofsky, Rhode Island College, at (401) 456-8040 or write: Professor Carolyn Panofsky, Rhode Island College, Department of Education Studies, 600 Mount Pleasant Avenue, Providence, RI 02908.

If you would like to talk to someone other than the researcher about (1) concerns regarding this study, (2) research participant rights, (3) research-related injuries, or (4) other human subjects issues, please contact Sue Pearlmutter, Rhode Island College Committee on Human Participants in Research at (401) 456-8753 or write: Sue Pearlmutter, c/o Rhode Island College Committee on Human Participants in Research at Office of Research and Grants Administration, Roberts Hall, 600 Mount Pleasant Avenue, Providence, RI 02908.

6. I understand that my participation in this study is entirely voluntary and that I may discontinue my participation at any point without penalty to myself. My participation or lack of participation will have no bearing on my current or future assistantships in the department. I acknowledge that the contents of this form have been explained to me and that I have been given the opportunity to ask questions. I have been given a copy of this form.

7. My consent to participate in this study will expire on May 31, 2006.

\section{Statement of Consent}

I have read the above information. I have received answers to the questions I have asked. I consent to participate in this research. I am at least 18 years of age.

Print Name of Participant:

Signature of Participant:

Date: 


\section{Appendix B}

\section{Undergraduate Participant Informed Consent Form}

1. I understand that I have been asked to participate in a study of communication patterns between teaching assistants and undergraduate students in university-level science labs that will involve my interactions with my teaching assistant being observed and recorded on audiotape and/or videotape. I understand that I may also be contacted by the researcher to participate in follow-up, confidential interviews to obtain my perspective on the communicative exchanges and interactions I have with my teaching assistant. I understand that these follow-up interviews will take approximately 10-20 minutes of my time and will occur outside of the regularly scheduled class. I understand that the purpose of this research is to investigate those communication and interaction strategies between graduate student teaching assistants and undergraduate students that facilitate undergraduate learning in the academic environment of a science laboratory.

2. I understand that the risks could include: additional time outside of class to participate in follow-up interviews with the researcher and that I could reasonably expect benefits from my participation in the study. These could include improved instructional practices of teaching assistant with their undergraduate students. Research findings from this study may be shared at academic conferences. Conversations recorded and collected in the course of this research project may be used solely for improving the instructional practices of teaching assistants with their undergraduate students. Only positive examples of successful interactions will be used for instructional purposes.

3. I understand that the possible alternative procedures or course of treatment that may be advantageous to me could include not participating in this research study.

4. I understand that my responses will be kept confidential to the extent permitted by law and that I may request an interpretation of the results once the study is complete. The records of this research will be kept private. In any sort of report we might publish, we will not include any information that will make it possible to identify a participant. Research records, audio recordings, and video recordings will be kept in a locked file, and access will be limited to the researchers, the College Human Participants in Research Committee, and regulatory agencies. Audio and video recordings will be archived in a locked file cabinet for a period of 5 years. At the end of this time, they will be destroyed.

5. I understand that if I have any questions about the study or if I experience any discomfort or have any concerns that I would like to express I may contact:

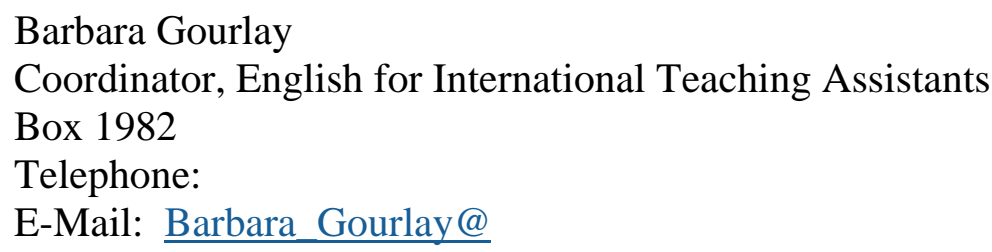


Appendix B (Continued)

Undergraduate Participant Informed Consent Form

If the researcher cannot be reached, or if you would like to talk to someone other than the researcher about concerns regarding the study, please contact Professor Carolyn Panofsky, Rhode Island College, at (401) 456-8040 or write: Professor Carolyn Panofsky, Rhode Island College, Department of Educational Studies, 600 Mount Pleasant Avenue, Providence, RI 02908.

If you would like to talk to someone other than the researcher about (1) concerns regarding this study, (2) research participant rights, (3) research-related injuries, or (4) other human subjects issues, please contact Sue Pearlmutter, Rhode Island College Committee on Human Participants in Research at (401) 456-8753 or write: Sue Pearlmutter, c/o Rhode Island College Committee on Human Participants in Research at Office of Research and Grants Administration, Roberts Hall, 600 Mount Pleasant Avenue, Providence, RI 02908.

6. I understand that my participation in this study is entirely voluntary and that I may discontinue my participation at any point without penalty to myself. My participation or lack of participation in this study will have no bearing on my grade in the course. I acknowledge that the contents of this form have been explained to me and that I have been given the opportunity to ask questions. I have been given a copy of this form.

7. My consent to participate in this study will expire on May 31, 2006.

\section{Statement of Consent}

I have read the above information. I have received answers to the questions I have asked. I consent to participate in this research. I am at least 18 years of age.

Print Name of Participant:

Signature of Participant:

Date: 


\section{Appendix C}

Undergraduate Participant Background Information Questionnaire (Front)

\section{Name:}

2. Age:

3. Sex: Male Female

4. Home town and state:

5. Did you grow up primarily in an urban, suburban, or rural environment?

6. Entry Year:

7. Concentration:

If you have not selected your concentration, what is a likely concentration?

8. Contact information for follow interview questions.

Telephone:

E-mail:

9. What language(s) do you speak at home with your family?

10. Indicate other languages you have studied and your proficiency level.

\begin{tabular}{|l|l|l|l|}
\hline 11. Please describe any experience of travel or living abroad. \\
\hline Location & Length of time & Dates & Purpose \\
\hline & & & \\
\hline & & & \\
\hline & & & \\
\hline
\end{tabular}


Appendix C (Continued)

Undergraduate Participant Background Information Questionnaire (Back)

12. Have you taken chemistry in high school? YES NO

If YES, please answer the following:

How many semesters have you studied chemistry?

In what year did you study Chemistry: $9^{\text {th }} \quad 10^{\text {th }} \quad 11^{\text {th }} \quad 12^{\text {th }}$

Did you take an AP Chemistry course? YES NO

Have you studied Calculus? YES NO

How many years of Math did you study in high school?

\begin{tabular}{|l|l|}
\hline Area of Math & Semesters Studied \\
\hline & \\
\hline & \\
\hline & \\
\hline & \\
\hline
\end{tabular}

How many semesters of Math have you studied in college?

\begin{tabular}{|l|l|}
\hline Area of Math & Semesters Studied \\
\hline & \\
\hline & \\
\hline & \\
\hline & \\
\hline
\end{tabular}




\section{Appendix D}

Teaching Assistant Participant Background Information Questionnaire

\section{Name:}

2. Age:

3. Sex: — Male _ Female

4. Native Country:

5. Native Language:

6. Entry Year:

7. How long have you been in the United States?

If you have studied in the United States prior to your current graduate school experience, please indicate where and for how long you studied. Also, indicate any degrees you have received from an American institution.

8. Have you taught Chemistry before?

If yes, please describe your previous teaching experience. Please include information about country where taught, subject taught, level taught, and type of teaching (tutoring or lab instruction).

9. In a typical day, in what situations do you speak using English?

10: In a typical day, in what situations do you speak using your native language? 


\section{Appendix E}

Undergraduate Background Characteristics Summary Tables

Frequency and Percentage of Undergraduate Background Characteristics by Section

Part 1: General Characteristics

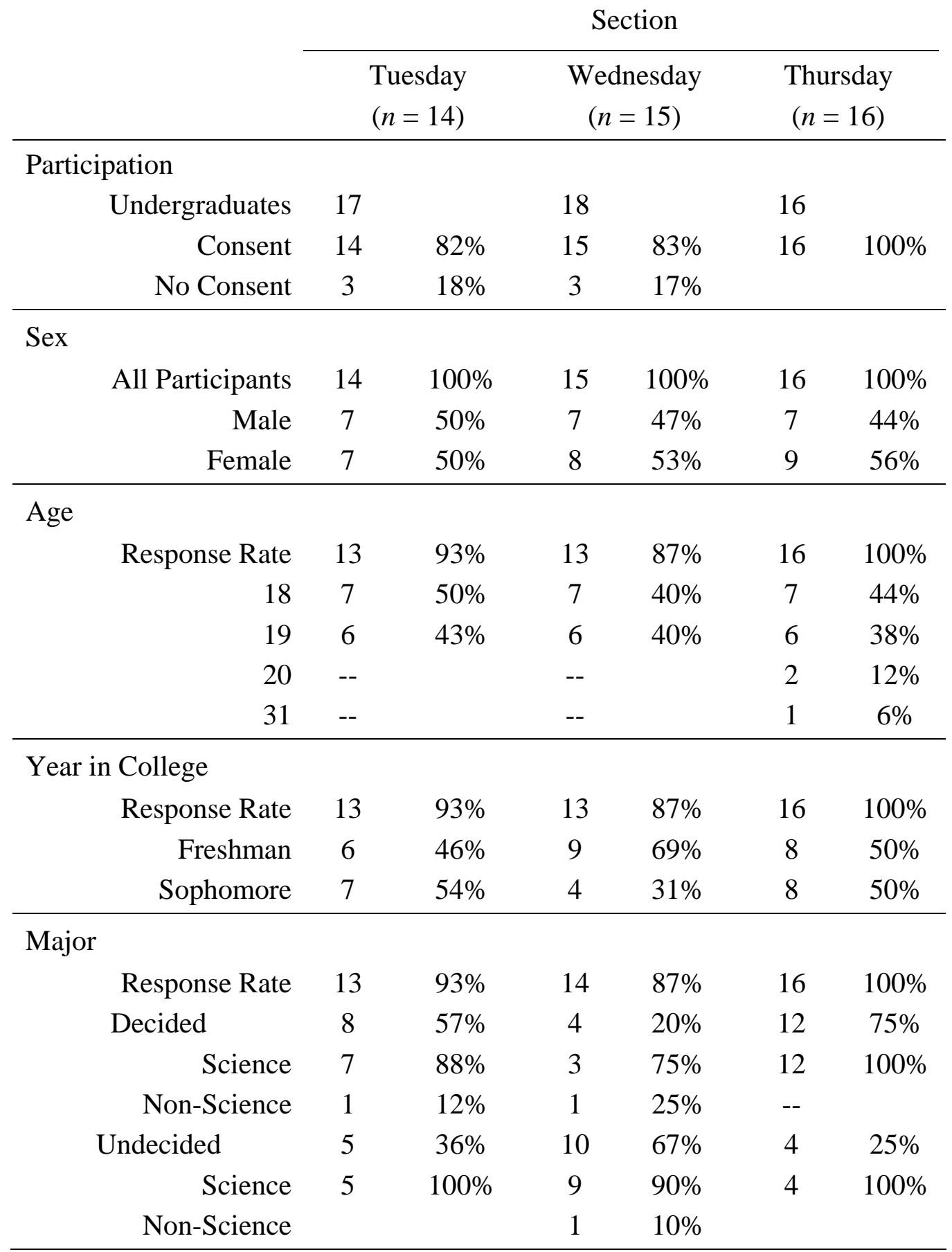


Appendix E (Continued)

Undergraduate Background Characteristics Summary Tables

Frequency and Percentage of Undergraduate Background Characteristics by Section

Part 2: Cultural and Linguistic Background

Section

\begin{tabular}{|c|c|c|c|c|c|c|}
\hline Growing Up US/Abroad & \multicolumn{2}{|c|}{$\begin{array}{l}\text { Tuesday } \\
(n=14)\end{array}$} & \multicolumn{2}{|c|}{$\begin{array}{l}\text { Wednesday } \\
\quad(n=15)\end{array}$} & \multicolumn{2}{|c|}{$\begin{array}{l}\text { Thursday } \\
(n=16)\end{array}$} \\
\hline Response Rate & 13 & $93 \%$ & 13 & $87 \%$ & 16 & $100 \%$ \\
\hline US & 13 & $100 \%$ & 13 & $100 \%$ & 15 & $94 \%$ \\
\hline Other Country & -- & & -- & & 1 & $6 \%$ \\
\hline \multicolumn{7}{|l|}{ Community Growing Up } \\
\hline Response Rate & 11 & $79 \%$ & 11 & $73 \%$ & 16 & $100 \%$ \\
\hline Urban & 1 & $9 \%$ & 1 & $8 \%$ & 2 & $13 \%$ \\
\hline Suburban & 9 & $82 \%$ & 9 & $69 \%$ & 13 & $81 \%$ \\
\hline Rural & 1 & $9 \%$ & 1 & $23 \%$ & 1 & $6 \%$ \\
\hline \multicolumn{7}{|c|}{ Language Spoken At Home } \\
\hline Response Rate & 13 & $93 \%$ & 13 & $87 \%$ & 16 & $100 \%$ \\
\hline English Only & 10 & $76 \%$ & 8 & $61 \%$ & 11 & $69 \%$ \\
\hline English + 1 Language & 1 & $8 \%$ & 4 & $31 \%$ & 5 & $31 \%$ \\
\hline English +2 Languages & 1 & $8 \%$ & 1 & $8 \%$ & -- & \\
\hline Other Language Only & 1 & $8 \%$ & -- & & -- & \\
\hline \multicolumn{7}{|l|}{ Languages Studied } \\
\hline Response Rate & 13 & $93 \%$ & 13 & $87 \%$ & 16 & $100 \%$ \\
\hline No Language & -- & $0 \%$ & 2 & $15 \%$ & 1 & $6 \%$ \\
\hline 1 Language & 7 & $54 \%$ & 8 & $54 \%$ & 11 & $69 \%$ \\
\hline 2 Languages & 5 & $38 \%$ & 2 & $15 \%$ & 4 & $25 \%$ \\
\hline 3 Languages & 1 & $8 \%$ & 1 & $8 \%$ & -- & \\
\hline \multicolumn{7}{|l|}{ Travel Abroad } \\
\hline Response Rate & 13 & $93 \%$ & 13 & $87 \%$ & 16 & $100 \%$ \\
\hline Lived Abroad & -- & & 2 & $15 \%$ & 1 & $6 \%$ \\
\hline Traveled Abroad & 10 & $77 \%$ & 8 & $62 \%$ & 8 & $50 \%$ \\
\hline No Travel Abroad & 3 & $23 \%$ & 3 & $23 \%$ & 7 & $44 \%$ \\
\hline
\end{tabular}


Appendix E (Continued)

Undergraduate Background Characteristics Summary Tables

Frequency and Percentage of Undergraduate Background Characteristics by Section

Part 3: Chemistry and Mathematics Background

Section

\begin{tabular}{|c|c|c|c|c|c|c|}
\hline \multirow{2}{*}{ High School Chemistry } & \multicolumn{2}{|c|}{$\begin{array}{l}\text { Tuesday } \\
(n=14)\end{array}$} & \multicolumn{2}{|c|}{$\begin{array}{l}\text { Wednesday } \\
\quad(n=15)\end{array}$} & \multicolumn{2}{|c|}{$\begin{array}{l}\text { Thursday } \\
(n=16)\end{array}$} \\
\hline & & & & & & \\
\hline Response Rate & 13 & $93 \%$ & 13 & $87 \%$ & 16 & $100 \%$ \\
\hline Yes & 13 & $100 \%$ & 13 & $100 \%$ & 16 & $100 \%$ \\
\hline No & -- & & -- & & -- & \\
\hline \multicolumn{7}{|l|}{ AP Chemistry } \\
\hline Yes & 4 & $29 \%$ & 5 & $33 \%$ & 8 & $50 \%$ \\
\hline No & 9 & $64 \%$ & 8 & $53 \%$ & 8 & $50 \%$ \\
\hline \multicolumn{7}{|l|}{ Semesters } \\
\hline Response Rate & 6 & $43 \%$ & 10 & $67 \%$ & 13 & $81 \%$ \\
\hline 1 & 3 & $50 \%$ & 1 & $10 \%$ & 1 & $8 \%$ \\
\hline 2 & 2 & $33 \%$ & 4 & $40 \%$ & 5 & $38 \%$ \\
\hline 3 & -- & & -- & & -- & \\
\hline 4 & 1 & $17 \%$ & 5 & $50 \%$ & 3 & $23 \%$ \\
\hline 5 & -- & & -- & & 3 & $23 \%$ \\
\hline 6 & -- & & -- & & 1 & $8 \%$ \\
\hline \multicolumn{7}{|l|}{ High School Calculus } \\
\hline Response Rate & 13 & $93 \%$ & 13 & $87 \%$ & 15 & $94 \%$ \\
\hline Yes & 13 & $100 \%$ & 13 & $100 \%$ & 15 & $100 \%$ \\
\hline No & -- & & -- & & -- & \\
\hline \multicolumn{7}{|l|}{ Semesters } \\
\hline 4 & -- & & -- & & 3 & $20 \%$ \\
\hline 5 & -- & & -- & & 2 & $13 \%$ \\
\hline 6 & 1 & $8 \%$ & 1 & $8 \%$ & -- & \\
\hline 7 & -- & -- & 1 & $8 \%$ & -- & \\
\hline 8 & 12 & $92 \%$ & 10 & $76 \%$ & 9 & $60 \%$ \\
\hline 9 & -- & & 1 & $8 \%$ & -- & \\
\hline 10 & -- & & -- & & 1 & $7 \%$ \\
\hline \multicolumn{7}{|l|}{ College Math } \\
\hline Response Rate & 11 & $79 \%$ & 10 & $67 \%$ & 15 & $94 \%$ \\
\hline Yes & 9 & $82 \%$ & 8 & $80 \%$ & 12 & $80 \%$ \\
\hline No & 2 & $18 \%$ & 2 & $20 \%$ & 3 & $20 \%$ \\
\hline \multicolumn{7}{|l|}{ Semesters } \\
\hline 1 & 9 & $100 \%$ & 5 & $63 \%$ & 10 & $84 \%$ \\
\hline 2 & -- & & 2 & $25 \%$ & 1 & $8 \%$ \\
\hline 3 & -- & & 1 & $12 \%$ & -- & \\
\hline 4 & -- & & -- & & 1 & $8 \%$ \\
\hline
\end{tabular}




\section{Appendix F}

Lab Communication Summary Tables

Part 1: By Lab Session

Lab Session

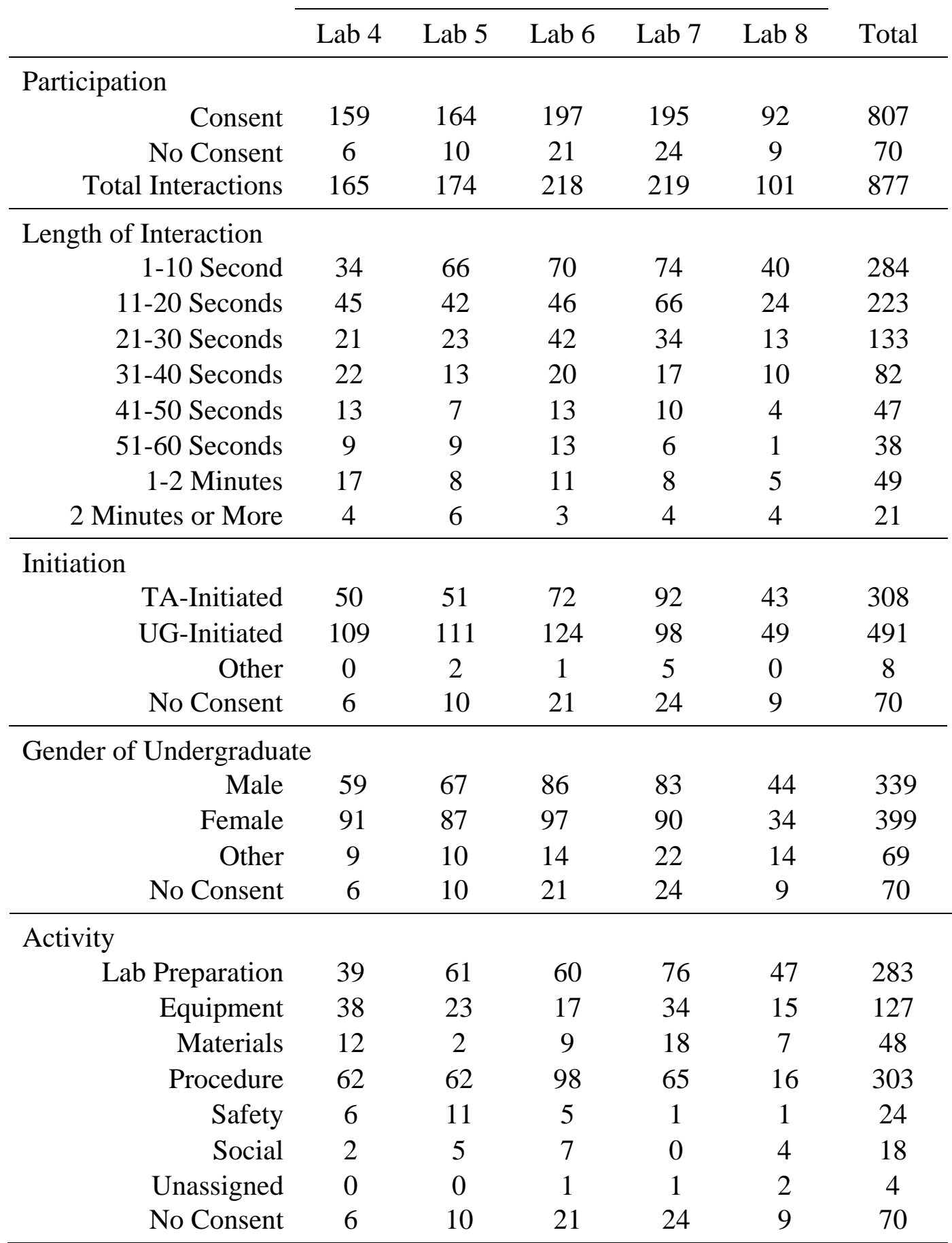

Note. Frequency counts illustrate the communicative demand placed on international teaching assistants in the lab environment during the first hour of the labs. All data from non-participants have been excluded from student analysis. 
Appendix F (Continued)

Lab Communication Summary Tables

Part 2: By Lab Section

\begin{tabular}{|c|c|c|c|c|}
\hline & \multicolumn{3}{|c|}{ Lab Section } & \multirow[b]{2}{*}{ Total } \\
\hline & Tuesday & Wednesday & Thursday & \\
\hline \multicolumn{5}{|l|}{ Participation } \\
\hline Consent & 282 & 331 & 194 & 807 \\
\hline No Consent & 22 & 44 & 4 & 70 \\
\hline Total Interactions & 304 & 375 & 198 & 877 \\
\hline \multicolumn{5}{|l|}{ Length of Interaction } \\
\hline 1-10 Second & 120 & 103 & 61 & 284 \\
\hline 11-20 Seconds & 79 & 105 & 39 & 223 \\
\hline 21-30 Seconds & 46 & 58 & 29 & 133 \\
\hline 31-40 Seconds & 21 & 38 & 23 & 82 \\
\hline 41-50 Seconds & 11 & 22 & 14 & 47 \\
\hline 51-60 Seconds & 10 & 16 & 12 & 38 \\
\hline 1-2 Minutes & 12 & 22 & 15 & 49 \\
\hline 2 Minutes or More & 5 & 11 & 5 & 21 \\
\hline \multicolumn{5}{|l|}{ Initiation } \\
\hline TA-Initiated & 82 & 169 & 57 & 308 \\
\hline UG-Initiated & 194 & 162 & 135 & 491 \\
\hline Other & 6 & 0 & 2 & 8 \\
\hline No Consent & 22 & 44 & 4 & 70 \\
\hline \multicolumn{5}{|l|}{ Gender of Undergraduate } \\
\hline Male & 132 & 118 & 89 & 339 \\
\hline Female & 128 & 177 & 94 & 399 \\
\hline Other & 22 & 36 & 11 & 69 \\
\hline No Consent & 22 & 44 & 4 & 70 \\
\hline \multicolumn{5}{|l|}{ Activity } \\
\hline Lab Preparation & 108 & 131 & 44 & 283 \\
\hline Equipment & 50 & 50 & 27 & 127 \\
\hline Materials & 12 & 22 & 14 & 48 \\
\hline Procedure & 96 & 105 & 102 & 303 \\
\hline Safety & 9 & 10 & 5 & 24 \\
\hline Social & 5 & 12 & 1 & 18 \\
\hline Unassigned & 2 & 1 & 1 & 4 \\
\hline No Consent & 22 & 44 & 4 & 70 \\
\hline
\end{tabular}

Note. Frequency counts illustrate the communicative demand placed on international teaching assistants in the lab environment during the first hour of the labs. All data from non-participants have been excluded from student analysis. 


\section{Appendix G}

Undergraduate Interview Participant Characteristics Summary Tables Frequency and Percentage Comparisons of Undergraduate Background Characteristics of Study Participants and Interview Participants

Part 1: General Characteristics

\begin{tabular}{|c|c|c|c|c|}
\hline \multirow{2}{*}{ Participation } & \multicolumn{2}{|c|}{$\begin{array}{c}\text { Study } \\
\text { Participants } \\
(N=45) \\
\end{array}$} & \multicolumn{2}{|c|}{$\begin{array}{c}\text { Interview } \\
\text { Participants } \\
(n=16)\end{array}$} \\
\hline & & & & \\
\hline Total Students & 51 & & 45 & \\
\hline Consent & 45 & $88 \%$ & 16 & $36 \%$ \\
\hline No Consent & 6 & $12 \%$ & 29 & $64 \%$ \\
\hline \multicolumn{5}{|l|}{ Sex } \\
\hline Male & 21 & $47 \%$ & 5 & $31 \%$ \\
\hline Female & 24 & $53 \%$ & 11 & $69 \%$ \\
\hline \multicolumn{5}{|l|}{ Age } \\
\hline 18 & 21 & $47 \%$ & 7 & $44 \%$ \\
\hline 19 & 18 & $40 \%$ & 7 & $44 \%$ \\
\hline 20 & 2 & $4 \%$ & 1 & $6 \%$ \\
\hline 31 & 1 & $2 \%$ & 1 & $6 \%$ \\
\hline \multicolumn{5}{|l|}{ Year in College } \\
\hline Freshman & 23 & $51 \%$ & 9 & $56 \%$ \\
\hline Sophomore & 19 & $42 \%$ & 7 & $44 \%$ \\
\hline \multicolumn{5}{|l|}{ Major } \\
\hline Decided & 24 & $53 \%$ & 9 & $56 \%$ \\
\hline Science & 22 & $49 \%$ & 9 & $56 \%$ \\
\hline Non-Science & 2 & $4 \%$ & & \\
\hline Undecided & 19 & $42 \%$ & 7 & $44 \%$ \\
\hline Science & 18 & $40 \%$ & 7 & $44 \%$ \\
\hline Non-Science & 1 & $2 \%$ & -- & \\
\hline
\end{tabular}




\section{Appendix G (Continued)}

Undergraduate Interview Participant Characteristics Summary Tables Frequency and Percentage Comparisons of Undergraduate Background Characteristics of Study Participants and Interview Participants

Part 2: Cultural and Linguistic Background

\begin{tabular}{|c|c|c|c|c|}
\hline \multirow{2}{*}{ Growing Up US/Abroad } & \multicolumn{2}{|c|}{$\begin{array}{c}\text { Study } \\
\text { Participants } \\
(N=45)\end{array}$} & \multicolumn{2}{|c|}{$\begin{array}{c}\text { Interview } \\
\text { Participants } \\
(n=16)\end{array}$} \\
\hline & & & & \\
\hline US & 41 & $91 \%$ & 15 & $94 \%$ \\
\hline Other Country & 1 & $2 \%$ & 1 & $6 \%$ \\
\hline \multicolumn{5}{|l|}{ Community Growing Up } \\
\hline Urban & 4 & $9 \%$ & 3 & $19 \%$ \\
\hline Suburban & 31 & $69 \%$ & 10 & $63 \%$ \\
\hline Rural & 3 & $7 \%$ & 2 & $13 \%$ \\
\hline \multicolumn{5}{|c|}{ Language Spoken At Home } \\
\hline English Only & 29 & $64 \%$ & 10 & $63 \%$ \\
\hline English + 1 Language & 10 & $22 \%$ & 3 & $19 \%$ \\
\hline English +2 Languages & 2 & $4 \%$ & 2 & $13 \%$ \\
\hline Other Language Only & 1 & $2 \%$ & 1 & $6 \%$ \\
\hline \multicolumn{5}{|l|}{ Languages Studied } \\
\hline No Language & 3 & $7 \%$ & 1 & $6 \%$ \\
\hline 1 Language & 26 & $58 \%$ & 7 & $44 \%$ \\
\hline 2 Languages & 11 & $24 \%$ & 7 & $44 \%$ \\
\hline 3 Languages & 2 & $4 \%$ & 1 & $6 \%$ \\
\hline \multicolumn{5}{|l|}{ Travel Abroad } \\
\hline Lived Abroad & 3 & $7 \%$ & 3 & $19 \%$ \\
\hline Traveled Abroad & 26 & $58 \%$ & 9 & $56 \%$ \\
\hline No Travel Abroad & 13 & $29 \%$ & 4 & $25 \%$ \\
\hline
\end{tabular}




\section{Appendix G (Continued)}

Undergraduate Interview Participant Characteristics Summary Tables Frequency and Percentage Comparisons of Undergraduate Background Characteristics of Study Participants and Interview Participants

Part 3: Chemistry and Mathematics Background

\begin{tabular}{|c|c|c|c|c|}
\hline \multirow{2}{*}{$\begin{array}{l}\text { High School Chemistry } \\
\end{array}$} & \multicolumn{2}{|c|}{$\begin{array}{c}\text { Study } \\
\text { Participants } \\
(N=45)\end{array}$} & \multicolumn{2}{|c|}{$\begin{array}{c}\text { Interview } \\
\text { Participants } \\
(n=16)\end{array}$} \\
\hline & & & & \\
\hline Yes & 42 & $93 \%$ & 16 & $100 \%$ \\
\hline No & -- & & -- & \\
\hline \multicolumn{5}{|l|}{ AP Chemistry } \\
\hline Yes & 17 & $38 \%$ & 8 & $50 \%$ \\
\hline No & 25 & $56 \%$ & 8 & $50 \%$ \\
\hline \multicolumn{5}{|l|}{ Semesters } \\
\hline 1 & 5 & $11 \%$ & 2 & $13 \%$ \\
\hline 2 & 11 & $24 \%$ & 5 & $31 \%$ \\
\hline 3 & -- & & -- & \\
\hline 4 & 9 & $20 \%$ & 4 & $25 \%$ \\
\hline 5 & 3 & $7 \%$ & 2 & $13 \%$ \\
\hline 6 & 1 & $2 \%$ & -- & \\
\hline \multicolumn{5}{|l|}{ High School Calculus } \\
\hline Yes & 41 & $91 \%$ & 15 & $94 \%$ \\
\hline No & -- & & -- & \\
\hline \multicolumn{5}{|l|}{ Semesters } \\
\hline 4 & 3 & $7 \%$ & 3 & $19 \%$ \\
\hline 5 & 2 & $4 \%$ & 1 & $6 \%$ \\
\hline 6 & 2 & $4 \%$ & -- & \\
\hline 7 & 1 & $2 \%$ & -- & \\
\hline 8 & 31 & $69 \%$ & 11 & $69 \%$ \\
\hline 9 & 1 & $2 \%$ & -- & \\
\hline 10 & 1 & $2 \%$ & -- & \\
\hline \multicolumn{5}{|l|}{ College Mathematics } \\
\hline Yes & 29 & $64 \%$ & 9 & $56 \%$ \\
\hline No & 7 & $16 \%$ & 4 & $25 \%$ \\
\hline \multicolumn{5}{|l|}{ Semesters } \\
\hline 1 & 24 & $53 \%$ & 9 & $56 \%$ \\
\hline 2 & 3 & $7 \%$ & -- & \\
\hline 3 & 1 & $2 \%$ & -- & \\
\hline 4 & 1 & $2 \%$ & -- & \\
\hline
\end{tabular}


Appendix $\mathrm{H}$

Summary Tables of Participant Agreement of Interview Items

Part 1: Frequency

Participant Opinions

\begin{tabular}{|c|c|c|c|c|c|c|}
\hline \multirow[b]{2}{*}{$\begin{array}{l}\text { Interview } \\
\text { Item }\end{array}$} & \multirow[b]{2}{*}{ Comparison } & & \multirow[b]{2}{*}{$\begin{array}{l}\text { Insufficient } \\
\text { Degree of } \\
\text { Certainty }\end{array}$} & \multirow[b]{2}{*}{$\begin{array}{l}\text { Missing } \\
\text { Response }\end{array}$} \\
\hline & & $\begin{array}{l}\text { Cor } \\
\text { Agree }\end{array}$ & $\begin{array}{l}\text { 1gruent } \\
\text { Disagree }\end{array}$ & Divergent & & \\
\hline \multirow[t]{4}{*}{1} & UG-TA-Faculty & 35 & & 2 & 9 & 4 \\
\hline & UG-TA & 39 & & 2 & 9 & \\
\hline & UG-Faculty & 36 & & 2 & 8 & 4 \\
\hline & TA- Faculty & 41 & & & 5 & 4 \\
\hline \multirow[t]{4}{*}{2} & UG-TA-Faculty & 25 & & 5 & 17 & 3 \\
\hline & UG-TA & 33 & & 3 & 14 & \\
\hline & UG-Faculty & 29 & & 2 & 16 & 3 \\
\hline & TA- Faculty & 30 & & 5 & 12 & 3 \\
\hline \multirow[t]{4}{*}{3} & UG-TA-Faculty & & 24 & 5 & 18 & 3 \\
\hline & UG-TA & & 29 & 6 & 15 & \\
\hline & UG- Faculty & 2 & 27 & 2 & 16 & 3 \\
\hline & TA- Faculty & & 32 & 6 & 9 & 3 \\
\hline \multirow[t]{4}{*}{4} & UG-TA-Faculty & 28 & & 7 & 12 & 3 \\
\hline & UG-TA & 31 & & 7 & 12 & \\
\hline & UG- Faculty & 32 & & 6 & 9 & 3 \\
\hline & TA- Faculty & 44 & & & 3 & 3 \\
\hline \multirow[t]{4}{*}{5} & UG-TA-Faculty & 20 & 1 & 8 & 18 & 3 \\
\hline & UG-TA & 27 & 1 & 6 & 16 & \\
\hline & UG- Faculty & 29 & 2 & 6 & 10 & 3 \\
\hline & TA- Faculty & 24 & 1 & 8 & 14 & 3 \\
\hline \multirow[t]{4}{*}{6} & UG-TA-Faculty & 35 & & & 11 & 4 \\
\hline & UG-TA & 38 & & & 12 & \\
\hline & UG- Faculty & 38 & & & 8 & 4 \\
\hline & TA- Faculty & 41 & & & 5 & 4 \\
\hline \multirow[t]{4}{*}{7} & UG-TA-Faculty & 25 & & 2 & 19 & 4 \\
\hline & UG-TA & 31 & & & 19 & \\
\hline & UG- Faculty & 29 & & 2 & 15 & 4 \\
\hline & TA- Faculty & 32 & & 2 & 12 & 4 \\
\hline \multirow[t]{4}{*}{8} & UG-TA-Faculty & 25 & & & 21 & 4 \\
\hline & UG-TA & 31 & & & 19 & \\
\hline & UG- Faculty & 30 & & & 16 & 4 \\
\hline & TA- Faculty & 32 & & & 14 & 4 \\
\hline \multirow[t]{4}{*}{9} & UG-TA-Faculty & & 19 & 9 & 18 & 4 \\
\hline & UG-TA & & 28 & 6 & 16 & \\
\hline & UG- Faculty & & 26 & 6 & 14 & 4 \\
\hline & TA- Faculty & 1 & 25 & 8 & 12 & 4 \\
\hline \multirow[t]{4}{*}{10} & UG-TA-Faculty & 28 & & & 18 & 4 \\
\hline & UG-TA & 31 & & & 19 & \\
\hline & UG- Faculty & 33 & & & 13 & 4 \\
\hline & TA- Faculty & 34 & & & 12 & 4 \\
\hline
\end{tabular}


Appendix H (Continued)

Summary Tables of Participant Agreement of Interview Items

Part 2: Percentage

Participant Opinions

\begin{tabular}{|c|c|c|c|c|c|c|}
\hline \multirow[b]{2}{*}{$\begin{array}{l}\text { Interview } \\
\text { Item }\end{array}$} & \multirow[b]{2}{*}{ Comparison } & & \multirow[b]{2}{*}{$\begin{array}{l}\text { Insufficient } \\
\text { Degree of } \\
\text { Certainty }\end{array}$} & \multirow[b]{2}{*}{$\begin{array}{l}\text { Missing } \\
\text { Response }\end{array}$} \\
\hline & & $\begin{array}{l}\text { Cor } \\
\text { Agree }\end{array}$ & $\begin{array}{l}\text { gruent } \\
\text { Disagree }\end{array}$ & Divergent & & \\
\hline \multirow[t]{4}{*}{1} & UG-TA-Faculty & $70 \%$ & & $4 \%$ & $18 \%$ & $8 \%$ \\
\hline & UG-TA & $78 \%$ & & $4 \%$ & $18 \%$ & \\
\hline & UG-Faculty & $72 \%$ & & $4 \%$ & $16 \%$ & $8 \%$ \\
\hline & TA- Faculty & $82 \%$ & & & $10 \%$ & $8 \%$ \\
\hline \multirow[t]{4}{*}{2} & UG-TA-Faculty & $50 \%$ & & $10 \%$ & $34 \%$ & $6 \%$ \\
\hline & UG-TA & $66 \%$ & & $6 \%$ & $28 \%$ & \\
\hline & UG-Faculty & $58 \%$ & & $4 \%$ & $32 \%$ & $6 \%$ \\
\hline & TA- Faculty & $60 \%$ & & $10 \%$ & $24 \%$ & $6 \%$ \\
\hline \multirow[t]{4}{*}{3} & UG-TA-Faculty & & $48 \%$ & $10 \%$ & $36 \%$ & $6 \%$ \\
\hline & UG-TA & & $58 \%$ & $12 \%$ & $30 \%$ & \\
\hline & UG- Faculty & $4 \%$ & $54 \%$ & $4 \%$ & $32 \%$ & $6 \%$ \\
\hline & TA- Faculty & & $64 \%$ & $12 \%$ & $18 \%$ & $6 \%$ \\
\hline \multirow[t]{4}{*}{4} & UG-TA-Faculty & $56 \%$ & & $14 \%$ & $24 \%$ & $6 \%$ \\
\hline & UG-TA & $62 \%$ & & $14 \%$ & $24 \%$ & \\
\hline & UG- Faculty & $64 \%$ & & $12 \%$ & $18 \%$ & $6 \%$ \\
\hline & TA- Faculty & $88 \%$ & & & $6 \%$ & $6 \%$ \\
\hline \multirow[t]{4}{*}{5} & UG-TA-Faculty & $40 \%$ & $2 \%$ & $16 \%$ & $36 \%$ & $6 \%$ \\
\hline & UG-TA & $54 \%$ & $2 \%$ & $12 \%$ & $32 \%$ & \\
\hline & UG- Faculty & $58 \%$ & $4 \%$ & $12 \%$ & $20 \%$ & $6 \%$ \\
\hline & TA- Faculty & $48 \%$ & $2 \%$ & $16 \%$ & $28 \%$ & $6 \%$ \\
\hline \multirow[t]{4}{*}{6} & UG-TA-Faculty & $70 \%$ & & & $22 \%$ & $8 \%$ \\
\hline & UG-TA & $76 \%$ & & & $24 \%$ & \\
\hline & UG- Faculty & $76 \%$ & & & $16 \%$ & $8 \%$ \\
\hline & TA- Faculty & $82 \%$ & & & $10 \%$ & $8 \%$ \\
\hline \multirow[t]{4}{*}{7} & UG-TA-Faculty & $50 \%$ & & $4 \%$ & $38 \%$ & $8 \%$ \\
\hline & UG-TA & $62 \%$ & & & $38 \%$ & \\
\hline & UG- Faculty & $58 \%$ & & $4 \%$ & $30 \%$ & $8 \%$ \\
\hline & TA- Faculty & $64 \%$ & & $4 \%$ & $24 \%$ & $8 \%$ \\
\hline \multirow[t]{4}{*}{8} & UG-TA-Faculty & $50 \%$ & & & $42 \%$ & $8 \%$ \\
\hline & UG-TA & $62 \%$ & & & $38 \%$ & \\
\hline & UG- Faculty & $60 \%$ & & & $32 \%$ & $8 \%$ \\
\hline & TA- Faculty & $64 \%$ & & & $28 \%$ & $8 \%$ \\
\hline \multirow[t]{4}{*}{9} & UG-TA-Faculty & & $38 \%$ & $18 \%$ & $36 \%$ & $8 \%$ \\
\hline & UG-TA & & $56 \%$ & $12 \%$ & $32 \%$ & \\
\hline & UG- Faculty & & $52 \%$ & $12 \%$ & $28 \%$ & $8 \%$ \\
\hline & TA- Faculty & $2 \%$ & $50 \%$ & $16 \%$ & $24 \%$ & $8 \%$ \\
\hline \multirow[t]{4}{*}{10} & UG-TA-Faculty & $56 \%$ & & & $36 \%$ & $8 \%$ \\
\hline & UG-TA & $62 \%$ & & & $38 \%$ & \\
\hline & UG- Faculty & $66 \%$ & & & $26 \%$ & $8 \%$ \\
\hline & TA- Faculty & $68 \%$ & & & $24 \%$ & $8 \%$ \\
\hline
\end{tabular}




\section{Appendix I}

Overview of Successful and Partially Successful Interview Interactions

\begin{tabular}{|c|c|c|c|}
\hline & \multicolumn{3}{|c|}{ Interview Interactions } \\
\hline & $\begin{array}{l}\text { Successful } \\
(n=28)\end{array}$ & $\begin{array}{c}\text { Partially } \\
\text { Successful } \\
(n=22)\end{array}$ & $\begin{array}{l}\text { Totals } \\
(n=50)\end{array}$ \\
\hline \multicolumn{4}{|l|}{ Lab Session } \\
\hline Lab 4 & 3 & 12 & 15 \\
\hline Lab 5 & 8 & 2 & 10 \\
\hline Lab 6 & 4 & 2 & 6 \\
\hline Lab 7 & 11 & 3 & 14 \\
\hline Lab 8 & 2 & 3 & 5 \\
\hline \multicolumn{4}{|l|}{ Lab Section } \\
\hline Tuesday & 18 & 7 & 25 \\
\hline Wednesday & 1 & 4 & 5 \\
\hline Thursday & 9 & 11 & 20 \\
\hline \multicolumn{4}{|l|}{ Gender } \\
\hline Male & 11 & 10 & 21 \\
\hline Female & 17 & 12 & 29 \\
\hline \multicolumn{4}{|l|}{ Length (in seconds) } \\
\hline $1-10$ & 6 & 1 & 7 \\
\hline $11-20$ & 6 & 3 & 9 \\
\hline $21-30$ & 5 & 3 & 8 \\
\hline $31-40$ & 3 & 4 & 7 \\
\hline $41-50$ & 3 & 3 & 6 \\
\hline $51-60$ & 1 & 0 & 1 \\
\hline $61-120$ & 1 & 8 & 9 \\
\hline$>120$ & 3 & -- & 3 \\
\hline \multicolumn{4}{|l|}{ Activity } \\
\hline Lab Preparation & & 2 & 2 \\
\hline Equipment & 10 & 3 & 13 \\
\hline Material & 4 & 1 & 5 \\
\hline Procedure & 14 & 16 & 30 \\
\hline
\end{tabular}


Appendix J

Transcription Key for Interaction Examples

\begin{tabular}{|c|c|}
\hline UG & Undergraduate who initiates interaction \\
\hline UG2 & $\begin{array}{l}\text { A second undergraduate who participates in an interaction, } \\
\text { usually the lab partner of the primary undergraduate who } \\
\text { initiates an interaction. }\end{array}$ \\
\hline TA & Teaching assistant \\
\hline $\begin{array}{l}\text { T = Tuesday } \\
\text { W = Wednesday } \\
\text { Th = Thursday }\end{array}$ & $\begin{array}{l}\text { Interactions are identified using the following scheme: } \\
\text { Lab Session + Lab Section + Number of Interaction. } \\
\text { For example, } 4 \text { Th } 23 \text { is the twenty-third interaction that } \\
\text { occurred in Lab } 4 \text { in the Thursday Section }\end{array}$ \\
\hline , & $\begin{array}{l}\text { In the interaction examples, a comma indicates a brief pause, } \\
\text { approximately the length of time it would take to inhale a breath } \\
\text { before continuing to speak. }\end{array}$ \\
\hline$\ldots$ & $\begin{array}{l}\text { In the interaction examples, a series of dots indicates a longer } \\
\text { pause, where the speaker may be searching for a word or what to } \\
\text { say. }\end{array}$ \\
\hline [ ] & $\begin{array}{l}\text { Brackets indicate that speech exists, but that speech was not } \\
\text { captured by the recording equipment. For example, replacing } \\
\text { speech that was not audible is marked, [inaudible]. }\end{array}$ \\
\hline & $\begin{array}{l}\text { A decimal point in numerical expressions is spoken as "point," } \\
\text { as in ".019 molarity” is spoken as "point oh one nine molarity." }\end{array}$ \\
\hline$\cdot$ & $\begin{array}{l}\text { Period at the end of a sentence represents a pause and end of a } \\
\text { turn. }\end{array}$ \\
\hline$?$ & A question mark indicates a speaker's question, in form or tone. \\
\hline Italics & $\begin{array}{l}\text { Italics in transcriptions are used to describe an action in the } \\
\text { communicative exchange, e.g., Student carries out the } \\
\text { instruction. }\end{array}$ \\
\hline “ ” & $\begin{array}{l}\text { Quotation marks indicate words of a speaker. } \\
\text { Italics in quotation marks are used to replace information that } \\
\text { would identify one of the participants. The italicized }\end{array}$ \\
\hline “Italics" & $\begin{array}{l}\text { information describes the type of the information expressed, } \\
\text { e.g., "Tuesday teaching assistant's name." }\end{array}$ \\
\hline (Italics) & $\begin{array}{l}\text { Parenthesis indicate additional information about the way speech } \\
\text { was delivered. For example, if a speaker delivers a word or } \\
\text { vocalization and laughs simultaneously, the transcribed speech } \\
\text { is Uhum (laughs). }\end{array}$ \\
\hline $\mathrm{NaOH}$ & $\begin{array}{l}\text { Chemical names are written in their short version when } \\
\text { undergraduates refer to them as "N-A-O-H." When students } \\
\text { describe the material as sodium hydroxide, the name sodium } \\
\text { hydroxide is used. }\end{array}$ \\
\hline
\end{tabular}




\section{Appendix K}

Overview of Interview Interaction Examples Used to Illustrate Topics of Interactions

\begin{tabular}{|c|c|c|c|c|c|c|}
\hline \multirow[b]{3}{*}{ Activity } & & & \multicolumn{4}{|c|}{ Success Category } \\
\hline & \multicolumn{2}{|c|}{$\begin{array}{c}\text { Interview } \\
\text { Interactions }\end{array}$} & \multicolumn{2}{|c|}{$\begin{array}{l}\text { Successful } \\
\text { Examples }\end{array}$} & \multicolumn{2}{|c|}{$\begin{array}{l}\text { Partially Successfu } \\
\text { Examples }\end{array}$} \\
\hline & Total & Examples & Possible & Used & Possible & Used \\
\hline \multicolumn{7}{|l|}{ Lab Materials } \\
\hline Advice & 2 & & & & 2 & 2 \\
\hline Total & 2 & 2 & & & 2 & \\
\hline \multicolumn{7}{|l|}{ Equipment } \\
\hline Locate/Acquire & 3 & 3 & 3 & 3 & & \\
\hline Identify Item & 5 & 4 & 4 & 3 & 1 & 1 \\
\hline Function & 5 & 3 & 3 & 3 & 2 & \\
\hline Total & 13 & 10 & 10 & 9 & 3 & 1 \\
\hline \multicolumn{7}{|l|}{ Materials } \\
\hline Locate/Acquire & 2 & 1 & 1 & & 1 & 1 \\
\hline Identify Sub-type & 3 & 3 & 3 & 3 & & \\
\hline Quantity & 2 & 2 & 1 & 1 & 1 & 1 \\
\hline Total & 7 & 6 & 5 & 4 & 2 & 2 \\
\hline \multicolumn{7}{|l|}{ Procedures } \\
\hline What to Do & 15 & 7 & 8 & 6 & 7 & 1 \\
\hline How to Carry Out & 8 & 2 & 3 & 2 & 5 & \\
\hline Problem Solving & 5 & 3 & 2 & 1 & 5 & 2 \\
\hline Total & 28 & 12 & 13 & 9 & 15 & 3 \\
\hline
\end{tabular}




\section{BIBLIOGRAPHY}

Anderson, S. (2005, November 16). America's future is stuck oversees. The New York Times, A23

Anderson-Hsieh, J., \& Dauer, R. M. (1997, March). Slowed-down speech: A teaching tool for listening/pronunciation. Paper presented at the annual meeting of the Teachers of English to Speakers of Other Languages, Orlando, FL.

Axelson, E. R., \& Madden, C. G. (1994). Discourse strategies for ITAs across instructional contexts. In C. Madden and C. Myers (Eds.), Discourse performance of international teaching assistants (pp. 153-185). Alexandria, VA: TESOL Publications.

Bailey, K. M. (1984). The “foreign TA problem.” In K. M. Bailey, F. Pialorsi, \& J. Zukowski/Faust (Eds.), Foreign teaching assistants in U. S. universities (pp. 315). Washington, DC: National Association for Foreign Student Affairs.

Bailey, K. M., Pialorsi, F., \& Zukowski/Faust, J. (Eds.) (1984). Foreign teaching assistants in U. S. universities. Washington, DC: National Association for Foreign Student Affairs.

Benrabah, M. (1997). Word-stress: A source of unintelligibility in English. International Review of Applied Linguistics in Language Teaching, 35, 157-166.

Bollag, B. (2006). Enrollment of foreign students holds steady. The Chronicle of Higher Education. Retrieved May, 19, 2007, from http://chronicle.com/weekly/v53/i13/13a044401.htm.

Bradlow, A. R., \& Bent, T. (2008). Perceptual adaptation to non-native speech. Cognition, 106, 707-729. 
Bresnahan, M. J., Ohasi, R., Nebashi, R., Liu, W.Y., \& Shearman, S.M. (2002). Attitudinal and affective response toward accented English. Language \& Communication, 22, 171-185.

Brown, G., \& Yule, G. (1983). Discourse analysis. New York: Cambridge University Press.

Brown, K. A., Fishman, P. F., \& Jones, N. L. (1991). Language proficiency legislation and the ITA. In J. Nyquist,, R. Abbot, D. Wulff, \& J. Sprague (Eds.). Preparing the professoriate of tomorrow to teach: Selected readings in TA training. (pp. 393-403). Dubuque, Iowa: Kendall/Hunt Publishing Company.

Browne, S. C., \& Huckin, T. N. (1987). Pronunciation tutorials for nonnative technical professionals: A program description. In J. Morley (Ed.), Current perspectives on pronunciation (pp. 29-40). Washington, DC: TESOL Publications.

Byrd, P., \& Constantinides, J. (1992). The language of teaching Mathematics: Implications for training ITAs. TESOL Quarterly, 26, 163-167.

Cazden, C. B. (2001). Classroom discourse: The language of teaching and learning $\left(2^{\mathrm{nd}}\right.$ ed.). Portsmouth, NH: Heinemann.

Clyne, M. (1994). Intercultural communication at work: Cultural values in discourse. New York: Cambridge University Press.

Davies, C. E., \& Tyler, A. E. (1994). Demystifying cross-cultural (mis)communication: Improving performance through balanced feedback in a situated context. In C. Madden \& C. Myers (Eds.), Discourse performance of international teaching assistants (pp. 201-220). Alexandria, VA: TESOL Publications. 
Derwing, T. M. (2001). What speaking rates do non-native listeners prefer? Applied Linguistics, 22, 324-337.

Derwing, T. M., \& Munro, M. J. (1997). Accent, intelligibility, and comprehensibility: Evidence from 4 L1s. Studies in Second Language Acquisition, 19, 1-16.

Derwing, T. M., \& Munro, M. J. (1998). The effects of speaking rate on listener evaluations of native and foreign-accented speech. Language Learning, 48, 159-182.

Derwing, T. M., \& Munro, M. J. (2001). What speaking rates do non-native listeners prefer? Applied Linguistics, 22, 324-337.

Derwing, T. M., \& Munro, M. J. (2005). Second language accent and pronunciation teaching: A research-based approach. TESOL Quarterly, 39, 379-398.

Derwing, T. M., Munro, M. J., \& Wiebe, G. (1998). Evidence in favor of a broad framework for pronunciation instruction. Language Learning, 48, 393-410.

Derwing, T. M., \& Rossiter, M. (2002). ESL learners' perceptions of their pronunciation needs and strategies. System, 30, 155-166.

Derwing, T. M., Rossiter, M. J., Munro, M. J., \& Thomson, R. I. (2004). Second language fluency: Judgments on different tasks. Language Learning, 54, 655-679.

Derwing, T. M., Thomson, R. I., \& Munro, M. J. (2006). English pronunciation and fluency development in Mandarin and Slavic speakers. System, 30, 183-193.

Drew, P., \& Heritage, J. (Eds.) (1992). Talk at work: Interaction in institutional settings. New York: Cambridge University Press. 
Ege, S. N., Coppola, B. P., \& Lawton, R.G. (1997). The University of Michigan undergraduate chemistry curriculum 1. philosophy, curriculum, and the nature of change. Journal of Chemical Education, 74, 74-83.

Fairclough, N. (2003). Analyzing discourse: Textual analysis of social research. New York: Routledge.

Fayer, J., \& Krasinski. (1995). Perception of hesitation in nonnative speech. Bilingual Review, 20, 114-121.

Field, J. (2005). Intelligibility and the listener: The role of lexical stress. TESOL Quarterly, 39, 399-424.

Finder, A., (2005, June 24). Unclear on American campus: What the foreign teacher said. New York Times, pp. A1, A18.

Flowerdew, J. (1994). Academic listening: Research perspectives. New York: Cambridge University Press.

Flowerdew, J., \& Miller. L. (1995). On the notion of culture in L2 lectures. TESOL Quarterly, 29, 345-373.

Flowerdew, J., \& Miller, L. (2005). Second language listening: Theory and practice. New York: Cambridge University Press.

Fortanet, I. (2004). The use of 'we' in university lectures: Reference and function. English for Specific Purpose, 23, 45-66.

Gee, J. P. (2005). An introduction to discourse analysis: Theory and method ( $2^{\text {nd }}$ ed.). New York: Routledge. 
Gilbert, J. (1987). Pronunciation and listening comprehension. In J. Morley (Ed.), Current perspectives on pronunciation (pp. 29-40). Washington, DC: TESOL Publications.

Goffman, E. (1971). Relations in public: Microstudies of the public order. New York: Basic Books, Inc. Publishers.

Gonzalez, V. (2004). Second language learning: Cultural adaptation processes in international graduate students in U.S. universities. Lanham, MD: University Press of America, Inc.

Gravios, J. (2005). Teach impediment. When the student can’t understand the instructor, who is to blame? The Chronicle of Higher Education. A1, A10-12.

Hahn, L. (2004). Primary stress and intelligibility: Research to motivate the teaching of suprasegmentals. TESOL Quarterly, 38, 201-224.

Halliday, M. A. K., \& Hasan, R. (1976). Cohesion in English. Essex, England: Pearson Education Limited.

Hamilton, R. P. (2001). The insignificance of learners’ errors: A philosophical investigation of the interlanguage hypothesis. Language \& Communication, 21, 73-88.

Hoekje, B., \& Williams, J. (1992). Communicative competence and the dilemma of international teaching assistant education. TESOL Quarterly, 26, 243-270.

Jenkins, S., \& Parra, I. (2003). Multiple layers of meaning in an oral proficiency test: The complementary roles of nonverbal, paralinguistic, and verbal behaviors in assessment decisions. The Modern Language Journal, 87, 90-107. 
Kaufman, D., \& Brownworth, B. (2006). Collaborative paradigms and future directions in international teaching assistant professional development. In J. Burton (Series Ed.) \& D. Kaufman \& B. Brownworth (Vol. Eds.) Case studies in TESOL practice series: Professional development of international teaching assistants. (pp. 1-13). Alexandria, VA: TESOL Publications.

Kennedy, P. (2002). Learning cultures and learning styles: Myth-understandings about adult (Hong Kong) learners. International Journal of Lifelong Education, 21, 430-445.

Kendon, A. (1980). Gesticulation and speech; Two aspects of the process of utterance. In M. R. Key (Ed.), The relationship of verbal and nonverbal communication (pp. 207). The Hague: Mouton.

Kendon, A. (1990). Do gestures communicate? A review. Research on Language and Social Interaction, 27, 175-200.

Kearsley, G. P. (1976). Questions and question asking in verbal discourse: A crossdisciplinary view. Journal of Psycholinguistic Research, 5, 355-375.

Kirk, J., \& Miller, M. L. (1986). Reliability and validity in qualitative research. In J. VanMaanen (Series Ed.), Qualitative research method series: Vol. 1. Thousand Oaks, CA: Sage Publications.

Leather, J. (1999). Second-language speech research: An introduction. Language Learning, 49, 1-56.

Levis, J. (1999). Intonation in theory and practice, revisited. TESOL Quarterly, 33, 37-63. 
Levis, J. (2004). Intonation and discourse: Three approaches. TESOL Quarterly, 38, 353-356.

Levis, J. (2005). Changing contexts and shifting paradigms in pronunciation teaching. TESOL Quarterly, 39, 369-378.

Lippi-Green, R. (1997), English with an accent: Language, ideology, and discrimination in the United States. New York: Routledge Presss.

Llurda, E. (2000). Effects of intelligibility and speaking rate on judgments of non-native speakers' personalities. International Review of Applied Linguistics in Language Teaching, 38, 289-300.

Lynch, T. (1994). Training lectures for international audiences. In J. Flowerdew, Academic listening: Research perspectives (pp. 269-289). New York: Cambridge University Press.

Major, R., Fitzmaurice, S., Bunta, F., \& Balasubramanian, C. (2002). The effects of non-native accent on listening comprehension: Implications for ESL assessment. TESOL Quarterly, 36, 173-190.

McChesney, B. J. (1994). The functional language of the US TA during office hours. In C. Madden \& C. Myers (Eds.), Discourse performance of international teaching assistants (pp. 134-152). Alexandria, VA: TESOL Publications.

McGregor, A. (2007, March). Comprehensibility of international teaching assistants. Paper presented at the annual meeting of the Teachers of English to Speakers of Other Languages, Seattle, WA.

McNeill, D. (1992). Hand and mind: What gestures reveal about thought. Chicago: University of Chicago Press. 
McNeill, D. (Ed.) (2000). Language and gesture. New York: Cambridge University Press.

Mehan, H. (1985). The structure of classroom discourse. In. T. A. Van Dijk (Ed.) Handbook of discourse analysis: Vol. 3. Discourse and dialogue (pp. 119-131). New York: Academic Press.

Morley, J. (Ed.) (1987). Current perspectives on pronunciation. Alexandria, VA: TESOL Publications.

Morley, J. (1991). The pronunciation component in teaching English to speakers of other languages. TESOL Quarterly, 25, 481-520.

Munro, M. J. (1998). The effects of noise on the intelligibility of foreign-accented speech. Studies in Second Language Acquisition, 20, 139-154.

Munro, M. J., \& Derwing, T. M. (1995). Processing time, accent, and comprehensibility in the perception of native and foreign-accented speech. Language Learning, 45, 289-306.

Munro, M. J., \& Derwing, T. M. (1998). The effects of speaking rate on listener evaluations of native and foreign-accented speech. Language Learning, 48, 159-182.

Munro, M. J., \& Derwing, T. M. (1999). Foreign accent, comprehensibility, and intelligibility in the speech of second language learners. Language Learning, 49, 285-310.

Munro, M. J., Derwing, T. M., \& Morton, S. L. (2006). The mutual intelligibility of L2 speech. Studies in Second Language Acquisition, 28, 111-131. 
Murphy, J. (2004). Attending to word-stress while learning now vocabulary. English for Specific Purposes, 23, 67-83.

Murphy, J., \& Kandil, M. (2004). Word-level stress patterns in the academic word list. System, 32, 61-75.

Myers, C. L. (1994). Question-based discourse in science labs: Issues for ITAs. In C. Madden \& C. Myers (Eds.), Discourse performance of international teaching assistants (pp. 83-102). Alexandria, VA: TESOL Publications.

Nisbett, R. E. (2003). The geography of thought: How Asians and Westerners think differently...and why. New York: The Free Press.

Nyquist, J., Abbot, R., Wulff, D., \& J. Sprague (Eds.). (1991). Preparing the professoriate of tomorrow to teach: Selected readings in TA training. Dubuque, Iowa: Kendall/Hunt Publishing Company.

Patton, M. Q. (2002). Qualitative research \& evaluation methods (3rd ed.). Thousand Oaks, CA: Sage Publications, Inc.

Pennycook, A. (1985). Actions speak louder than words: Paralanguage, communication, and education. TESOL Quarterly, 19, 259-282.

Pickering, L. (2001). The role of tone choice in improving ITA communication in the classroom. TESOL Quarterly, 35, 233-255.

Pickering, L. (2004). The structure and function of intonational paragraphs in native and nonnative speaker instructional discourse. English for Specific Purposes, 23, 19-43. 
Piñero, C. (2006). The evolution of an international teaching assistant program. . In J. Burton (Series Ed.) \& D. Kaufman \& B. Brownworth (Vol. Eds.) Case studies in TESOL practice series: Professional development of international teaching assistants. (pp. 83-93). Alexandria, VA: TESOL Publications.

Piske, T., MacKay, I. R. A., \& Flege, J. E. (2001). Factors affecting degree of foreign accent in an L2: A review. Journal of Phonetics, 29, 191-215.

Plakans, B. (1997). Undergraduate experiences with and attitudes towards international teaching assistants. TESOL Quarterly, 31, 95-119.

Publication Manual of the American Psychological Association (5th Ed.). (2001). Washington, DC: American Psychological Association.

Redden, E. (2006, November 2) Out of Step. Inside Higher Ed. Retrieved November 2, 2006, from http://insidehighered.com.

Riggenbach, H. (Ed.) (2000). Perspectives on fluency. Ann Arbor: The University of Michigan Press.

Riney, T. J., Takagi, N., \& Inutsuka, K. (2005). Phonetic parameters and perceptual judgments of accent in English by American and Japanese listeners. TESOL Quarterly, 39, 441-466.

Roth, W.-M. (2000). From gesture to scientific language. Journal of Pragmatics, 32, $1683-1714$.

Roth, W.-M. (2003). Gesture-speech phenomena, learning, and development. Educational Psychologist, 32, 249-283. 
Roth, W.-M., McGinn, M. K.,, Woszcyna, C., \& Boutonné, S. (1999). Differential participation during science conversations: The interaction of focal artifacts, social configurations, and physical arrangements. The Journal of the Learning Sciences, 8, 293-347.

Rounds, P. (1987). Characterizing successful classroom discourse for NNS teaching assistants. TESOL Quarterly 21, 643-671.

Rounds, P. (1994). Student questions: When, where, why, and how many. In C. Madden \& C. Myers (Eds.), Discourse performance of international teaching assistants (pp. 103-115). Alexandria, VA: TESOL Publications.

Sarwark, S. (2007, March). Administrative patterns in ITA programming. Paper presented at the annual meeting of the Teachers of English to Speakers of Other Languages, Seattle, WA.

Schmid, P., \& Yeni-Komshian, G. (1999). The effects of speaker accent and target predictability on perception of mispronunciations. Journal of Speech, Language \& Hearing Research, 42, 56-65.

Scollon, S. (1999). Not to waste words or students: Confusian and Socractic discourse in the tertiary classroom. In M. H. Long \& J. C. Richards (Series Eds.) \& E. Hinkel (Vol. Ed.) Culture in Second Language Teaching and Learning. (pp. 1327). New York: Cambridge University Press.

Scollon, R., \& Scollon, S. (2001). Intercultural communication (2 ${ }^{\text {nd }}$ ed.). Malden, MA: Blackwell Publishing.

Shi, Y. (2007, March). ITA program evaluation. Paper presented at the annual meeting of the Teachers of English to Speakers of Other Languages, Seattle, WA. 
Smith, R. M., Byrd, P., Nelson, G. L., Barrett, R. P., \& Constantinides, J. (1992).

Crossing Pedagogical Oceans: International Teaching Assistants in U.S. Undergraduate Education: (ASHE-ERIC Higher Education Report No. 8).

Washington DC: The George Washington University School of Education and Human Development.

Tannen, D. (1989). Talking voices: Repetition, dialogue, and imagery in conversational discourse. New York: Cambridge University Press.

Tanner, M. W. (1991). NNSTA-student interactions: An analysis of TAs questions and students' responses in a laboratory setting. Unpublished Ph.D. dissertation, University of Pennsylvania.

TESOL (Teachers of English to Speakers of Other Languages) Website (2007). ITA Interest Section Statement of Purpose/Goals (2007) (Retrieved on 5/15/07 from http://www.tesol.org/s_tesol/sec_document.asp?CID=309\&DID=537.

The Almanac of Higher Education (2006, August). The Chronicle of Higher Education, 53 (1). Retrieved December 18, 2006, from http://chronicle.com/free/almanac/2006/index.htm.

Tyler, A. (1992). Discourse structure and the perception of incoherence in international teaching assistants’ spoken discourse. TESOL Quarterly, 26, 671-688.

Tyler, A. (1995). Cross-cultural miscommunication: Conflicts in perception, negotiation, and enactment of participant role and status. Studies in Second Language Acquisition, 17, 129-152.

Wennerstrom, A. (1998). Intonation as cohesion in academic discourse: A study of Chinese speakers of English. Studies in Second Language Acquisition, 20, 1-25. 
Wennerstrom, A. (2000). The role of intonation in fluency. In H. Riggenbach (Ed.), Perspectives on fluency (pp. 102-127). Ann Arbor: University of Michigan Press.

Williams, J. (1992). Planning, discourse marking, and the comprehensibility of international teaching assistants. TESOL Quarterly, 26, 693-711.

Williams, J., Inscoe, R., \& Tasker, T. (1997). Communication strategies in an interactional context: The mutual achievement of comprehension. In C. N. Candlin (General Editor) \& G. Kasper \& E. Kellerman (Vol. Eds.), Communication strategies: Psycholinguistic and sociolinguistic perspectives (pp. 304-322). New York: Addison Wesley Longman.

Wood, D. (2001). In search of fluency: What is it and how can we teach it? The Canadian Modern Language Review, 57, 573-589.

Yankelovich, D. (2005, November 25). Ferment and change: Higher education in 2015. The Chronicle of Higher Education, B6.

Yeni-Komshian, G. H., Robbins, M., \& Flege, J. E. (2001). Effects of word class differences on L2 pronunciation accuracy. Applied Psycholinguistics, 22, 283-299. 